\title{
CALGRID Photochemical Modeling of Air Quality Impacts of Alternative Transportation Fuel Use in Los Angeles
}

\author{
G.E. Moore, R.J. Londergan, and M.E. Fernau \\ Earth Tech, Inc. \\ Concord, Massachusetts \\ NREL Technical Monitor: P. Bergeron
}

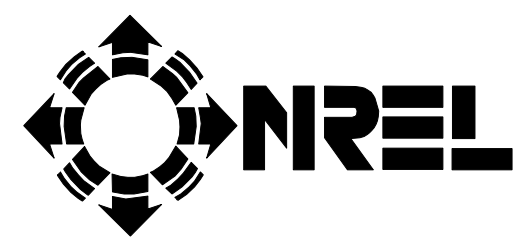

Alternative Fuels Hotline: 1-800-423-1DOE

Alternative Fuels Data Center World Wide Web Site: http://www.afdc.doe.gov
\end{abstract}

National Renewable Energy Laboratory

1617 Cole Boulevard

Golden, Colorado 80401-3393

A national laboratory of the

U.S. Department of Energy

Managed by the Midwest Research Institute

For the U.S. Department of Energy

Under Contract No. DE-AC36-83CH10093 


\title{
CALGRID Photochemical Modeling of Air Quality Impacts of Alternative Transportation Fuel Use in Los Angeles
}

\author{
G.E. Moore, R.J. Londergan, and M.E. Fernau
}

Earth Tech, Inc.

Concord, Massachusetts

NREL Technical Monitor: P. Bergeron

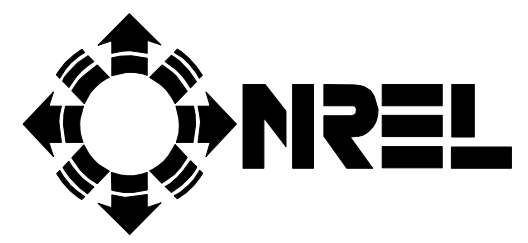

Alternative Fuels Hotline: 1-800-423-1DOE

Alternative Fuels Data Center World Wide Web Site: http://www.afdc.doe.gov

National Renewable Energy Laboratory

1617 Cole Boulevard

Golden, Colorado 80401-3393

A national laboratory of the

U.S. Department of Energy

Managed by the Midwest Research Institute

For the U.S. Department of Energy

Under Contract No. DE-AC36-83CH10093

Prepared under Subcontract Number YCC--5-14072-01

November 1998 


\section{NOTICE}

This report was prepared as an account of work sponsored by an agency of the United States government. Neither the United States government nor any agency thereof, nor any of their employees, makes any warranty, express or implied, or assumes any legal liability or responsibility for the accuracy, completeness, or usefulness of any information, apparatus, product, or process disclosed, or represents that its use would not infringe privately owned rights. Reference herein to any specific commercial product, process, or service by trade name, trademark, manufacturer, or otherwise does not necessarily constitute or imply its endorsement, recommendation, or favoring by the United States government or any agency thereof. The views and opinions of authors expressed herein do not necessarily state or reflect those of the United States government or any agency thereof.

Available to DOE and DOE contractors from:

Office of Scientific and Technical Information (OSTI)

P.O. Box 62

Oak Ridge, TN 37831

Prices available by calling 423-576-8401

Available to the public from:

National Technical Information Service (NTIS)

U.S. Department of Commerce

5285 Port Royal Road

Springfield, VA 22161

703-605-6000 or 800-553-6847

or

DOE Information Bridge

http://www.doe.gov/bridge/home.html

Printed on paper containing at least $50 \%$ wastepaper, including $20 \%$ postconsumer waste 


\section{TABLE OF CONTENTS}

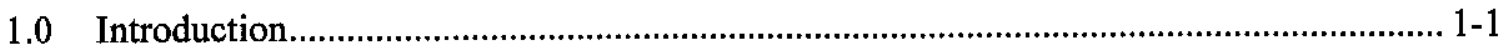

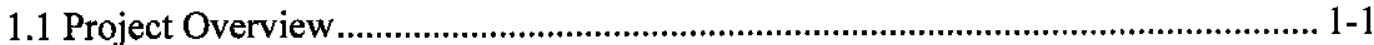

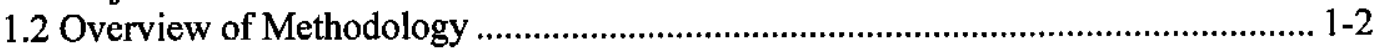

1.3 Organization of the Report............................................................................ 1-4

2.0 CALGRID SAPRC90/93 Implementation................................................................... 2-1

2.1 Addition of Explicit Reactions for Several Toxic Compounds ............................. 2-1

2.2 Photolysis Rate Upgrades ............................................................................. 2-5

2.3 Kinetic Parameter Upgrades ........................................................................... 2-6

2.4 Yield Parameter Upgrades ............................................................................ 2-7

2.5 Testing of the Chemistry Revisions..................................................................... 2-8

2.6 Comparison of CB-4 with the SAPRC90 ........................................................ 2-9

3.0 Development of CALGRID Input Data Sets.............................................................. 3-1

3.1 Description of the Modeling Scenario.............................................................. 3-1

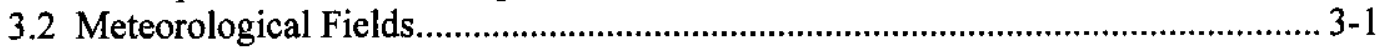

3.3 Analysis of Air Flow Transport

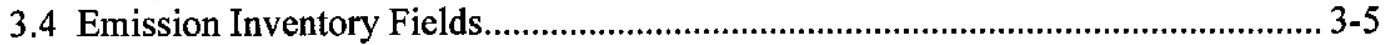

3.5 Initial and Boundary Concentration Fields..................................................... 3-7

4.0 Comparison and Evaluation of 1987 Base Year CALGRID Simulations............................ 4-1

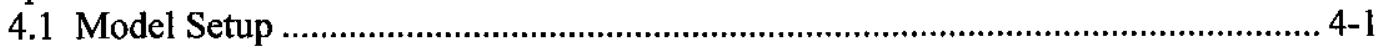

4.2 Ozone Model Performance Evaluation - UAM-IV versus CALGRID .................... 4-2

4.3 Ozone Model Performance Evaluation - CALGRID CB-4 versus SAPRC90 ......... 4-4

4.4 Ozone Time Series Analysis ........................................................................... 4-4

4.5 Comparisons of Model Predicted Formaldehyde Concentrations........................... 4-6

5.0 Analysis of Future Year Modeling Results ..................................................................... 5-1

5.1 Surface Emissions Inventory Description .................................................... 5-1

5.2 Intercomparisons of Maximum Hourly Ozone................................................... 5-2

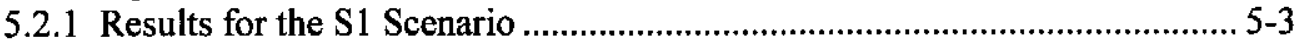

5.2.2 Ozone Predictions for the RFG Scenario ................................................. 5-3

5.2.3 Comparison of the CNG and M85 Alternative Fuel Scenarios..................... 5-4

5.3 Comparisons of 8-hr Average Ozone Concentrations........................................ 5-5

5.4 Comparisons of Exposure to Ozone Concentrations.............................................. 5-6

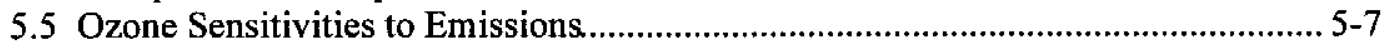

5.6 Comparisons for Toxic Compounds............................................................. 5-8

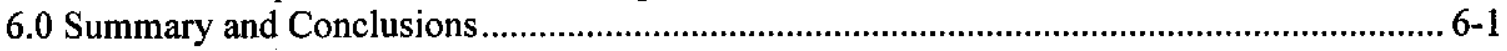

6.1 Results of Modifications of the SAPRC Chemical Mechanism............................. 6-1

6.2 Results from CALGRID Model Input Preparation............................................. 6-2

6.3 Results from CALGRID Model Quality Assurance Evaluation Exercises............. 6-2

6.4 Results from Comparisons of CALGRID Predicted Future Year Ozone and Toxic Compound Concentrations................................................................ 6-3

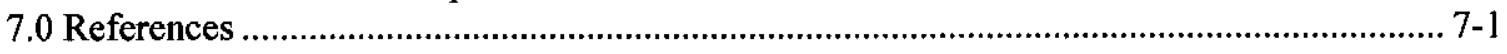

Appendix A Listing of CALMET Input File

Appendix B Listing of CALGRID Input File 


\section{LIST OF TABLES}

1-1 A Summary of Model Simulations (and Their Run Designations) Conducted for the Present Study

2-1 A Summary of the User-Specified Chemical Box Model Parameters Used to Study the Destruction of the Toxic Compounds BENZ and BUDl

2-2 A Summary of the Initial Condition Concentrations Used for the Chemical Box Model Simulation Testing of the SAPRC90 Toxics Version.

2-3 A Summary of the Cross-Section and Quantum Yield Products for Selected Photolytic Reactions in Units of $10^{-20} \mathrm{~cm}^{2}$

2-4 A Listing of the Chemical Rate Coefficient Parameters for the Three Reactions Revised in SAPRC93

2-5 A Summary of HO. Radical Yields from the Reactions of Alkenes with Ozone for the Los Angeles Hydrocarbon Mixture.

2-6 Maximum Concentrations for Selected SAPRC90/93 Active Species.

2-7 A Summary of the Initial Condition (IC) Concentrations Used in the Ozone Buildup Experiment

2-8 Maximum Concentrations for Selected SAPRC90 Versus CB-4 Box Chemistry Comparison

3-1 A Summary of the SAPRC90 PREPEMIT Lumped Species Average Carbon Number and Molecular Weights Used in the Present Study for the RFG Case

4-1 A Comparison of the 27 August 1987 Maximum Daily Ozone (pphm) Predicted Using the CB-4 Chemical Mechanism...

4-2 A Summary of the Maximum Daily Ozone (pphm) at Selected Sites in the Los Angeles Basin Produced by CALGRID and UAM-IV on 28 August 1998

5-1 Estimated Emissions in Los Angeles Modeling Domain for 2007 for S1 Scenario and RFG, CNG, and M85 Scenario Incremental Emissions .

5-2 A Comparison of UAM CB-4 and CALGRID SAPRC90/93 Domain-Wide Peak Predicted 1-hr Ozone Concentrations (ppb) for the Vehicle Fuel Use Scenarios.

5-3 A Summary of the Domain-Wide Peak Predicted Daily Maximum 8-hr Average Ozone Concentrations for the Various Modeling Scenarios.

5-4 A Summary of the CALGRID SAPRC90/93 Predicted Ozone Sensitivity Coefficients (ppb-O $\mathrm{O}_{3} /$ Ton Emissions) for the Various Fuel Scenarios

5-5 CALGRID SAPRC90/93 Predicted Domain-Wide Maximum 1-hr Predicted Concentrations (ppb) for the Four Toxic Species Analyzed. 


\section{LIST OF FIGURES}

2-1 SAPRC90 predicted concentration time series of selected compounds......................................... 2-4

2-2 Time series comparison of SAPRC90 versus SAPRC90/93 concentrations for selected species ... 2-11

2-3 Comparison of CB4 and SAPRC90 concentrations during ozone buildup ............................... 2-13

3-1 Map of the Los Angeles modeling domain showing terrain, landuse, and significant sites............. 3-8

3-2 Surface winds and mixing heights over the Los Angeles basin using CALMET 27 August 19870700 LST.

3-3 Surface winds and mixing heights over the Los Angeles basin using CALMET 27 August 1300 LST.

3-4 Surface winds and mixing heights over the Los Angeles basin using CALMET 27 August 1800 LST...

3-5 Surface temperatures and $500 \mathrm{~m}$ winds over the Los Angeles basin derived using CALMET 27 August 19870700 LST..

3-6 Surface temperatures and $500 \mathrm{~m}$ winds over the Los Angeles basin derived using CALMET 27 August 1300 LST.

3-7 Surface temperatures and $500 \mathrm{~m}$ winds over the Los Angeles basin derived using CALMET 27 August 19871800 LST.

3-8 Surface trajectories and mixing heights in the Los Angeles Basin derived using CALMET 27 August 19871300 LST.

3-9 Surface trajectories and mixing heights over the Los Angeles basin derived using CALMET 27 August 19871800 LST.

3-10 Surface winds and mixing heights over the Los Angeles basin using CALMET 28 August 19870700 LST.

3-11 Surface winds and mixing heights over the Los Angeles basin using CALMET 28 August 19871300 LST.

3-12 Surface winds and mixing heights over the Los Angeles basin using CALMET 28 August 19871800 LST.

3-13 Surface temperatures and $500 \mathrm{~m}$ winds over the Los Angeles basin using CALMET 28 August 19871300 LST.

3-14 Surface temperatures and $500 \mathrm{~m}$ winds over the Los Angeles basin using CALMET 28 August 19871800 LST.

3-15 Surface trajectories and mixing heights in the Los Angeles Basin derived using CALMET 28 August 19871300 LST.

3-16 Surface trajectories and mixing heights in the Los Angeles Basin derived using CALMET 28 August 19871800 LST.

4-1a Daily maximum 1-hr ozone over SCAQMD during 27 August 1987-CB4 chemistry UAM-SIP

4-1b Daily maximum 1-hr ozone over SCAQMD during 27 August 1987-CB4 chemistry CALGRID-SIP.

4-2a Daily maximum 1-hr ozone over SCAQMD during 28 August 1987-CB4 chemistry UAM-SIP

4-2b Daily maximum 1-hr ozone over SCAQMD during 28 August 1987-CB4 chemistry CALGRID-SIP.

4-3 Daily maximum 1-hr ozone over SCAQMD during 27 August 1987-S90 chemistry CALGRID-SIP. Contours are C(CB4) - C(SAPRC90) differences (ppb)

4-4 Daily maximum 1-hr ozone over SCAQMD during 28 August 1987-S90 chemistry CALGRID-SIP. Contours are C(CB4) - C(SAPRC90) differences (ppb).

4-5 Time series of predicted and observed ozone at Rubidoux 


\section{LIST OF FIGURES (CONT'D)}

4-6 Time series of predicted and observed ozone at Glendora........................................................ 4-14

4-7 Time series of predicted and observed ozone at Whittier ......................................................... 4-15

4-8 Time series of predicted and observed ozone at Crestline.............................................................. 4-16

4-9 Time series of predicted and observed ozone at Reseda........................................................... 4-17

4-10 Time series of predicted and observed ozone at Redlands......................................................... 4-18

4-11 Daily maximum 1-hr HCHO over SCAQMD during 27 August 1987 - CB4 chemistry CALGRID

SIP. Contours are (UAMCB4) - C(CB4) differences (ppb) ....................................................... 4-19

4-12 Daily maximum 1-hr HCHO over SCAQMD during 28 August 1987 - CB4 chemistry CALGRID

SIP. Contours are (UAMCB4) - C(CB4) differences (ppb) ..................................................... 4-20

4-13 Daily maximum 1-hr HCHO over SCAQMD during 27 August 1987 (SAPRC90) - CB4 chemistry CALGRID SIP. Contours are (UAMCB4) - C(CB4) differences (ppb) ........................ 4-21

4-14 Daily maximum 1-hr HCHO over SCAQMD during 28 August 1987 (SAPRC90) - CB4 chemistry CALGRID SIP. Contours are (UAMCB4) - C(CB4) differences (ppb)....................... 4-22

5-1a Daily maximum hourly ozone predicted by CALGRID for 27 August 2007 - no onroad vehicle (S1) scenario with SAPRC90/93 ................................................................................. 5-11

5-1b Daily maximum 1-hr ozone during August 272007 - S1 w/ SAPRC90/93 minus

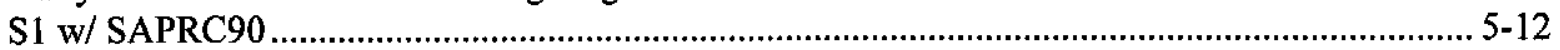

5-2a Daily maximum hourly ozone predicted by CALGRID for 28 August 2007 - no onroad vehicle (S1) scenario with SAPRC90/93 ................................................................................ 5-13

5-2b Daily maximum 1-hr ozone predicted by CALGRID for 28 August 2007 - S1 w SAPRC90/93 minus S1 w/ SAPRC90 ..................................................................................................... 5-14

5-3a Daily maximum hourly ozone predicted by CALGRID for 27 August 2007 - RFG fueled vehicle scenario with SAPRC 90/93 ................................................................................. 5-15

5-3b Daily maximum 1-hr ozone during August 272007 - RFG w/ SAPRC90/93 minus

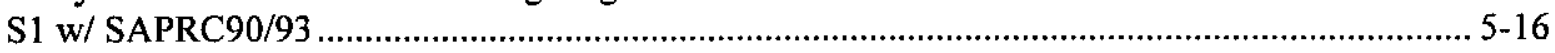

5-4a Daily maximum hourly ozone predicted by CALGRID for 28 August 2007 - RFG fueled vehicle fueled vehicle scenario with SAPRC 90/93.................................................................. 5-17

5-4b Daily maximum 1-hr ozone during August 28 2007 - RFG SAPRC90/93 minus S1 w/ SAPRC90/93 .................................................................................................. 5-18

5-5a Daily maximum 1-hr ozone during August 272007 - RFG SAPRC90/93 minus

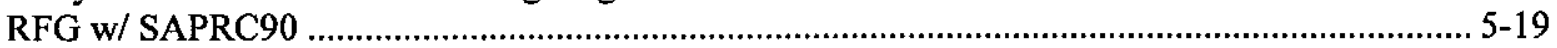

5-5b Daily maximum 1-hr ozone during August 282007 - RFG w/ SAPRC90/93 minus RFG w/ SAPRC90 ................................................................................................... 5-20

5-6a Daily maximum hourly ozone predicted by CALGRID for 27 August 2007 - CNG fueled vehicle scenario with SAPRC 90/93 …................................................................................... 5-21

5-6b Daily maximum 1-hr ozone during August 27 2007-CNG SAPRC90/93 minus

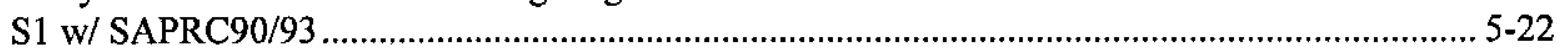

5-7a Daily maximum hourly ozone predicted by CALGRID for 28 August 2007 - CNG fueled vehicle scenario with SAPRC 90/93 ................................................................................. 5-23

5-7b Daily maximum 1-hr ozone during August 282007 - CNG SAPRC90/93 minus

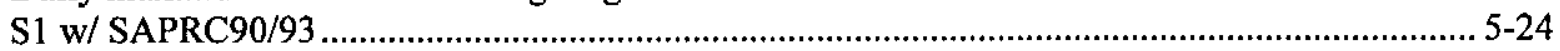

5-8a Daily maximum 1-hr ozone during August 272007 - CNG w/ SAPRC90/03 minus

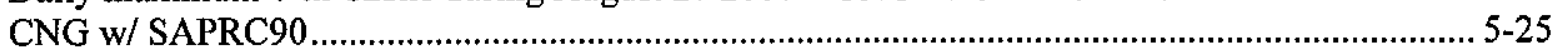

5-8b Daily maximum 1-hr ozone during August 282007 - CNG w/ SAPRC90/93 minus

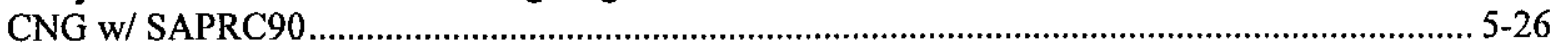

5-9a Daily maximum hourly ozone predicted by CALGRID for 27 August 2007 - M85 fueled vehicle scenario with SAPRC 90/93 …..................................................................................... 5-27

5-9b Daily maximum 1-hr ozone during August 272007 - M85 w/ SAPRC90/93 minus S1 w/ SAPRC90/93 


\section{LIST OF FIGURES (CONT'D)}

5-10a Daily maximum hourly ozone predicted by CALGRID for 28 August 2007 - M85 fueled vehicle scenario with SAPRC 90/93.

5-10b Daily maximum 1-hr ozone during August 282007 - M85 w/ SAPRC90/93 minus

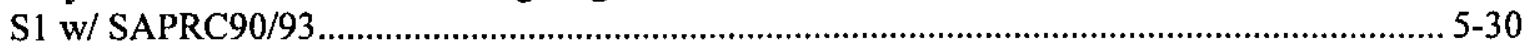

5-11a Daily maximum 1-hr ozone during August 272007 - M85 w/ SAPRC90/93 minus M85 w/ SAPRC90 ................................................................................................................ 5-31

5-11b Daily maximum 1-hr ozone during August 282007 - M85 w/ SAPRC90/93 minus

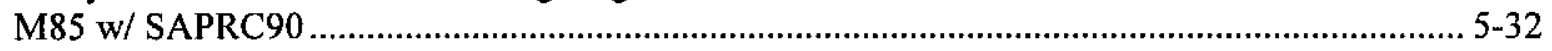

5-12a Daily maximum 8-hr ozone predicted by CALGRID for 27 August 2007 - RFG fueled vehicle scenario with SAPRC90/93 …............................................................................. 5-33

5-12b Daily maximum 8-hr ozone predicted by CALGRID for 28 August 2007 - RFG fueled vehicle scenario with SAPRC90/93 ...................................................................................... 5-34

5-13a Daily maximum 8-hr ozone during August 27 2007-RFG w SAPRC90/93 minus RFG w/ SAPRC90

5-13b Daily maximum 8-hr ozone during August 282007 - RFG w SAPRC90/93 minus RFG w/ SAPRC90

5-14a Daily maximum 8-hr ozone during August 272007 - RFG w SAPRC90/93 minus CNG w/ SAPRC90/93

5-14b Daily maximum 8-hr ozone during August 282007 - RFG w SAPRC90/93 minus

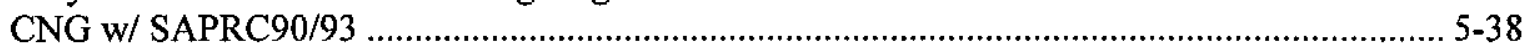

5-15a Daily maximum 1-hr ozone during August 272007 - RFG w SAPRC90/93 minus

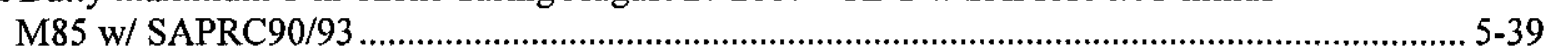

5-15b Daily maximum 8-hr ozone during August 282007 - RFG w SAPRC90/93 minus

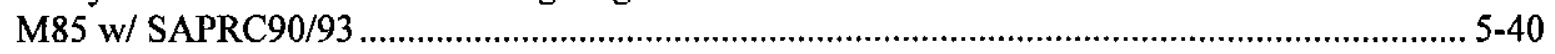

5-16a Cumulative 1-hr ozone exposure (>120 ppb) percentile differences during August 272007. RFG w/ SAPRC90/93 minus CNG w/SAPRC90/93 …............................................................. 5-41

5-16b Cumulative 1-hr ozone exposure (>120 ppb) percentile differences during August 282007 . RFG w/ SAPRC90/93 minus CNG w/ SAPRC90/93 ........................................................... 5-42

5-16c Cumulative 8-hr ozone exposure (>80 ppb) percentile differences during August 272007. RFG w/ SAPRC90/93 minus CNG w/ SAPRC90/93 ................................................................... 5-43

5-16d Cumulative 8-hr ozone exposure ( $>80 \mathrm{ppb}$ ) percentile differences during August 282007. RFG w/ SAPRC90/93 minus CNG w/ SAPRC90/93 ................................................................. 5-44

5-17a Cumulative 1-hr ozone exposure ( $>120 \mathrm{ppb})$ percentile differences during August 272007. RFG w/ SAPRC90/93 minus M85 w/ SAPRC90/93 ............................................................ 5-45

5-17b Cumulative 1-hr ozone exposure (>120 ppb) percentile differences during August 282007. RFG w/ SAPRC90/93 minus M85 w/ SAPRC90/93 ........................................................ 5-46

5-17c Cumulative 8-hr ozone exposure (>80 ppb) percentile differences during August 272007. RFG w/ SAPRC90/93 minus M85 w/ SAPRC90/93 ................................................................ 5-47

5-17d Cumulative 8-hr ozone exposure ( $>80 \mathrm{ppb}$ ) percentile differences during August 282007. RFG w/ SAPRC90/93 minus M85 w/ SAPRC90/93 .............................................................. 5-48

5-18a Daily maximum hourly HCHO predicted by CALGRID for 27 August 2007 - RFG fueled vehicle scenario with SAPRC 90/93 .................................................................................... 5-49

5-18b Daily maximum hourly HCHO predicted by CALGRID for 28 August 2007 - RFG fueled vehicle scenario with SAPRC 90/93 ......................................................................................... 5-50

5-19a Daily maximum hourly CCHO predicted by CALGRID for 27 August 2007 - RFG fueled vehicle scenario with SAPRC 90/93 ................................................................................... 5-51

5-19b Daily maximum hourly CCHO predicted by CALGRID for 28 August 2007 - RFG fueled vehicle scenario with SAPRC 90/93... 


\section{LIST OF FIGURES (CONT'D)}

5-20a Daily maximum hourly benzene predicted by CALGRID for 27 August 2007 - RFG fueled vehicle scenario with SAPRC 90/93.

5-20b Daily maximum hourly benzene predicted by CALGRID for 28 August 2007 - RFG fueled vehicle scenario with SAPRC 90/93.

5-21a Daily maximum hourly butadiene predicted by CALGRID for 27 August 2007 - RFG fueled vehicle scenario with SAPRC 90/93.

5-21b Daily maximum hourly butadiene predicted by CALGRID for 28 August 2007 - RFG fueled vehicle (RFG) scenario with SAPRC 90/93 .................................................................. 5-56

5-22a Daily maximum 1-hr HCHO during August 272007 - RFG w SAPRC90/93 minus S1 w

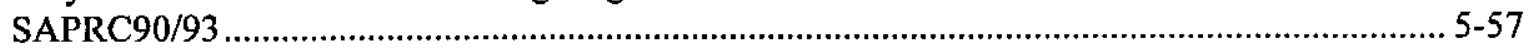

5-22a Daily maximum 1-hr HCHO during August 282007 - RFG w SAPRC90/93 minus S1 w

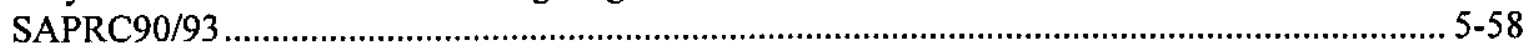

5-23a Daily maximum 1-hr HCHO during August 27 2007 - RFG w SAPRC90/93 minus CNG w

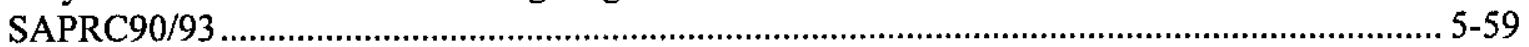

5-23b Daily maximum 1-hr HCHO during August 28 2007 - RFG w SAPRC90/93 minus CNG w

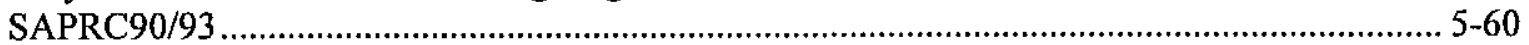

5-24a Daily maximum 1-hr HCHO during August 27 2007 - RFG w SAPRC90/93 minus M85 w SAPRC90/93...

5-24b Daily maximum 1-hr HCHO during August 28 2007 - RFG w SAPRC90/93 minus M85 w SAPRC90/93.

5-25a Daily maximum 8-hr HCHO during August 27 2007 - RFG w SAPRC90/93 minus CNG w

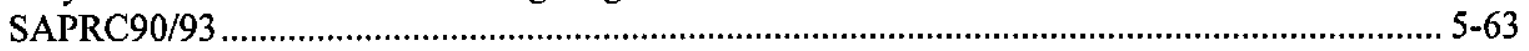

5-25b Daily maximum 8-hr HCHO during August 282007 - RFG w SAPRC90/93 minus CNG w

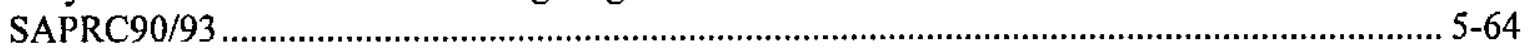

5-26a Daily maximum 8-hr HCHO during August 272007 - RFG w SAPRC90/93 minus M85 w

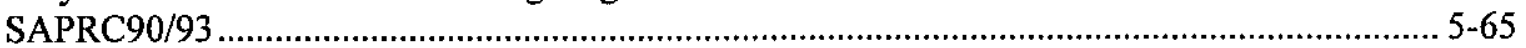

5-26b Daily maximum 8-hr HCHO during August 28 2007 - RFG w SAPRC90/93 minus M85 w

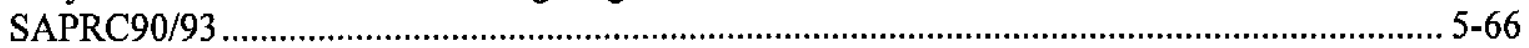

5-27a Cumulative 1-hr HCHO exposure percentile differences during August 27 2007. RFG w SAPRC90/93 minus CNG w SAPRC90/93

5-27b Cumulative 1-hr HCHO exposure percentile differences during August 28 2007. RFG w SAPRC90/93 minus CNG w SAPRC90/93 …................................................................... 5-68

5-28a Cumulative 1-hr HCHO exposure percentile differences during August 27 2007. RFG w SAPRC $90 / 93$ minus M85 w SAPRC90/93.

5-28b Cumulative 1-hr HCHO exposure percentile differences during August 28 2007. RFG w SAPRC $90 / 93$ minus M85 w SAPRC90/93. 


\section{List of Acronyms}

\begin{tabular}{|c|c|}
\hline ACET & Acetone \\
\hline ACRO & Acrolein \\
\hline ALD2 & Higher Aldehydes and Acetaldehyde \\
\hline ALK1 & Alkane Group 1 \\
\hline ALK2 & Alkane Group 2 \\
\hline AQMP & Air Quality Management Plan \\
\hline ARO1 & Aromatic Group 1 \\
\hline $\mathrm{ARO} 2$ & Aromatic Group 2 \\
\hline BENZ & Benzene \\
\hline BUDI & 1,3,-Butadiene \\
\hline CARB & California Air Resource Board \\
\hline CB-4 & Carbon Bond 4 \\
\hline $\mathrm{CCHO}$ & Acetaldehyde \\
\hline $\mathrm{CCO}-\mathrm{O}_{2} / \mathrm{C}_{2} \mathrm{O}_{3}$ & Peroxy acetyl radical \\
\hline CNG & Compressed Natural Gas \\
\hline $\mathrm{CO}$ & Carbon Monoxide \\
\hline $\mathrm{CO}_{2}$ & Carbon Dioxide \\
\hline CRES & Cresols \\
\hline CRO & Methylphenoxy radical \\
\hline DOLA & Downtown Los Angeles \\
\hline ETH/ETHE & Ethene \\
\hline ETOH & Ethanol \\
\hline FCM & Flexible Chemical Mechanism \\
\hline FORM & Formaldehyde \\
\hline $\mathrm{g} / \mathrm{s}$ & grams per second \\
\hline $\mathrm{H}_{2} \mathrm{O}_{2}$ & Hydrogen Peroxide \\
\hline HALD & Higher Aldehydes \\
\hline $\mathrm{HCHO}$ & Formaldehyde \\
\hline HCHOM & Formaldehyde - non-radical formation path \\
\hline HCHOR & Formaldehyde - radical formation path \\
\hline $\mathrm{HNO}_{3}$ & Nitric Acid \\
\hline $\mathrm{HO} / \mathrm{OH}$ & Hydroxyl radical \\
\hline $\mathrm{HO}_{2} / \mathrm{HO}_{2}$ & Hydroperoxy radical \\
\hline IOLE & Internal Olefin \\
\hline ISOP & Isoprene \\
\hline $\mathrm{m}$ & meters \\
\hline MEOH & Methanol \\
\hline MEK & Methylethyl Ketone \\
\hline MGLY & Methylglyoxal \\
\hline MTBE & Methyl Terbutyl Ether \\
\hline $\mathrm{m} / \mathrm{s}$ & meters per second \\
\hline M85 & $85 \%$ Methanol \\
\hline NAAQS & National Ambient Air Quality Standards \\
\hline $\mathrm{NO}$ & Nitric Oxide \\
\hline $\mathrm{NO}_{2}$ & Nitrogen Dioxide \\
\hline $\mathrm{NO}_{\mathrm{x}}$ & Nitrogen Oxides \\
\hline
\end{tabular}




\section{List of Acronyms}

\begin{tabular}{|c|c|}
\hline NR & Non Reactive Carbon \\
\hline NREL & National Renewable Energy Laboratory \\
\hline O1D & Excited Atomic Oxygen \\
\hline $\mathrm{O}_{3}$ & Ozone \\
\hline O3P & Atomic Oxygen \\
\hline OLE/OLE(N) & Olefins \\
\hline OLE1 & Olefins Group 1 \\
\hline OLE2 & Olefins Group 2 \\
\hline OLE3 & Olefins Group 3 \\
\hline OPEN & Open/Broken Carbon Ring Compounds \\
\hline PAN & Peroxy acetyl nitrate \\
\hline PAR & Paraffins \\
\hline PNA & Peroxynitric Acid \\
\hline $\mathrm{ppb}$ & parts per billion \\
\hline pphm & parts per hundred million \\
\hline ppm & parts per million \\
\hline PPN & Peroxy Propionyl Nitrite \\
\hline $\mathrm{RCHO}$ & Acetaldehyde \\
\hline $\mathrm{RCO}_{3}$ & Total Peroxyacyl Radical \\
\hline RFG & Reformulated Gasoline \\
\hline $\mathrm{RNO}_{3}$ & Methyl Nitrate \\
\hline $\mathrm{RO}_{2}$ & Total Alkyl Peroxy Radical \\
\hline ROR & Secondary Organic Oxy Radical (CB-4) \\
\hline $\mathrm{R} 2 \mathrm{O} 2$ & NO to $\mathrm{NO}_{2}$ Conversion Operator \\
\hline SAPRC & State-Wide Air Pollution Research Center \\
\hline SCAQMD & South Coast Air Quality Management District \\
\hline SCAQS & South Coast Air Quality Study \\
\hline SIP & State Implementation Plan \\
\hline $\mathrm{SO}_{2}$ & Sulfur Dioxide \\
\hline $\mathrm{SO}_{3}$ & Sulfur Trioxide \\
\hline $\mathrm{TO}_{2}$ & Toluene - hydroxyl radical adduct (CB-4) \\
\hline TOL & Toluene \\
\hline UAM-IV & Urban Airshed Model Version IV \\
\hline UNR & Unreactive \\
\hline VOC & Volatile Organic Compounds \\
\hline $\mathrm{XO} 2$ & $\mathrm{NO}-$ to $\mathrm{NO}_{2}$ operation $(\mathrm{CB}-4)$ \\
\hline $\mathrm{XO} 2 \mathrm{~N}$ & $\mathrm{NO}-$ to $\mathrm{NO}_{3}$ operation (CB-4) \\
\hline XYL & Xylene \\
\hline
\end{tabular}




\subsection{INTRODUCTION}

The National Renewable Energy Laboratory (NREL) has been conducting a comprehensive program to quantify and assess the air quality impacts of the emissions of ozone precursors, air toxins, and greenhouse gases from alternative fueled vehicles. This comprehensive program includes both an emission estimation component and a photochemical modeling component to study three fuels, reformulated gasoline (RFG), compressed natural gas (CNG), and $85 \%$ methanol (M85). The photochemical modeling component includes (1) the development of photochemical model inputs, (2) the exercise of the photochemical model, and (3) the interpretation of the model results in terms of the impacts of the emissions on ozone and toxic chemical exposure. In previous reports, photochemical modeling was conducted using the Urban Airshed Model (UAM-IV) and the Carbon Bond 4 (CB-4) chemical mechanism.

This report describes the use of the CALGRID model (Yamartino et. al. 1992 and Scire and Yamartino 1989) in the Los Angeles modeling domain using the State-Wide Air Pollution Research Center (SAPRC90) chemical mechanism and an early version of the SAPRC93 mechanism (Carter 1995). The simulation was conducted on the Los Angeles modeling domain for the year 2007 using the emissions inventories developed by Radian and Earth Tech in previous portions of the work under NREL subcontract YCC-05-14072-01. Model simulations of ozone and four toxic compounds for each of the three fuels are described and intercompared. Measures of maximum daily concentration and population exposure are presented to assist in evaluating each of the alternative fuels.

\subsection{Project Overview}

The main objective of NREL in supporting this phase of the study is to use a second photochemical model, CALGRID, and a subsequent chemical mechanism, the SAPRC90/93 mechanism, to evaluate the impact of the three fuels on air quality in the year 2007. The use of a second model and chemical mechanism is intended to provide alternative estimates of the impacts of fuel use on ozone and toxic concentration exposures for Los Angeles. Eventually the results will be compared with other modeling studies such as those using UAM-IV and CB-4 (e.g., Balentine et al. 1997a and Moore, Fernau and Londergan 1998) in order to provide a more robust consensus view of the air impacts of the use of alternative fuels.

The SAPRC chemical scheme has been used in several studies to estimate the incremental reactivities (IR's) of alternative fuels (e.g., Carter 1994). The incremental reactivities of several chemical families such as aromatics have been found to differ between chemical mechanisms. One objective of the present study is to see how those differences affect predicted ozone and toxic exposure response when M85 or CNG is used instead of RFG in light- and medium-duty gas fueled vehicles. The CALGRID model provides better spatial resolution, and improved representation of physical processes such as deposition and turbulent diffusion near roadways. A secondary objective is to quantify how the modeling limitations imposed by the use of a model such as UAM-IV might affect the air quality impacts predicted for each type of fuel. 


\subsection{Overview of Methodology}

The photochemical modeling protocol (Balentine et al. 1997c) reviewed the 1994 Air Quality Management Plan (AQMP) developed by the South Coast Air Quality Management District (SCAQMD). The review indicated the model performance by UAM-IV CB-4 for the 27-28 August 1987 ozone episode was rather poor by the standards set out by California Air Resources Board (CARB 1990). The volatile organic compound (VOC) emissions inventory and the meteorology were identified as two major reasons for significant underpredictions of the daily peak hourly ozone concentrations.

It was recommended that improved meteorological modeling might improve performance in conjunction with an increased number of model layers. However, the original AQMP UAM-IV CB-4 meteorological inputs were ultimately used (Balentine et al. 1997a). Earlier work by Kumar et al. (1994) found that CALGRID model performance is much the same as UAM-IV when low-resolution model input data were used. Applying CALGRID in that manner negates many of the numerical and scientific advantages of the CALGRID model, particularly in terms of how transport and diffusion are represented. Rather than altering only the chemical mechanism such as was done for the flexible chemistry version of UAM-IV (Kumar et al. 1995), the choice was made to apply CALGRID using a new set of meteorological inputs in order to take advantage of its technical features.

CALGRID was run with the same horizontal grid, but with greater vertical resolution (twelve fixed layers, versus five layers with variable depth for UAM-IV). The CALMET diagnostic meteorology model (Scire et al. 1995) was used to create meteorological inputs for CALGRID, starting from the same meteorological observations used to create UAM-IV inputs. CALGRID model simulations were first made for the base year emissions scenario using both the CB- 4 and SAPRC90 chemical mechanisms. For SAPRC simulations, the emissions and initial concentration and boundary concentration $(\mathrm{IC} / \mathrm{BC})$ input files were modified to reflect the different chemical species definitions (compared to CB-4). For CB-4 simulations, the existing UAM -IV emissions were used, while IC/BC inputs were converted to the CALGRID vertical layer structure.

The original SAPRC90 chemical mechanism described in Carter (1993) was upgraded by incorporating improvements in the photolysis rate estimates, chemical reaction yields, and reaction rate coefficients. The upgrades are described in Carter (1995), however the SAPRC93 mechanism did not become formalized until the mechanism with a larger number of reactions was incorporated into the UAM-IV flexible chemical mechanism (FCM) (Lurmann et al. 1996). In this study the SAPRC90/93 set of reactions described by Carter (1995) with the common lumping of two alkane, three alkene, and two aromatic groups is used since previous emission inventory estimates and model input preprocessors have been developed for the species making up the SAPRC90 mechanism.

The SAPRC mechanism required the implementation of two toxic "ghost" species for estimation of exposure to air pollutants identified as toxic compounds. The reactions of benzene (BENZE) and 1,3- butadiene (BUDI) with ozone, the hydroxyl radical, and the nitrate radical are implemented so that these chemicals are destroyed, but their products do not affect the chemical 
mass budget. Chemical box modeling results are presented showing how the toxic compounds degrade with time, and how the SAPRC90/93 mechanism differs from the original SAPRC90 mechanism and from the CB-4 mechanism.

The modeling analysis focused on ozone and four toxic compounds including:

- Formaldehyde (HCHO)

- Acetaldehyde (CCHO)

- Benzene (BENZ)

- 1,3-butadiene (BUDI)

Several quality assurance simulations were conducted:

- Base year 1987 with CALGRID using CB-4 (QA1)

- Base year 1987 with CALGRID using SAPRC90 (QA2)

- Future year 2007 with no light duty vehicle emissions (S1) using SAPRC90 (QA3)

- Future year 2007 with no light duty vehicle emissions (S1) using SAPRC 90/93 (QA4).

The base year simulations are compared with their UAM-IV counterparts and with observed ozone air quality in order to determine how each model given the same CB-4 chemistry. A second run with SAPRC90 chemistry demonstrates how the change in the chemical mechanism will affect the results. A third run indicates how the future year emissions, without light- and medium-duty gas vehicles, will generate ozone and toxic concentrations when the SAPRC90 chemical mechanism is used. The results of this run are compared against the results of a fourth simulation where the only difference is the use of the SAPRC90/93 mechanism.

A series of CALGRID simulations were conducted using both versions of the SAPRC chemistry. At the outset it was not known if the upgrade of the SAPRC mechanism would result in significant changes in predicted ozone and toxic compound maximum concentrations and population exposures. As a precaution, both versions of the chemical mechanism were exercised for each of the three fuel scenarios studied. A total of eight fuel scenario simulations were conducted as summarized in Table 1-1.

Table 1-1. A Summary of Model Simulations (and Their Run Designations) Conducted for the Present Study.

\begin{tabular}{|l|l|l|}
\hline \multirow{2}{*}{ Fuel Scenario } & \multicolumn{2}{|c|}{ Chemistry } \\
\cline { 2 - 3 } & SAPRC90 & SAPRC 90/93 \\
\hline Null - no vehicle emissions (S1) & QA3 & QA4 \\
\hline RFG & S-R1 & S-R2 \\
\hline CNG & S-C1 & S-C2 \\
\hline M85 & S-M1 & S-M2 \\
\hline
\end{tabular}




\subsection{Organization of the Report}

Section 2 describes the photochemical mechanisms, including modifications made to the original SAPRC90 mechanism, and presents the results of numerical 'smog chamber' predictions of $\mathrm{O}_{3}$, $\mathrm{HCHO}$, and CCHO concentrations. In Section 3 the model input preparation is described. A major portion of Section 3 is devoted to meteorological modeling. The remainder of the section describes a preprocessing system that was used to convert UAM-IV CB-4 (toxics) boundary and initial concentrations and emissions input into equivalent CALGRID SAPRC90 (toxics) input files.

Section 4 contains a description and analysis of the base year (1987) simulations conducted using both CB4 and the original SAPRC90 mechanism. The differences in ozone and HCHO concentrations are analyzed. Section 5 presents the results of the CALGRID simulations for the no light-duty vehicle (S1) scenario, the RFG fueled vehicle scenario, the CNG fueled vehicle scenario, and the M85 fueled vehicle scenario. The study results and conclusions are summarized in Section 6. 


\subsection{CALGRID SAPRC90/93 Implementation}

One of the objectives of the present study is to model the concentrations and population exposure to several toxic compounds including BENZ and BUDI using the SAPRC chemical mechanism. This chemical mechanism has evolved as our understanding of atmospheric chemistry increases, making it desirable to implement the more recent versions into the CALGRID photochemical model. This section describes some of the changes made to the SAPRC90 mechanism used in CARB's original version of CALGRID.

The original SAPRC90 implementation to CALGRID does not have an explicit representation of the BUDI or the BENZ chemistry. These two chemicals are lumped into group 1 olefins (OLE1) and group 1 aromatics (ARO1) respectively. Using the same techniques as were used in the UAM-IV with CB-4, these two species were implemented as 'ghost' species so that their chemical breakdown could be modeled explicitly, yet their explicit presence would not perturb the gas-phase chemistry.

A second series of revisions were made to the original SAPRC90 chemistry (Carter 1990) in order to upgrade the chemistry in a version of what is now referred to as the SAPRC93 chemistry. Earth Tech proposed to make changes in the chemical module so that it resembles the chemistry described in Carter (1995). While the structural form of the mechanism was not changed by adding species and reactions, however, several types of parametric revisions were made:

1) Updates to the photolysis rate data

2) Upgrades in the rate coefficients for some reactions

3) Changes in product yield coefficients for some lumped species.

The SAPRC93 version described in Carter (1995) further evolved; by 1997 the mechanism has considerably more radical species and reactions than the original SAPRC93. The mechanism used in this study is actually a precursor to the present SAPRC93 and so will be referred to as SAPRC90/93.

\subsection{Addition of Explicit Reactions for Several Toxic Compounds}

The original work of Killus (1996) which began adding 'ghost' species to the SAPRC90 chemical routine DIFUN was continued. A total of six additional reactions for BENZ, BUDI and acrolein (ACRO) were added to the chemistry bringing the total number of reactions up to 135 and the number of active species to 42 . The reactions are the following:

$$
\begin{aligned}
& (\mathrm{R} 130)[\mathrm{BENZ}]+[\mathrm{OH}]=[\text { Ghost products }] \mathrm{K}=1.82 \times 10^{3} \\
& (\mathrm{R} 131)[\mathrm{BUDI}]+[\mathrm{OH}]=[\text { Ghost products }] \mathrm{K}=9.90 \times 10^{4} \\
& \text { (R132) }[\mathrm{BUDI}]+[\mathrm{O} 3]=[\text { Ghost products }] \mathrm{K}=1.00 \times 10^{-3}
\end{aligned}
$$


(R133) $[\mathrm{BUDI}]+[\mathrm{NO}]=[$ Ghost products $] \mathrm{K}=1.45 \times 10^{2}$

(R134) $[\mathrm{ACRO}]+[\mathrm{OH}]=[$ Ghost products $] \mathrm{K}=3.00 \times 10^{-4}$

$(\mathrm{R} 135)[\mathrm{ACRO}]+[\mathrm{O} 3]=[$ Ghost products $] \mathrm{K}=1.10 \times 10^{-3}$

where the rate coefficients are in units of $\mathrm{ppm}^{-1} \mathrm{~min}^{-1}$.

Chemical box model testing was used to evaluate how quickly BENZ and BUDI are destroyed. A one-day smog chamber simulation was made using the CALGRID chemical routines and solver. The user-specified parameters and initial condition concentrations for the box model simulation are given in Tables 2-1 and 2-2, respectively.

Table 2-1. A Summary of the User-Specified Chemical Box Model Parameters Used to Study the Destruction of the

Toxic Compounds BENZ and BUDI.

\begin{tabular}{|c|c|}
\hline Parameter & Assigned value \\
\hline pressure (mb) & 1013 \\
\hline Temperature (deg K) & 300.0 \\
\hline Relative humidity (\%) & 50.0 \\
\hline Columnar ozone (DU) & 320 \\
\hline UV tropospheric attenuation & 0.0 \\
\hline UV albedo & 0.0 \\
\hline Tendency convergence increment & $1.0 \times 10^{-8}$ \\
\hline Smallest temperature increment & 0.15 \\
\hline julian day & 180 \\
\hline lat/lon & $37 \mathrm{~N} 105 \mathrm{~W}$ \\
\hline Solver & $2=$ flexible step SS \\
\hline Emissions model & $1=$ fraction of initial conc \\
\hline
\end{tabular}

The box model experiment is one where volatile organic compounds (VOC's) are initially injected and used up. This type of test is particularly useful if the breakdown history of toxic species is being studied. The ozone forming reactions are sustained through the day by continuous emissions of $\mathrm{NO}$ and $\mathrm{NO}_{2}$ in a realistic combustion profile.

Figure 2-1 shows the resulting time series of concentrations of BENZ and BUDI. The percent of maximum concentrations percentiles are defined by:

$$
\mathrm{c}^{\prime}=100\left[\mathrm{C}-\mathrm{C}_{\min }\right] /\left[\mathrm{C}_{\max }-\mathrm{C}_{\min }\right]
$$


Table 2-2. A Summary of the Initial Condition Concentrations Used for the Chemical Box Model Simulation Testing of the SAPRC90 Toxics Version.

\begin{tabular}{|c|c|c|}
\hline Specie & $\begin{array}{c}\text { Initial } \\
\text { concentration }\end{array}$ & $\begin{array}{c}\text { Emission fraction } \\
\text { (\% of initial) }\end{array}$ \\
\hline $\mathrm{O}_{3}$ & $.400 \mathrm{E}-01$ & .000 \\
\hline NO & $.250 \mathrm{E}-01$ & .300 \\
\hline $\mathrm{NO}_{2}$ & $.750 \mathrm{E}-01$ & .030 \\
\hline ALK1 & $.100 \mathrm{E}+00$ & .000 \\
\hline ALK2 & $.100 \mathrm{E}+00$ & .000 \\
\hline ARO1 & $.300 \mathrm{E}-01$ & .000 \\
\hline ARO2 & $.200 \mathrm{E}-01$ & .000 \\
\hline MEOH & $.100 \mathrm{E}-02$ & .000 \\
\hline ETOH & $.500 \mathrm{E}-03$ & .000 \\
\hline MTBE & $.100 \mathrm{E}-08$ & .000 \\
\hline ETHE & $.300 \mathrm{E}-01$ & .000 \\
\hline OLE1 & $.600 \mathrm{E}-02$ & .000 \\
\hline OLE2 & $.200 \mathrm{E}-04$ & .000 \\
\hline $\mathrm{OLE}_{3}$ & $.200 \mathrm{E}-04$ & .000 \\
\hline $\mathrm{HCHO}$ & $.250 \mathrm{E}-01$ & .000 \\
\hline$\overline{\mathrm{CCHO}}$ & $.250 \mathrm{E}-03$ & .000 \\
\hline $\mathrm{RCHO}$ & $.100 \mathrm{E}-03$ & .000 \\
\hline MEK & $.300 \mathrm{E}-03$ & .000 \\
\hline CRES & $.100 \mathrm{E}-08$ & .000 \\
\hline$\overline{M G L Y}$ & $.100 \mathrm{E}-08$ & .000 \\
\hline AFG2 & $.100 \mathrm{E}-08$ & .000 \\
\hline $\mathrm{NO}_{3}$ & $.100 \mathrm{E}-08$ & .000 \\
\hline $\mathrm{N}_{2} \mathrm{O}_{5}$ & $.100 \mathrm{E}-08$ & .000 \\
\hline $\mathrm{HNO}_{3}$ & $.100 \mathrm{E}-08$ & .000 \\
\hline HONO & $.100 \mathrm{E}-08$ & .000 \\
\hline $\mathrm{HNO}_{4}$ & $.100 \mathrm{E}-08$ & .000 \\
\hline $\mathrm{HO}_{2}$ & $.100 \mathrm{E}-08$ & .000 \\
\hline $\mathrm{CO}$ & $.220 \mathrm{E}+00$ & .000 \\
\hline $\mathrm{HO}_{2} \mathrm{H}$ & $.100 \mathrm{E}-08$ & .000 \\
\hline $\mathrm{SO}_{2}$ & $.100 \mathrm{E}-02$ & .000 \\
\hline $\mathrm{RO}_{2}$ & $.100 \mathrm{E}-08$ & .000 \\
\hline $\mathrm{CCO}-\mathrm{O}_{2}$ & $.100 \mathrm{E}-08$ & .000 \\
\hline $\mathrm{C}_{2} \mathrm{CO}-\mathrm{O}_{2}$ & $.100 \mathrm{E}-08$ & .000 \\
\hline$-\mathrm{OOH}$ & $.100 \mathrm{E}-08$ & .000 \\
\hline $\mathrm{RNO}_{3}$ & $.100 \mathrm{E}-08$ & .000 \\
\hline PAN & $.100 \mathrm{E}-08$ & .000 \\
\hline$\overline{\mathrm{PPN}}$ & $.100 \mathrm{E}-08$ & .000 \\
\hline BENZ & $.100 \mathrm{E}-02$ & .000 \\
\hline BUDI & $.100 \mathrm{E}-02$ & .000 \\
\hline ACRO & $.100 \mathrm{E}-02$ & .000 \\
\hline
\end{tabular}




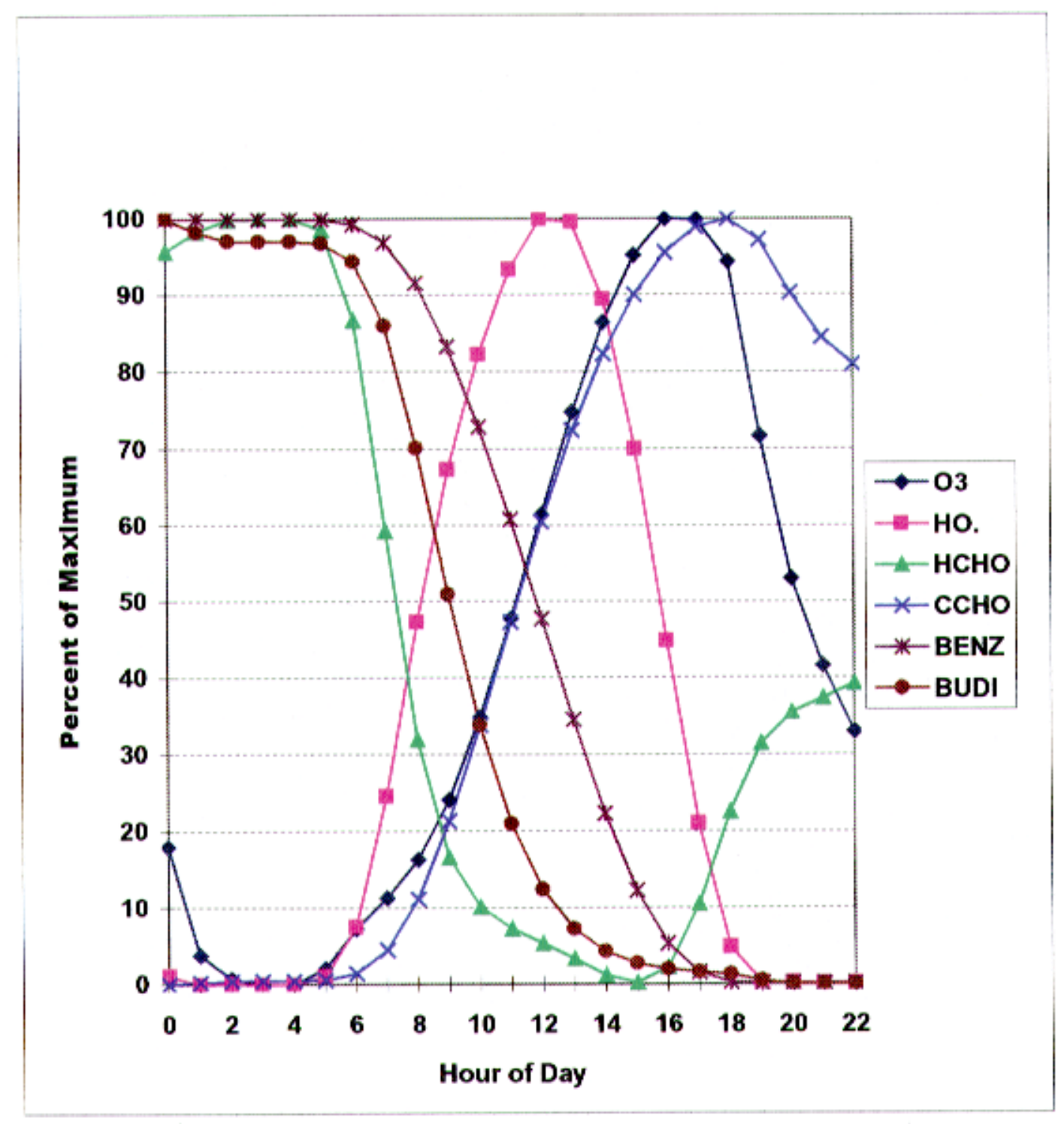

Figure 2-1. SAPRC90 predicted concentration time series of selected compounds. 
The maximum concentrations of BENZ and BUDI, which correspond to the initial concentrations, are $1 \mathrm{ppb}$ for BENZ and $1 \mathrm{ppb}$ for BUDI. From Figure 2-1 it can be noted that during the night the "dark" reactions of BUDI are rather slow, and BENZ does not react at all. As soon as the sun comes up and appreciable HO. radical concentrations build up the concentrations of BENZ and BUDI decrease much more rapidly. For the present experiment, the factor of ten decay time is of the order 9 hours for BENZ and 6 hours for BUDI. The initial decay rate for BENZ under SAPRC90 is greater than it was for CB-4 owing to the use of different rate coefficients and different predicted HO. concentrations in the morning. The rate of decay for BENZ, while large, does not seem to be unreasonable.

\subsection{Photolysis Rate Upgrades}

The largest differences between the SAPRC90 chemical mechanism (Carter 1990) and the SAPRC93 chemical mechanism (Carter 1995) lie in the photolysis rate coefficients. Included in the modifications were the following data set upgrades:

- HCHO absorption cross-sections were updated to those of Cantrell et al. (1990) and Rodgers (1990).

- ACRO action spectra were used to estimate the aromatic fragmentation rate due to photolysis (replace AROMUNK).

- The acetone quantum yields were modified.

In addition a few minor differences were found in the photoloysis rates for $\mathrm{CCHO}$ and the higher aldehydes. Values from the SAPRC93 data set (Carter 1995) were used preferentially over those found in the older chemical parameter files.

The SAPRC93 photolysis data files contain the spectral band center, the cross-section, and the quantum yield (the product of cross section and yield are called action parameters). Because of parametric fitting of the solar radiation flux spectrum, the solar photolysis rate algorithms in CALGRID require 27 predefined spectral bands. Software was developed to map the action spectra accurately to the 27 bands used by CALGRID.

The differences in the product of quantum yields and cross-sections between SAPRC90 and SAPRC93 are presented in Table 2-3 for $\mathrm{HCHO}$ and the generic action spectra.

It can be noted from Table 2-3 that new action spectra in SAPRC90/93 tend to have larger values at longer wave lengths where the solar actinic flux is greater, leading to larger photolysis rates. Thus it is expected that $\mathrm{HCHO}$ will be destroyed more rapidly as will the aromatic fragments. 
Table 2-3. A Summary of the Cross-Section and Quantum Yield Products for Selected Photolytic Reactions in Units of $10^{-20} \mathrm{~cm}^{2}$.

\begin{tabular}{|l|c|c|c|c|c|c|}
\hline $\begin{array}{l}\text { Spectral } \\
\text { Interval (nm) }\end{array}$ & \multicolumn{2}{|c|}{ HCHOM } & \multicolumn{2}{c|}{ HCHOR } & \multicolumn{2}{c|}{ GENERIC } \\
\hline & SAPRC90 & SAPRC93 & SAPRC90 & SAPRC93 & SAPRC90 & SAPRC93 \\
\hline $0.295-0.300$ & 0.59 & 0.62 & 1.95 & 2.04 & 7.90 & 2.43 \\
\hline $0.300-0.305$ & 0.62 & 0.64 & 2.16 & 2.22 & 7.90 & 3.06 \\
\hline $0.305-0.310$ & 0.65 & 0.6 & 2.20 & 2.08 & 7.90 & 3.71 \\
\hline $0.310-0.315$ & 0.54 & 0.63 & 1.41 & 1.60 & 7.90 & 4.38 \\
\hline $0.315-0.320$ & 0.95 & 0.91 & 1.90 & 1.82 & 7.90 & 4.97 \\
\hline $0.320-0.325$ & 0.43 & 0.34 & 0.53 & 0.44 & 7.90 & 5.54 \\
\hline $0.325-0.330$ & 1.64 & 2.05 & 1.05 & 1.34 & 7.90 & 5.69 \\
\hline $0.330-0.335$ & 0.52 & 0.44 & 0.21 & 0.18 & 7.90 & 6.19 \\
\hline $0.335-0.340$ & 0.87 & 1.25 & 0.05 & 0.06 & 7.90 & 5.77 \\
\hline $0.340-0.345$ & 0.69 & 0.64 & 0.00 & 0.00 & 7.90 & 5.48 \\
\hline $0.345-0.350$ & 0.05 & 0.03 & 0.00 & 0.00 & 3.95 & 5.78 \\
\hline $0.350-0.360$ & 0.13 & 0.14 & 0.00 & 0.00 & 0.00 & 3.90 \\
\hline $0.360-0.370$ & 0.00 & 0.00 & 0.00 & 0.00 & 0.00 & 2.75 \\
\hline $0.370-0.380$ & 0.00 & 0.00 & 0.00 & 0.00 & 0.00 & 0.48 \\
\hline $0.380-0.390$ & 0.00 & 0.00 & 0.00 & 0.00 & 0.00 & 0.00 \\
\hline $0.390-0.400$ & 0.00 & 0.00 & 0.00 & 0.00 & 0.00 & 0.00 \\
\hline $0.400-0.410$ & 0.00 & 0.00 & 0.00 & 0.00 & 0.00 & 0.00 \\
\hline $0.410-0.420$ & 0.00 & 0.00 & 0.00 & 0.00 & 0.00 & 0.00 \\
\hline $0.420-0.430$ & 0.00 & 0.00 & 0.00 & 0.00 & 0.00 & 0.00 \\
\hline $0.430-0.440$ & 0.00 & 0.00 & 0.00 & 0.00 & 0.00 & 0.00 \\
\hline $0.440-0.450$ & 0.00 & 0.00 & 0.00 & 0.00 & 0.00 & 0.00 \\
\hline $0.450-0.460$ & 0.00 & 0.00 & 0.00 & 0.00 & 0.00 & 0.00 \\
\hline $0.460-0.470$ & 0.00 & 0.00 & 0.00 & 0.00 & 0.00 & 0.00 \\
\hline $0.470-0.480$ & 0.00 & 0.00 & 0.00 & 0.00 & 0.00 & 0.00 \\
\hline $0.480-0.490$ & 0.00 & 0.00 & 0.00 & 0.00 & 0.00 & 0.00 \\
\hline $0.490-0.500$ & 0.00 & 0.00 & 0.00 & 0.00 & 0.00 & 0.00 \\
\hline $0.500-1.000$ & 0.00 & 0.00 & 0.00 & 0.00 & 0.00 & 0.00 \\
\hline
\end{tabular}

\subsection{Kinetic Parameter Upgrades}

The kinetic parameters of the reactions of $\mathrm{CCO}-\mathrm{O}_{2}$. (peroxy acetyl radical) with $\mathrm{NO}$ and $\mathrm{NO}_{2}$ were upgraded as was the thermal decomposition of PAN. The reactions modified were

(C13) $\mathrm{CCO}-\mathrm{O}_{2} \cdot+\mathrm{NO}=\mathrm{CO}_{2}+\mathrm{NO}_{2}+\mathrm{HCHO}+\mathrm{RO}_{2}-\mathrm{R} .+\mathrm{RO}_{2}$.

(C14) $\mathrm{CCO}-\mathrm{O}_{2} \cdot+\mathrm{NO}_{2}=\mathrm{PAN}$

(C18) $\quad \mathrm{PAN}=\mathrm{CCO}-\mathrm{O}_{2} \cdot+\mathrm{NO}_{2}+\mathrm{RCO}_{3}$.

where the rate coefficients are for $300 \mathrm{~K}$ and surface pressure. These revised rates were made in the chemical input file. Reactions $\mathrm{C} 14$ and $\mathrm{C} 18$ are governed by the falloff (Troe) reaction rate 
formulas. The $\mathrm{C} 13$ reaction rate is an Arrhenius kinetic formula. The SAPRC93 falloff relationship was fitted to the Arrhenius formula over the range $275-315 \mathrm{~K}$ so that the mechanism input parameter (*.MOD) file would not have to be completely reworked. The differences in the reaction coefficients between SAPRC90 and SAPRC90/93 are presented in Table 2-4.

Table 2-4. A Listing of the Chemical Rate Coefficient Parameters for the Three Reactions Revised in SAPRC93.

\begin{tabular}{|l|c|c|}
\hline Parameter & SAPRC90 & SAPRC90/93 \\
\hline C13 - A & $7.486 \mathrm{E}+03$ & $2.828 \mathrm{E}+04$ \\
\hline C13 - B & -0.397 & 0.000 \\
\hline C13- EA & -1.000 & -2.205 \\
\hline C14 - f & 0.270 & 0.300 \\
\hline C14 - N & 1.000 & 1.000 \\
\hline C14 - A0 & 7.003 & 9.229 \\
\hline C14 - E0 & 0.000 & 0.000 \\
\hline C14 - B0 & -6.000 & -9.100 \\
\hline C14 - A1 & $1.23 \mathrm{E}+04$ & $1.761 \mathrm{E}+04$ \\
\hline C14 - E1 & 0.000 & 0.000 \\
\hline C14 - B1 & -1.000 & -1.900 \\
\hline C18 - f & 0.270 & 0.300 \\
\hline C18 - N & 1.000 & 1.000 \\
\hline C18 - A0 & $9.248 \mathrm{E}+13$ & $7.193 \mathrm{E}+12$ \\
\hline C18 - E0 & 25.410 & 23.970 \\
\hline C18 - B0 & -1.000 & -1.00 \\
\hline C18 - A1 & $1.320 \mathrm{E}+18$ & $2.400 \mathrm{E}+18$ \\
\hline C18 - E1 & 26.700 & 27.080 \\
\hline C18 - B1 & 0.000 & 0.000 \\
\hline
\end{tabular}

\subsection{Yield Parameter Upgrades}

The reaction of HO. with acetone (ACET) was modified so that no methylgyoxal (MGLY) is formed, rather the yield is now completely formaldehyde plus radicals, e.g.,

$$
\mathrm{ACET}+\mathrm{HO} .=\mathrm{R}_{2} \mathrm{O}_{2} \cdot+\mathrm{HCHO}+\mathrm{CCO}-\mathrm{O}_{2} \cdot+\mathrm{RCO}_{3} \cdot+\mathrm{RO}_{2} .
$$

The yields of the reactions of ozone with alkenes (OLEn) were modified to produce higher yields of $\mathrm{HO}$ radicals via the proposed agency of substituted Crigee biradical formation. To avoid adding reactions the HO. yields of ethene (ETHE) and OLEn were modified. The modification of the ETHE yield was relatively straightforward.

$$
\mathrm{ETHE}+\mathrm{O}_{3}=\mathrm{HCHO}+0.12 \mathrm{HO}_{2}+0.12 \mathrm{HO} .+0.12 \mathrm{CO}+0.88(\mathrm{UNR})(\text { reaction \#110) }
$$

The three classes of olefins posed a more difficult challenge since the product yield parameters were derived from the structural parameters (OnPX's) given in the reaction parameter (*.RXP) 
file. These parameters appear in more than one reaction other than for just the $\mathrm{OnO}_{3} \mathrm{OH}$ term. As a result of this a different strategy was pursued. The product yield term for HO. is given by:

$$
\mathrm{OnO}_{3} \mathrm{OH}=0.5[0.12 \mathrm{OnP} 2+0.12 \mathrm{OnP} 3+0.2 \mathrm{OnP} 4+0.2 \mathrm{OnP} 5]
$$

which is easily estimated for SAPRC90 from the structure parameters in the reaction parameter file. In SAPRC90 the HO. yields were significantly smaller than the $\mathrm{HO}_{2}$ yields, but in SAPRC93 the decay pathway through biradicals suggests that the $\mathrm{OH}$ yields are actually equal to or slightly larger than the $\mathrm{HO}_{2}$ yields. A revised set of $\mathrm{OnO}_{3} \mathrm{OH}$ 's were estimated for the upgraded SAPRC90/93 and are reported in Table 2-5. This table illustrates how the yield parameters were increased using an across-the-board multiplier for the $\mathrm{OnO}_{3} \mathrm{OH}$ terms.

Table 2-5. A Summary of the HO. Radical Yields from the Reactions of Alkenes with Ozone for the Los Angeles Hydrocarbon Mixture.

\begin{tabular}{|l|l|l|}
\hline Product yield parameter & SAPRC90 & SAPRC90/93 \\
\hline $\mathrm{O} 1 \mathrm{O}_{3} \mathrm{OH}-(61)$ & 0.063 & 0.104 \\
\hline $\mathrm{O}_{2} \mathrm{OH}-(96)$ & 0.111 & 0.133 \\
\hline $\mathrm{O}_{3} \mathrm{O}_{3} \mathrm{OH}-(131)$ & 0.060 & 0.074 \\
\hline
\end{tabular}

The modifications were hardwired into the model code, which constructs the $\mathrm{OnO}_{3} \mathrm{OH}$ terms by multiplying the original resultant product yields by the ratio of SAPRC90/93/SAPRC90 in Table 2-6. As a result of the changes slightly more $\mathrm{HO}$. was produced than $\mathrm{HO}_{2}$ (Carter 1995) indicated that the NO-peroxy radical reaction forms small fractions of hydroxyalkyl nitrate (e.g.,10\%) for isobutene experiments. This minor revision was not made in the present study. Changes were made in the CALGRID routines DIFUNS90 $=>$ DIFFUNS93 and CNSTRS90 $=>$ CNSTRS93 as well as the chemical parameter file (COND223P.MOD).

\subsection{Testing of the Chemistry Revisions}

Several box model tests were conducted to examine the effects of each of the various types of model upgrades. The midnight to midnight chemical box model experiment described previously was used to compare the effects of the photolysis. The differences in maximum concentrations for several important chemicals are summarized in Table 2-6. This table shows that maximum ozone concentration was increased by nearly $28 \mathrm{ppb}(13 \%)$.

Table 2-6. Maximum Concentrations for Selected SAPRC90/93 Active Species.

\begin{tabular}{|l|l|l|}
\hline \multirow{2}{*}{ Species } & \multicolumn{2}{|c|}{ Maximum Concentrations (ppm) } \\
\cline { 2 - 3 } & SAPRC90 & SAPRC90/93 \\
\hline $\mathrm{O}_{3}$ & 0.222 & 0.250 \\
\hline $\mathrm{NO}_{2}$ & 0.145 & 0.138 \\
\hline $\mathrm{HCHO}$ & $0.025^{*}$ & $0.025^{*}$ \\
\hline $\mathrm{HO}$. & $8.89 \times 10^{-8}$ & $9.67 \times 10^{-8}$ \\
\hline *maximum user-supplied initial concentrations \\
\hline \multicolumn{2}{|l|}{} \\
\hline
\end{tabular}


The HO. concentrations rose by $8 \%$ due to the greater HO. production rate which in turn is due to the altered photolysis rates for $\mathrm{HCHO}$ as well as the change in HO. yields for the alkene classes. The $\mathrm{NO}_{2}$ maximum concentrations decrease slightly $(\sim 5 \%)$ as a consequence of changes in $\mathrm{HO}$. concentrations during midday. The HCHO maximums are the initial condition and are expected to remain the same. Figure 2-2 shows the time evolution of species during the same kind of box model test as was described earlier. The largest differences occur in the late morning HCHO concentrations where the SAPRC90/93 chemistry and inputs are consuming ozone more rapidly. The effects of the OLE ozone chemistry differences appear in the evening, where the effects of higher HO. yields with SAPRC90/93 are apparent. The differences in the predicted concentrations seem physically consistent with the previously described alterations.

\subsection{Comparison of CB-4 with the SAPRC90}

Previous alternative fueled vehicle modeling scenarios have been conducted using the CB-4 chemical mechanism (e.g., Balentine et al. 1997a). It is instructive to examine how differently ozone and toxic species such as HCHO may be predicted by the two chemical mechanisms. To this end an ozone "build up" box model test was made of both chemical mechanisms using the same environmental conditions and chemical solver. The urban "profile" of species described in Kumar and Lurmann (1995) were used with some slight modifications to ensure equivalent total carbon and nitrogen mass. The initial concentrations are presented in Table 2-7.

Table 2-7. A Summary of the Initial Condition (IC) Concentrations Used in the Ozone Buildup Experiment .

\begin{tabular}{|c|c|c|c|}
\hline CB-4 Species & IC (ppm) & SAPRC90 Species & IC (ppm) \\
\hline $\mathrm{NO}$ & $9.00 \mathrm{E}-02$ & $\mathrm{NO}$ & $9.00 \mathrm{E}-02$ \\
\hline $\mathrm{NO}_{2}$ & $1.00 \mathrm{E}-02$ & $\mathrm{NO}_{2}$ & $1.00 \mathrm{E}-02$ \\
\hline $\mathrm{O}_{3}$ & $1.00 \mathrm{E}-12$ & $\mathrm{O}_{3}$ & $1.00 \mathrm{E}-12$ \\
\hline $\mathrm{HONO}$ & $1.00 \mathrm{E}-12$ & $\mathrm{HONO}_{3}$ & $1.00 \mathrm{E}-12$ \\
\hline $\mathrm{HNO}_{3}$ & $1.00 \mathrm{E}-12$ & $\mathrm{HNO}_{3}$ & $1.00 \mathrm{E}-12$ \\
\hline $\mathrm{N}_{2} \mathrm{O}_{5}$ & $1.00 \mathrm{E}-12$ & $\mathrm{~N}_{2} \mathrm{O}_{5}$ & $1.00 \mathrm{E}-12$ \\
\hline $\mathrm{NO}_{3}$ & $1.00 \mathrm{E}-12$ & $\mathrm{NO}_{3}$ & $1.00 \mathrm{E}-12$ \\
\hline $\mathrm{HO}_{2}$ & $1.00 \mathrm{E}-12$ & $\mathrm{HO}_{2}$ & $1.00 \mathrm{E}-12$ \\
\hline $\mathrm{CO}$ & $1.00 \mathrm{E}+00$ & $\mathrm{CO}$ & $1.00 \mathrm{E}+00$ \\
\hline $\mathrm{FORM}$ & $2.50 \mathrm{E}-02$ & $\mathrm{HCHO}$ & $2.50 \mathrm{E}-02$ \\
\hline $\mathrm{ALD}$ & $1.25 \mathrm{E}-02$ & $\mathrm{CCHO}$ & $3.75 \mathrm{E}-03$ \\
\hline--- & --- & RCHO & $1.66 \mathrm{E}-03$ \\
\hline $\mathrm{PAN}$ & $1.00 \mathrm{E}-12$ & PAN & $1.00 \mathrm{E}-12$ \\
\hline $\mathrm{C}_{2} \mathrm{O}$ & $1.00 \mathrm{E}-12$ & CCO-O & $1.00 \mathrm{E}-12$ \\
\hline $\mathrm{MGLY}$ & $1.00 \mathrm{E}-12$ & MGLY & $1.00 \mathrm{E}-12$ \\
\hline $\mathrm{PAR}$ & $6.00 \mathrm{E}-01$ & ALK1 & $6.75 \mathrm{E}-02$ \\
\hline--- & --- & ALK2 & $3.75 \mathrm{E}-02$ \\
\hline--- & --- & MEK & $1.50 \mathrm{E}-03$ \\
\hline $\mathrm{ETH}$ & $5.00 \mathrm{E}-02$ & ETHE & $2.50 \mathrm{E}-02$ \\
\hline $\mathrm{OLE}$ & $2.50 \mathrm{E}-02$ & OLE1 & $1.25 \mathrm{E}-02$ \\
\hline ISOP & $5.00 \mathrm{E}-03$ & OLE2 & $6.00 \mathrm{E}-03$ \\
\hline--- & --- & OLE3 & $7.50 \mathrm{E}-04$ \\
\hline
\end{tabular}


Table 2-7. (Continued)

\begin{tabular}{|c|c|c|c|}
\hline CB-4 Species & IC (ppm) & SAPRC90 Species & IC (ppm) \\
\hline TOL & $2.14 \mathrm{E}-02$ & ARO1 & $2.14 \mathrm{E}-02$ \\
\hline XYL & $1.25 \mathrm{E}-02$ & $\mathrm{ARO} 2$ & $1.25 \mathrm{E}-02$ \\
\hline OPEN & $1.00 \mathrm{E}-12$ & AFG2 & $1.00 \mathrm{E}-12$ \\
\hline CRES & $1.00 \mathrm{E}-12$ & CRES & $1.00 \mathrm{E}-12$ \\
\hline ROR & $1.00 \mathrm{E}-12$ & ROR-2 & $1.00 \mathrm{E}-12$ \\
\hline--- & --- & ROR-N & $1.00 \mathrm{E}-12$ \\
\hline $\mathrm{H}_{2} \mathrm{O}_{2}$ & $1.00 \mathrm{E}-12$ & $\mathrm{HO}_{2} \mathrm{H}$ & $1.00 \mathrm{E}-12$ \\
\hline MEOH & $1.00 \mathrm{E}-12$ & $\mathrm{MEOH}$ & $1.00 \mathrm{E}-12$ \\
\hline ETOH & $1.00 \mathrm{E}-12$ & ETOH & $1.00 \mathrm{E}-12$ \\
\hline $\mathrm{SO}_{2}$ & $1.00 \mathrm{E}-12$ & $\mathrm{SO}_{2}$ & $1.00 \mathrm{E}-12$ \\
\hline $\mathrm{SO}_{3}$ & $1.00 \mathrm{E}-12$ & --- & --- \\
\hline $\mathrm{OH}$ & $1.00 \mathrm{E}-12$ & HO. & $1.00 \mathrm{E}-12$ \\
\hline $\mathrm{O}_{3} \mathrm{P}$ & $1.00 \mathrm{E}-12$ & $\mathrm{O}_{3} \mathrm{P}$ & $1.00 \mathrm{E}-12$ \\
\hline O1D & $1.00 \mathrm{E}-12$ & O1D & $1.00 \mathrm{E}-12$ \\
\hline $\mathrm{XO}_{2} \mathrm{~N}$ & $1.00 \mathrm{E}-12$ & $\mathrm{C}_{2} \mathrm{CO}-\mathrm{O}_{2}$ & $1.00 \mathrm{E}-12$ \\
\hline PNA & $1.00 \mathrm{E}-12$ & $\mathrm{HNO}_{4}$ & $1.00 \mathrm{E}-12$ \\
\hline $\mathrm{XO}_{2}$ & $1.00 \mathrm{E}-12$ & MTBE & $1.00 \mathrm{E}-12$ \\
\hline $\mathrm{CRO}$ & $1.00 \mathrm{E}-12$ & $\mathrm{R}_{2} \mathrm{O}_{2}$ & $1.00 \mathrm{E}-12$ \\
\hline $\mathrm{TO}_{2}$ & $1.00 \mathrm{E}-12$ & $\mathrm{RO}_{2}$ & $1.00 \mathrm{E}-12$ \\
\hline UNR & $1.00 \mathrm{E}-12$ & $\mathrm{RNO}_{3}$ & $1.00 \mathrm{E}-12$ \\
\hline--- & --- & PPN & $1.00 \mathrm{E}-12$ \\
\hline--- & --- & $\mathrm{O}_{3} \mathrm{OL}-\mathrm{SB}$ & $1.00 \mathrm{E}-12$ \\
\hline--- & --- & HOCOO & $1.00 \mathrm{E}-12$ \\
\hline--- & --- & BZ-O & $1.00 \mathrm{E}-12$ \\
\hline
\end{tabular}

The resulting maximum concentrations of selected predicted species are tabulated in Table 2-8. This table shows that the CB- 4 mechanism produces larger maximum ozone concentrations ( $5 \%$ more) than SAPRC90. This may be offset by the use of SAPRC93 chemistry, which also produces more ozone.

Table 2-8. Maximum Concentrations for Selected SAPRC90 Versus CB-4 Box Chemistry Comparison

\begin{tabular}{|l|c|l|}
\hline \multirow{2}{*}{ Species } & \multicolumn{2}{|c|}{ Maximum Concentration (ppm) } \\
\cline { 2 - 3 } & SAPRC90 & CB-4 \\
\hline $\mathrm{O}_{3}$ & 0.125 & 0.131 \\
\hline $\mathrm{NO}_{2}$ & 0.171 & 0.161 \\
\hline $\mathrm{HCHO}$ & 0.029 & 0.038 \\
\hline $\mathrm{HO}$. & $10.20 \times 10^{-8}$ & $9.94 \times 10^{-8}$ \\
\hline
\end{tabular}




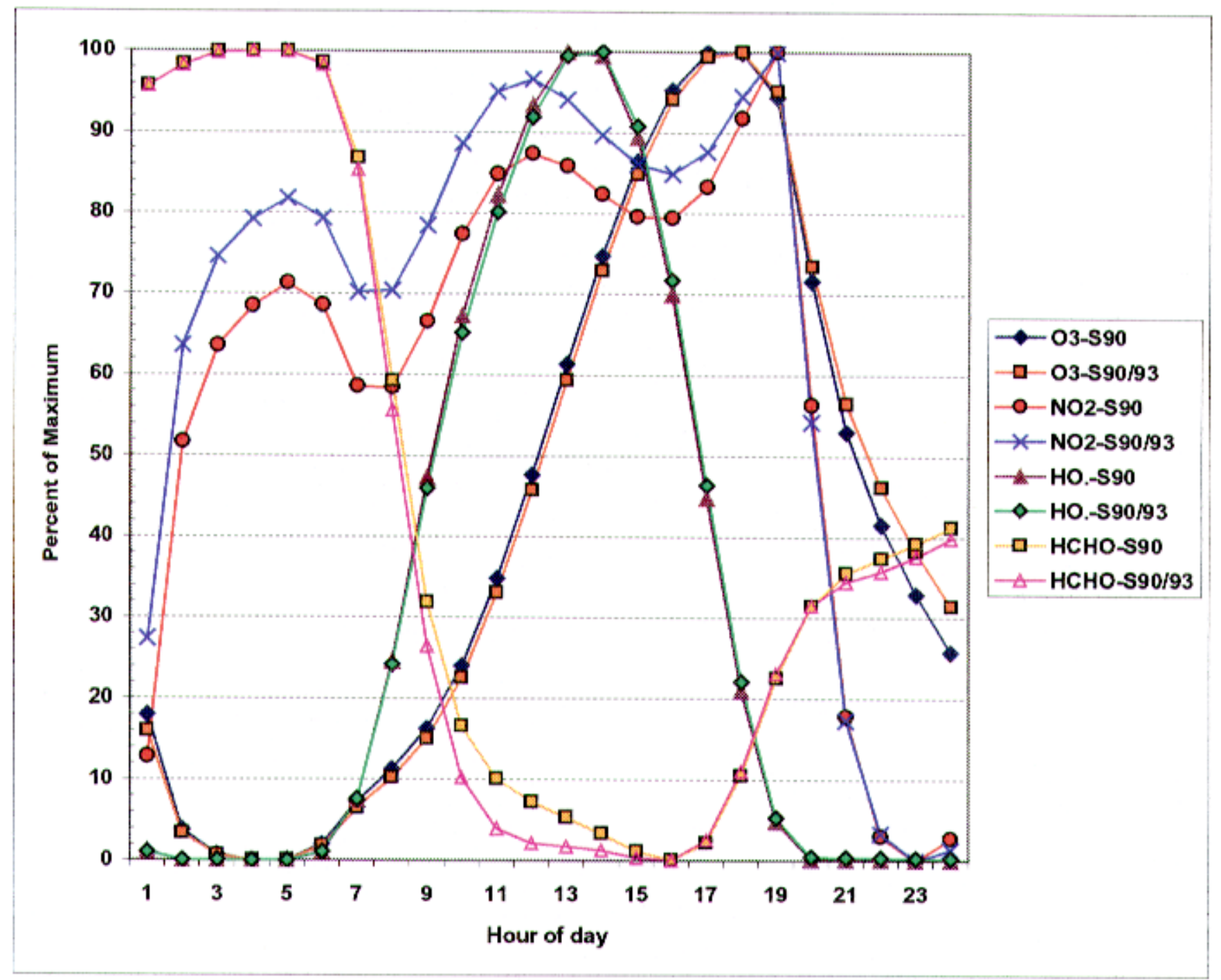

Figure 2-2. Time series comparison of SAPRC90 versus SAPRC90/93 concentrations for selected species. 
The time history of ozone production shown in Figure 2-3 indicates that the rate of ozone buildup in the morning is significantly greater for the SAPRC 90 chemistry than for the CB-4. While both mechanisms produce a maximum concentration in the mid-afternoon, the SAPRC90 chemical mechanism also decreases faster during the evening. The build up of $\mathrm{NO}_{2}$ during the day is also faster for SAPRC90 than CB-4 with SAPRC90, producing a slightly larger $\mathrm{NO}_{2}$ maximum.

The diurnal variation of $\mathrm{HCHO}$ is greater for SAPRC90. HCHO builds up rapidly in the morning to a maximum concentration at 0900 Local Standard Time (LST), then crashes in the afternoon when VOC's are exhausted. Later in the day, secondary formation produces a rally in the SAPRC90 HCHO concentration that slows abruptly when the sun goes down. The CB-4 HCHO chemistry exhibits a continuous increase throughout the day as a by-product of the breakdown of other CB-4 VOC species. The difference in the maximum concentration is about $33 \%$ with CB-4 predicting a maximum of $39 \mathrm{ppb}$ and SAPRC 90 predicting a maximum of $29 \mathrm{ppb}$. The hydroxyl radical $\mathrm{OH}$, also has a time history that varies significantly between the chemical mechanisms. In the SAPRC90 mechanism the $\mathrm{OH}$ concentration reaches a peak soon after sunrise. In contrast, the $\mathrm{CB} 4$ mechanism has $\mathrm{OH}$ increasing until solar noon when a peak is reached. Given the dependence of $\mathrm{OH}$ on $\mathrm{O}^{1} \mathrm{D}$, the peak at solar noon seems reasonable and agrees with observations (e.g., Eisele et. al. 1997). The OH concentrations of SAPRC90 seem to be more sensitive to competition between the $\mathrm{HO}_{2}$ production (consistent with rapid ozone rise) and the destruction because of formation of nitric acid $\mathrm{HNO}_{3}$. Again, despite the differing balance in the $\mathrm{OH}$ production and destruction terms between the two mechanisms, the maximum predicted concentrations are quite similar as shown in Table 2-8. 


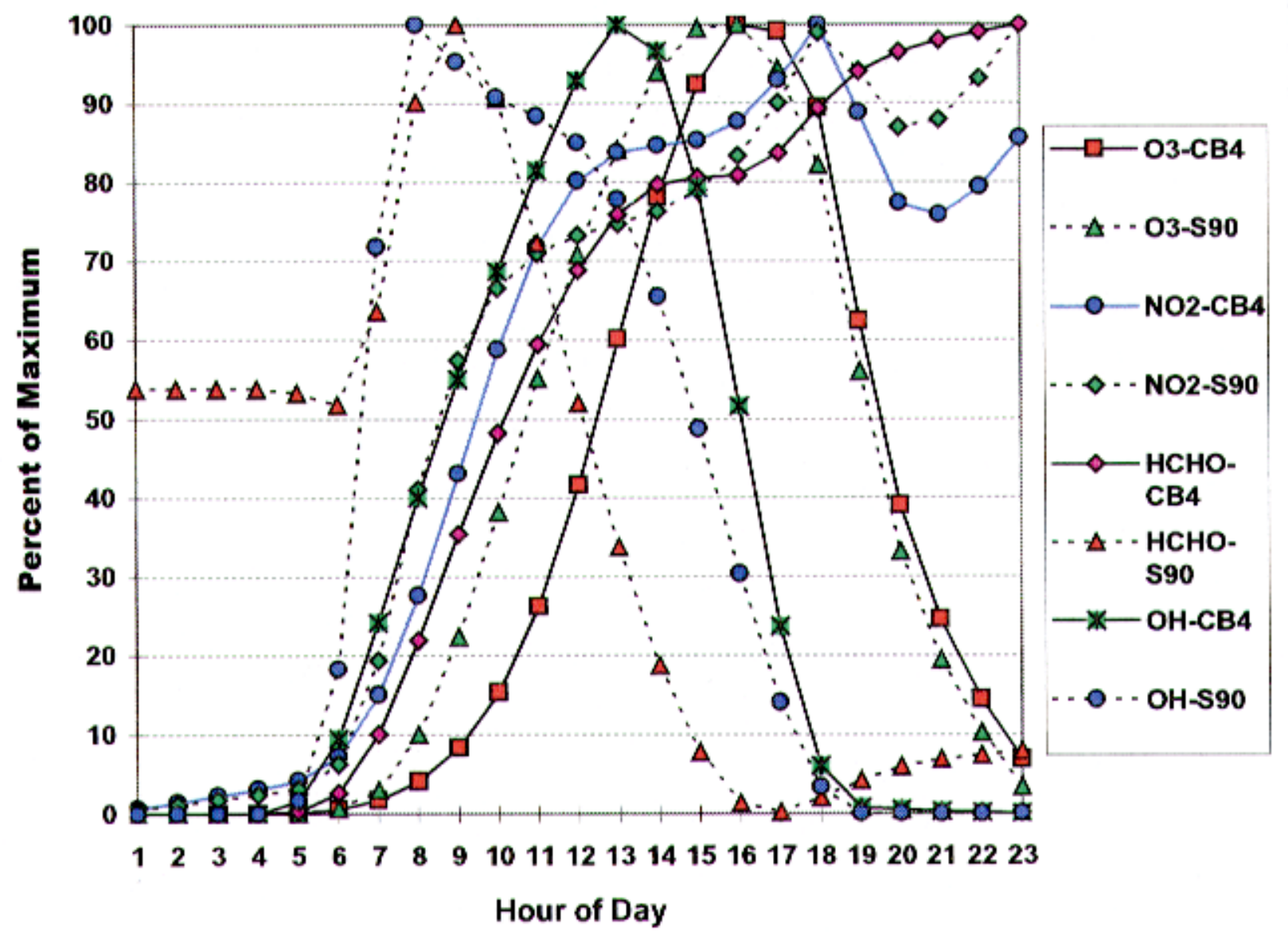

Figure 2-3. Comparison of CB-4 and SAPRC90 concentrations during ozone buildup. 


\subsection{Development of CALGRID Input Data Sets}

The CALGRID model requires meteorological fields, IC/BC files, and area and point source emission files. The CALGRID model directly reads a CALMET diagnostic meteorological output file for needed meteorological data such as wind fields, temperatures, mixing heights, and solar radiation information. The boundary and initial concentration files were generated by translating the UAM-IV concentration files into the layers and species needed by CALGRID. The emission files were obtained from the emission inventory data sets developed for UAM-IV. The remainder of this section is devoted to describing how input files were developed.

\subsection{Description of the Modeling Scenario}

The modeling domain and the horizontal resolution of the modeling system remain unchanged using a 65 by 40 cell grid consisting of 5 by $5 \mathrm{~km}$ cells extending over the region shown in Figure 3-1. Figure 3-1 also displays the terrain elevated contours for the modeling domain. The land use of the region is displayed as a color code tile plot to show the extent of urbanization of the region, and to show where the urban-rural transitions occur. Also shown are several air quality and meteorological monitoring sites which serve as important landmarks for analyzing transport in areas with high observed and predicted air quality. Many of the highest ozone concentrations are observed in the suburbanized foothills to the east and north of the Los Angeles urban basin.

\subsection{Meteorological Fields}

Two approaches were considered for obtaining CALGRID meteorological inputs: converting UAM-IV input files to fit the CALGRID vertical layer structure, or using the diagnostic meteorological model CALMET to create new input files from observed meteorology. The modeling protocol (Balentine et al. 1997c) recommended against the direct conversion of the UAM-IV input meteorological files because of limited vertical resolution of fields used for UAM-IV. Such a conversion had been done for the 27- 28 August 1987 modeling episode as reported in Kumar et al. (1994). CALMET is the diagnostic meteorological model designed for use with CALGRID. Creating new meteorological fields using CALMET offers the following advantages for a CALGRID application:

- Use of high vertical resolution (near the ground) developed by CALMET

- Use of improved mixing depth estimates and vertical diffusivity profiles

- Use of improved vertical source profiles which exploit the enhanced vertical resolution.

CALMET meteorological files were developed using the South Coast Air Quality Study (SCAQS) archived meteorological data set. This work was coordinated with the CARB which supplied selected sets of surface and upper air meteorological data (Jackson 1998) for the 27-28 August, 1987 episode. A recent version of CALMET, which uses the Holtslag-van Ulden similarity theory model (van Ulden 1985) of the wind and temperature structure in the surface layer, was applied.

The modeling scenario defined 12 layers with ceilings at 20, 50, 100, 200, 400, 600, 800, 1100, $1400,1700,2000$, and $2400 \mathrm{~m}$. CALMET was operated in the mode which provides CALGRID 
with three-dimensional mass consistent winds and temperatures. Smoothing of the surface layer winds was conducted (five passes of a centered five-point filter). The O'Brien surface adjustment scheme was not used by CALMET to minimize divergence. The maximum spheres of influence at the surface and aloft were 100 and $200 \mathrm{~km}$, respectively. The nine closest sites within the sphere of influence were used in the inverse distance weighted interpolation. Terrain effects have a sphere of influence of $30 \mathrm{~km}$ and temperature stations had a maximum sphere of influence of $500 \mathrm{~km}$. Equal weighting of the first guess field and the observation was made at a distance of $10 \mathrm{~km}$ from the site for the surface and $25 \mathrm{~km}$ for the layers aloft. No temperature interpolation adjustment with elevation was employed. The cloud cover field was filled, not interpolated, using information from the nearest site. CALMET was exercised using an unbiased weighting aloft of the first guess wind field and the observations. The domain mean wind was selected using the El Monte sounding rather than using a domain average of the four available soundings. This was done to avoid averaging easterly and westerly winds together from soundings with greatly different terrain elevations (e.g., Riverside versus Long Beach).

CALMET is not a terrain following model, yet the subsidence inversion at $1000-1250 \mathrm{~m}$ follows a pressure contour and intersects the highest terrain. The inversion will suppress the growth of the mixed layer for parcels of air moving eastward and northward out of the basin. As a result the normal convective mixed layer growth will overpredict the mixed layer depth outside of the Los Angeles basin. To explore the effects of mixed layer depth, CALGRID base case simulations were made with two different sets of CALMET meteorological fields, the first developed with a maximum mixing height of $2400 \mathrm{~m}$ and the second with $1250 \mathrm{~m}$. The use of the lower maximum mixing height led to peak predicted hourly ozone concentrations in the area east of Los Angeles that were higher by $20-40 \mathrm{ppb}$, in better agreement with peak observed concentrations.

The use of similarity theory would result in the extrapolation of surface wind speeds in the basin up to the ceiling of the mixing height. Sounding observations indicate that the wind speeds actually decrease with height (the large winds are associated with a shallow seabreeze circulation). Because of this, the wind speeds in the CALMET surface input file which are greater than $1 \mathrm{~m} / \mathrm{s}$ in the basin were adjusted to provide the appropriate $20 \mathrm{~m}$ surface layer average. Because of a domain-wide wind field convergence at the surface, the O'Brien scheme was not used to minimize divergence despite the known tendency for large variations in the vertical wind to occur in the lee of the San Pedro Promontory (Brocchini et al. 1995). Unless the domain wide divergence is reduced, the divergence minimizer in CALMET can create larger localized divergences than it resolves, so it was not used. Vertical recirculation areas are likely to be overstated by the similar extrapolation of wind, because the surface flow divergences induced by the terrain are generally shallower than the overall mixed layer.

A total of 47 surface data sites were used, most of these located along the coast and within the air basin proper. Surface calms were filled in by preprocessing the data entered into the surface data input file. The filling method involved using linear interpolation and persistence. Hourly surface meteorological data over water was supplied from a single ocean buoy located near the middle of the western boundary relatively far from the coast. During each day there were four sounding sites which included the airport at Riverside and special sites at Long Beach, El Monte, and Burbank. While other sites were available, gaps in the data record precluded their direct use in CALMET. As a result most of the wind information comes from within the basin and is extrapolated rather than interpolated to the edges of the modeling domain. 


\subsection{Analysis of Air Flow Transport}

On the morning of 27 August the surface winds at 0700 LST (Figure 3-2) are extremely light, of the order $1 \mathrm{~m} / \mathrm{s}$ over most of the Los Angeles basin. Only along the coast near Long Beach and in the southwest corner of the domain do the winds increase to $5 \mathrm{~m} / \mathrm{s}$. Throughout the modeling domain the majority of the winds are dominated by a westerly component. The winds pick up in speed by the early afternoon (1300 LST) as displayed in Figure 3-3. The strongest winds occur at the coastline. As one moves northeastward across the basin the winds lighten and become more southerly. The mixing heights along the coast are of the order $400-750 \mathrm{~m}$ deep. A trough in the mixing height field occurs in a zone of low wind speeds extending northeastward through the Los Angeles National Forest. The highest mixing heights occur in the northwesterly portion of the domain; mixing heights are less than $2200 \mathrm{~m}$ across the domain. By 1800 LST the surface winds slacken off (Figure 3-4) and generally turn to more out of the southwest. The trough in the mixing height field described earlier persists (mixing heights less than $1000 \mathrm{~m}$ ), with its zone of nearly calm winds.

During the morning of 27 August the winds above the mixing height, at $500 \mathrm{~m}$ (Figure 3-5) are light and out of the northeast, in direct opposition to the surface winds. The surface temperature field exhibits a maximum in the Palm Springs area $\left(<303^{\circ} \mathrm{K}\right)$ and a minimum temperature in the very northeastern portion of the domain. Figure 3-6 shows that by 1300 LST the minimum temperatures are found along the coast, with a $10^{\circ} \mathrm{K}$ temperature gradient between the coast and the foothills of the mountains. The highest temperatures are found in the vicinity of Barstow. The winds at $500 \mathrm{~m}$ remain out of the east in the very eastern portion of the modeling domain, while in the western portion of the domain the winds are out of the west. By 1800 LST the surface temperatures are beginning to cool rapidly (Figure 3-7) with relatively light winds occurring at $500 \mathrm{~m}$ over most of the domain. The vertical velocity estimates suggest an overall tendency for air flow convergence rather than divergence which is in contradiction to the inferred synoptic scale motions since a subsidence inversion is noted around $1000-1300 \mathrm{~m}$ above sea level. No attempt was made to introduce wind speed-up along the surface outflow boundaries to achieve domain-wide subsidence.

In order to track the movement of air across the Los Angeles basin, trajectories arriving and leaving selected sites at 1300 LST were estimated using the surface hourly wind fields (Figure 38). In the foothills, air reaching Glendora comes from nearby and does not really go anywhere later in the afternoon due to day-long light winds. At LAX the air comes from out over the ocean during the morning and takes roughly four hours to proceed across the basin into the foothills. Air reaching Fontana area (Rubidoux) comes from the West Covina area, and later during the afternoon makes its way eastwards towards Banning. Air arriving at Crestline also originates in the morning from the general area around West Covina. Later in the afternoon the air around Crestline moves out towards Big Bear City. To the south, and nearer to the coast, air reaching El Toro comes from out over the ocean, and later in the day moves inland so that by late in the afternoon this air reaches Perris.

Air which reaches Glendora by 0600 LST on the 27th came five or six hours earlier (around 1200 LST) from downtown Los Angeles (Figure 3-9). Air that reaches Crestline at the same time again originated in the late morning from the West Covina area. At Fontana, air reaching the site 0600 LST originates from Lynnwood around noontime. Air reaching Simi Valley, LAX, and El Toro originates from well out over the ocean. 
On the morning of 28 August (0700 LST), Figure 3-10 shows the very light surface winds that persist over the whole modeling domain with only a few areas of winds higher than $2 \mathrm{~m} / \mathrm{s}$. The mixing heights are lower than $200 \mathrm{~m}$ almost everywhere except near the coast between Long Beach and Santa Ana. By early afternoon (1300 LST), a trough in the mixing height again runs inland from the basin foot hills across the Los Angeles National Forest out towards Victorville. Figure 3-11 shows that in the trough, the mixing heights are less than $750 \mathrm{~m}$, like those along the coast. The highest mixing heights are out in the Banning area and the Cleveland National Forest. During the early afternoon of the $28^{\text {th }}$, the wind speeds generally increase from the near calm winds of the morning hours. The winds are usually out of the west with air coming onshore and converging along a sea breeze convergence zone. In the northern portion of Riverside County, the winds are generally directly out of the west. As one proceeds eastward towards the Palm Springs area, the winds swing around to come from the south out of the Imperial Valley area. By evening (1800 LST) Figure 3-12 shows that the wind begins to die down, so only winds near Edwards AFB are above $5 \mathrm{~m} / \mathrm{s}$; throughout the basin they are less than $3 \mathrm{~m} / \mathrm{s}$. The highest mixing heights (unclipped) are 1250 - $2000 \mathrm{~m}$ over broad inland regions to the east and to the north of the Los Angeles basin.

On 28 August 1987, the surface temperatures at 1300 LST are generally warmer than on the $27^{\text {th }}$. The maximum surface temperatures occur near Indio (Figure 3-13). The coolest temperature occurs along the coastline. There is a $15^{\circ} \mathrm{C}$ temperature gradient between the two areas. The winds at $500 \mathrm{~m}$ are generally out of the west, with northwesterly winds occurring in the northwest (Ventura County) portion of the modeling domain and south westerly winds occurring in the Indio area. The winds over the Los Angeles basin proper are light $(<4 \mathrm{~m} / \mathrm{s})$. The wind speeds at $500 \mathrm{~m}$ increase in the eastern portion of the domain to $10 \mathrm{~m} / \mathrm{s}$ out of the southwest in the vicinity of Indio and are very high $(15 \mathrm{~m} / \mathrm{s})$ in Ventura County. By 1800 LST in the evening, the Los Angeles basin has cooled about $5^{\circ} \mathrm{C}$ from the afternoon maximum (Figure 3-14). The winds north of the Los Angeles basin show significant spatial variation and have begun to slow down over the basin. South of the basin the winds along the coast are out of the south and are quite light.

Surface wind trajectories on 28 August (Figure 3-15) show that the air mass arriving at Glendora during the early afternoon comes from nearby (just south of West Covina) reflecting very light early morning winds. At both LAX and El Toro the air mass comes from out over the ocean just a couple of hours previously. During the rest of the afternoon the air from these sites moves inland approximately $50 \mathrm{~km}$. Once again the wind passing through Fontana and Crestline at 1300 LST originates in the morning from the general vicinity of West Covina. Just as on the $27^{\text {th }}$, the air masses continue to move eastward toward Great Bear City and Banning, respectively. Air parcels arriving at sites at 1800 LST are shown in Figure 2-16. The Glendora, Crestline, and Fontana sites all have air which originated 6-8 hours earlier (late morning) in the general vicinity of Anaheim and Lakewood. Air arriving at both LAX and El Toro originates from out over the ocean. The air arriving at Simi Valley at 1800 LST comes from the Ventura coast during the late morning.

Several interesting notes should be made about the air mass sources during the ozone episode. The first is that the afternoon maximum concentrations that are predicted at the Glendora, Fontana, and Crestline sites all share a common emission region in the Los Angeles basin in the mid- to late-morning hours. The impact of mobile source emissions is likely to be strongest following the initial morning rush hour. The timing of the sea breeze intrusion and the time history of the rise of the mixing height over the localized source regions in the basin could 
significantly affect the dilution history of air masses, producing the largest ozone concentrations at each of the three sites.

\subsection{Emission Inventory Fields}

During Phase I of the study, Radian developed model-ready, gridded, hourly emission files of the SAPRC90 species. Model-ready files were provided for the S1, CNG, and first guess M85 scenario emissions. The data files had been created using the chemical profiles developed using the PREPEMIT software supplied with the CALGRID modeling system (Scire and Yamartino 1989). Subsequent checks of the carbon mass of the emissions revealed that SAPRC90 emissions had 15 - $30 \%$ more carbon mass than the corresponding CB4 emission files suggesting either a lack of conservation or a bias in the class average carbon number and molecular weight in the *.RXP file. Because of this discrepancy and because SAPRC-speciated emissions were not available for the RFG and final M85 scenarios, a second approach was used to derive the emissions inputs directly from the UAM-IV CB-4 emissions files. To accomplish this, a processor based on the UAM-IV SAPRC implementation work of Lurmann, Gery and Carter (1991) was utilized. The advantage of this approach is that the emissions files used for the simulations are consistent across all modeling scenarios. The disadvantage is that some distortions occur in the representation of the chemical reactivity of the emissions inventory. However, since internal olefins and acetaldehyde had been explicitly broken out in the CB-4 toxics version, the degree of reactivity mismatch is considerably reduced.

The molar concentrations of the CB-4 toxics organic species: PAR, ETHE, OLE, TOL, XYL, FORM, ACET, HALD, IOLE, ISOP, MEOH, ETOH, MTBE, and NR (see list of acronyms) are used to estimate the total lumped organic carbon mass emitted. The output from the PREPEMIT program is used to assign the number of carbon atoms for the corresponding SAPRC90 lumped organic species including; ALK1, ALK2, ARO1, ARO2, OLE1, OLE2, OLE3, FORM, CCHO, $\mathrm{RCHO}$, and MEK (see list of acronyms). The number of carbon atoms per species is presented in Table 3-1.

Table 3-1. A Summary of the SAPRC90 PREPEMIT Lumped Species Average Carbon Number and Molecular Weights Used in the Present Study for the RFG Case.

\begin{tabular}{|c|c|c|}
\hline $\begin{array}{c}\text { Lumped species } \\
\text { name }\end{array}$ & $\begin{array}{c}\text { Average number of } \\
\text { carbons }\end{array}$ & $\begin{array}{c}\text { Molecular weight } \\
\text { (g/mole) }\end{array}$ \\
\hline ALK1 & 3.337 & 55.90 \\
\hline ALK2 & 7.511 & 110.14 \\
\hline ARO1 & 6.985 & 91.94 \\
\hline ARO2 & 8.567 & 114.05 \\
\hline OLE1 & 3.795 & 53.23 \\
\hline OLE2 & 4.760 & 66.37 \\
\hline OLE3 & 6.578 & 89.37 \\
\hline
\end{tabular}

The chemical species mapping is based on the scheme of Lurmann, Gery, and Carter (1991) was used as a starting point, but was modified for the revised toxics chemistry. The mapping is summarized by the relations below.

- $[\mathrm{ALK} 1]_{\mathrm{S} 90}=0.5[\mathrm{ALKC}] / \mathrm{NC}(\mathrm{ALK} 1)$ 
- $[\mathrm{ALK} 2] \mathrm{S} 90=0.5[\mathrm{ALKC}] / \mathrm{NC}(\mathrm{ALK} 2)$

- $[\mathrm{ARO} 1]_{\mathrm{S} 90}=[\mathrm{TOL}]$

- $[\mathrm{ARO} 2]_{\mathrm{S} 90}=[\mathrm{XYL}]$

- $[\mathrm{ETHE}]_{\mathrm{S} 90}=[\mathrm{ETH}]$

- $[\mathrm{OLE} 1]_{\mathrm{S} 90}=[\mathrm{OLE}]$

- $[\mathrm{OLE} 2] \mathrm{S} 90=[\mathrm{IOLE}]$

- $[\mathrm{OLE} 3] \mathrm{S} 90=[\mathrm{ISOP}]$

- $[\mathrm{HCHO}]_{\mathrm{S} 90}=[\mathrm{FORM}]$

- $[\mathrm{CCHO}]_{\mathrm{S} 90}=[\mathrm{ACET}]$

- $[\mathrm{RCHO}]_{\mathrm{S} 90}=[\mathrm{HALD}]$

- $[\mathrm{MEK}]_{\mathrm{S} 90}=0.0025[\mathrm{PAR}]$

- $[\mathrm{MEOH}]_{\mathrm{S} 90}=[\mathrm{MEOH}]$

- $[\mathrm{ETOH}]_{\mathrm{S} 90}=[\mathrm{ETOH}]$

- $[\mathrm{MTBE}]_{\mathrm{S} 90}=[\mathrm{MTBE}]$

where $[\mathrm{ALKC}]$ is given by the relation:

$$
\begin{aligned}
& {[\mathrm{ALKC}]=[\mathrm{ROG}]-2[\mathrm{ETHE}] \mathrm{S} 90-\mathrm{NC}(\mathrm{OLE} 1)[\mathrm{OLE} 1] \mathrm{S} 90-\mathrm{NC}(\mathrm{OLE} 2)[\mathrm{OLE} 2] \mathrm{S} 90} \\
& \text { - NC(OLE3)[OLE3] S90 - NC(ARO1)[ARO1] } 390 \text { - NC(ARO2)[ARO2]S90 } \\
& \text { - [HCHO }]_{S} 90-2[\mathrm{CCHO}]_{\mathrm{S} 90}-3[\mathrm{RCHO}]_{\mathrm{S} 90}-4[\mathrm{MEK}]_{\mathrm{S} 90}-[\mathrm{MEOH}]_{\mathrm{S} 90} \\
& -2[\mathrm{ETOH}] \mathrm{S} 90-5[\mathrm{MTBE}] \mathrm{S} 90 \text {. }
\end{aligned}
$$

The CB-4 ROG (VOC) methane equivalent concentration (ppm C) is estimated as:

$$
\begin{aligned}
{[\mathrm{ROG}] } & =[\mathrm{PAR}]+2[\mathrm{ETH}]+2[\mathrm{OLE}]+5[\mathrm{ISOP}]+7[\mathrm{TOL}]+8[\mathrm{XYL}] \\
& +[\mathrm{FORM}]+2[\mathrm{ALD} 2]+[\mathrm{MEOH}]+2[\mathrm{ETOH}]+5[\mathrm{MTBE}] .
\end{aligned}
$$

The alkane match of the paraffinic carbon in PAR is assumed to be equally divided between species with $\mathrm{K}_{\mathrm{OH}}<10^{4} \mathrm{ppm}^{-1}-\mathrm{min}^{-1}$ and $\mathrm{K}_{\mathrm{OH}}>10^{4} \mathrm{ppm}^{-1} \mathrm{~min}^{-1}$. It is assumed that methylethyl keatone (MEK) is about $1 \%$ of PAR carbon. The second lumped olefin category is assumed to consist mainly of internal olefin (IOLE) species, while the third lumped class is primarily isoprene or its olefinic counterparts. The effects of reactivity weighing on ALK1 and ARO1 are roughly equivalent to the partitioning of less reactive species between PAR and nonreactive carbon (NR) while the effect on AR01 is equivalent to partitioning between TOL and $\mathrm{NR}$ in the CB-4 mechanism.

All of the CB-4 toxics emissions files, both area and point sources, for the RFG, CNG, and M85 modeling scenarios were converted from UAM-IV CB-4 emission files (moles/hr) to CALGRID SAPRC90 emissions $(\mathrm{g} / \mathrm{s})$ files using the matching described above. In all cases the carbon mass was conserved, and the changes in the unreactive component of the carbon was altered by a few percent. A description of the $\mathrm{VOC}$ and $\mathrm{NO}_{\mathrm{x}}$ and toxics emission inventory is presented in earlier reports such as Moore, Fernau and Londergan (1998) and Balentine et al. (1997a) and is not repeated here. 


\subsection{Initial and Boundary Concentration Fields}

The initial and boundary condition files used in the UAM-IV modeling were converted to the CALGRID SAPRC species concentrations. The UAM-IV initial and boundary concentration fields were first linearly interpolated to the 12 CALGRID layers assuming mass conservation. The CB-4 specie concentrations were then converted into their SAPRC90 analogs using the species mass conversion described earlier. 


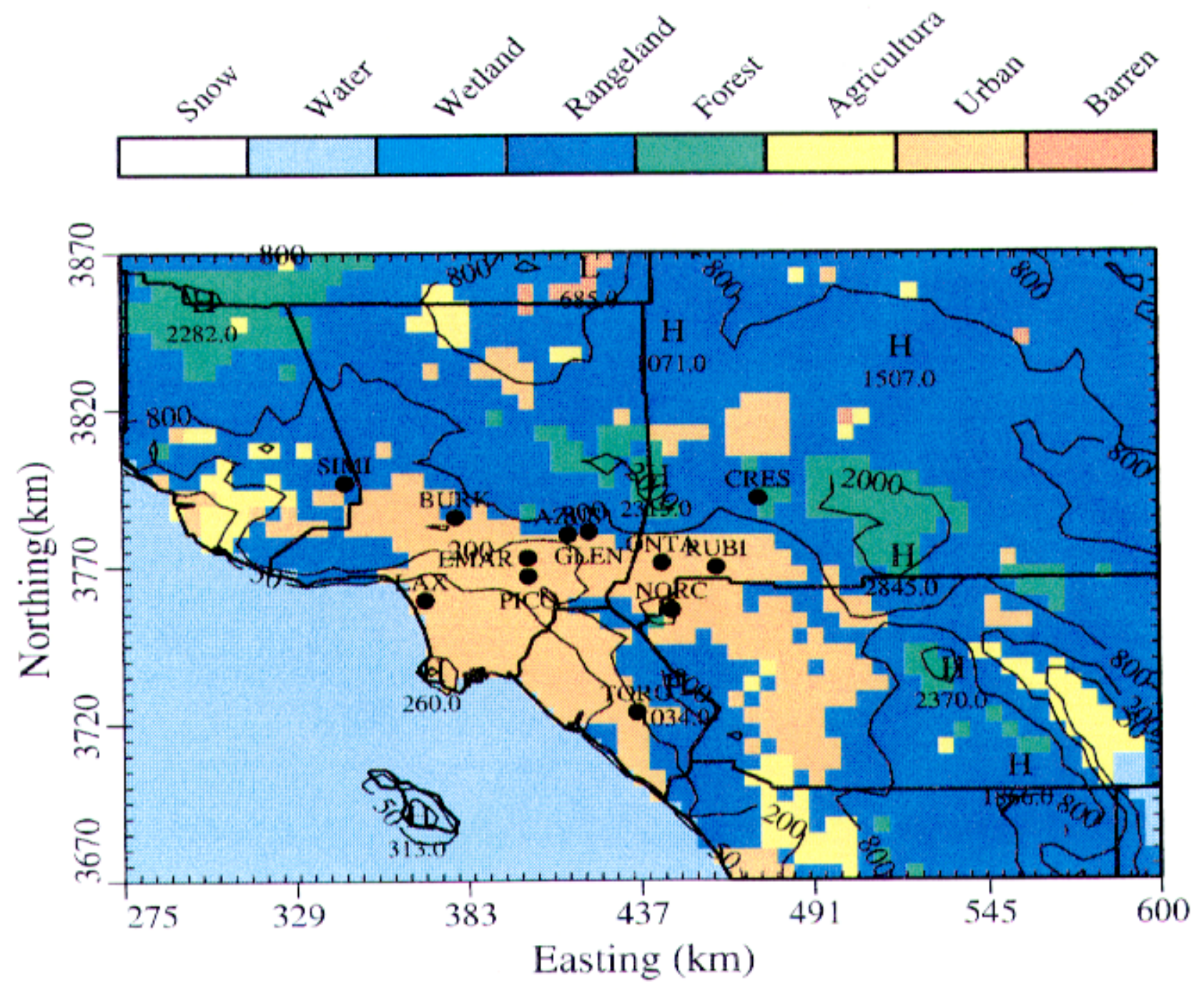

Figure 3-1. Map of the Los Angeles modeling domain showing terrain, landuse, and significant sites. 

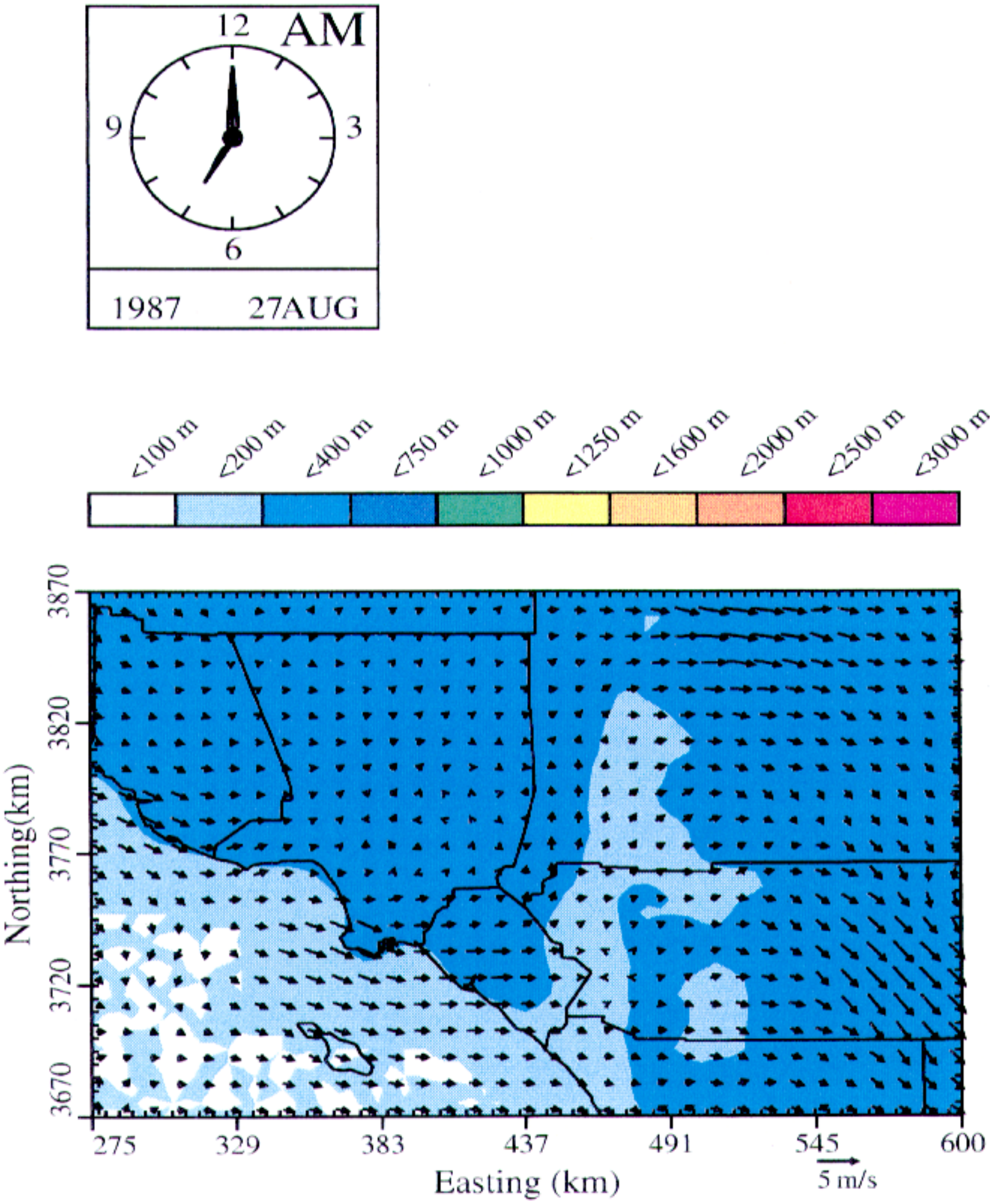

Figure 3-2. Surface winds and mixing heights over the Los Angeles basin derived using CALMET (V5) 

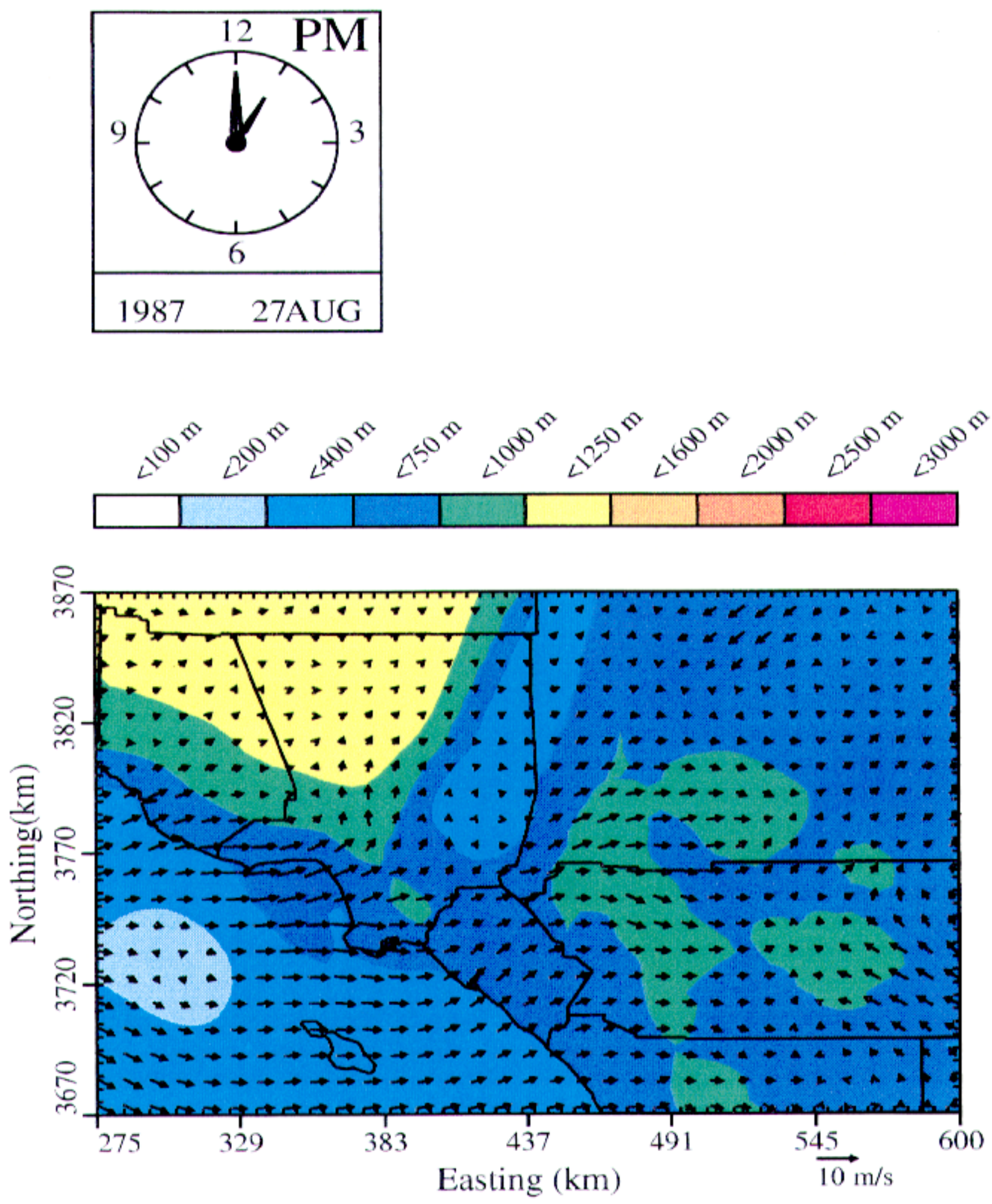

Figure 3-3. Surface winds and mixing heights over the Los Angeles basin derived using CALMET (V5). 

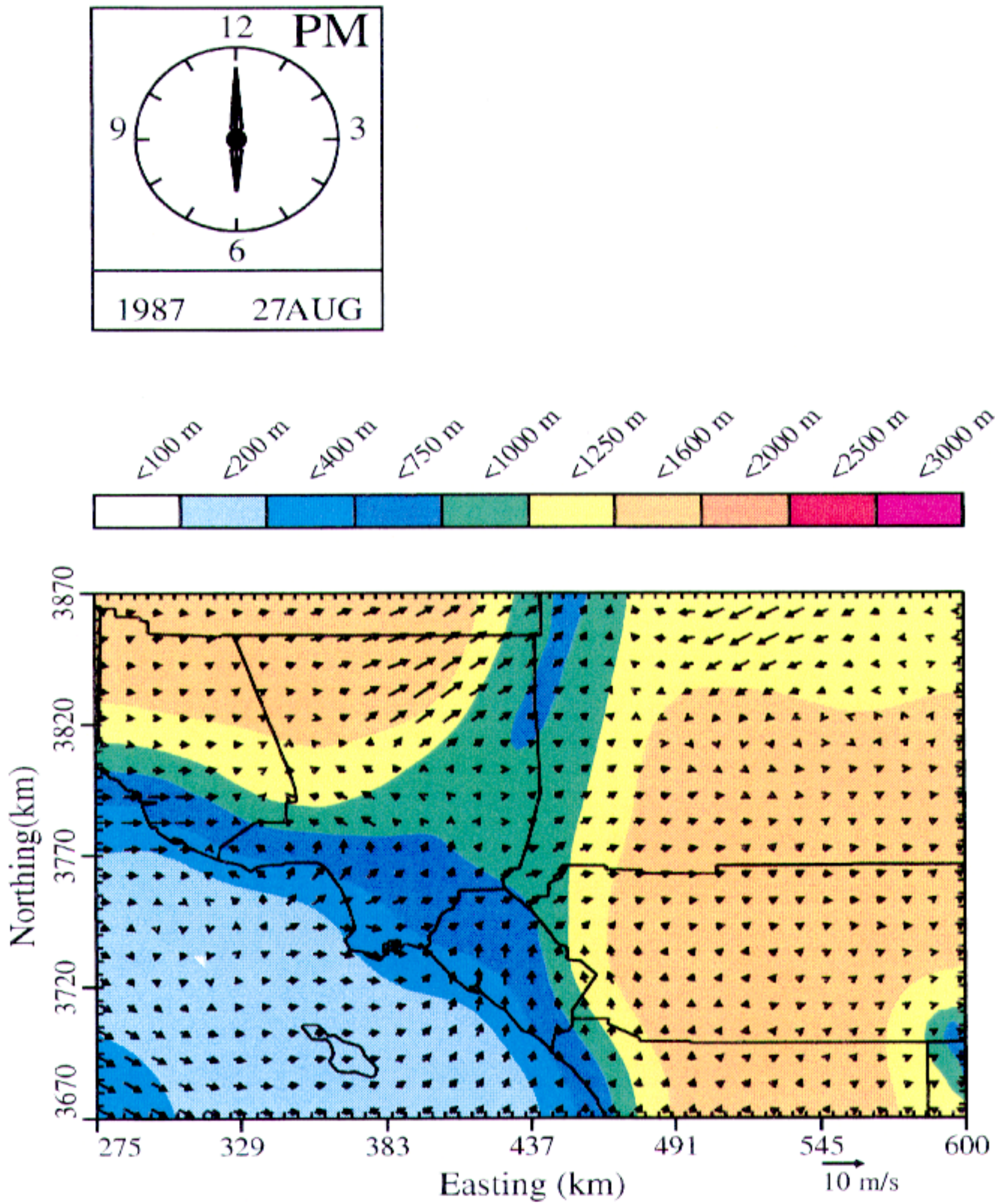

Figure 3-4. Surface winds and mixing heights over the Los Angeles basin derived using CALMET (V5) 

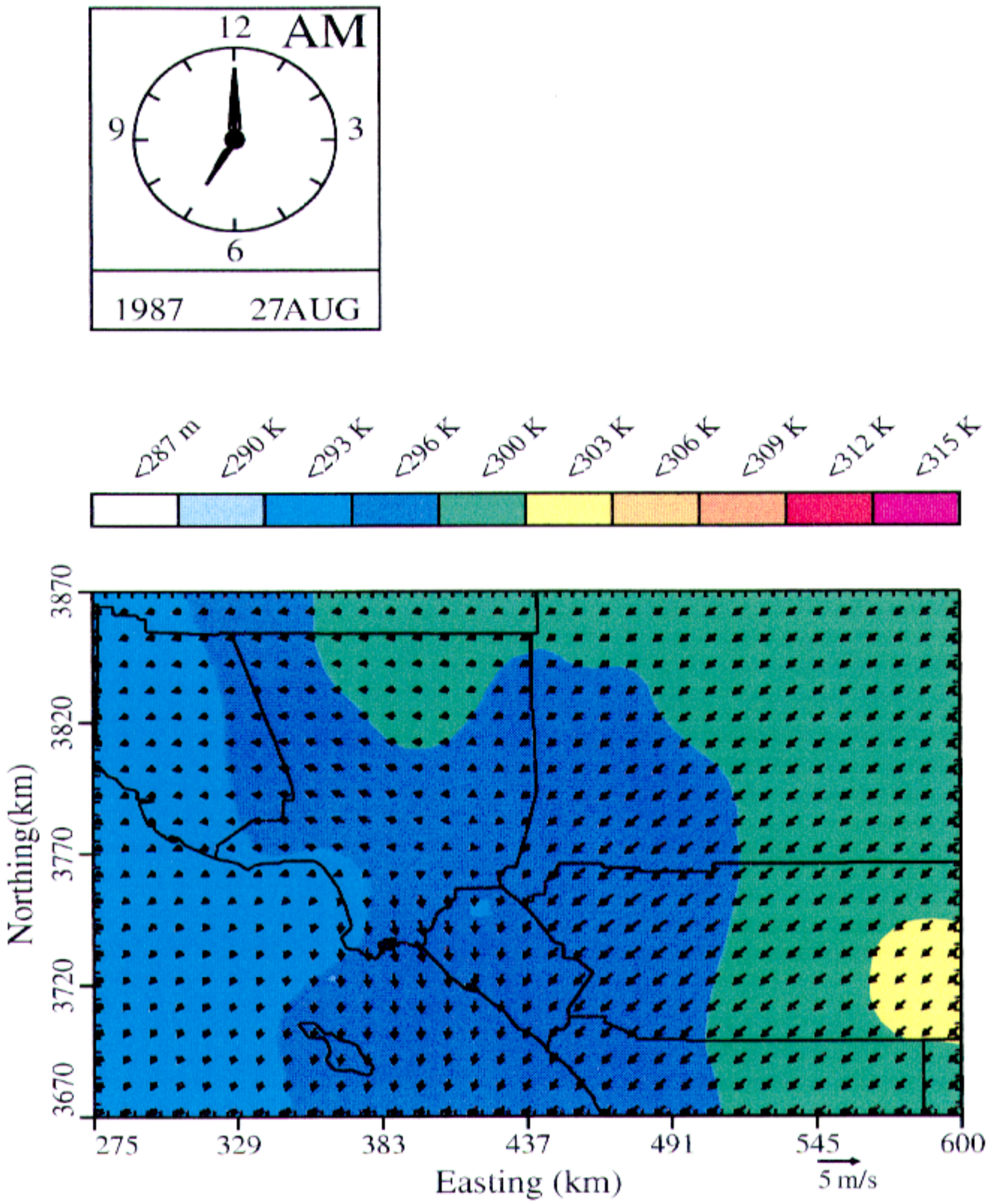

Figure 3-5. Surface temperatures and $500 \mathrm{~m}$ winds the Los Angeles basin derived using CALMET (V5) 

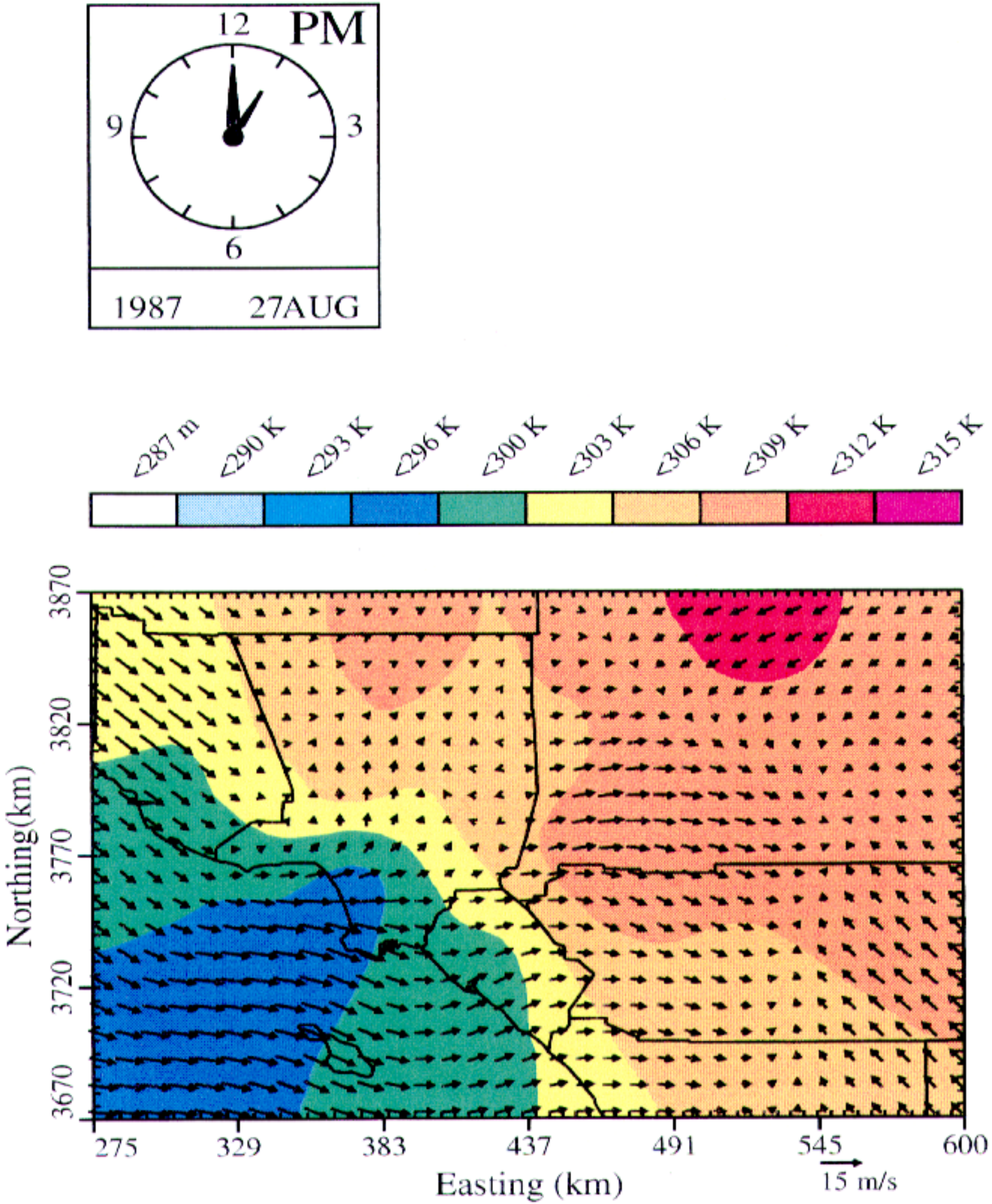

Figure 3-6. Surface temperatures and $500 \mathrm{~m}$ winds the Los Angeles basin derived using CALMET (V5) 

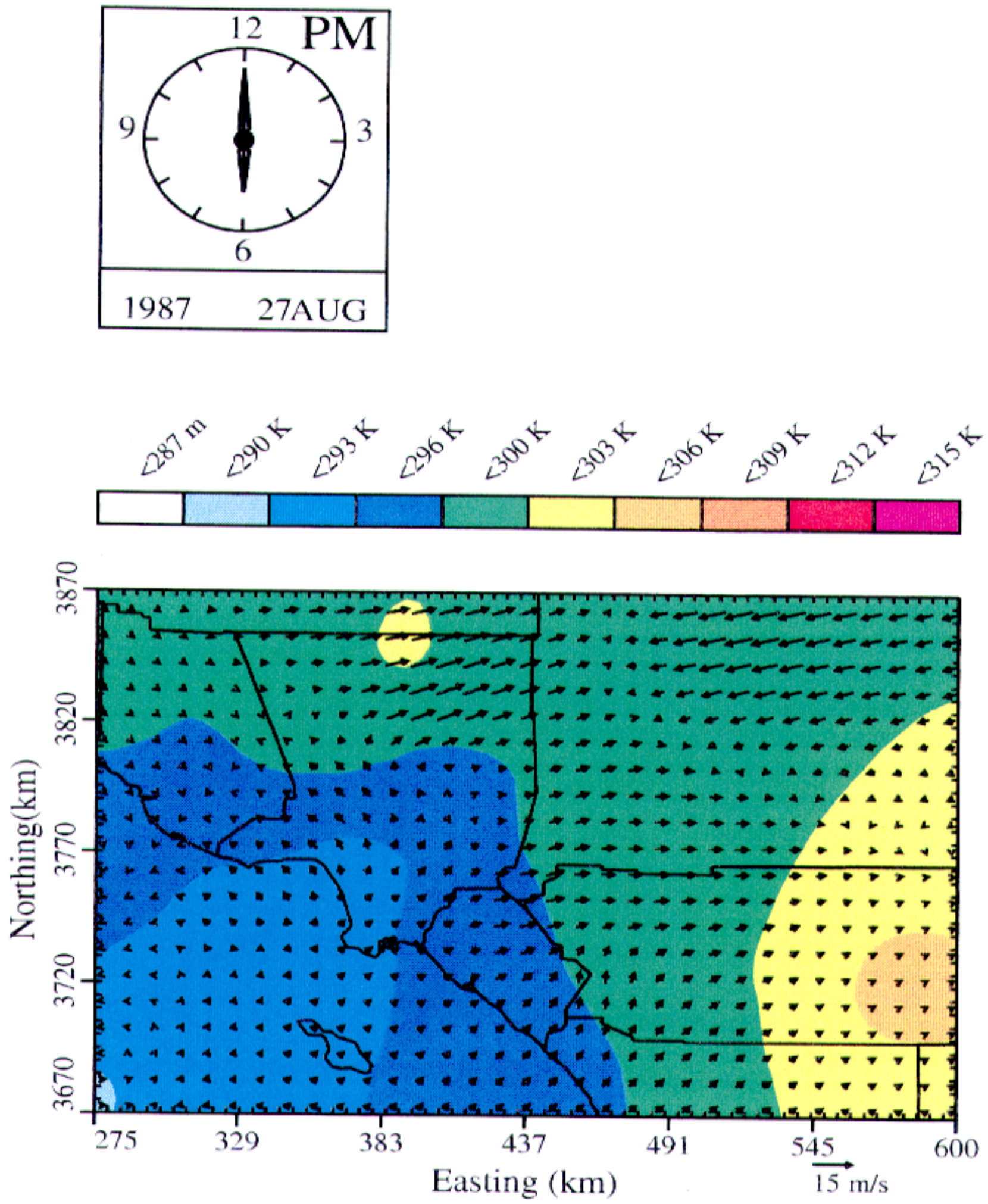

Figure 3-7. Surface temperatures and $500 \mathrm{~m}$ winds the Los Angeles basin derived using CALMET (V5) 

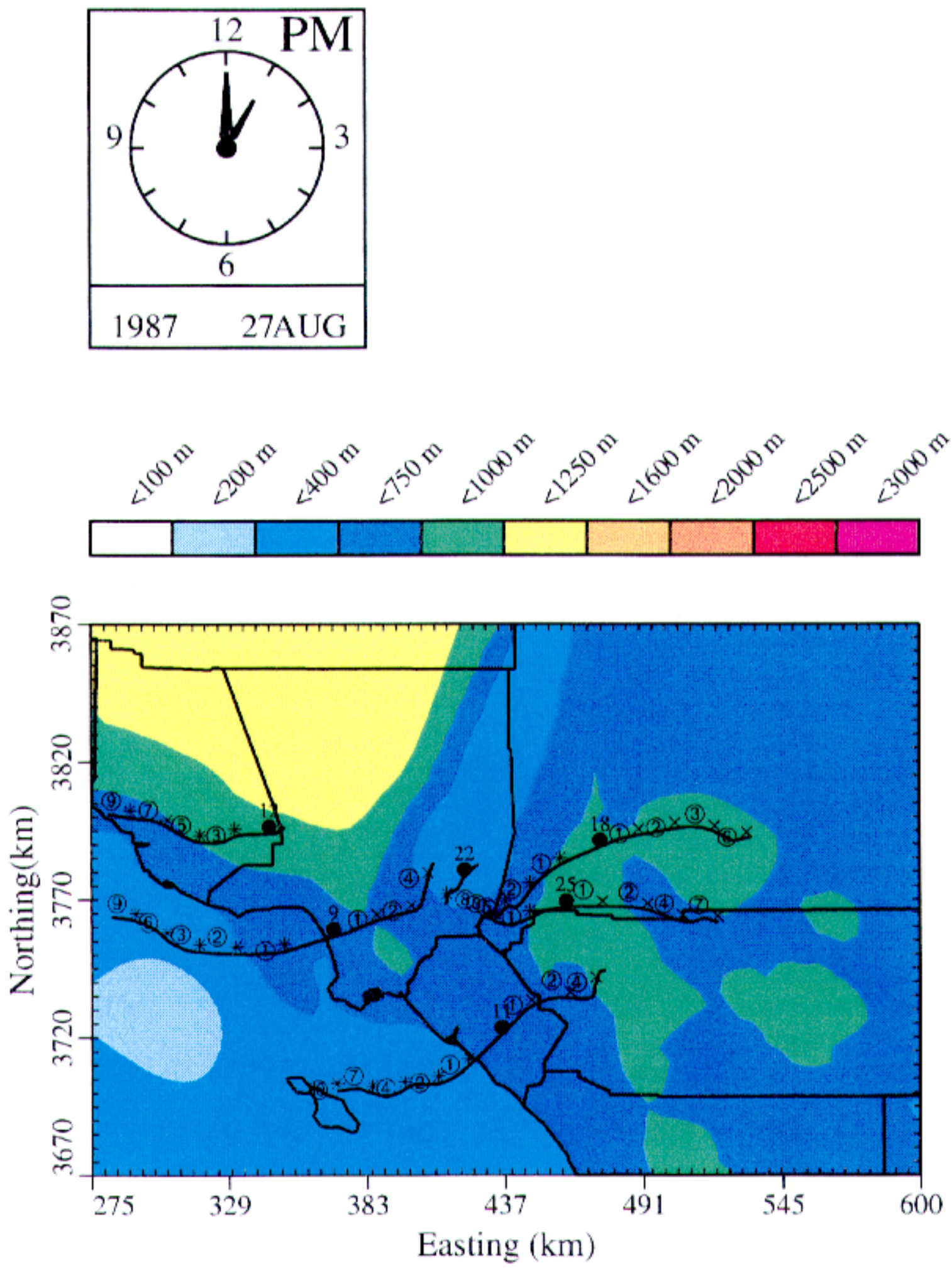

Figure 3-8. Surface trajectories and mixing heights in the Los Angeles basin derived using CALMET(V5) 

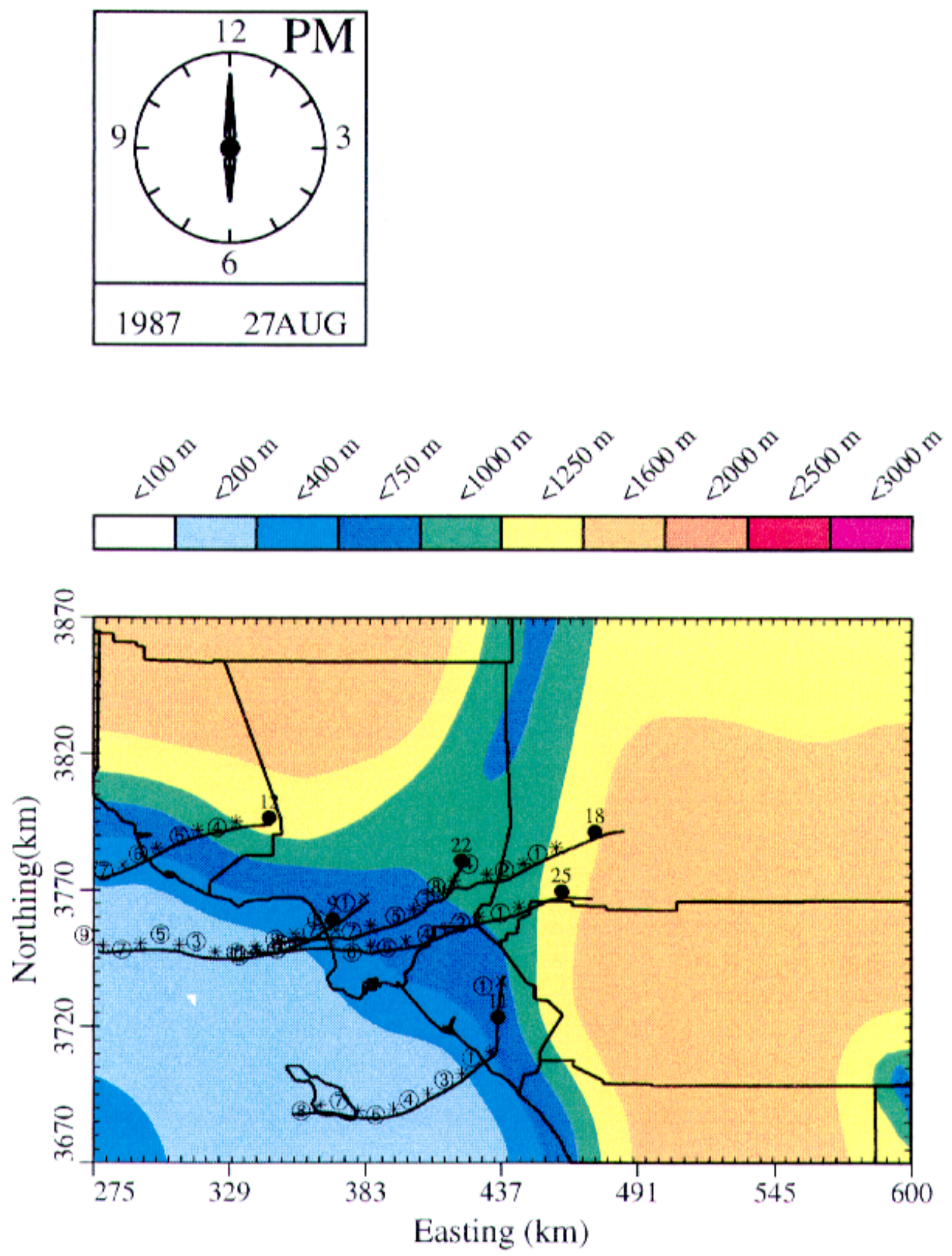

Figure 3-9. Surface trajectories and mixing heights in the Los Angeles basin derived using CALMET (V5) 

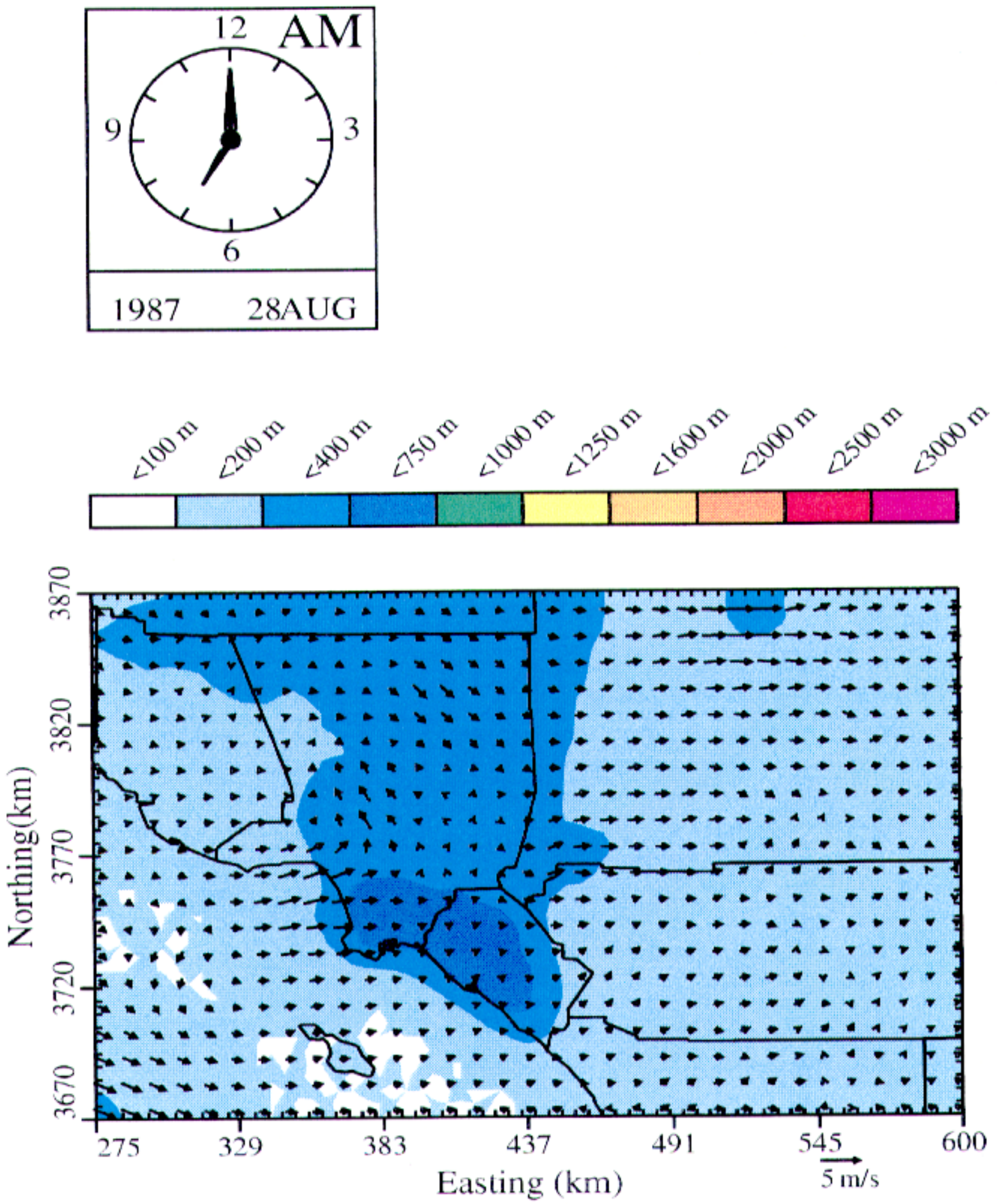

Figure 3-10. Surface winds and mixing heights over the Los Angeles basin derived using CALMET (V5) 

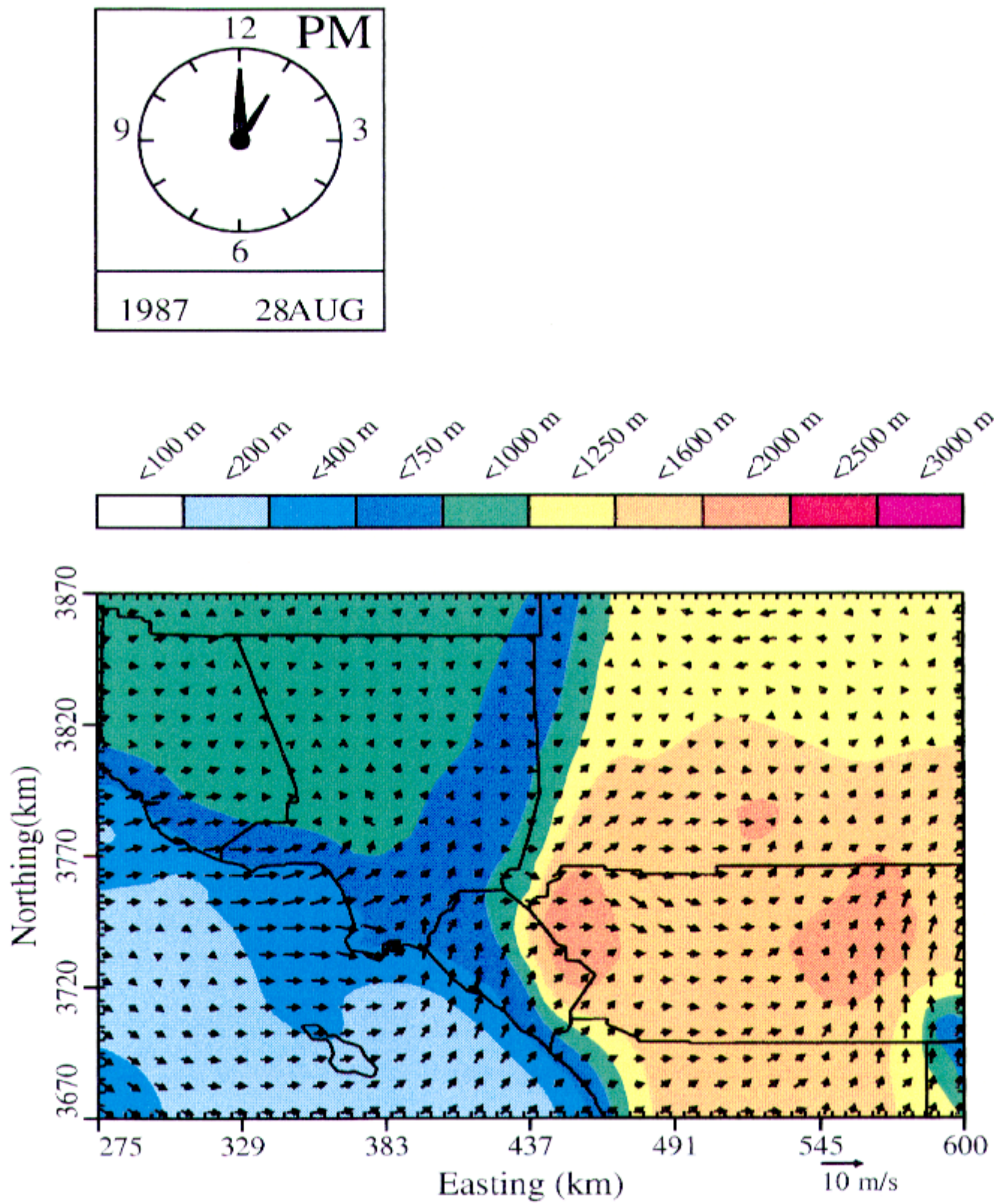

Figure 3-11. Surface winds and mixing heights over the Los Angeles basin derived using CALMET (V5) 

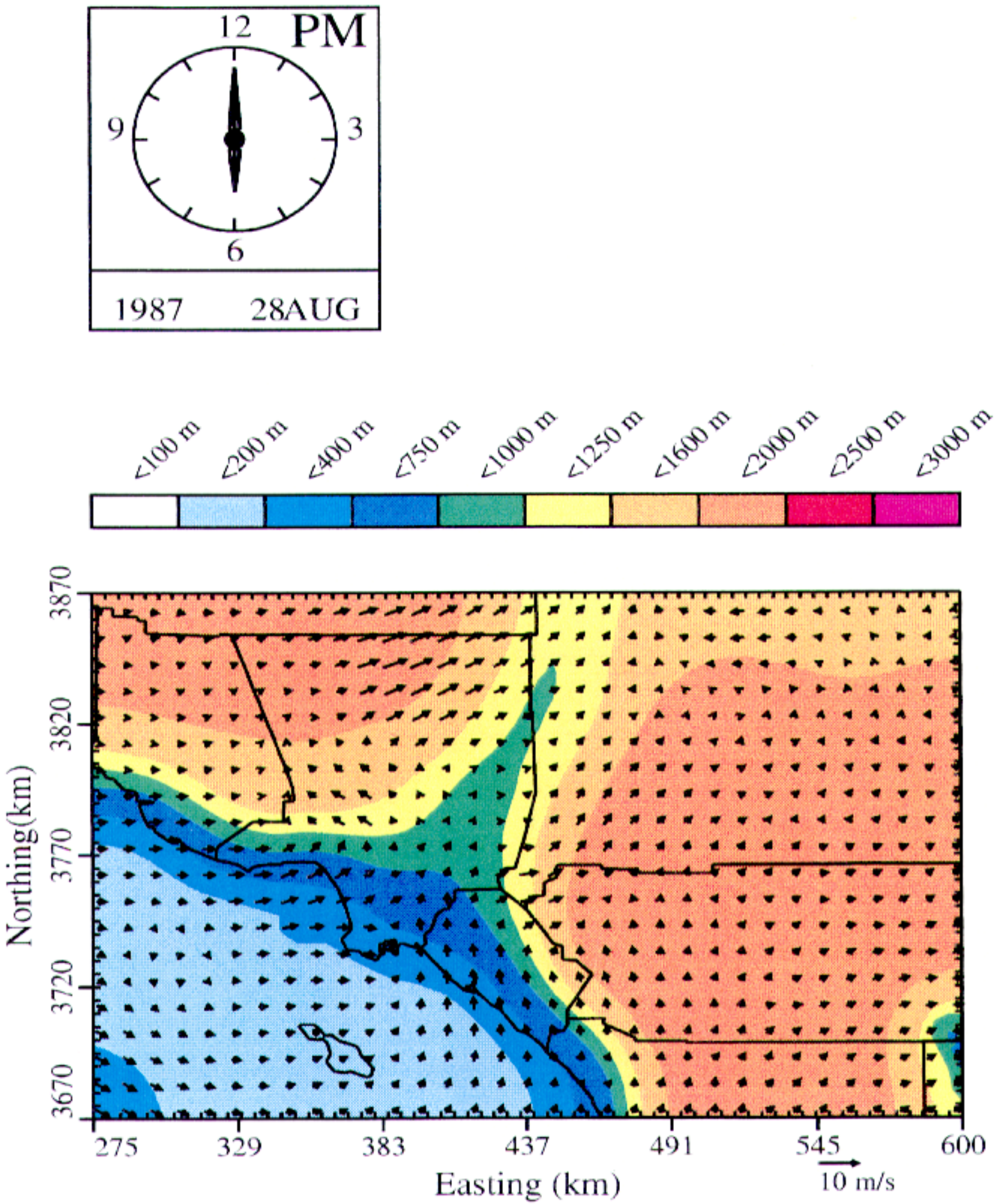

Figure 3-12. Surface winds and mixing heights over the Los Angeles basin derived using CALMET (V5) 

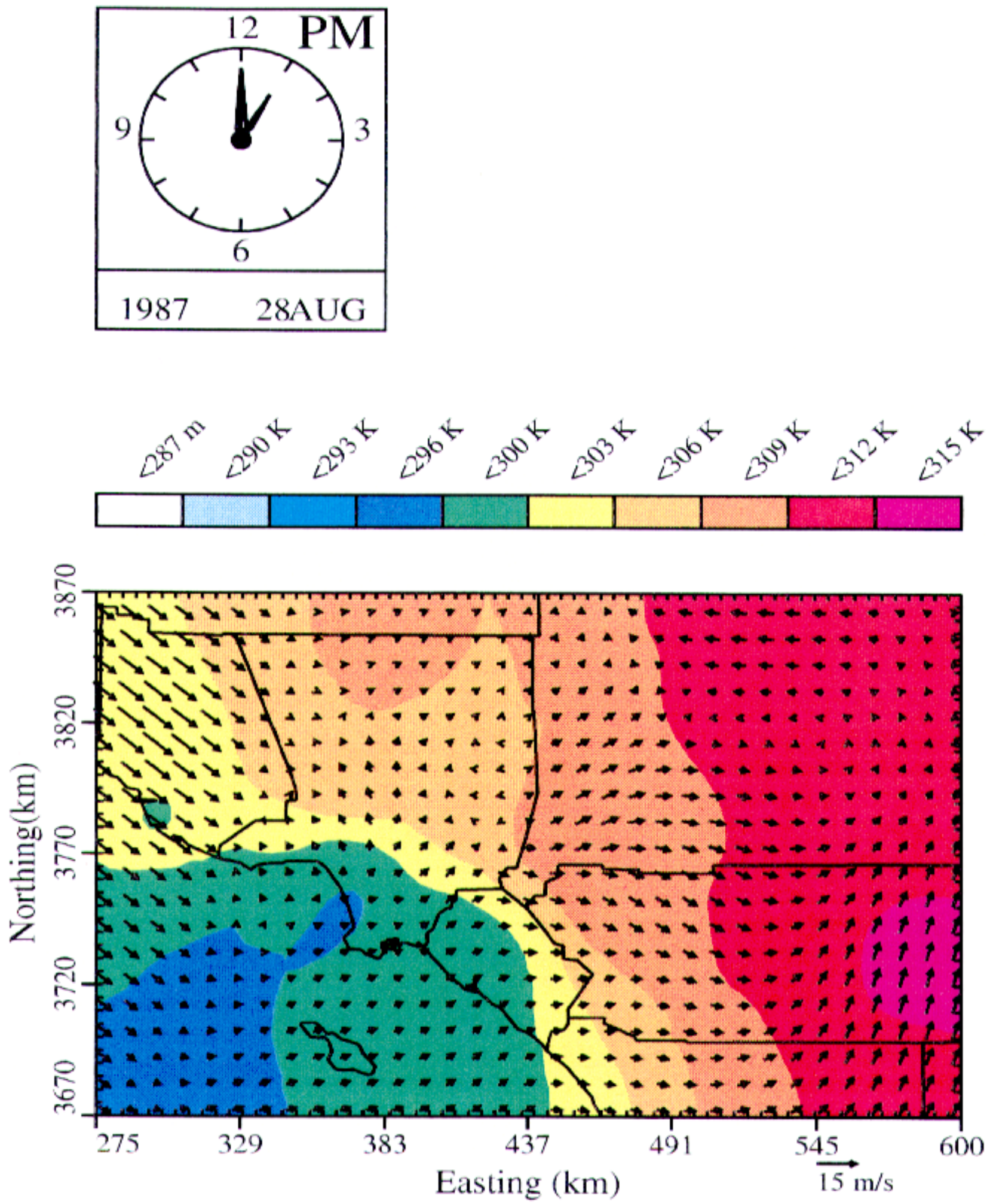

Figure 3-13. Surface temperatures and $500 \mathrm{~m}$ winds the Los Angeles basin derived using CALMET (V5) 


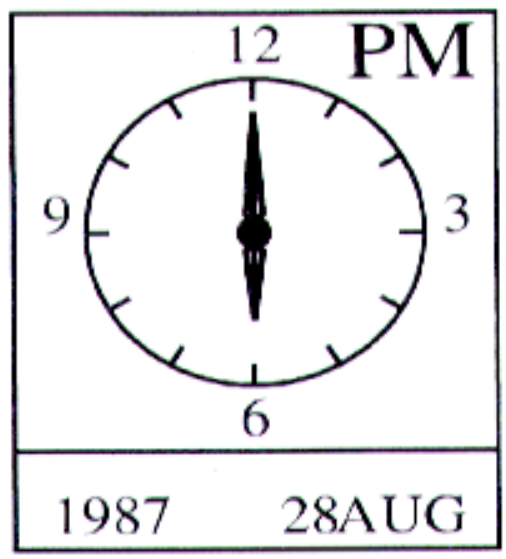

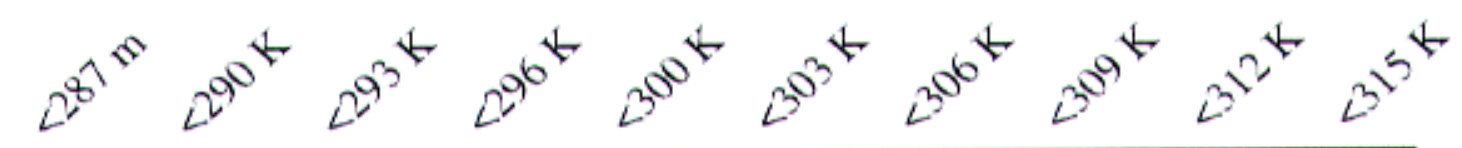
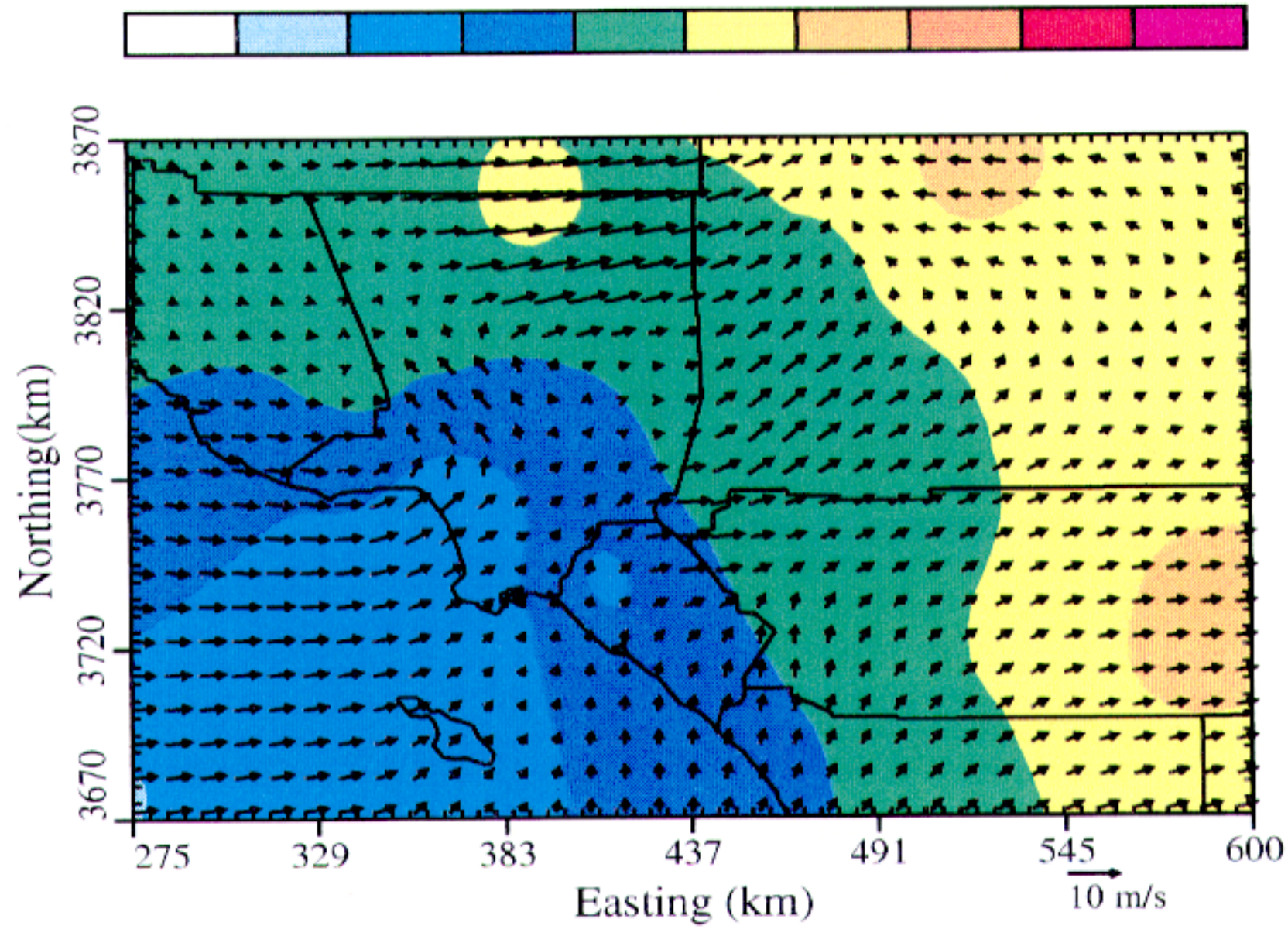

Figure 3-14. Surface temperatures and $500 \mathrm{~m}$ winds the Los Angeles basin derived using CALMET (V5) 

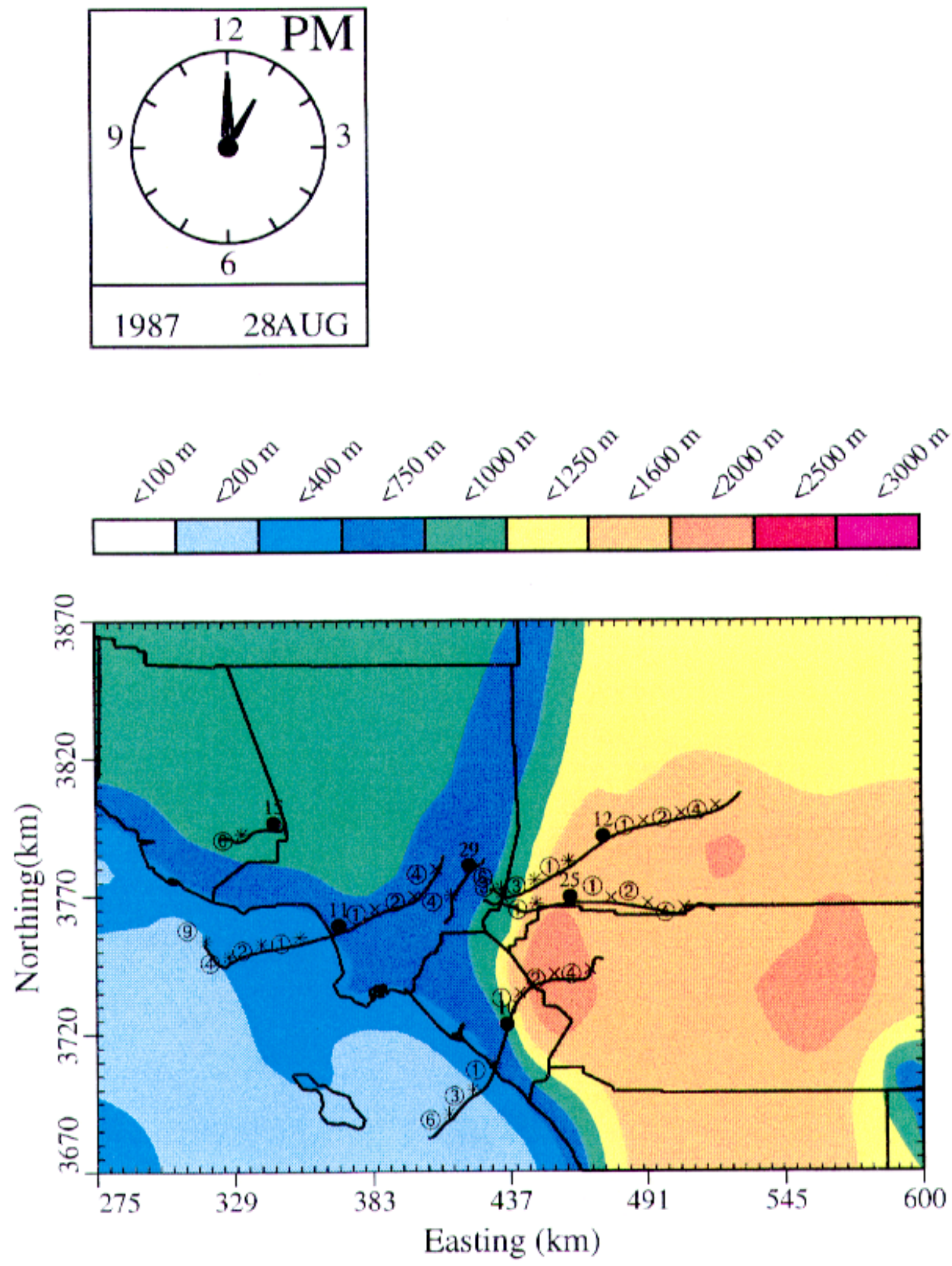

Figure $3-15$. Surface trajectories and mixing heights in the Los Angeles basin derived using CALMET (V5) 

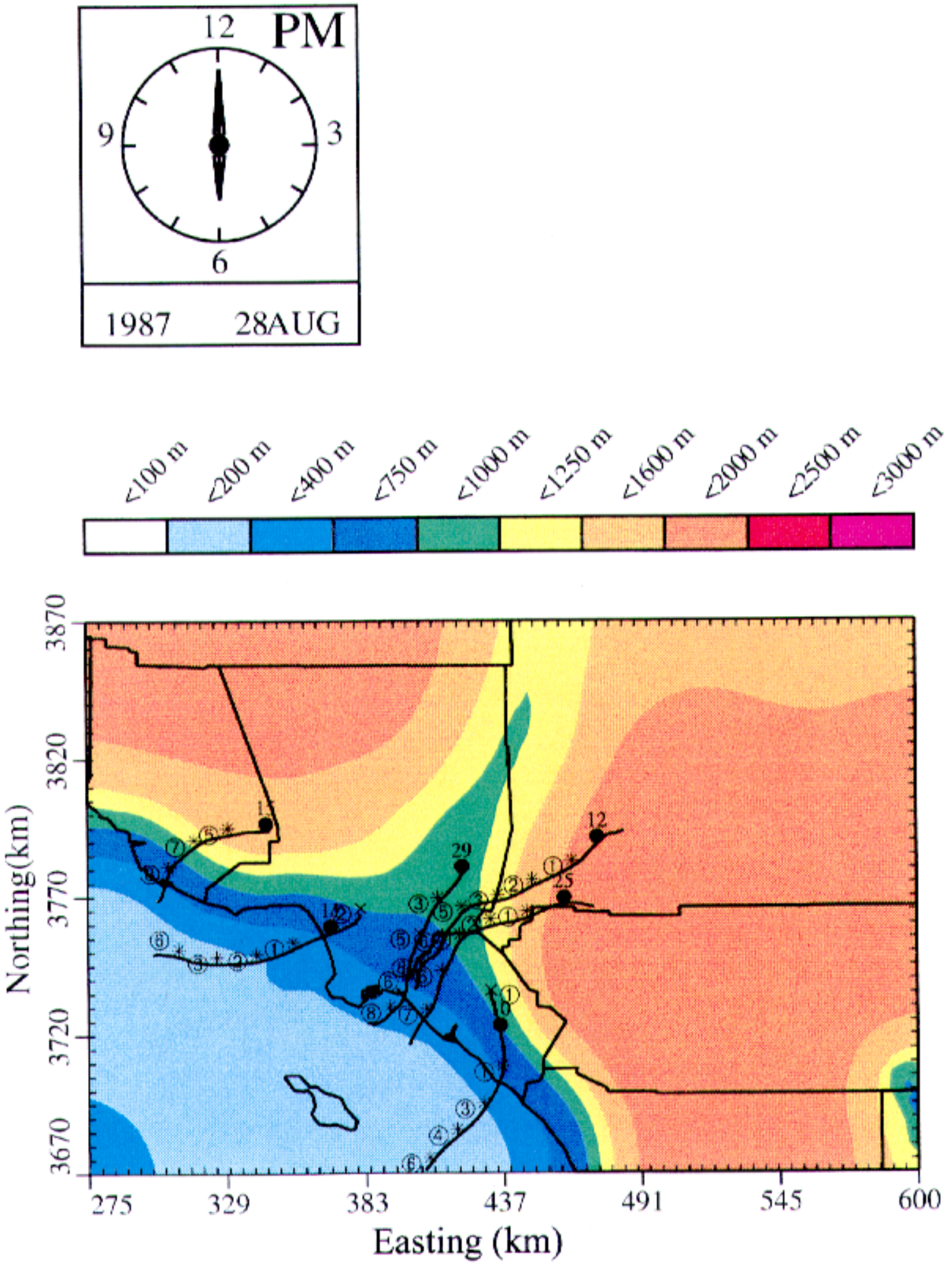

Figure 3-16. Surface trajectories and mixing heights in the Los Angeles basin derived using CALMET(V5) 


\subsection{Comparison and Evaluation of 1987 Base Year CALGRID Simulations}

In the initial modeling protocol document (Balentine et. al. 1997c) several possible reasons were presented to explain why the State Implementation Plan (SIP) UAM-IV modeling resulted in dramatic under predictions of ozone. One of the reasons suggested was that the limited spatial representation of several meteorological parameters used by UAM-IV led to significant ozone under-predictions. A second reason given was the under-estimation of the mobile source VOC emissions. The meteorological limitations of the UAM-IV and the CALGRID simulation described in Kumar et al. (1994) can be partly addressed by a more detailed input preparation for CALGRID modeling. Using the CALMET meteorological fields described previously, several CALGRID simulations (QA-1 and QA-2) were conducted in order to provide a basis of comparison with previous UAM-IV simulations.

CALGRID was applied within the range of recommended model input parameters. By using the same sources of input information as were used by UAM-IV, any differences in predicted ozone and toxic compound concentrations that arise would be primarily caused by how such information is processed and represented by CALMET and CALGRID. If the assertions made in the modeling protocol are correct, then the CALGRID simulations are expected to result in significant model performance improvements for the SIP application.

In addition to changes in the preparation of the meteorological input files, there has been a change in the chemical mechanism used. As noted earlier, the differences between CB-4 and SAPRC90 chemistry could result in some systematic differences in predicted concentrations of ozone and the four toxic species, because the rate of formation and destruction of these compounds seems to be slightly less for SAPRC90 than for CB-4. Predicted concentrations could be significantly different in regions of large spatial gradients in concentrations at the edges of the Los Angeles basin. This, in turn, could affect the findings concerning the air quality impacts of alternative fuel use.

\subsection{Model Setup}

The vertical layer structure used for CALGRID was the same as that used for the CALMET modeling described in the previous section. The modeling domain consists of 12 layers with a 65 by 40 cell domain consisting of $5 \mathrm{~km}$ by $5 \mathrm{~km}$ cells. CALGRID was operated in a regional mode so that factors, such as solar radiation, were explicitly estimated at the center of each grid cell rather than the domain center. The input data was updated once per hour. Newer deposition parameters like those found in CALPUFF (Scire et. al. 1997) were used. For CB-4 a total of 10 species were deposited (NO and most organic species were not), while for SAPRC90 a total of 16 species were deposited (NO and most organic species were not). For surface-based emissions, a profile with $90 \%$ of the mass emitted into layer one and two and the balance into layer three was used. Because of the strong, elevated inversion, light winds, and stable conditions expected aloft, the minimum vertical eddy diffusivity at the ceiling of the mixed layer was set to $0.01 \mathrm{~m} 2 / \mathrm{s}$, a value like that used by UAM-IV. Additional information on the CALGRID user input parameters can be found in Appendix B. 


\subsection{Ozone Model Performance Evaluation - UAM-IV versus CALGRID}

In the UAM-IV modeling reported in Balentine et. al. (1997a), the degree of model under prediction was examined. The 1994 SCAQMD SIP (SCAQMD, 1994) documents the large degree of under-predictions made by UAM-IV during the 27-28 August 1987 episode. The large degree of under-prediction was also noted in the UAM-IV and CALGRID comparison of Kumar et al. (1994). In the present study, we revisit the model evaluation exercise in order to demonstrate improved CALGRID model performance which is likely to translate into a more accurate model response to the use of alternative fuels.

The model performance evaluation begins with a side by side model comparison of the maximum daily ozone for each of the two episode days. The maximum observed concentrations for each day are plotted for a number of sites on the color contour plots. On 27 August, Figures 4-1a and $4-1 b$ shows that CALGRID is considerably better at predicting the maximum ozone concentrations at the edges and outside of the Los Angeles basin than UAM-IV. Notable regions of improvement are:

- The high ozone concentrations at the northeast edge of the basin are under-estimated to a lesser degree by CALGRID than by UAM-IV.

- The several sites like Whittier and Anaheim within the Los Angeles basin are predicted more accurately by CALGRID, which predicts a local ozone maximum in the lee of the San Pedro hills. UAM-IV, by contrast, predicts the whole basin as having rather low ozone concentrations.

- The domain-wide maximum ozone concentrations (observed $=24 \mathrm{pphm}$ ) are predicted more accurately by CALGRID than by UAM-IV (e.g., 26 pphm versus $16 \mathrm{pphm}$ ).

- The maximum ozone concentrations to the east of the basin in Riverside and San Bernardino counties are more accurately predicted by CALGRID than by UAM-IV.

- The highest concentrations of ozone are predicted by CALGRID to occur near the peaks of the highest terrain.

The same type of CALGRID - UAM-IV side by side comparison for maximum daily ozone concentrations for 28 August is shown in Figures 4-2a and 4-2b. Again, there are a number of regions where it can be visually noted that the peak concentration predictions made by CALGRID are more accurate than those made by UAM-IV. In several regions the peak concentrations of ozone predicted by CALGRID are significant over-estimations. From Figures $4-2 a$ and $4-2 b$ the following points can be noted:

- The region-wide maximum ozone concentrations predicted by CALGRID (26 pphm) are closer to the observed value of $29 \mathrm{pphm}$ than the $19 \mathrm{pphm}$ predicted by UAM-IV.

- CALGRID tends to over-estimate maximum ozone concentrations in elevated terrain in remote areas outside of the Los Angeles Basin. 
- CALGRID predicts a localized high concentration within the basin, which is spatially offset from the high value observed at Pico Riveria. UAM-IV predicts relatively low ozone concentrations for the whole Los Angeles basin.

- In the foothills, CALGRID and UAM-IV both under-predict significantly. Further inland, at sites like Redlands, CALGRID predicts significantly higher concentrations than UAM-IV.

To further explore model performance in predicting the daily maximum ozone in the modeling domain, several sites were selected to provide a focus. The maximum daily ozone unmatched in time for 27 August 1987 is tabulated in Table 4-1.

Table 4-1. A Comparison of the 27 August 1987 Maximum Daily Ozone (pphm) Predicted Using the CB-4 Chemical Mechanism.

\begin{tabular}{|l|c|c|c|}
\hline Area & Observed & CALGRID & UAM-IV \\
\hline Glendora & 22 & 13 & 7 \\
\hline Redlands & 24 & 18 & 10 \\
\hline Whittier & 12 & 11 & 11 \\
\hline Reseda & 16 & 13 & 6 \\
\hline Crestline & 17 & 17 & 11 \\
\hline
\end{tabular}

Table 4-1 shows that compared with UAM-IV, the degree of under-estimation of the peak ozone concentrations was significantly reduced by CALGRID in several regions of the modeling domain. High concentrations do, occur in the mountains near places like Crestline. A region of notable over-estimation by CALGRID is in the Palm Springs area. The peak ozone concentrations in the eastern portion of the domain are sensitive to the mixing height. If the mixing height cap at $1250 \mathrm{~m}$ is relaxed to allow mixing heights to grow to $2199 \mathrm{~m}$, the maximum ozone concentrations predicted in Palm Springs drop to $10 \mathrm{pphm}$, relatively close to those observed.

The local transient ozone maximum predicted by CALGRID in the Los Angeles basin may be the result of a re-circulation cell (eddy) in the lee of the San Pedro hills. The work of Burcchini et al. (1995) suggests that there is often a region of significant coupled divergence and convergence in the lee of San Pedro Point. Under the usual sea-breeze circulation, the eddies occur inland near the Orange County boundary such eddies are reflected in the observed winds and can lead to anomolous convergence air flows in the wind fields used by CALGRID.

The peak ozone predictions by CALGRID and UAM-IV for selected sites on 28 August are presented in Table 4-2. CALGRID predicts ozone concentrations better than or as well as UAM-IV at all sites except Reseda. The predictions in the north basin are strongly dependent on the choice of the domain mean wind and the mixing height. The same mixing height ceiling and domain mean wind site were used for 27 and 28 August despite the rise and weakening of the subsidence inversion on 28 August and the veering of the wind towards the southeast. In spite of this, the CALGRID predictions of peak ozone summarized in Table 4-2 generally outperform UAM-IV. 
Table 4-2. A Summary of Maximum Daily Ozone (pphm) at Selected Sites in Los Angeles Basin Produced by CALGRID and UAM-IV CB-IV on 28

August 1987.

\begin{tabular}{|l|c|c|c|}
\hline Area & Observed & CALGRID & UAM-IV \\
\hline Glendora & 29 & 10 & 10 \\
\hline Redlands & 21 & 17 & 13 \\
\hline Whittier & 14 & 7 & 4 \\
\hline Reseda & 15 & 11 & 14 \\
\hline Crestline & 12 & 19 & 11 \\
\hline
\end{tabular}

\subsection{Ozone Model Performance Evaluation - CALGRID CB-4 versus SAPRC90}

As demonstrated in Section 2, the SAPRC90 chemistry is expected to produce less ozone than the CB-4 chemistry. This proved to be true for CALGRID simulations in the Los Angeles modeling domain during 27 August. The domain-wide peak predicted ozone decreases from $258 \mathrm{ppb}$ to $205 \mathrm{ppb}$. Figure 4-3 shows that maximum ozone concentrations decreased over most of the domain. The largest decreases occur over the mountains in San Bernardino County. The reductions are of the order $50 \mathrm{ppb}$ in places like Redlands. In the foothills the peak ozone is reduced by over $20 \mathrm{ppb}$. The differences between CB-4 and SAPRC90 on 28 August are spatially complex as Figure 4-4 demonstrates. As on 27 August, ozone concentrations in the Los Angeles basin are relatively unchanged. In the foothills, the decrease of ozone is still about 20 $\mathrm{ppb}$, however, there is a positive-negative pattern in the San Bernardino mountains with decreases closer to the basin and increases further inland. This pattern corresponds to a shift downwind of the peak predicted ozone concentrations with SAPRC90 chemistry.

\subsection{Ozone Time Series Analysis}

The matching of predicted and observed ozone by time and location is a more rigorous comparison than the analysis of unmatched maximums. Ozone time series at several sites across the modeling domain were examined to determine how well CALGRID performs versus UAM-IV on an hourly basis. Figure 4-5 shows the observed and predicted ozone concentrations at Rubidoux. On both days the observed ozone concentrations range from zero in the evenings and early morning to over $200 \mathrm{ppb}$ in the afternoon (1500 LST). On 27 August CALGRID predicts the peak ozone slightly earlier in the day. The SAPRC90 maximum prediction is about $40 \mathrm{ppb}$ less than that with CB-4. The CALGRID SAPRC90 simulation produces slightly less ozone than UAM-IV. On 28 August the CALGRID predictions peak several hours before the observed maximum. The UAM-IV ozone peak prediction also occurs three hours later than the CALGRID peaks, and the high ozone persists later into the evening as do the observations. The peak ozone concentrations of CALGRID CB-4 are $20 \mathrm{ppb}$ greater than those of either CALGRID SAPRC90 or UAM-IV. 
The highest observed ozone concentrations of the episode occurred at the Glendora site in the San Bernardino foothills. The observed and predicted ozone concentrations time series at Glendora are shown in Figure 4-6. On 27 August, the CALGRID CB-4 ozone predictions rise later in the morning and fall earlier in the evening. The UAM-IV time series remains relatively flat from 0700 LST until 1700 LST. The CALGRID SAPRC90 ozone predictions peak at the same time as the observed, however, the peak concentration predicted by CALGRID is about 90 ppb lower than that observed. On 28 August, none of the model predictions exceed the $120 \mathrm{ppb}$ ozone standard. Both UAM-IV and CALGRID predict roughly the same peak concentration of around $100 \mathrm{ppb}$.

One of the monitoring sites where elevated ozone concentrations are observed within the Los Angeles basin is the Whittier site near the Orange County line. The observed and predicted time series of ozone for Whittier is presented in Figure 4-7. On 27 August, all of the model predictions are relatively close except for a single hour (1600 LST) when the CALGRID predicted concentrations (both SAPRC90 and CB-4) jump by over $50 \mathrm{ppb}$. On 28 August the three model predictions again track closely around $30-40$ ppb until about 1500 LST when the CALGRID predictions jump about $40 \mathrm{ppb}$ for an hour. This one hour jump is associated with the position of a sharply defined local ozone maximum.

The Crestline site is located well to the east of the basin in the San Bernardino Mountains. The observed and predicted time series for Crestline are presented in Figure 4-8. On 27 August 1987 the observed concentrations peak much later in the day than the CALGRID predicted concentrations. The CALGRID ozone predictions begin rising rapidly by mid-morning, which does not occur for either the observations or the UAM-IV ozone predictions. The CALGRID CB-4 peak ozone predictions are closest to those observed, but occur two hours earlier. All models predict ozone concentrations to drop rapidly after 1900 LST, while the observed ozone concentrations remain elevated until midnight. On 28 August the CALGRID SAPRC90 and UAM-IV CB-4 peak concentrations are close to the observed maximum of $120 \mathrm{ppb}$. Both models predict the peak to occur one to two hours before it is observed. The CALGRID CB-4 over-predicts the observed peak by more than $60 \mathrm{ppb}$. Significant over-prediction by CALGRID occurs during the morning hours. This morning bias could be explained by biases in the winds used by CALGRID. The degree of over-prediction is much larger for CB- 4 chemistry than for SAPRC90 chemistry.

At the northern end of the basin the Reseda site observed ozone concentrations were greater than $140 \mathrm{ppb}$ during both days as shown in Figure 4-9. On 27 August the CALGRID CB-4 ozone predictions reach a 4-hr plateau around $130 \mathrm{ppb}$ while the observed concentration rises to $160 \mathrm{ppb}$ and then falls rapidly. The peak UAM-IV and the CALGRID S90 ozone concentration predictions are about $30 \mathrm{ppb}$ lower. On 28 August the UAM-IV predicted ozone peak is $10 \mathrm{ppb}$ lower than the observed peak and occurs two hours later. The CALGRID CB-4 predicted peak is $40 \mathrm{ppb}$ lower than observed. The CALGRID predictions fall to zero three or four hours earlier in the evening than the observations and UAM-IV predictions.

Another area where relatively large peak ozone concentrations were observed is in San Bernardino County at Redlands. The observed and predicted ozone time series at Redlands are shown in Figure 4-10. On 27 August, the CALGRID CB-4 ozone predictions reach $180 \mathrm{ppb}$, but the observations are considerably larger $(240 \mathrm{ppb})$. The UAM-IV and CALGRID SAPRC90 predicted ozone concentration peaks are over $100 \mathrm{ppb}$ lower than observed. While the timing of the peak is predicted accurately by UAM-IV, the CALGRID peak occurs several hours earlier. 
The UAM-IV predicted ozone concentrations remain above zero during the evening hours, at about $50 \mathrm{ppb}$ while observed and CALGRID predicted concentrations fall to zero. On 28 August the CALGRID ozone predictions again peak several hours earlier than observed. The CALGRID $\mathrm{CB}-4$ peak concentration is about $35 \mathrm{ppb}$ lower than observed, but 50 ppb higher than that predicted by UAM-IV. Again, during the evening the UAM-IV predictions fall more slowly than the observed concentrations.

\subsection{Comparisons of Model Predicted Formaldehyde Concentrations}

The maximum daily CALGRID CB-4 predicted HCHO concentrations for 27 August are shown in Figure 4-11. In Figure 4-11 the differences between UAM-IV and CALGRID are shown as contours $[\triangle \mathrm{HCHO}=\mathrm{HCHO}(\mathrm{UAM})-\mathrm{HCHO}(\mathrm{CALGRID})]$. The CALGRID predicted peak on 27 August occurs in downtown Los Angeles (DOLA) with a maximum predicted HCHO concentration of $24 \mathrm{ppb}$. HCHO peak concentrations in excess of $10 \mathrm{ppb}$ extend up into the San Bernardino foothills, with a tongue extending from Redlands out toward Palm Springs. The differences in peak HCHO concentrations are generally less than $4 \mathrm{ppb}$, with the CALGRID predictions being higher than those of UAM-IV. The observed HCHO concentrations at Rubidoux are slightly higher than the CALGRID predicted concentrations. On 28 August the peak HCHO concentrations of $15-20 \mathrm{ppb}$ are again predicted by CALGRID across much of the Los Angeles basin. The maximum concentration predicted by CALGRID is $21 \mathrm{ppb}$. Again, a tongue of elevated formaldehyde concentrations reaches into the mountainous area of San Bernardino County. As on 27 August, HCHO concentrations predicted by CALGRID are $6 \mathrm{ppb}$ larger than those predicted by UAM-IV. Observations at Rubidoux are again larger than the CALGRID predicted concentrations.

The amount of HCHO predicted by SAPRC90 was also examined. Figures 4-13 and 4-14 show the differences in the maximum predicted $\mathrm{HCHO}$ resulting from the two chemical mechanisms for each episode day. The differences are of the order of $2 \mathrm{ppb}$ for 27 August, but reach $4 \mathrm{ppb}$ northwest of Glendora on 28 August. The CB-IV mechanism predicts the higher peak HCHO concentrations. 


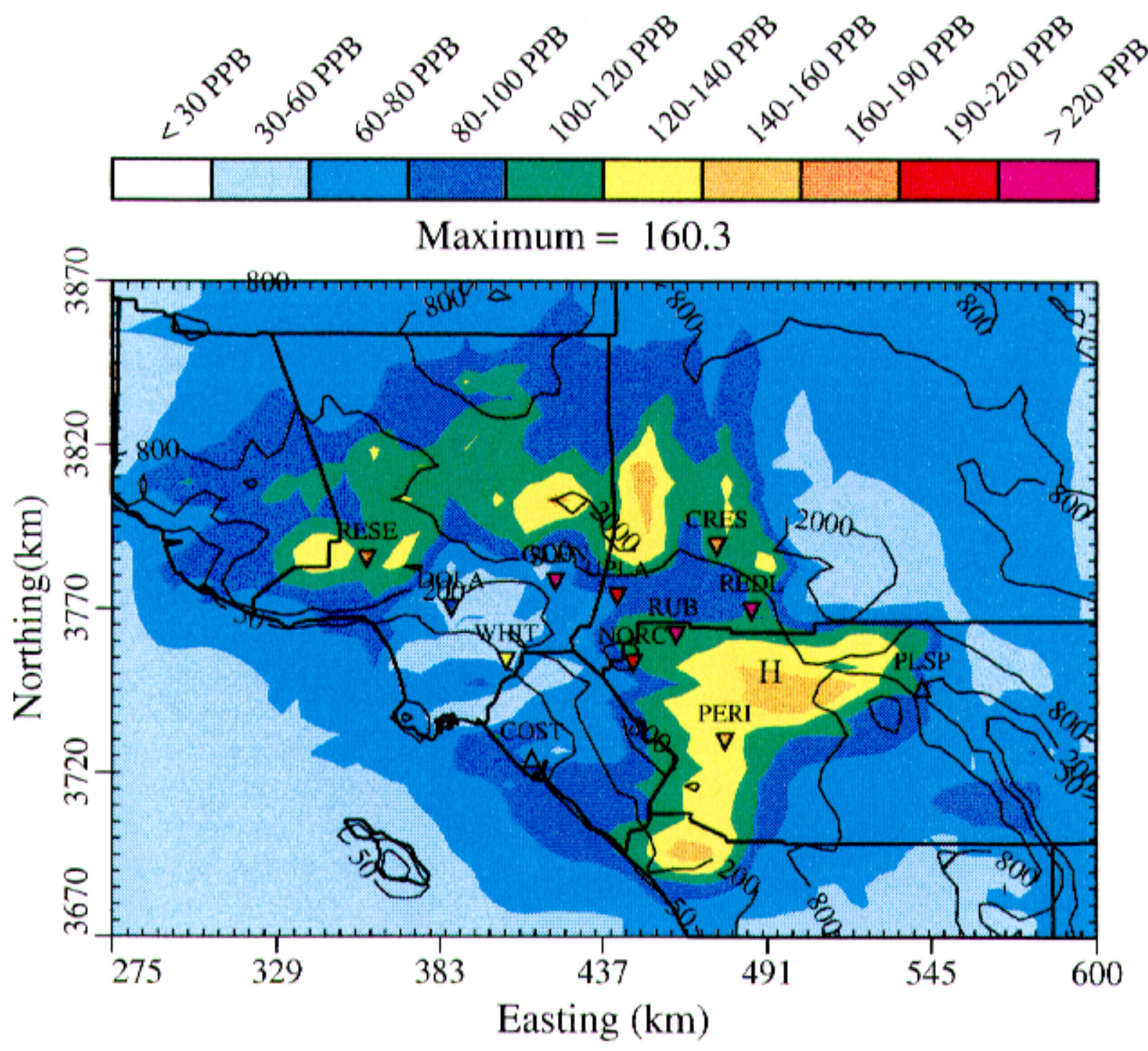

Figure 4-1a. Daily maximum 1-hr ozone over SCAQMD during 27 August 1987-CB4 chemistry - UAM-SIP. 


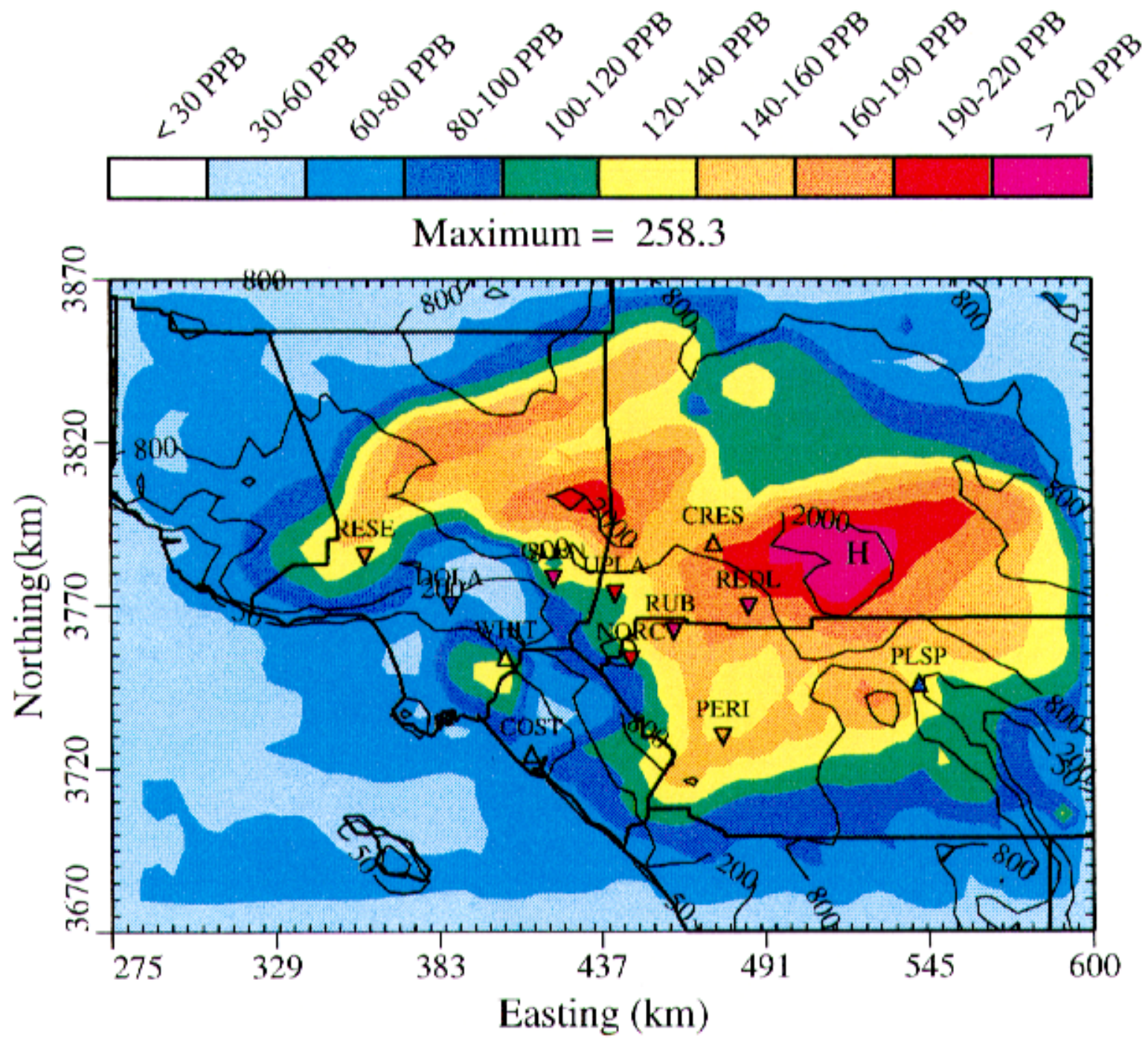

Figure 4-1b. Daily maximum 1-hr ozone over SCAQMD during 27 August 1987-CB4 chemistry - CALGRID-SIP. 


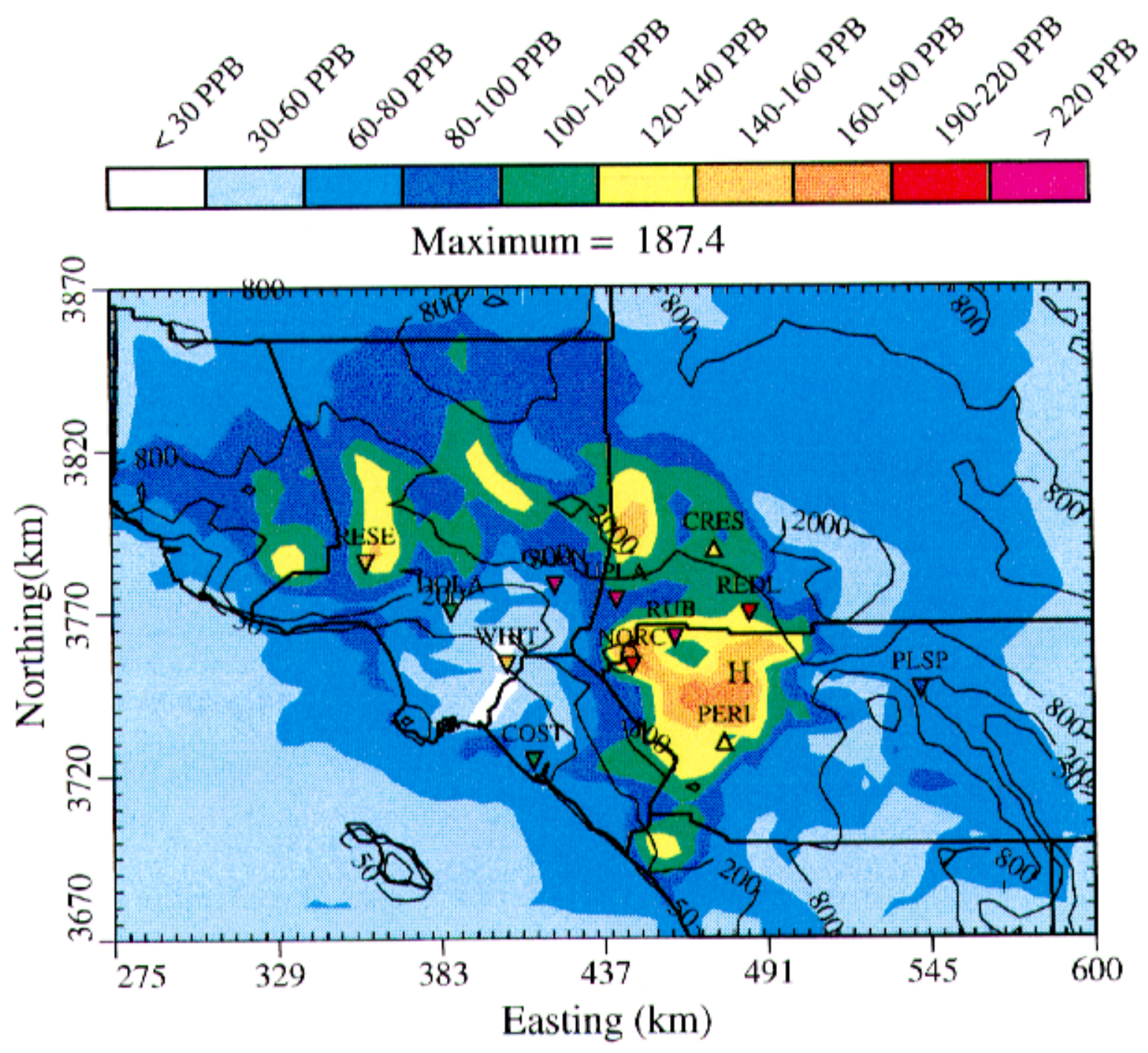

Figure 4-2a. Daily maximum 1-hr ozone over SCAQMD during 28 August 1987-CB4 chemistry - UAM-SIP. 


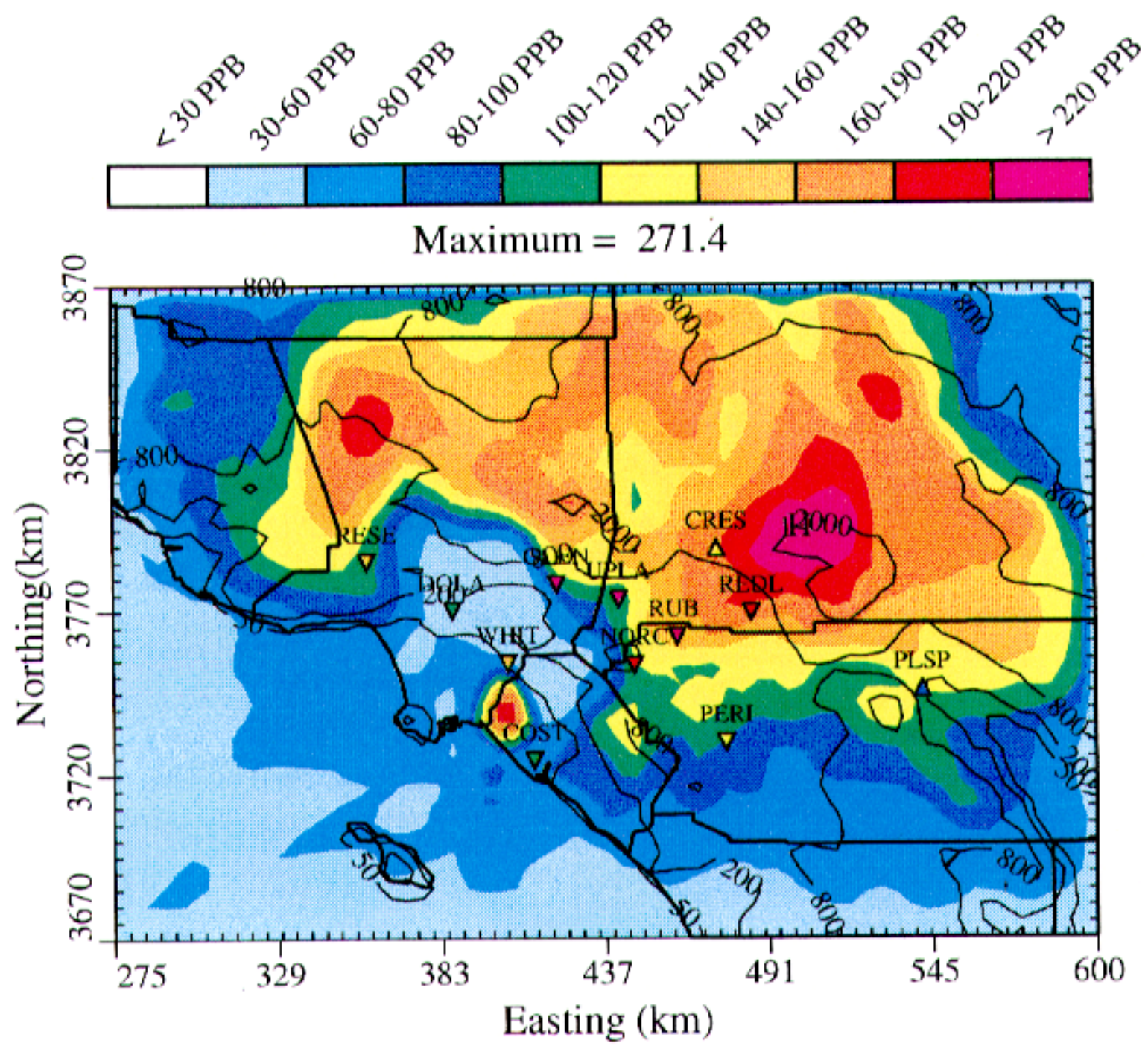

Figure 4-2b. Daily maximum 1-hr ozone over SCAQMD during 28 August 1987-CB4 chemistry - CALGRID-SIP. 

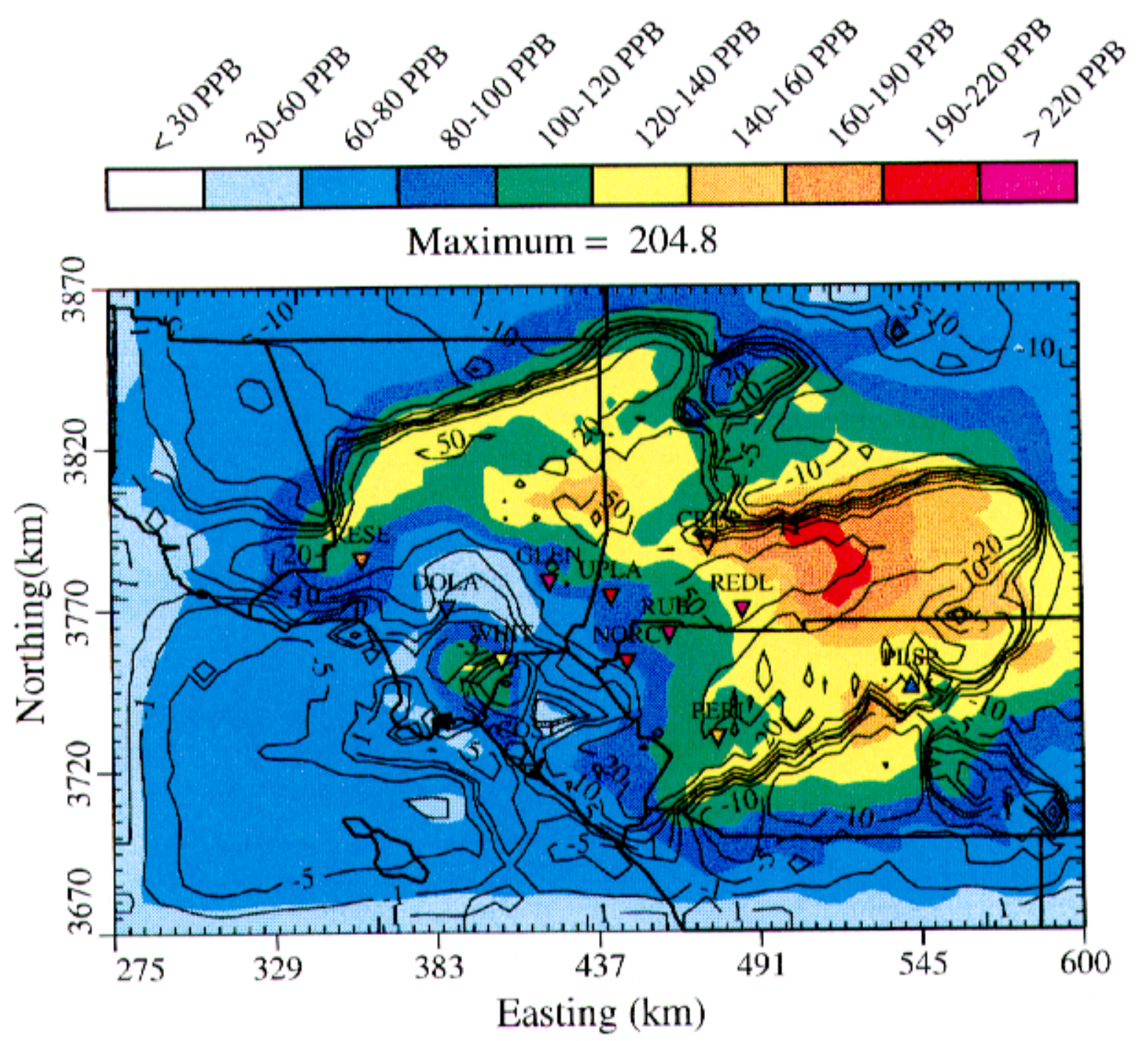

Figure 4-3. Daily maximum 1-hr ozone over SCAQMD during 27 August 1987-S90 chemistry - CALGRID-SIP. Contours are C(CB4) - C(SAPRC90) differences (ppb). 


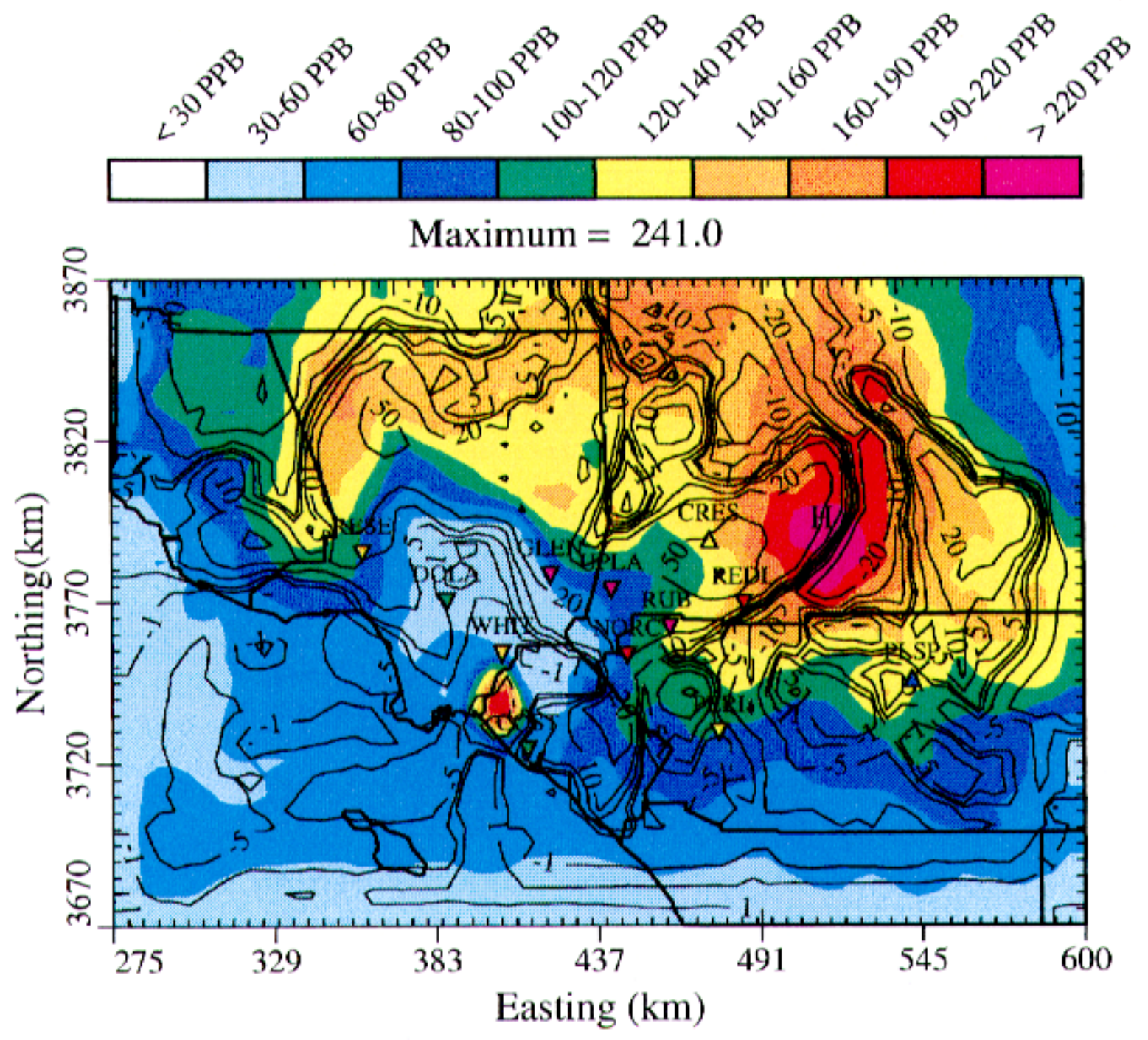

Figure 4-4. Daily maximum 1-hr ozone over SCAQMD during 28 August 1987-S90 chemistry - CALGRID-SIP. Contours are C(CB4) - C(SAPRC90) differences (ppb). 


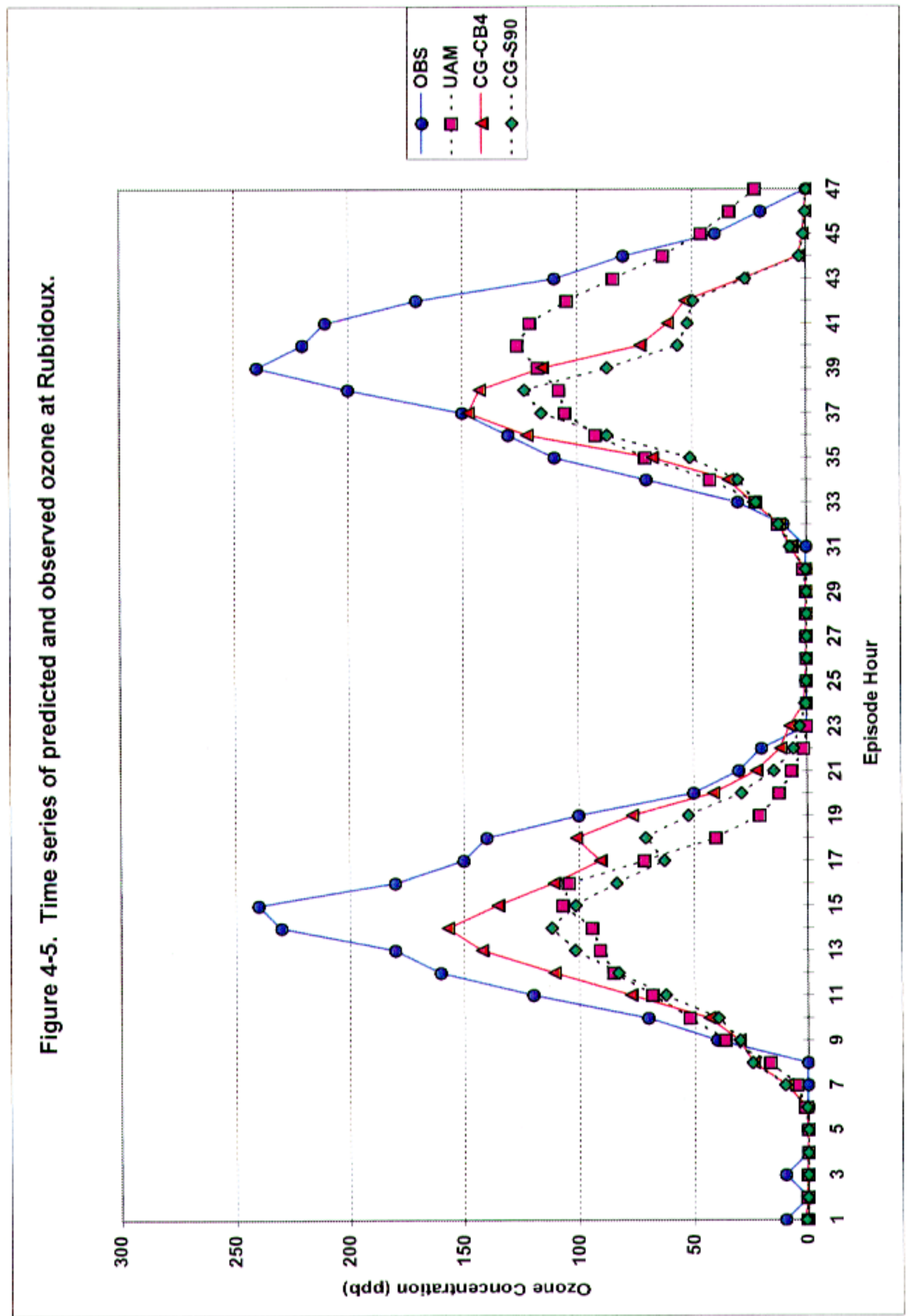




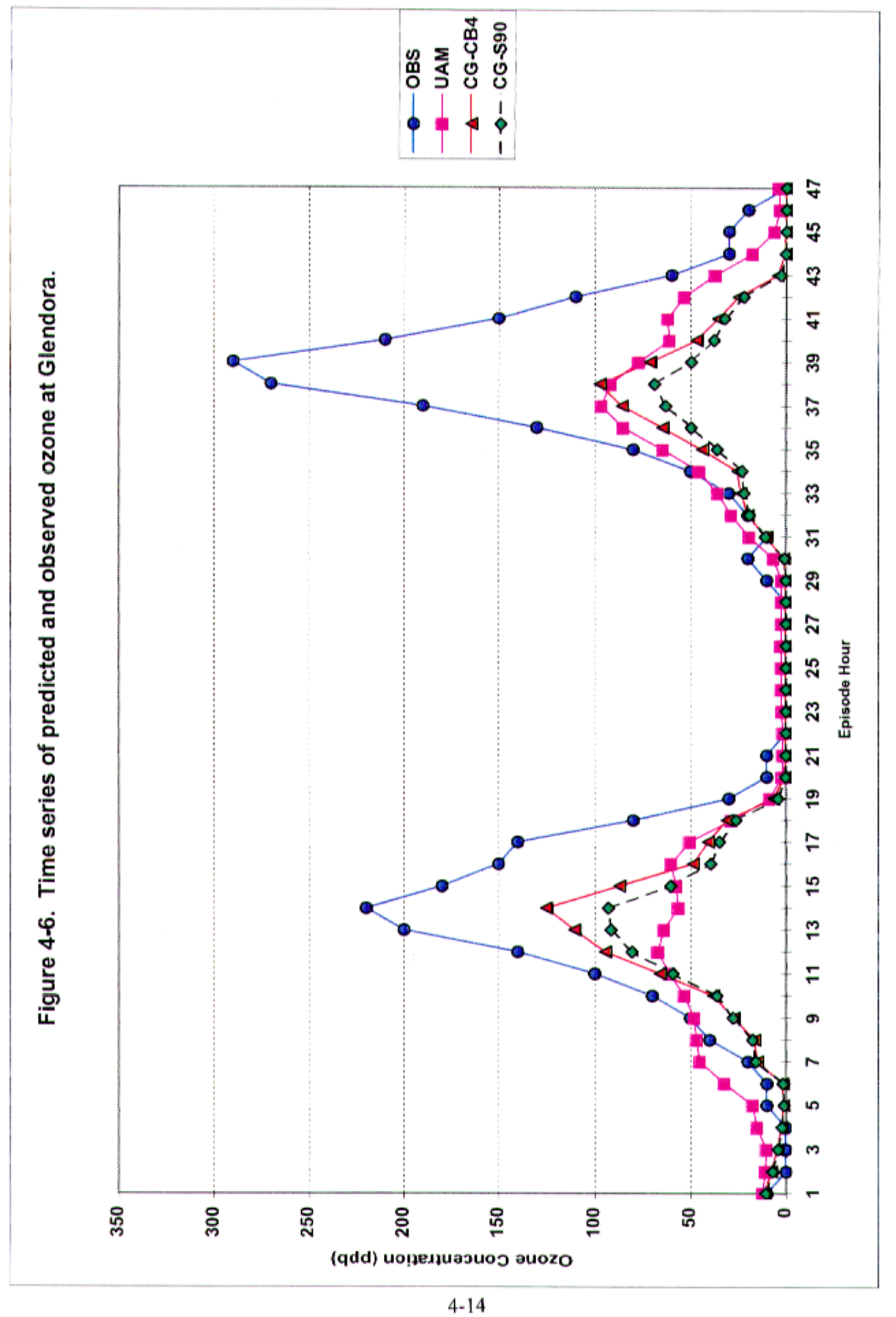




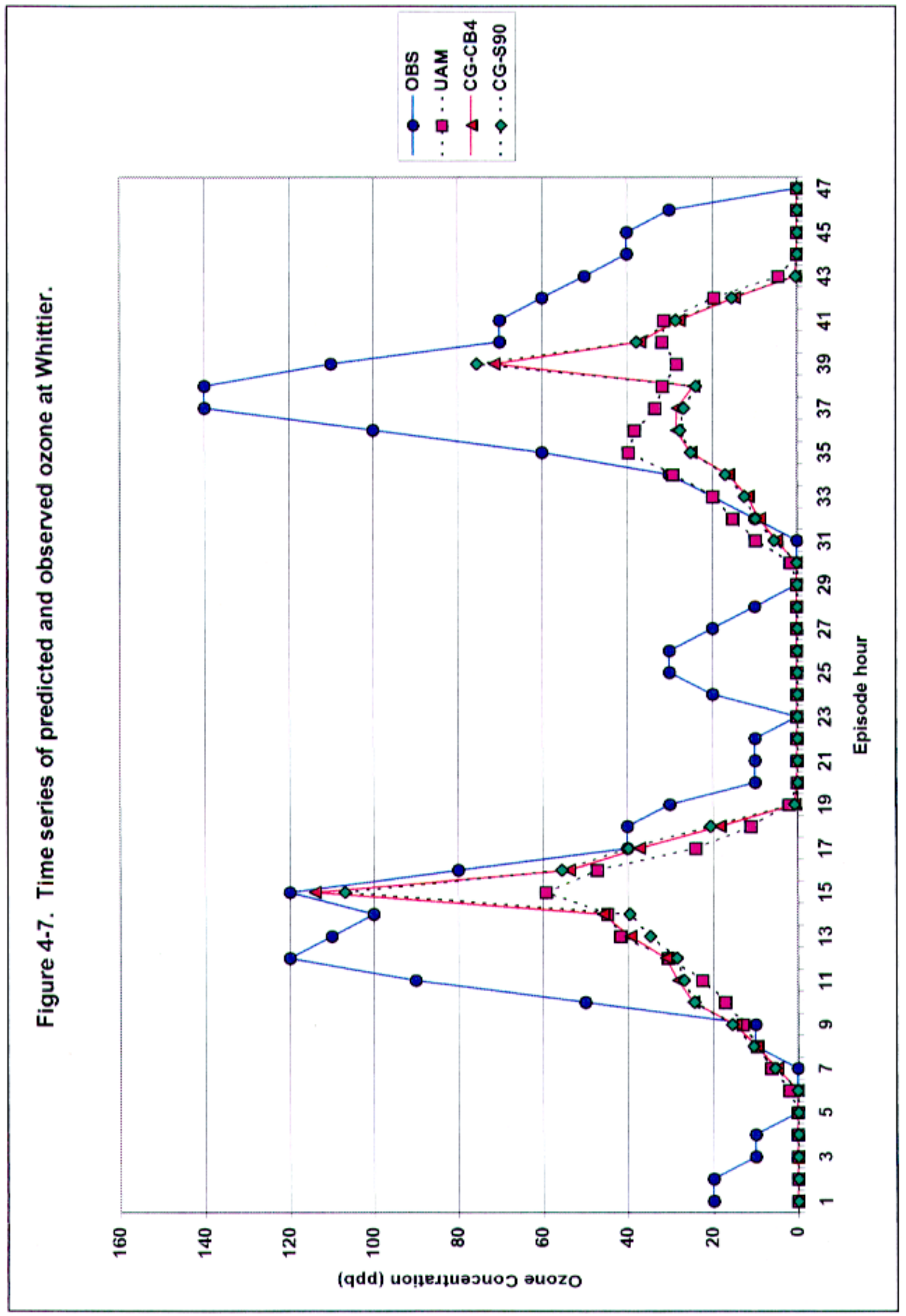



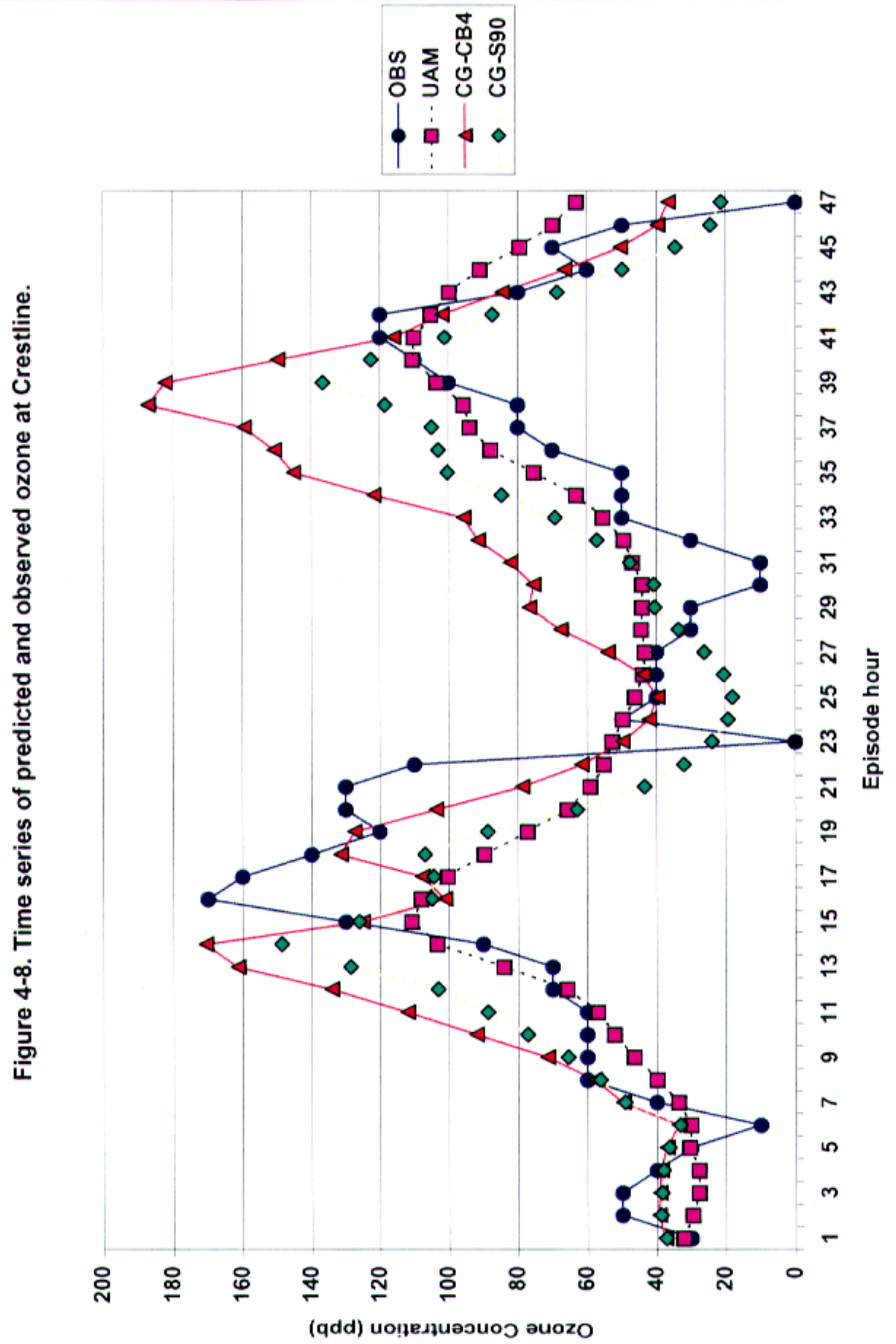


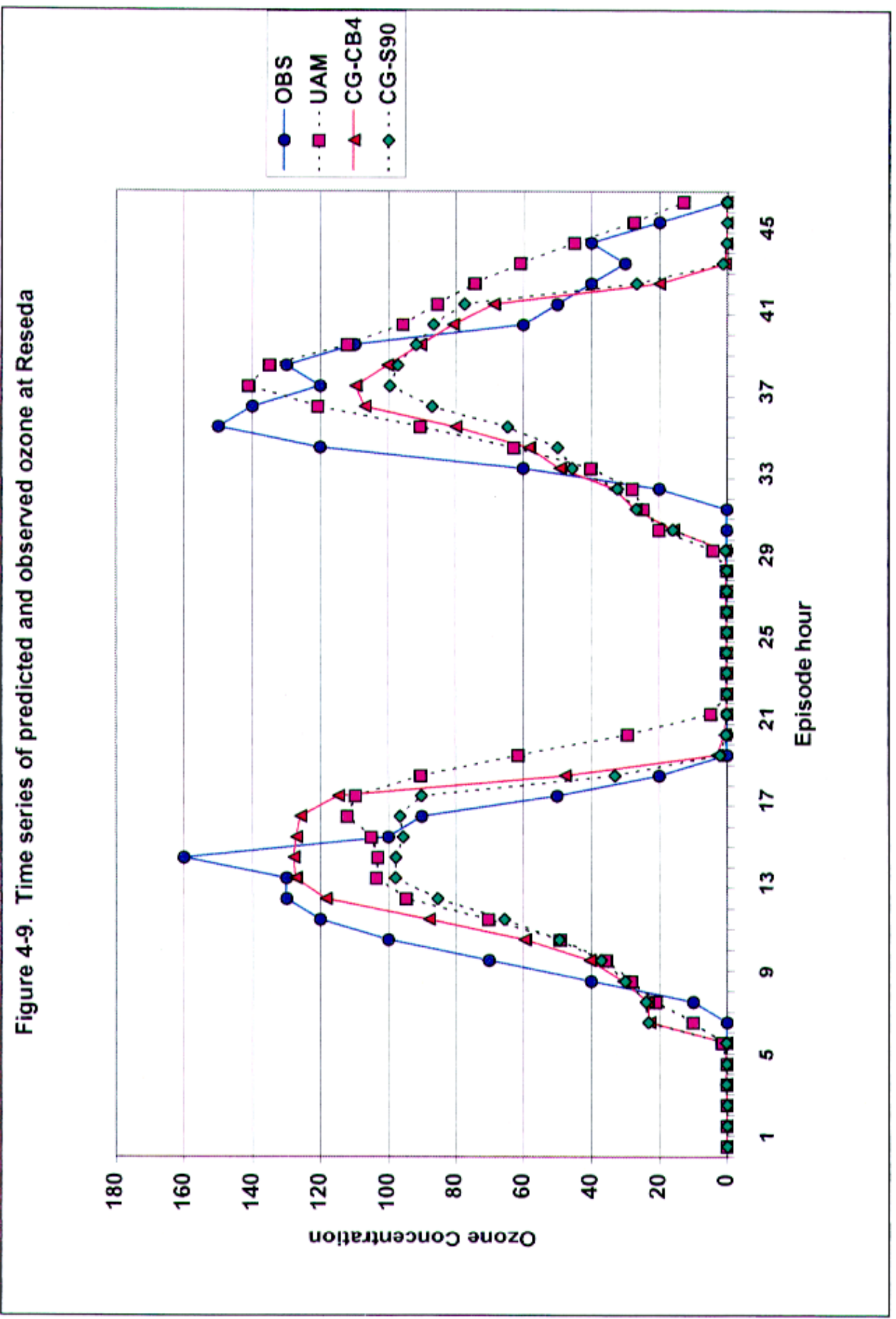




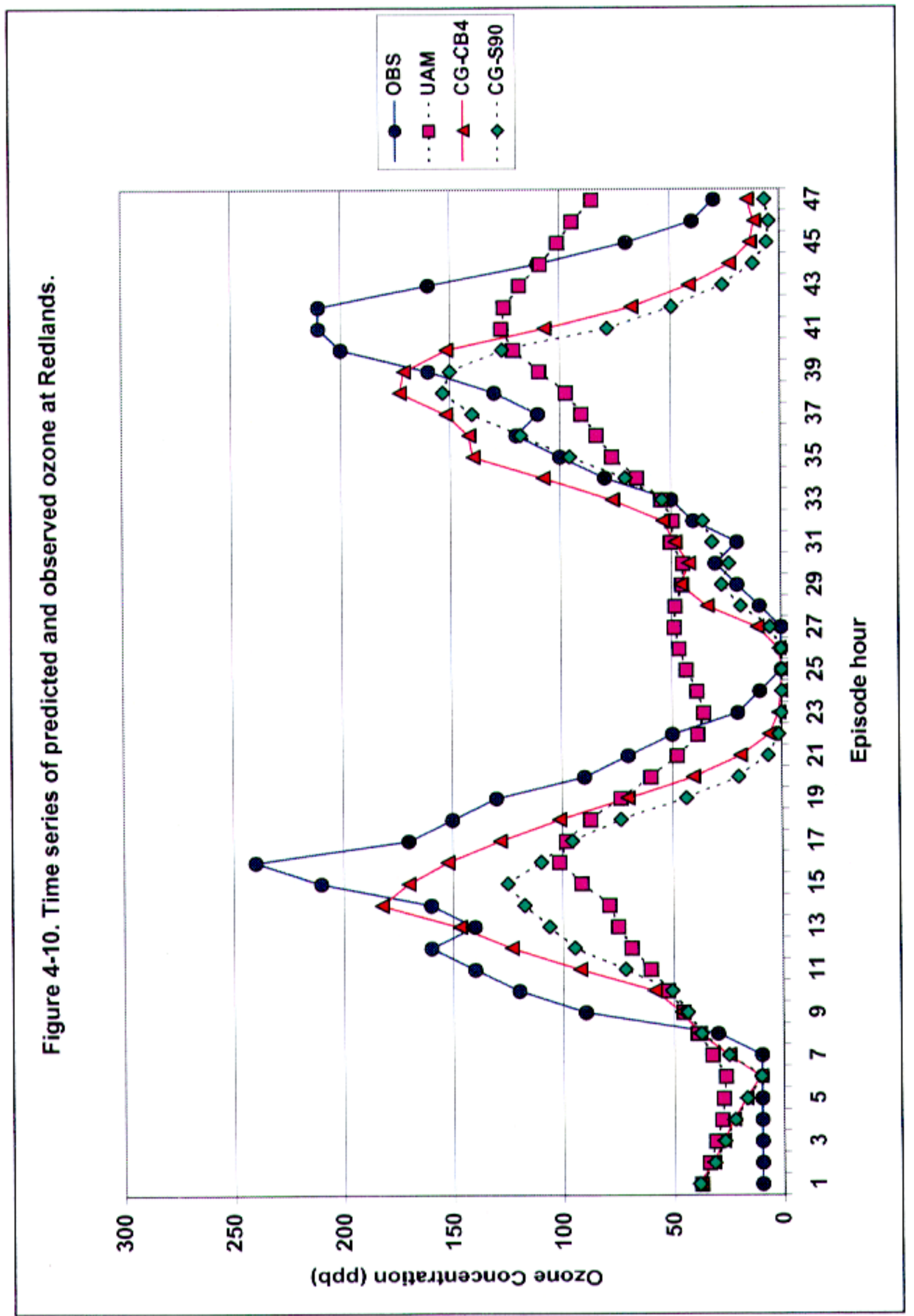




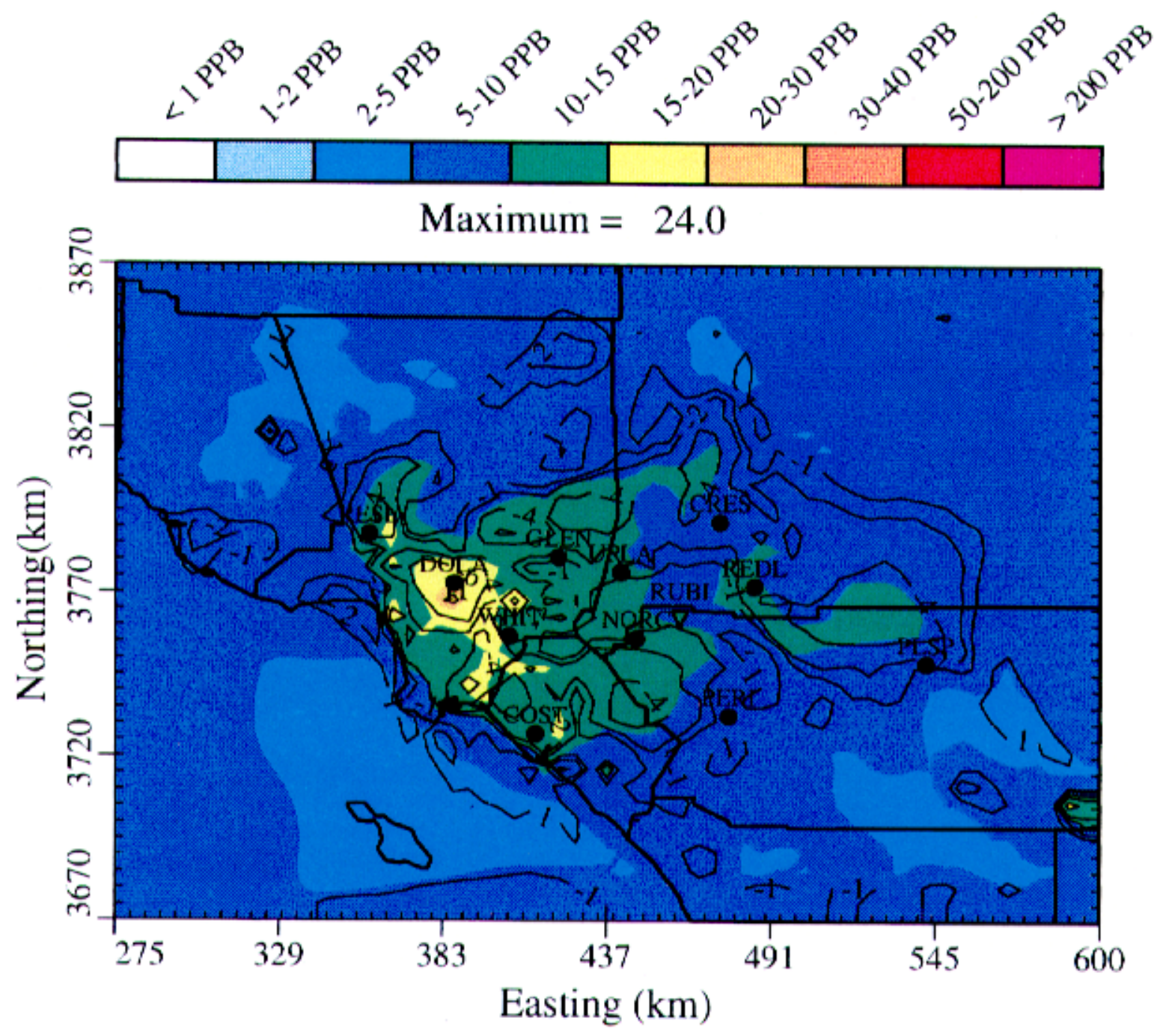

Figure 4-11. Daily maximum 1-hr HCHO over SCAQMD during 27 August 1987-CB4 chemistry - CALGRID-SIP. Contours are C(UAMCB4) - C(CB4) differences (ppb). 


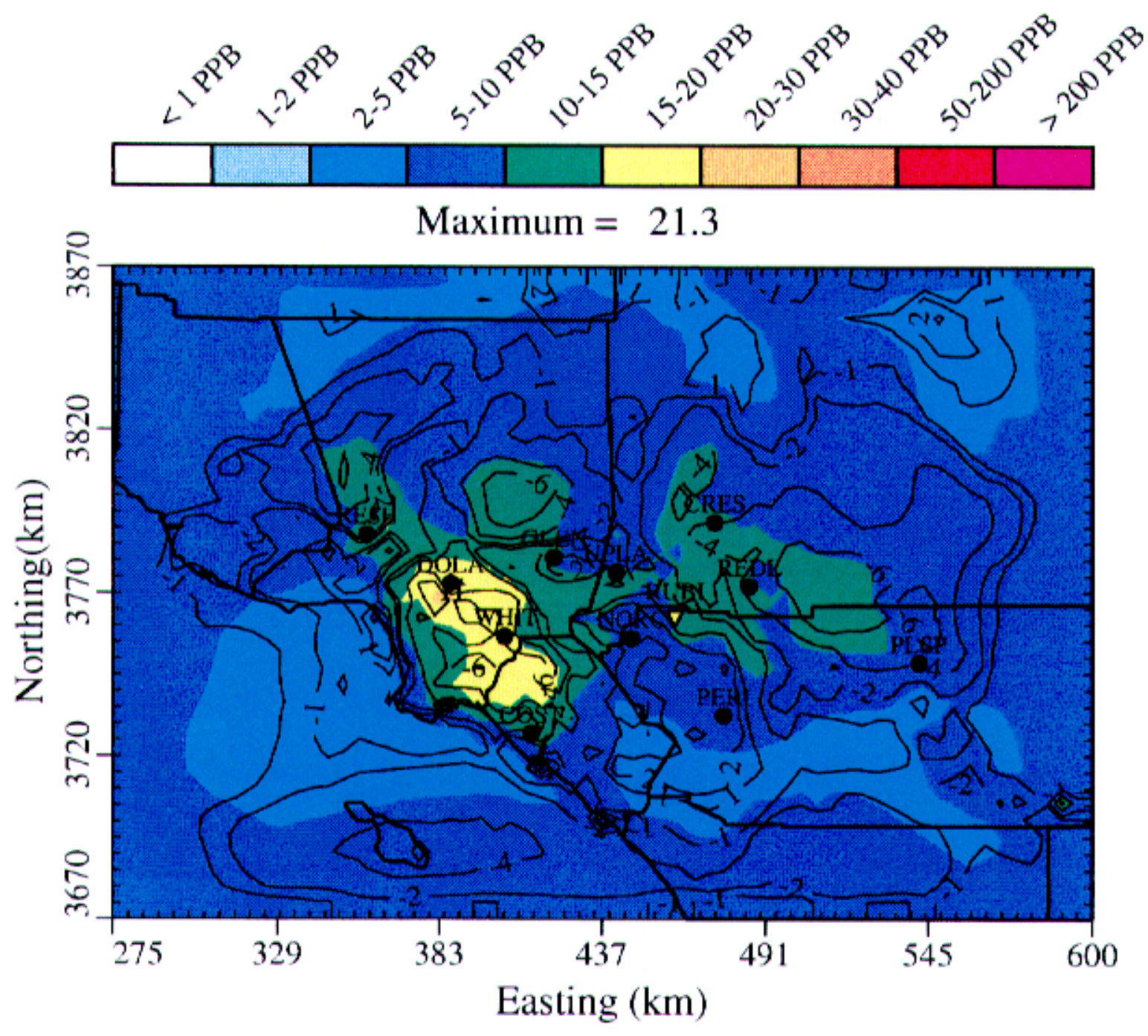

Figure 4-12. Daily maximum 1-hr HCHO over SCAQMD during 28 August 1987-CB4 chemistry - CALGRID-SIP. Contours are C(UAMCB4) - C(CB4) differences (ppb). 


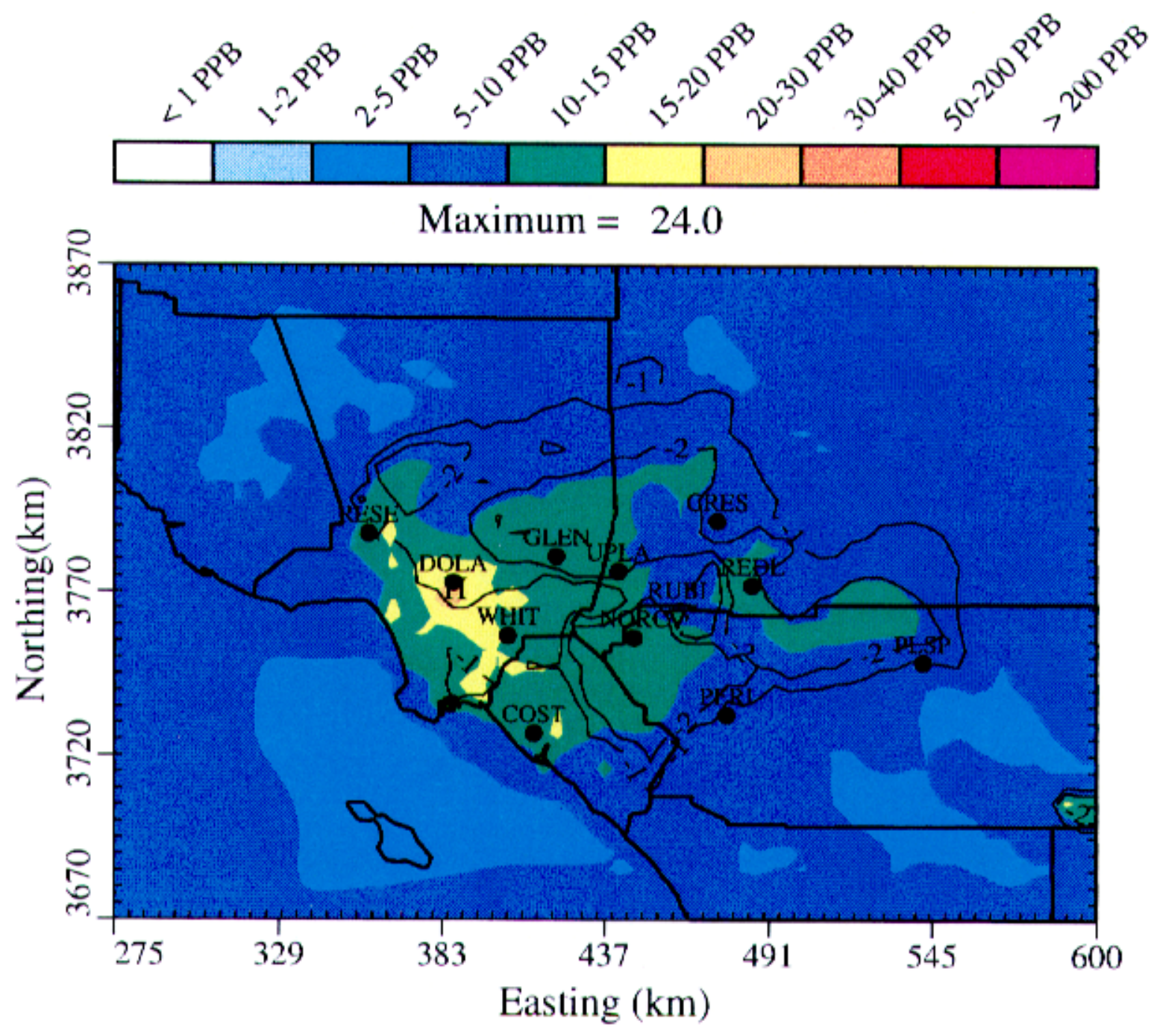

Figure 4-13. Daily maximum 1-hr HCHO over SCAQMD during 27 August 1987-CB4 chemistry - CALGRID-SIP. Contours are C(SAPRC90) - C(CB4) differences (ppb). 


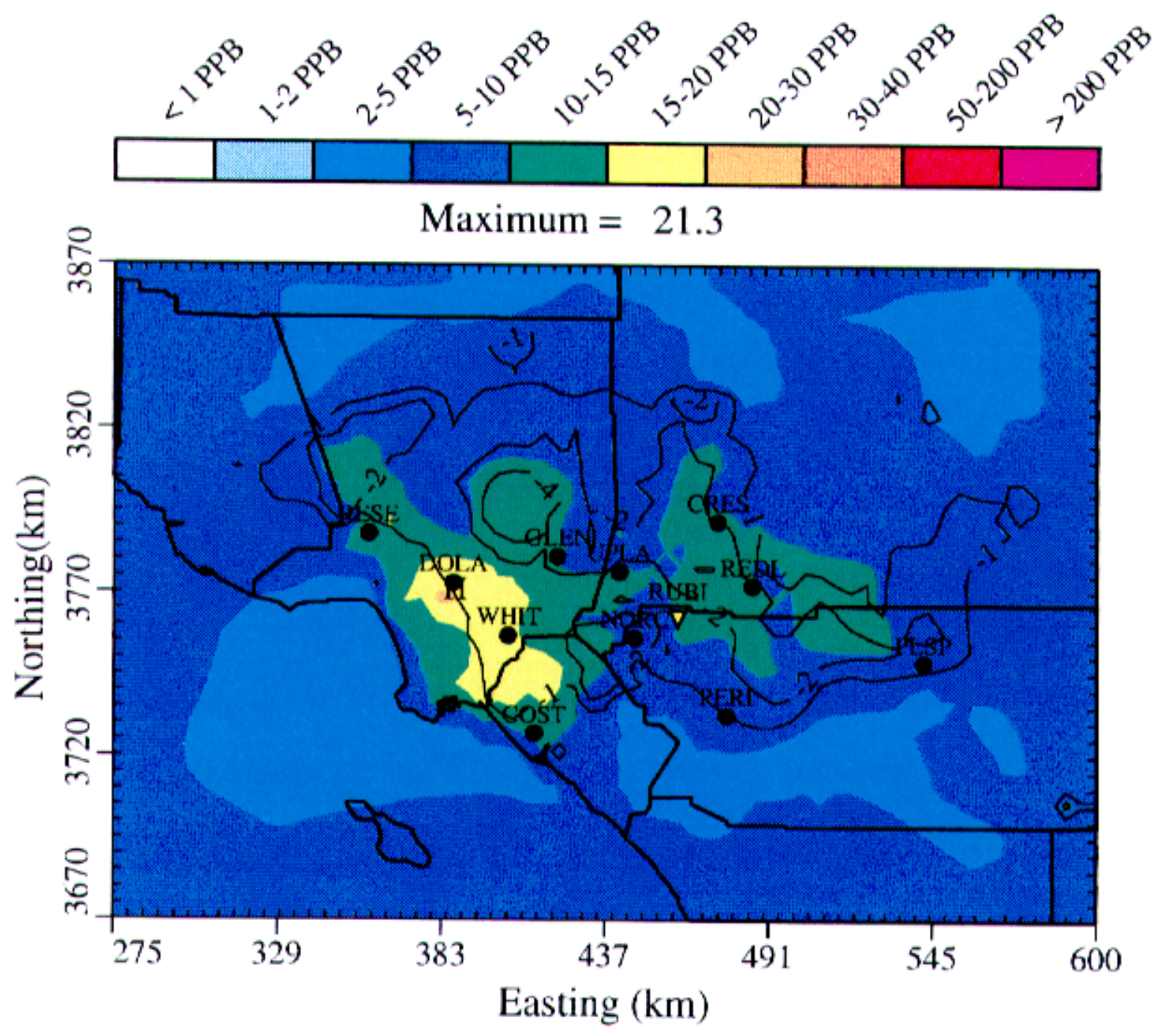

Figure 4-14. Daily maximum 1-hr HCHO over SCAQMD during 28 August 1987-CB4 chemistry - CALGRID-SIP. Contours are C(SAPRC90) - C(CB4) differences (ppb). 


\subsection{Analysis of Future Year Modeling Results}

CALGRID photochemical model simulations were conducted for the Los Angeles SCAQMD modeling domain for the future year 2007. The S1, RFG, CNG, and M85 fuel-use scenarios were modeled using emission inventories which have been prepared and described in Balentine et al. (1997a), and Moore, Fernau, and Londergan (1998). The major objective of the present study is quantify the degree to which RFG and the two alternative fuels, CNG and M85 used in light and medium duty vehicles may impact the concentrations of ozone and the toxic compounds $\mathrm{HCHO}, \mathrm{CCHO}, \mathrm{BENZ}$, and BUDI. This report presents the results of CALGRID modeling using the SAPRC90/93 chemical mechanism, which has a different ozone sensitivity to the reactivity of fuel combustion emissions. The analysis of modeling results follows that as described in Balentine et al. (1997a) and Moore, Fernau, and Londergan (1998) with the exception that the mass budget analyses and species-specific ozone sensitivities were not derived. This report includes a more detailed study of the differences between fuels, which were not fully addressed in the previous studies. The findings are also compared to those obtained previously using the UAM-IV with CB-4 chemistry.

CALGRID simulations for the alternative fuel scenarios were performed using both the SAPRC90 and SAPRC90/93 versions of the chemical mechanisms. The relative impacts and spatial patterns of ozone concentrations for different fuels predicted with the two mechanisms are very similar, but SAPRC $90 / 93$ consistently predicted higher peak ozone concentrations by 5 to $10 \mathrm{ppb}$ for both episode days. In this section, we have chosen to emphasize the CALGRID results obtained with the SAPRC90 mechanism. Selected results for each alternative fuel obtained with the newer SAPRC90/93 version are also presented for comparison purposes.

\subsection{Surface Emissions Inventory Description}

The main focus of the study is on the sensitivity of peak ozone concentrations and the human exposure resulting from variations in its primary emissions precursors, $\mathrm{NO}_{\mathrm{x}}$ and $\mathrm{VOCs}$. Of secondary interest are the predicted concentrations and human exposures to ozone and selected toxic compounds. The surface emissions inventory consists of four major components; biogenics, low-level points, off-road area emissions (fixed plus stationary), and on-road mobile emissions. For the sake of relative comparison, the domain-wide VOC and $\mathrm{NO}_{\mathrm{x}}$ emissions components for the RFG, CNG, and M85 inventories are summarized in Table 5-1. In this table, the daily tonnages of emissions for $\mathrm{NO}_{\mathrm{x}}$ are expressed as $\mathrm{NO}_{2}$ equivalents and the VOCs are expressed in terms of $\mathrm{CH}_{4}$ equivalent mass, in the same manner as in previous reports.

The emissions data indicate that biogenic emissions in Los Angeles constitute a relatively minor fraction of the total VOC emissions budget. No soil $\mathrm{NO}_{\mathrm{x}}$ emissions were contained in the SCAQMD emission inventory. Motor vehicle emissions of $\mathrm{NO}_{\mathrm{x}}$ are dominated by diesel vehicles and heavy-duty trucks, which are included in unaffected sources (S1). For the unaffected sources, area and low point emissions represent approximately $60-70 \%$ of the total VOC and $\mathrm{NO}_{\mathrm{x}}$ emissions. The incremental M85 scenario emissions represent about $20 \%$ less VOCs and about $17 \%$ more $\mathrm{NO}_{\mathrm{x}}$ emissions than the RFG scenario emissions, while the CNG scenario produces the lowest emissions of both VOC and $\mathrm{NO}_{\mathrm{X}}$. 
Table 5-1. Estimated Emissions in Los Angeles Modeling Domain for 2007 for S1 Scenario and RFG, CNG, and M85 Scenario Incremental Emissions.

\begin{tabular}{|c|c|c|c|c|c|}
\hline \multirow[b]{2}{*}{ Pollutant } & \multirow[b]{2}{*}{ Source Type } & \multirow[b]{2}{*}{$\begin{array}{l}\text { Unaffected Sources } \\
\text { (S1) (tons/day) }\end{array}$} & \multicolumn{3}{|c|}{ Fuel Scenario Incremental Emissions (tons/day) } \\
\hline & & & RFG & M85 & CNG \\
\hline \multirow[t]{5}{*}{ VOC } & Motor Vehicle & 28 & 138 & 114 & 3.7 \\
\hline & Area & 234 & 19 & 8.9 & 2.7 \\
\hline & Low-Level Point & 163 & 3.2 & 1.5 & 0.5 \\
\hline & Biogenics & 160 & 0 & 0 & 0 \\
\hline & Total VOC & 585 & 160 & 124 & 7 \\
\hline \multirow[t]{5}{*}{$\mathrm{NO}_{\mathrm{x}}$} & Motor Vehicle & 148 & 198 & 232 & 54 \\
\hline & Area & 229 & 0 & 0 & 0 \\
\hline & Low-Level Point & 109 & 0 & 0 & 0 \\
\hline & Biogenics & 0 & 0 & 0 & 0 \\
\hline & Total $\mathrm{NO}_{\mathrm{x}}$ & 486 & 198 & 232 & 54 \\
\hline
\end{tabular}

The spatial patterns of daily $\mathrm{NO}_{\mathrm{x}}$ and VOC emissions for these scenarios can be found in Balentine et al. (1997a) and Moore, Fernau, and Londergan (1998). Emissions of VOCs from all three fuel scenarios peak in the corridor between the coast and DOLA. On-road $\mathrm{NO}_{\mathrm{x}}$ emissions for all three fuel scenarios also peak in DOLA.

\subsection{Intercomparisons of Maximum Hourly Ozone}

The hourly maximum ozone concentration is one of the major air quality measures of interest in the present study. As noted in earlier sections, the peak 1-hr average predicted ozone concentration is likely to increase with the use of the upgraded SAPRC 90/93 chemistry. Given the domain-wide emission totals and the results of previous modeling, the anticipation is that CNG use will result in lower peak concentrations, while RFG and M85 use will produce roughly equivalent peak concentrations. This expectation is confirmed by the peak predicted 1-hr ozone concentrations summarized in Table 5-2. The transient peak at 1400 LST on 28 August is due to a predicted localized peak in the Los Angeles basin that is dominated by non-mobile emissions and is discussed in Section 4. 
Table 5-2. A Comparison of the UAM-CB4 and CALGRID SAPRC90/93 Domain-Wide Peak Predicted 1-hr Ozone Concentrations (ppb) for the Vehicle Fuel Use Scenarios.

\begin{tabular}{|l|l|l|l|l|}
\hline \multirow{2}{*}{ Modeled Fuel Scenario } & \multicolumn{2}{|c|}{ 27 August 2007 } & \multicolumn{2}{c|}{ 28 August 2007 } \\
\cline { 2 - 5 } & CALGRID & UAM-IV & CALGRID & UAM-IV \\
\hline (no light/medium duty vehicles) - S1 & 185 & 128 & $183^{*}$ & 137 \\
\hline California Reformulated Gasoline - RFG & 200 & 133 & $204^{*}$ & 150 \\
\hline Compressed Natural Gas - CNG & 190 & 129 & $188^{*}$ & 142 \\
\hline 85\% Methanol - M85 & 201 & 132 & $201^{*}$ & 145 \\
\hline
\end{tabular}

* Transient Peak of $231 \mathrm{ppb}$ at 1400 was removed

The predicted daily maximum 1-hr ozone concentrations indicate that the UAM-CB-4 ozone response is similar to the CALGRID SAPRC90/93 maximum ozone response. The larger predicted ozone concentrations produced by CALGRID make the maximum ozone responses to the alternative fuel scenario larger and more obvious. On both days the CNG scenario is predicted to produce significantly smaller peak ozone than either the RFG or M85 scenario. The only qualitative difference between models is that CALGRID tends to produce an M85 peak ozone response that is more like the RFG response than the corresponding UAM-CB4 response.

\subsubsection{Results for the S1 Scenario}

To evaluate the impacts of alternative fuels, it is important first to assess the spatial pattern of daily maximum 1-hr ozone without any light- and medium-duty vehicle emissions. Figure 5-1a illustrates the concentration pattern predicted by CALGRID with SAPRC90 for 27 August. The concentration pattern looks similar to that of the base simulations described earlier. The maximum concentrations occur to the north and east of the Los Angeles basin in the highest terrain as shown by the terrain contour also plotted in Figure 5-1a. A secondary ozone peak also occurs within the basin. The large concentrations produced by CALGRID CB-4 in the base simulation (as described in Section 4) have been significantly moderated by the use of SAPRC 90 and by the elimination of the light- and mediumduty mobile emissions. The use of the upgraded SAPRC 90/93 chemistry also has an effect. As expected Figure 5-1b shows that on 27 August the peak ozone concentrations increased by $5-10 \mathrm{ppb}$ with the upgraded chemistry.

The daily maximum 1-hr predicted ozone concentrations for 28 August with SAPRC90 are shown in Figure 5-2a for the S1 scenario. The elevated peak in the basin near the Orange County line was first noted in the base simulations. On this day the within-basin peak concentration is caused almost entirely by sources other than the light- and medium-duty vehicles and, as a result, the peak concentration reported in Table 5-2 reflects no variation between scenarios. The largest areas of peak ozone concentrations, like the base simulations, appear to the east of the basin in the mountainous areas of San Bernardino County. The effect of the use of the upgraded SAPRC90/93 chemistry for 28 August is illustrated in Figure 5-2b, which again shows increases in predicted peak ozone of the order of 5 - 10 $\mathrm{ppb}$.

\subsubsection{Ozone Predictions for the RFG Scenario}

The RFG fuel scenario is the scenario against which the other two alternative fuel scenarios will be compared. Therefore it is important to determine exactly what the ozone increment is which results from such fuel use. Figure 5-3a illustrates the concentration pattern for 27 August. The spatial concentration pattern looks similar to that of the S1 simulation, but with higher concentrations in the 
elevated terrain to the east. A difference plot between the RFG and the S1 scenarios is shown in Figure 5-3b. This figure provides a much clearer picture of the ozone differences than can be perceived from the side-by-side comparisons of the ozone concentrations used in the previous reporting. In particular a clear pattern of systematic ozone increases and decreases can be noted. The largest decreases occur in the eastern portion of the Los Angeles basin and in the foothills near Glendora and Upland. The largest increase in ozone occurs farther to the east, in the mountainous terrain and in the vicinity of Palm Springs. Very little difference is seen along the coast, in San Diego and Ventura Counties and in the extreme northeast portion of the modeling domain: all regions where automobile emissions are not significant and, trajectory studies indicate, such emissions play a minimal role in ozone formation.

On 28 August the daily maximum 1-hr ozone concentrations predicted by CALGRID in Figure 5-4a show an increase in the peak concentrations in the mountainous terrain in San Bernardino county plus some decreases in peak ozone within the Los Angeles basin proper. This observation is reinforced by the plot of ozone differences between the RFG and the S1 scenarios shown in Figure 5-4b. Again, there is a very distinctive pattern of ozone decreases and increases. As on 27 August, ozone decreases occur in the eastern portion of the Los Angeles basin. The one notable difference between the two days is that the region of ozone decreases doesn't reach as far up into the foothills on the $28^{\text {th }}$. Figure $5-4 \mathrm{~b}$ does show a region of much larger increases in San Bernardino County, with increases of greater than $20 \mathrm{ppb}$ occurring on the highest terrain.

A comparison was made between SAPRC90 and SAPRC93 for the RFG scenario. Figure 5-5a shows that for both days the upgraded SAPRC90/93 mechanism produces increases in the predicted maximum 1-hr ozone everywhere in the modeling domain on both days. The largest increases are $10 \mathrm{ppb}$. Comparing Figures 5-1a and 5-2b with Figures 5-5a and 5b the increases are relatively unaffected by the addition of the light- and medium-duty vehicle emissions from RFG.

\subsubsection{Comparison of the CNG and M85 Alternative Fuel Scenarios}

The maximum predicted 1-hr ozone on 27 August for the CNG fuel scenario is shown in Figure 5-6a, which is not very different from Figure 5-1a. The differences are highlighted in the difference plot shown in Figure 5-6b. The spatial pattern of increases and decreases in maximum daily ozone noted with RFG fuel use (Figure 5-3b) is again present but the maximum differences are only about half those resulting from RFG fuel use. The same result holds true for 28 August (Figures 5-7a and 5-7b). The impact of changes in the SAPRC mechanism was also checked, and the same increases were noted (Figures 5-8a and 5-8b).

The daily maximum 1-hr ozone predicted to result from M85 fuel use is shown in Figure 5-9a for 27 August. This figure indicates that the increases and decreases in the maximum daily ozone resemble those for RFG (Figure 5-3a), with big reductions in the eastern portion of the Los Angeles basin and significant increases in the mountainous areas to the east of the basin. The difference plot in Figure 5-9b illustrates that the decreases in the basin are 50\% larger than those for RFG (-18 ppb versus $-12 \mathrm{ppb}$ ). Increases occur in the mountainous regions of San Bernardino County, where the peak increase in the maximum daily ozone is $20 \mathrm{ppb}$ compared with $18 \mathrm{ppb}$ produced by RFG.

On 28 August (Figure 5-10) the maximum daily ozone concentrations are significantly increased in the areas of elevated terrain in San Bernardino County, while the concentrations within the basin proper are decreased significantly, compared to $S 1$. This is confirmed by Figure $5-10 \mathrm{~b}$, which shows that the magnitude of the maximum daily ozone increases and decreases are roughly equivalent and are of the magnitude of 21-22 ppb. The distinct in-basin - east-of-basin pattern of decreases and increases noted earlier is again apparent. While the increases of the maximum daily ozone are of the same magnitude 
as for the RFG scenario, the decreases in the eastern portion of the basin are a factor of two larger for the M85 scenario (-21 $\mathrm{ppb}$ versus $-10.5 \mathrm{ppb})$.

For all scenarios, the localized peak in the maximum daily 1-hr concentrations for 28 August which occurs within the Los Angeles basin around the Orange County line is unaffected by changes in mobile source emissions. Figure 5-10b illustrates this by showing that changes in the maximum daily ozone between M85 and S1 were less than $1 \mathrm{ppb}$ at the location of the predicted maximum concentration (indicated by the $\mathrm{H}$ ).

The differences in the predicted daily maximum ozone concentrations for the M85 fuel scenario caused by the SAPRC90/93 upgraded chemistry can be noted for each episode day in Figures 5-11a and 5-11b. As with the previous scenarios, the upgraded chemistry produced increases in maximum ozone throughout the domain, with 5-10 ppb increases noted in large areas extending from the eastern edge of the Los Angeles basin into the mountainous areas of San Bernardino County. The M85 fuel scenario produces the smallest increases because of the use of SAPRC90/93, with a domain-wide peak increase of only $9.3 \mathrm{ppb}$ for M85 use compared with $10.2 \mathrm{ppb}$ for RFG fuel use on 28 August.

\subsection{Comparisons of 8-hr Average Ozone Concentrations}

Peak 8-hr average ozone concentrations were calculated for the 27-28 August period as running averages from 1-hr ozone concentrations. The daily maximum concentrations for the RFG-fueled vehicle scenario are presented for 27 August in Figure 5-12a. The local maximum in the Los Angeles basin has disappeared, a result indicating that the 1-hr peak represents a sharp spike in both time and space. The peak concentrations occur in San Bernardino County over the highest terrain. The foothill sites such as Glendora, Upland, Norco, Asuza and Pasadena have maximum 8-hr average concentrations at or slightly in excess of the $80 \mathrm{ppb} 8$-hr standard.

For 28 August Figure 5-12b shows the same pattern of lower maximum ozone concentrations within the Los Angeles basin and higher concentrations over the elevated terrain in San Bernardino. The most pronounced difference in Figure 5-12b when compared with Figure 5-4a is the absence of the peak near the Orange County line. Many of the foothill monitoring sites have predicted maximum concentrations less than $80 \mathrm{ppb}$.

The maximum predicted 8-hr average concentration within the domain exceeds the 1-hr NAAQS for ozone, although no monitors are located within the region of concentrations greater than $120 \mathrm{ppb}$. This is in contrast to the UAM-IV modeling, which predicted a maximum 8-hr average concentration for RFG of $105 \mathrm{ppb}$. The domain-wide predicted maximum 8-hr average ozone concentrations are presented in Table 5-3 for both the CALGRID and UAM-IV modeling for each of the fuel use scenarios.

Table 5-3. A Summary of the Domain-Wide Peak Predicted Daily Maximum 8-hr Average Ozone Concentrations for the Various Modeling Scenarios.

\begin{tabular}{|l|c|c|c|c|}
\hline & \multicolumn{2}{|c|}{ 27 August } & \multicolumn{2}{c|}{ 28 August } \\
\hline Fuel Scenario & UAM-IV & S90/93 & UAM-IV & S90/93 \\
\hline RFG & 106 & 156 & 112 & 178 \\
\hline CNG & 105 & 148 & 106 & 169 \\
\hline M85 & 105 & 158 & 114 & 180 \\
\hline
\end{tabular}

The CALGRID predicted maximum ozone concentrations, like those produced by UAM-IV, indicate that the CNG scenario produces lower peak ozone in the eastern portions of the domain, while the M85 
fuel scenario predicts concentrations of the same order as the RFG scenario. The only difference is that the CALGRID SAPRC90/93 predictions show larger maximum ozone response between scenarios and more consistency from day to day than the UAM-IV results.

The upgraded SAPRC90/93 chemistry produces increases in the predicted daily maximum 8-hr average ozone concentrations throughout the modeling domain for both episode days, as shown by Figures 5$13 \mathrm{a}$ and 5-13b for the RFG scenario. The peak increases occur in the Redlands and the San Bernardino Forest areas and are in the range $7-8 \mathrm{ppb}$.

The differences between the predicted 8-hr maximum concentrations for RFG and CNG are shown in Figures 5-14a and 5-5b for 27 August and 28 August, respectively. The same spatial pattern of basin decreases and downwind increases noted with 1-hr concentrations is again present. On both days the maximum increases are about twice the magnitude of the decreases in the basin. Difference plots for the maximum daily 8-hr ozone were made to compare RFG and M85 predictions. Figures 5-15a and $5-15$ b show that the impacts of M85 form a pattern which is reversed from that for CNG, with the M85 scenario producing slightly higher maximum 8-hr average concentrations than RFG over the eastern portion of the Los Angeles basin and the eastern foothills. This spatial pattern of concentration differences is seen for both days. The increases in the daily maximum ozone concentrations in the foothills are of the order $5 \mathrm{ppb}$ on 27 August and rise to $8 \mathrm{ppb}$ on 28 August. Slight decreases are found at the extreme eastern edge of the modeling domain.

\subsection{Comparisons of Exposure to Ozone Concentrations}

The increases in predicted ozone noted in San Bernardino County are generally larger than the decreases noted within the Los Angeles basin. However, the majority of the population lives in the basin where decreasing motor vehicle emissions can produce increases in peak ozone. The product of population times concentration results in larger exposure impacts in areas with ozone increases. Concentrations in excess of the standards are of concern, and most such concentrations (with the exception of the in-basin transient peak) are predicted to occur outside of the basin. In order to provide a consistent means of comparing the exposures produced by the various fuel scenarios, a relative percentile metric was developed. A running sum was made for each day of the product of people multiplied by the concentration, for all hours and cells where the NAAQS of $120 \mathrm{ppb}$ for 1-hr ozone or $80 \mathrm{ppb}$ for 8-hr ozone was exceeded. The sum, denoted as E, was estimated for each scenario and day modeled. The maximum grid cell values of $\mathrm{E}, \mathrm{E}(\max )$, were used to normalize the exposures for the purposes of comparison in the following manner;

$E^{\prime}=200\left(E_{r f g}-E_{a}\right) /\left[E_{r f g}(\max )+E_{a}(\max )\right]$.

The resulting measure is a percentile, which provides an indication of the extent to which the predicted exposure changed between two scenarios. This metric serves to highlight the differences for cells which contribute significantly to the domain-wide exposure estimates.

Figure 5-16a shows the differences between the 1-hr ozone exposure for RFG and CNG for 27 August. The pattern of differences indicates that CNG fuel use relative to RFG increases the ozone exposure by up to $6 \%$ in the Upland-Glendora area. Conversely, the Crestline-Redlands area experiences a large decrease in ozone exposure. The use of CNG results in a $23 \%$ decrease in ozone exposure. During 28 August, Figure 5-16b shows no area with increased exposure from CNG, while a large decrease ( $>16 \%$ ) remains in the Crestline-Redlands corridor.

An increase in the 8-hr ozone exposure $(>10 \%)$ is indicated for 27 August in Figure 5-16c. In this figure there is relatively little predicted ozone decrease except in isolated areas like Palm Springs and 
Reseda. The foothills generally show areas of ozone exposure increase. The pattern of increase for CNG persists on 28 August where in Figure 5-15d a region of nearly (10\%) increase occurs between Crestline and Redlands.

The pattern of 1-hr ozone exposure differences between the RFG and M85 fuel scenarios is presented in Figure 5-17a for 27 August. There is essentially no area of ozone increase for M85 fuel use. Maximum percentage decreases in ozone exposure occur in the Crestline-Redlands corridor. This region of ozone exposure decrease for M85 becomes even larger in magnitude on 28 August where in Figure 5-17b the reduction exceeds $17 \%$. In Figure 5-17c, the 8-hr ozone exposures also show M85 ozone exposure decreasing in the basin foothills during 27 August. On 28 August the 8-hr ozone exposures shown in Figure 5-17d show a benefit of over $20 \%$ in the Crestline-Redlands corridor.

\subsection{Ozone Sensitivities to Emissions}

The sensitivity of peak ozone concentrations to changes in emissions of ozone precursors was examined. The sensitivities were estimated by comparing the fifth highest predicted ozone concentrations. The fifth highest values rather than the highest were chosen to eliminate the effects of the localized ozone maximum on 28 August. The sensitivity coefficient is determined as the ozone response to incremental daily precursor emissions. The calculated ozone sensitivities are presented in Table 5-4. The results show that M85 has the smallest ozone sensitivity, while CNG has the largest. The difference in the sensitivity coefficients appears to be dominated by the amount of $\mathrm{NO}_{\mathrm{x}}$ produced by each scenario, with the CNG emission increment being primarily $\mathrm{NO}_{\mathrm{x}}$. In the case of the RFG and M85 scenarios, where the $\mathrm{VOC} / \mathrm{NO}_{\mathrm{X}}$ ratio of the mobile source emissions increment is closer to $1: 1$, the sensitivity coefficients are nearly the same.

Table 5-4. A Summary of CALGRID SAPRC90/93 Predicted Ozone Sensitivity Coefficients (ppb-O3/Ton Emissions) for the Various Fuel Scenarios.

\begin{tabular}{|l|c|c|}
\hline Scenario - measure & 27 August & 28 August \\
\hline RFG - S1 - cell unmatched (fifth highest) & 0.038 & 0.052 \\
\hline CNG - S1 - cell unmatched (fifth highest) & 0.068 & 0.082 \\
\hline M85 - S1 - cell unmatched (fifth highest) & 0.038 & 0.050 \\
\hline RFG - S1 - max cell increase & 0.051 & 0.063 \\
\hline CNG - S1 - max cell increase & 0.095 & 0.103 \\
\hline M85 - S1 - max cell increase & 0.056 & 0.062 \\
\hline RFG - S1 - max cell decrease & -0.035 & -0.028 \\
\hline CNG - S1 - max cell decrease & -0.092 & -0.062 \\
\hline M85 - S1 - max cell decrease & -0.051 & -0.059 \\
\hline
\end{tabular}

One of the problems with the "cell unmatched" sensitivity metric is that the peak location can change between scenarios. A second way to examine the ozone sensitivity is to compute the sensitivity of the predicted ozone increments matched by cell. This provides an opportunity to factor in both ozone decreases and increases. The CNG emissions have the largest ozone sensitivities in both decreased and increased ozone exposure areas. The sensitivities for ozone increases (matched by location) are similar for RFG and M85, but the sensitivity for decreased ozone exposure is roughly twice as large for M85 ( -0.05 to $-0.06 \mathrm{ppb}-\mathrm{O}_{3}$ /ton emissions) as for RFG ( -0.028 to $-0.035 \mathrm{ppb}-\mathrm{O}_{3} /$ ton). 


\subsection{Comparisons for Toxic Compounds}

Four VOC species were selected to evaluate concentrations and exposures for toxic compounds: HCHO, CCHO, BENZ and BUDI. The domain-wide peak daily maximum 1-hr average concentrations for the three fuel scenarios are presented in Table 5-5.

Table 5-5. CALGRID SAPRC90/93 Predicted DomainWide Maximum 1-hr Predicted Concentrations (ppb) for the Four Toxic Species Analyzed.

\begin{tabular}{|l|r|r|r|}
\hline \multicolumn{4}{|c|}{ Alternative Fueled Vehicle Scenario } \\
\hline Date - species & \multicolumn{1}{|c|}{ RFG } & \multicolumn{1}{c|}{ CNG } & \multicolumn{1}{c|}{ M85 } \\
\hline 27 August & & & \\
\hline HCHO & 22.78 & 22.61 & 22.97 \\
\hline CCHO & 4.04 & 3.81 & 3.91 \\
\hline BENZ & 2.76 & 1.57 & 1.74 \\
\hline BUDI & 0.45 & 0.41 & 0.43 \\
\hline 28 August & & & \\
\hline HCHO & 17.99 & 17.89 & 18.04 \\
\hline CCHO & 3.94 & 3.76 & 3.79 \\
\hline BENZ & 2.57 & 1.58 & 1.67 \\
\hline BUDI & 0.36 & 0.35 & 0.36 \\
\hline
\end{tabular}

Table 5-5 indicates that HCHO is the most prevalent of the toxic compounds. The small variations between scenarios for all compounds except BENZ indicate that the peak concentrations are dominated by non-mobile sources. Table 5-5 indicates that CCHO, BENZ, and BUDI peak concentrations all have the largest concentrations for RFG and the smallest for CNG. For HCHO the peak concentrations occur for M85 fuel use, which is expected, given that the destruction of methanol by radicals produces $\mathrm{HCHO}$ as a breakdown product.

The spatial pattern of daily maximum 1-hr concentrations of each of the toxic species was examined for the RFG case. In Figure 5-18a the HCHO concentrations for 27 August are presented. The influence of the boundary conditions can be noted, where the boundary condition concentrations at the surface are the same as those used in Balentine et. al. (1997a). The majority of daily maximum concentrations in the modeling domain are in the $5-10 \mathrm{ppb}$ range. The peak concentration is the result of localized emission sources on the coast near LAX. Figure 5-18b shows that the same sources produce the maximum peak on 28 August as well. A localized region of $10-15 \mathrm{ppb}$ is predicted in the Los Angeles basin near the Orange County line, in the same area as the local ozone peak.

The daily maximum CCHO concentrations for 27 August are shown in Figure 5-19a. The CCHO concentrations exhibit a broad peak over the eastern edge of the basin extending into the areas of complex terrain. The concentrations of $\mathrm{CCHO}$ are relatively small with most regions having 1-3 ppb maximum concentrations. On 28 August the regions of the greatest daily maximum concentrations shrink in size and move farther to the east as shown in Figure 5-19b.

The BENZ concentrations for 27 August are shown in Figure 5-20a while those for 28 August are shown in Figure 5-20b. On both days the peak BENZ concentrations occur in downtown Los Angeles 
and in the industrialized area of Long Beach. A second localized peak occurs in the Riverside area. The concentrations vary little between the two days. The BUDI daily maximum concentrations are shown for 27 and 28 August in Figures 5-21a and 5-21b. The influence of boundary concentrations is obvious in both figures. The boundary inflows, however, do not extend very far into the domain, leaving the Los Angeles basin relatively unperturbed by the boundary inflow fluxes of BUDI. The domain-wide peak BUDI concentration occurs near LAX, with elevated concentrations in DOLA. The areas of peak concentrations of 20-30 ppb are spread over a much wider area on 27 August than on 28 August. The larger concentrations and broad peaks on 27 August are the result of initial conditions.

The daily maximum 1-hr HCHO concentration increment (RFG minus S1) is displayed for 27 August in Figure 5-22a. This figure indicates that RFG fuel use produces increased HCHO concentrations in two areas, the mid-portion of the Los Angeles basin and the region just east of Redlands in San Bernardino County. On 28 August (Figure 5-22b), the HCHO increase in DOLA is larger than on the previous day, rising by nearly $12 \mathrm{ppb}$ of $\mathrm{HCHO}$ at several points within the basin.

The CNG and RFG fueled vehicle scenario daily maximum 1-hr HCHO concentrations were compared. A plot of the differences in $\mathrm{HCHO}$ concentrations between the two fuel scenarios is presented in Figure 5-23a for 27 August. The increments indicate that RFG fuel use produces considerably larger HCHO concentrations than CNG. The areas with decreases from CNG use are located across the middle of Los Angeles basin and in the vicinity of Redlands in San Bernardino County. The maximum decreases amount to almost $9 \mathrm{ppb}$ of $\mathrm{HCHO}$. On 28 August the $\mathrm{HCHO}$ decreases with CNG use shown in Figure $5-23 b$ extend over a large portion of the modeling domain. The peak decreases in HCHO occur in the vicinity of DOLA.

The use of M85 compared to RFG results in increases in the predicted daily maximum HCHO concentrations. Figure 5-24a shows that the increases in HCHO concentrations from M85 use extend in a broad band across Los Angeles basin, with HCHO increases of over $8 \mathrm{ppb}$. On 28 August, the peak increase in daily maximum $\mathrm{HCHO}$ is nearly $17 \mathrm{ppb}, 70 \%$ of the peak HCHO predicted for the RFG scenario.

The daily maximum 8-hr average predicted HCHO concentrations for the CNG versus RFG fuel scenarios are presented in Figure 5-25a for 27 August. Slight decreases in 8-hr HCHO concentrations for CNG use can be noted in the same areas as the daily maximum 1-hr decreases. However, on 28 August, Figure 5-25b shows that the HCHO concentration decreases for CNG use are larger in magnitude and cover a much larger area, similar to the 1-hr results shown in Figure 5-23b. The peak decrease is of the order $10 \mathrm{ppb}$.

The use of M85 compared to RFG results in slightly increased daily maximum 8-hr average HCHO concentrations on 27 August (Figure 5-26a). The impacts of M85 use increase dramatically on 28 August, as shown in Figure 5-26b. The region of increased HCHO concentrations resulting from M85 fuel use peaks around DOLA, but extends over most of the Los Angeles basin. Several localized areas of small decreases occur just north of Glendora and Upland.

The same exposure metric as defined in Equation 5-1 was used to compare HCHO exposures for the CNG and M85 alternatively fueled vehicle scenarios with the RFG fuel scenario. No concentration threshold was used for $\mathrm{HCHO}$ in estimating population exposure. The percentile differences in the $\mathrm{HCHO}$ exposure are presented for 27 August in Figure 5-27a. This figure indicates that CNG use increases the exposure to HCHO in the central portion of the Los Angeles basin. The increases, however, are rather small, being approximately 2 - $3 \%$ of the maximum exposures predicted in the domain. Figure 5-27b shows the difference in exposure between RFG and CNG use for 28 August. There is a mixture of increases and decreases in the vicinity of DOLA. 
The changes in population exposure to HCHO between RFG and M85 fuel use in vehicles are shown for 27 August in Figure 5-28a. This figure indicates that exposure decreases of $1-2 \%$ occur in a few cells in the northern portion of the Los Angeles basin. On 28 August the plot of the exposure metric shown in Figure 5-28b depicts a mixture of increases and decreases in the HCHO exposure. The decreases in exposure in the vicinity of DOLA are slightly larger than the increases found elsewhere ( $2.7 \%$ versus $1.7 \%$ ). 


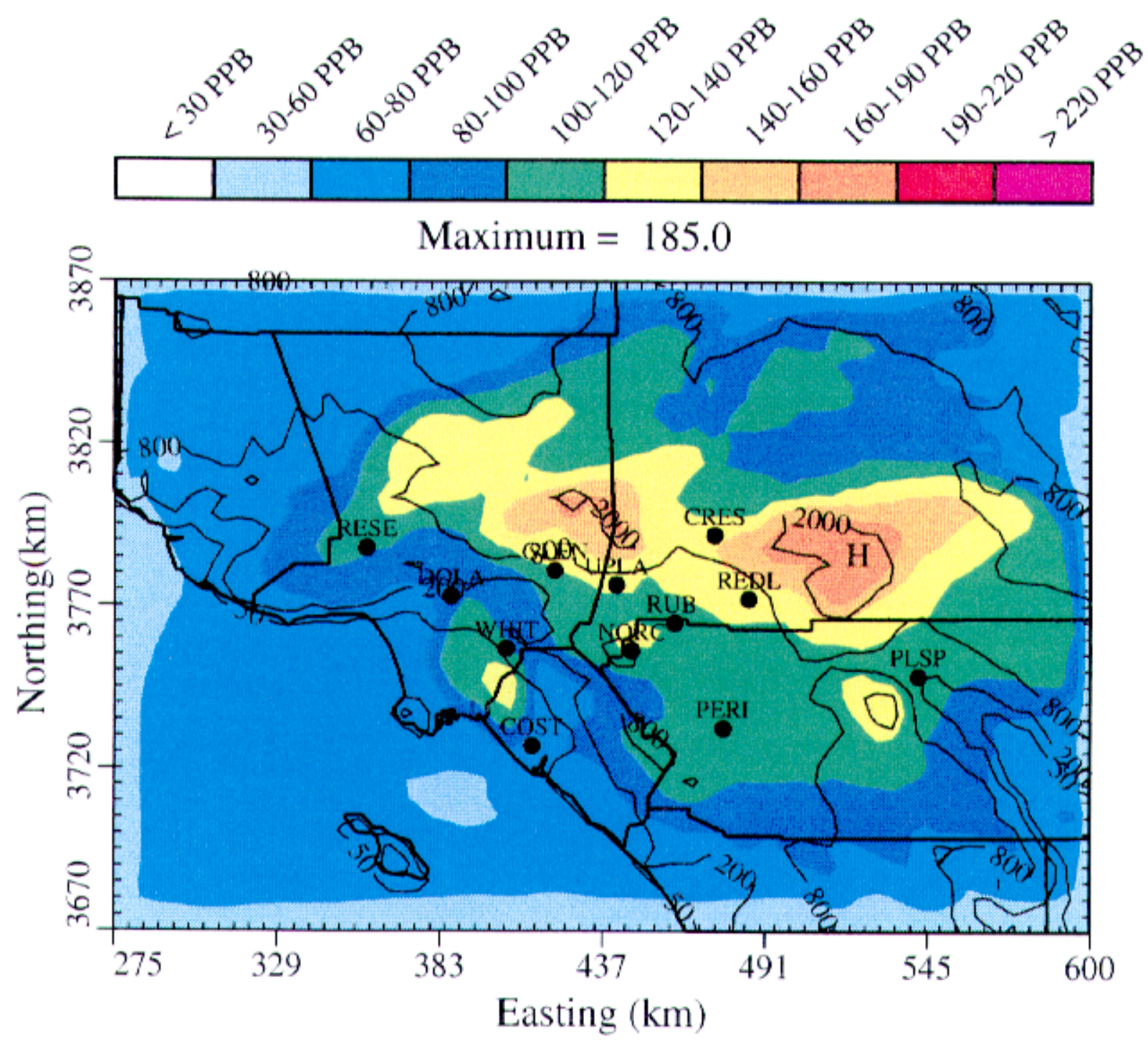

Figure 5-1a. Daily maximum hourly ozone predicted by CALGRID for 27 August 2007 - no onroad vehicle (S1) scenario with SAPRC 90/93. 


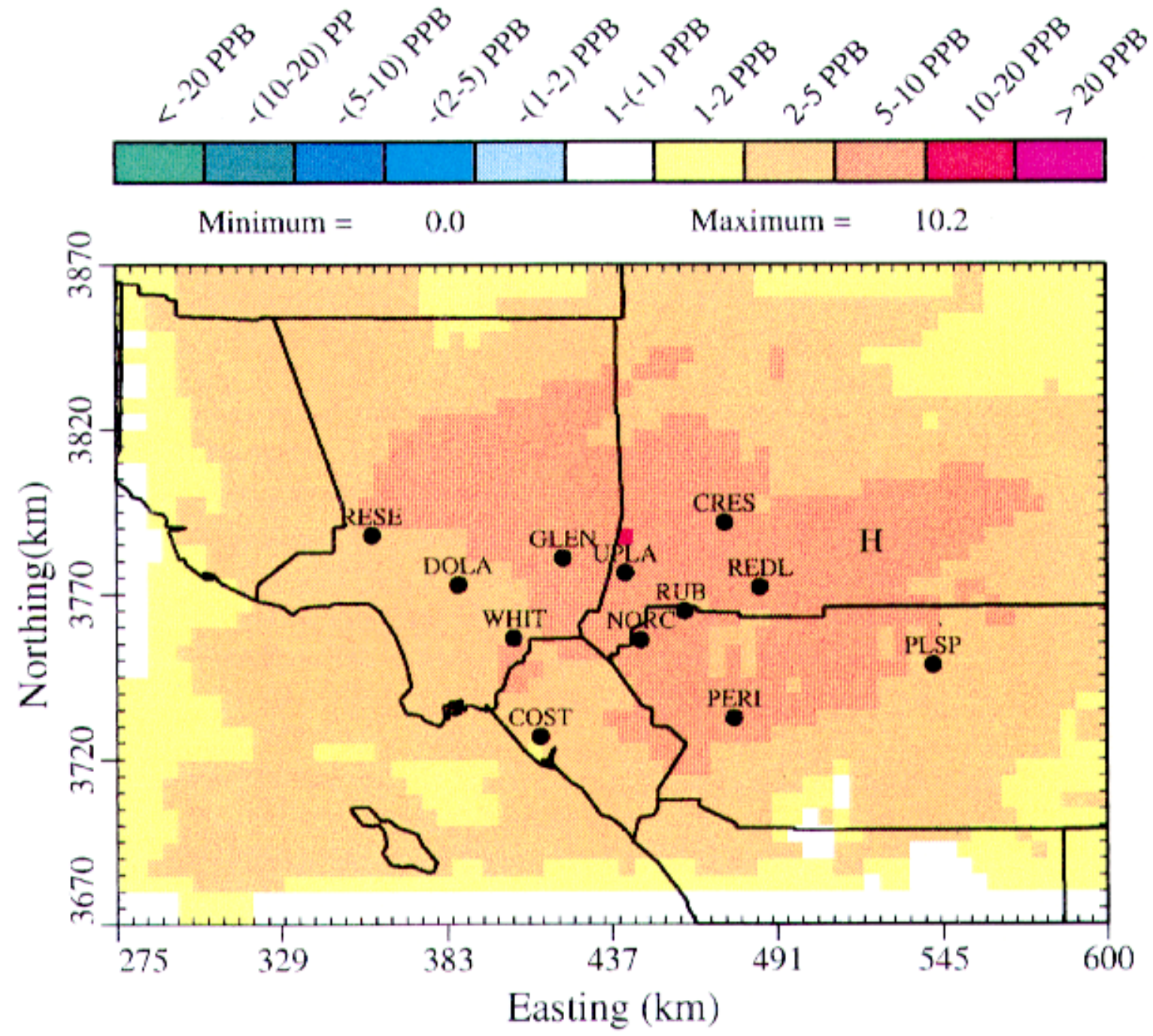

Figure 5-1b. Daily maximum 1-hr ozone during August 272007 - S1 w SAPRC90/93 minus S1 w SAPRC90. 


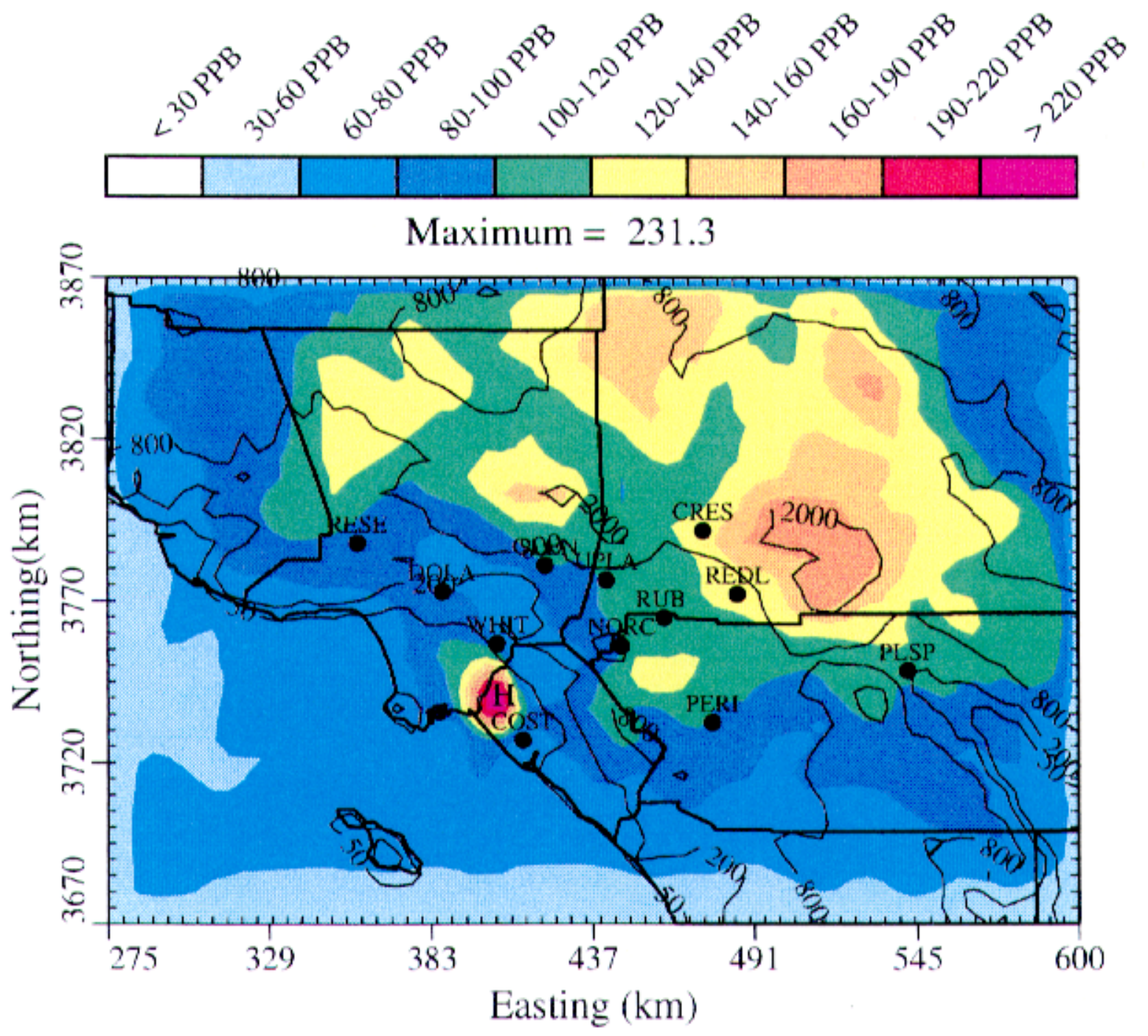

Figure 5-2a. Daily maximum hourly ozone predicted by CALGRID for 28 August 2007 - no onroad vehicle (S1) scenario with SAPRC 90/93. 


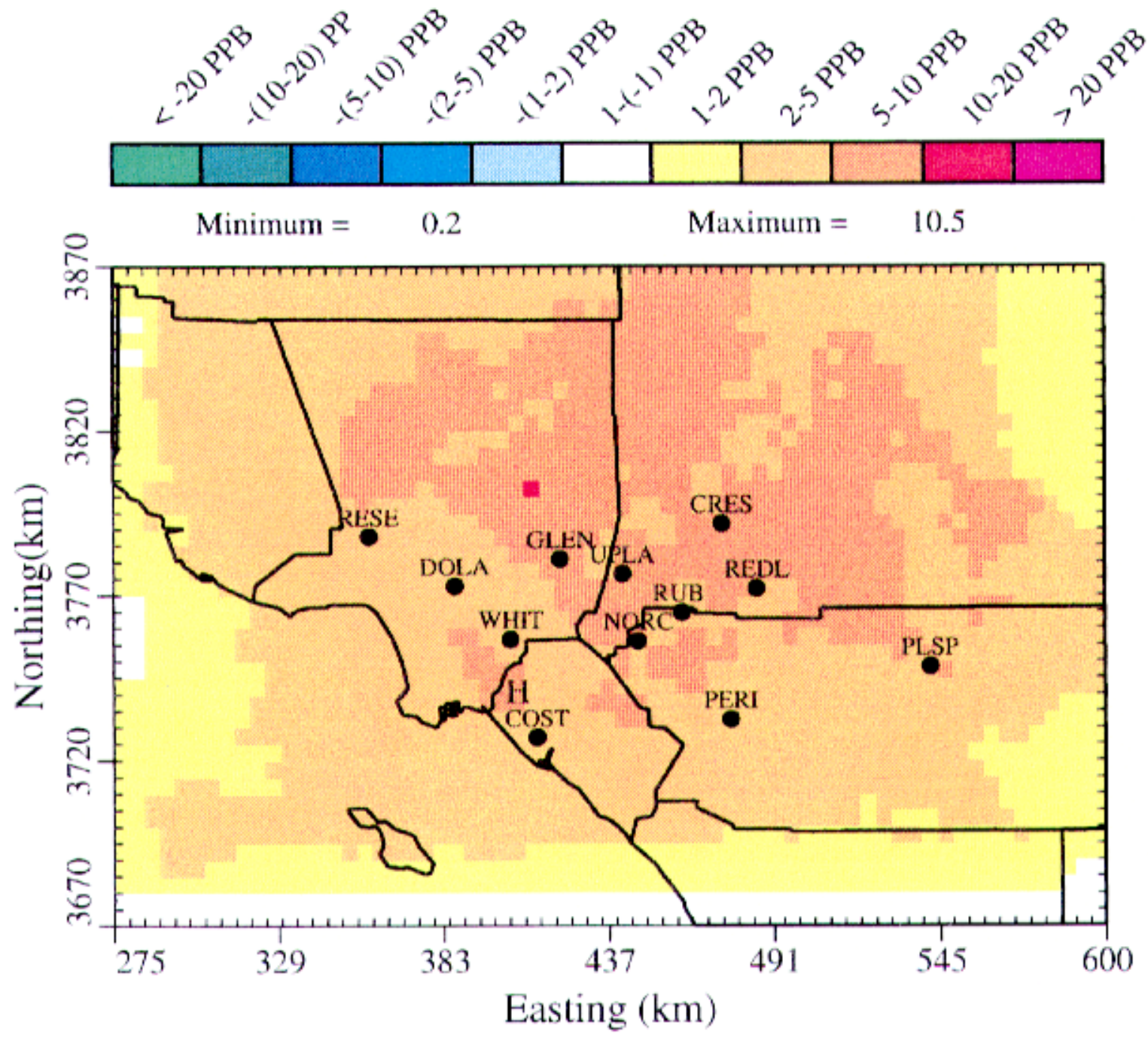

Figure 5-2b. Daily maximum 1-hr ozone during August 282007 - S1 w SAPRC90/93 minus S1 w SAPRC90. 


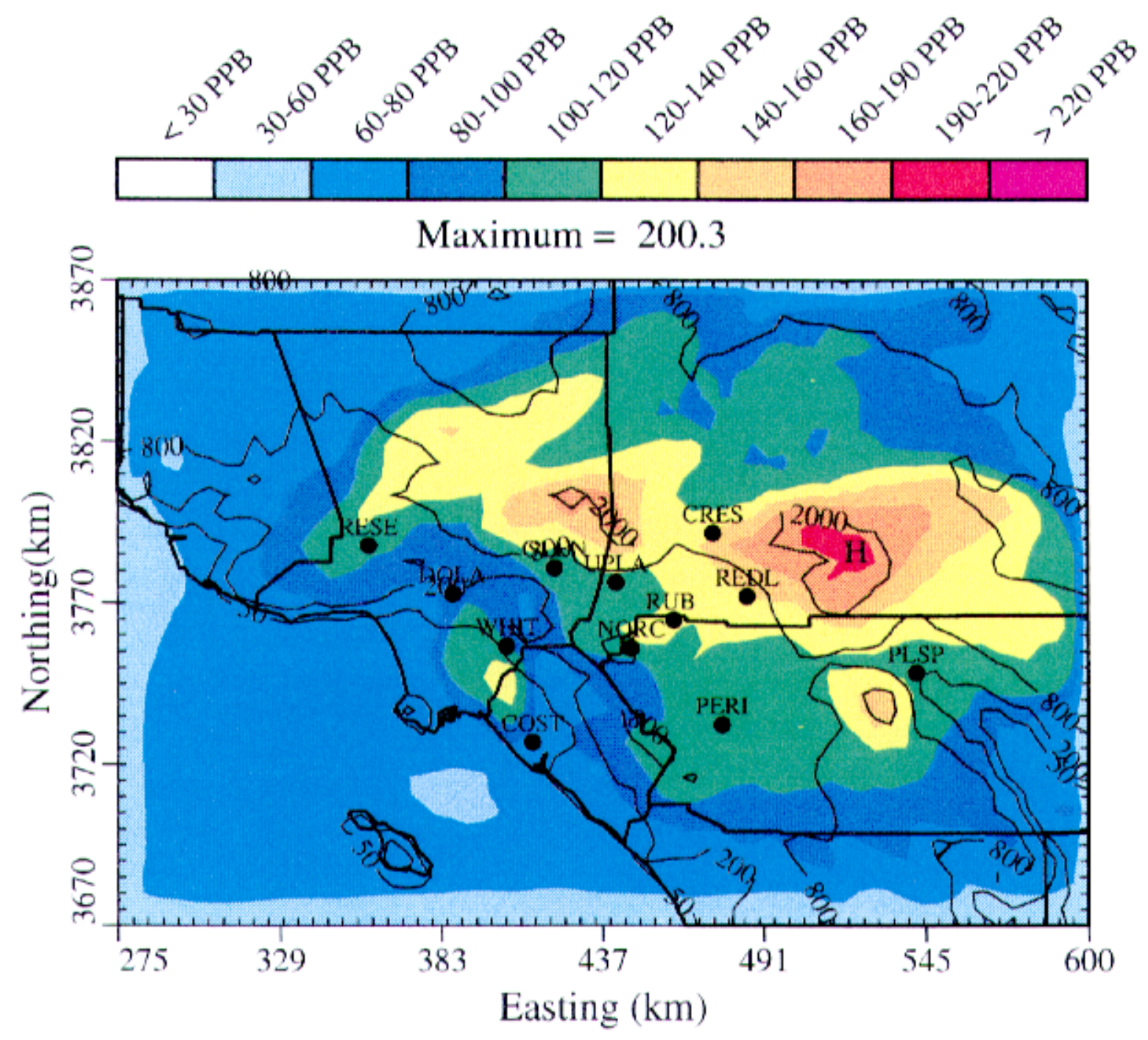

Figure 5-3a. Daily maximum hourly ozone predicted by CALGRID for 27 August 2007 - RFG fueled vehicle (RFG) scenario with SAPRC 90/93. 


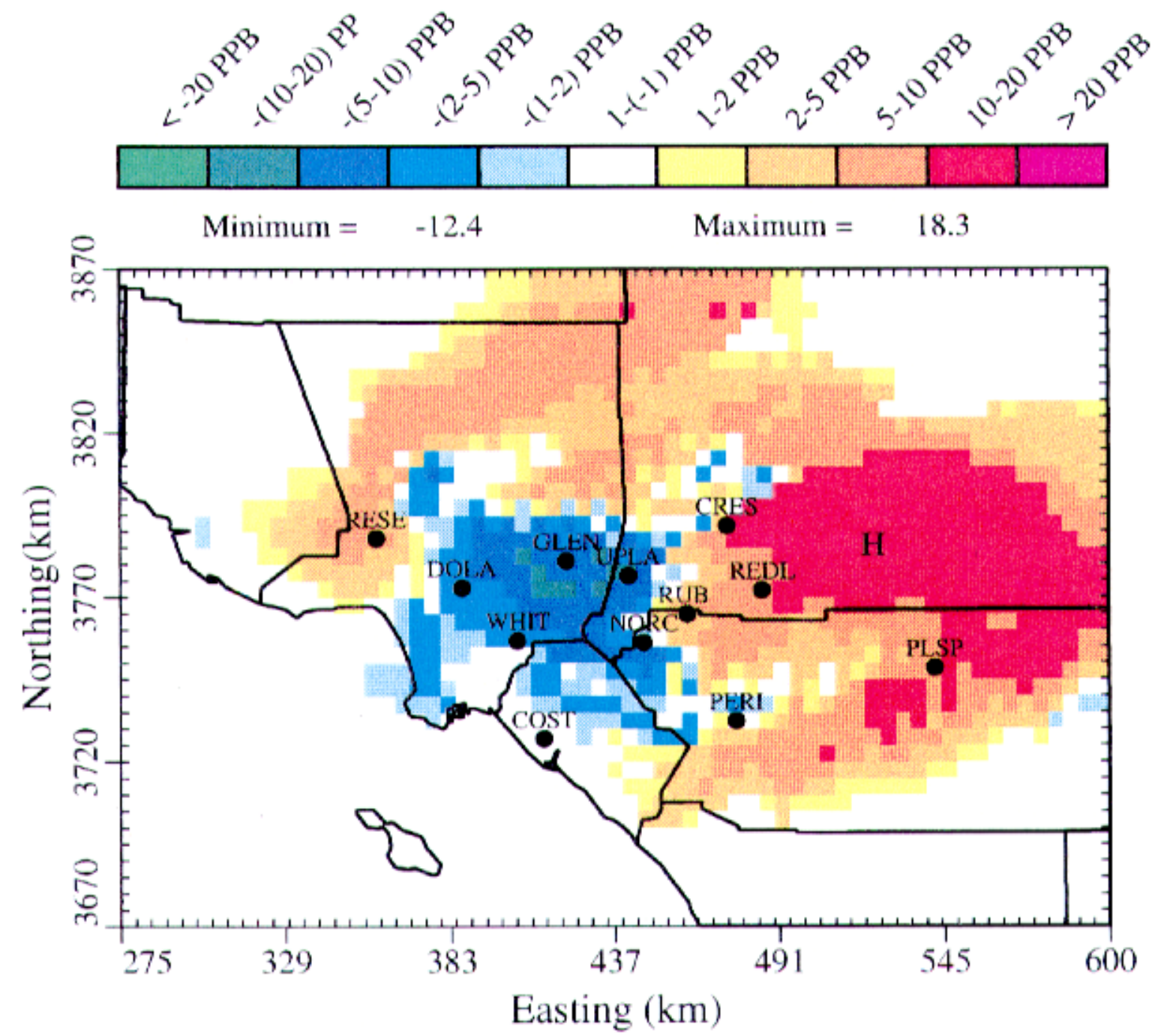

Figure 5-3b. Daily maximum 1-hr ozone during August 272007 - RFG w SAPRC90/93 minus S1 w SAPRC90/93. 


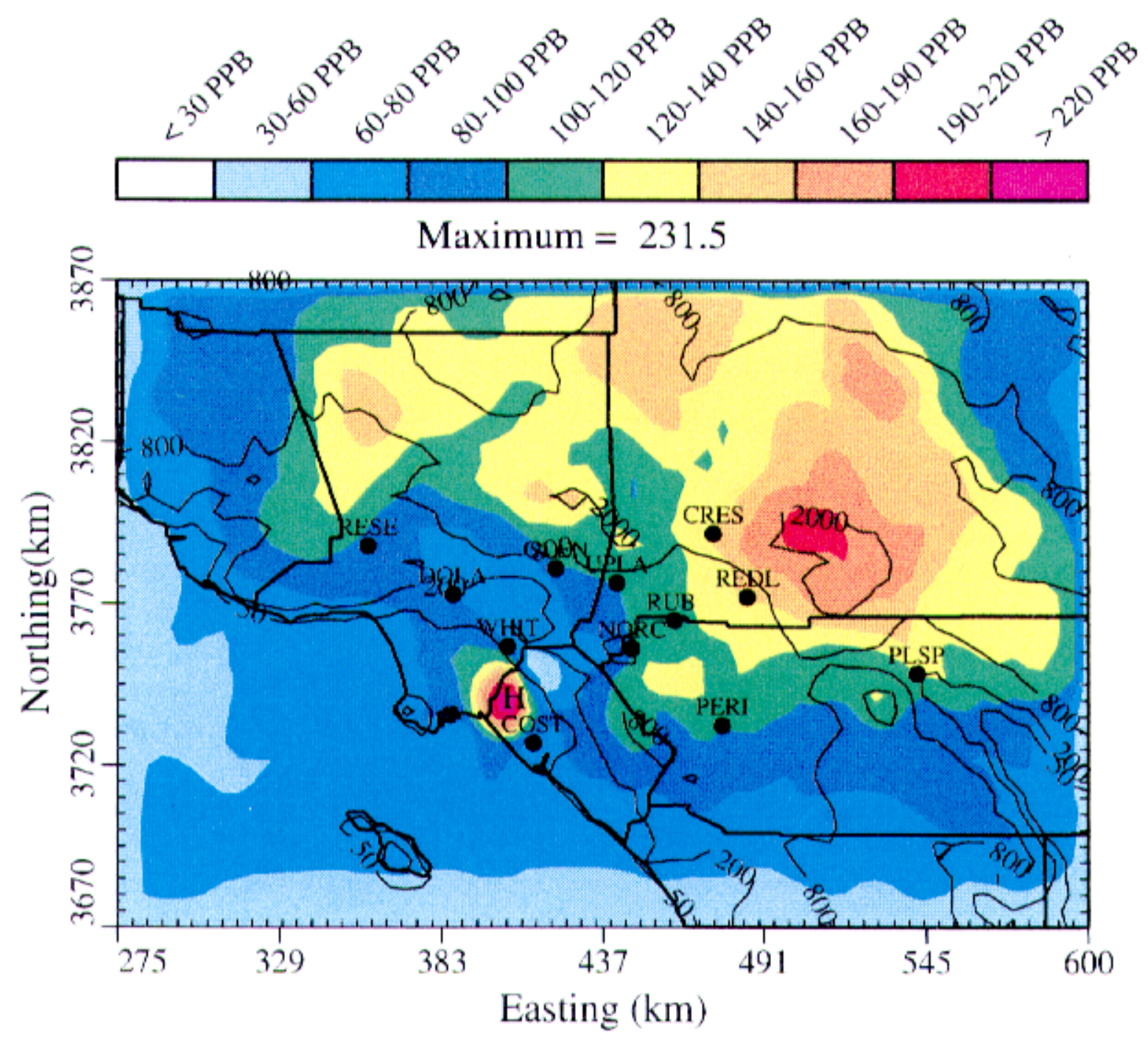

Figure 5-4a. Daily maximum hourly ozone predicted by CALGRID for 28 August 2007 - RFG fueled vehicle (RFG) scenario with SAPRC 90/93. 


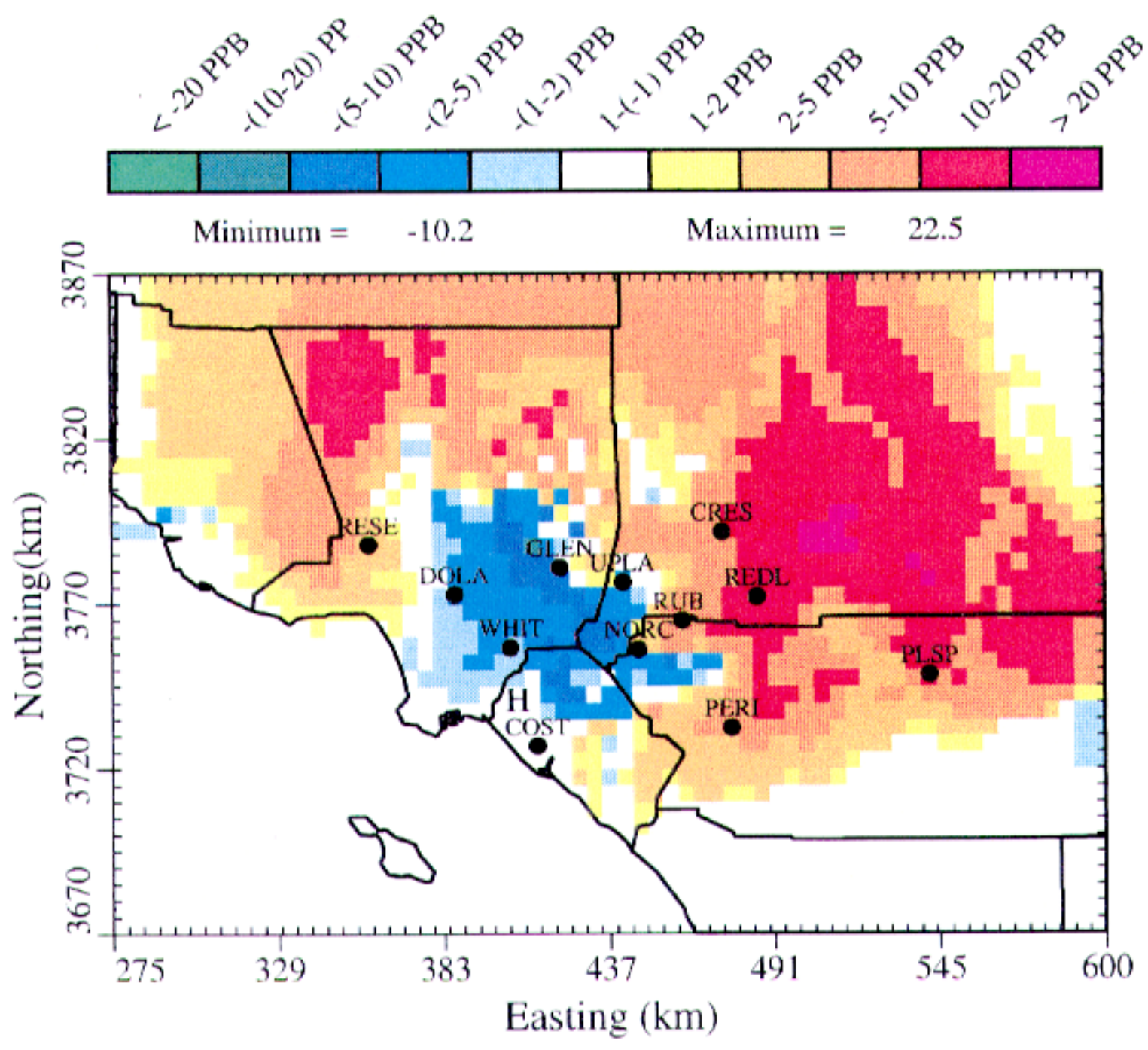

Figure 5-4b. Daily maximum 1-hr ozone during August 282007 - RFG w SAPRC90/93 minus S1 w SAPRC90/93. 


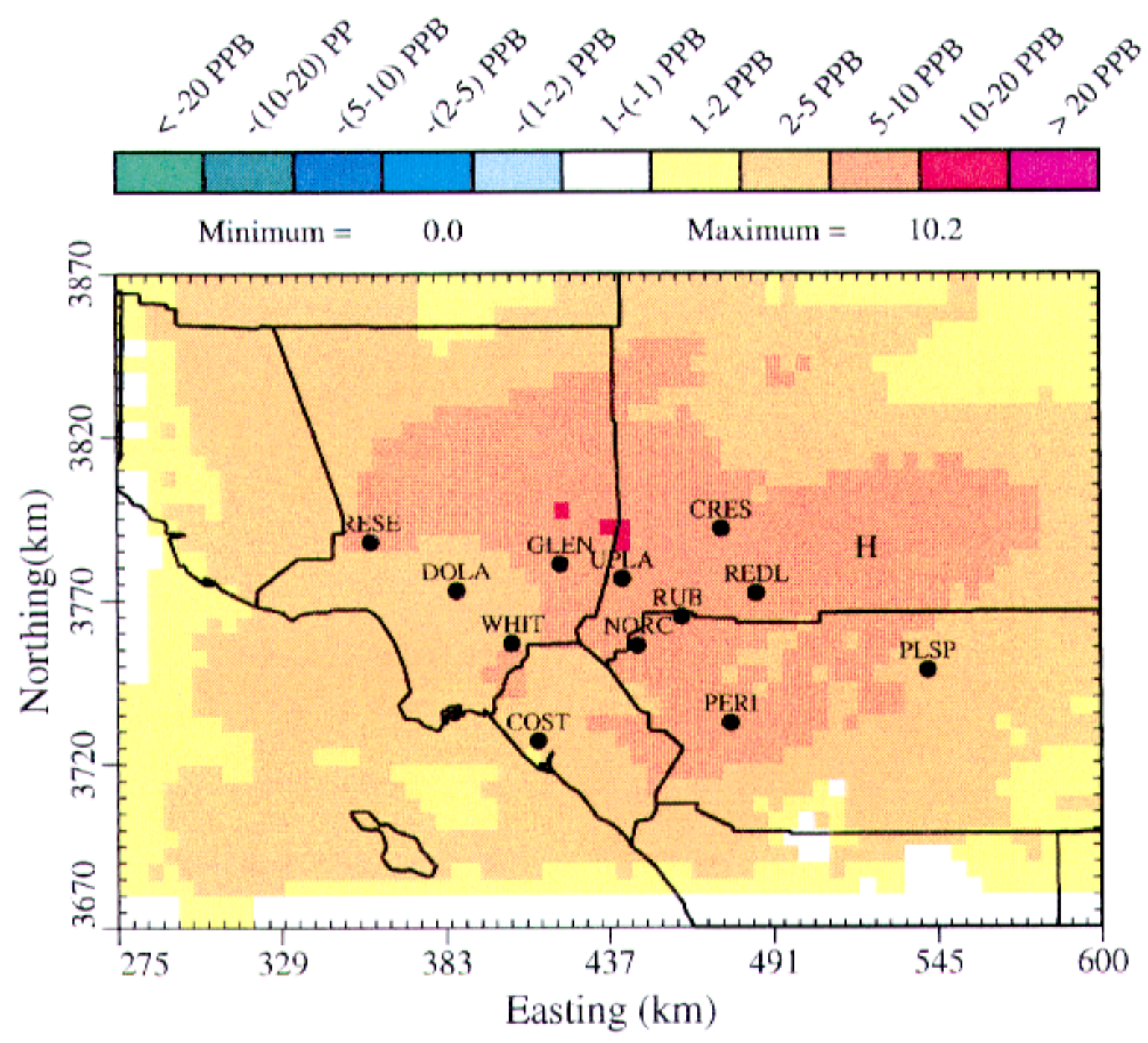

Figure 5-5a. Daily maximum 1-hr ozone during August 272007 - RFG w SAPRC90/93 minus RFG w SAPRC90. 


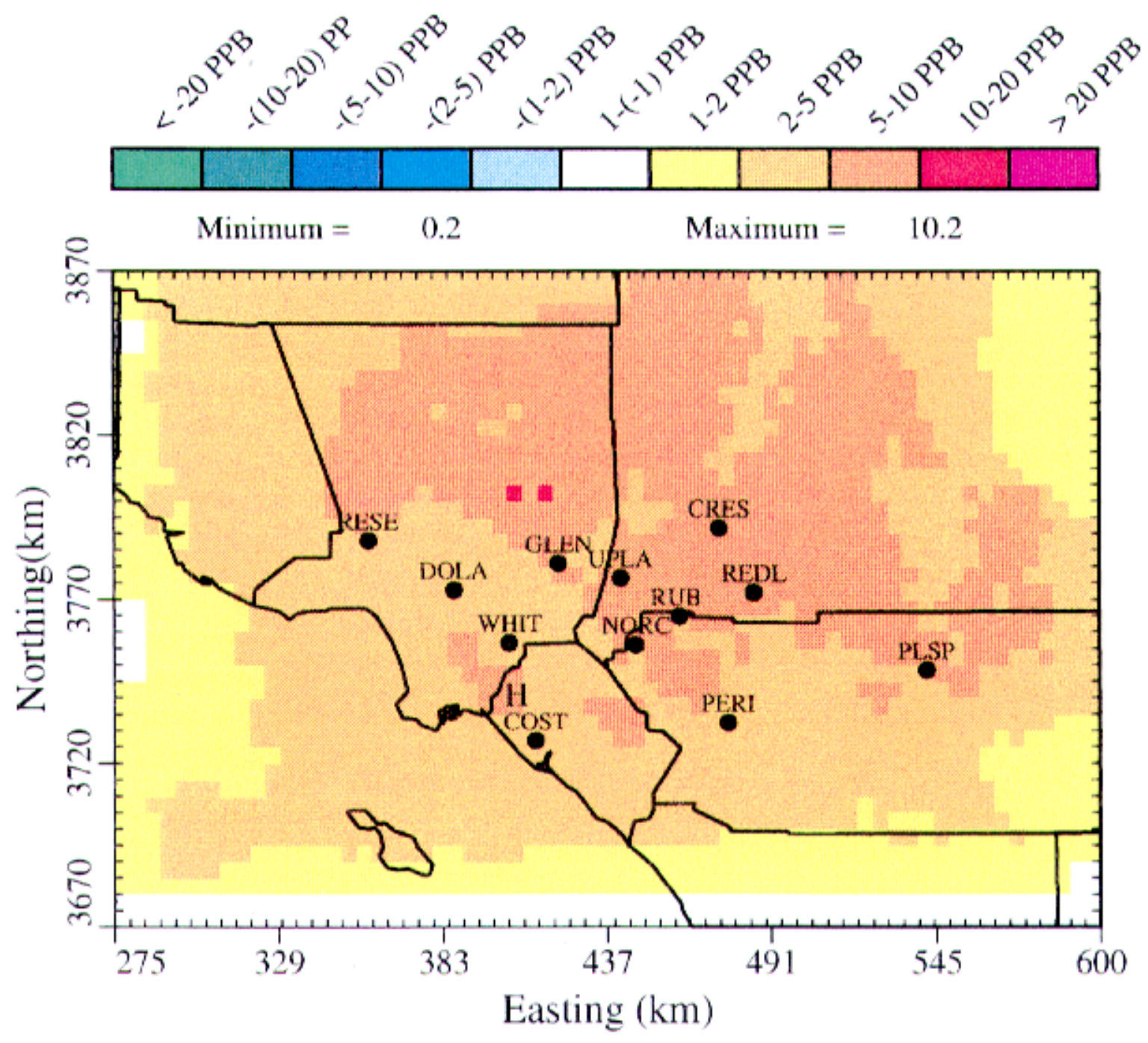

Figure 5-5b. Daily maximum 1-hr ozone during August 282007 - RFG w SAPRC90/93 minus RFG w SAPRC90. 


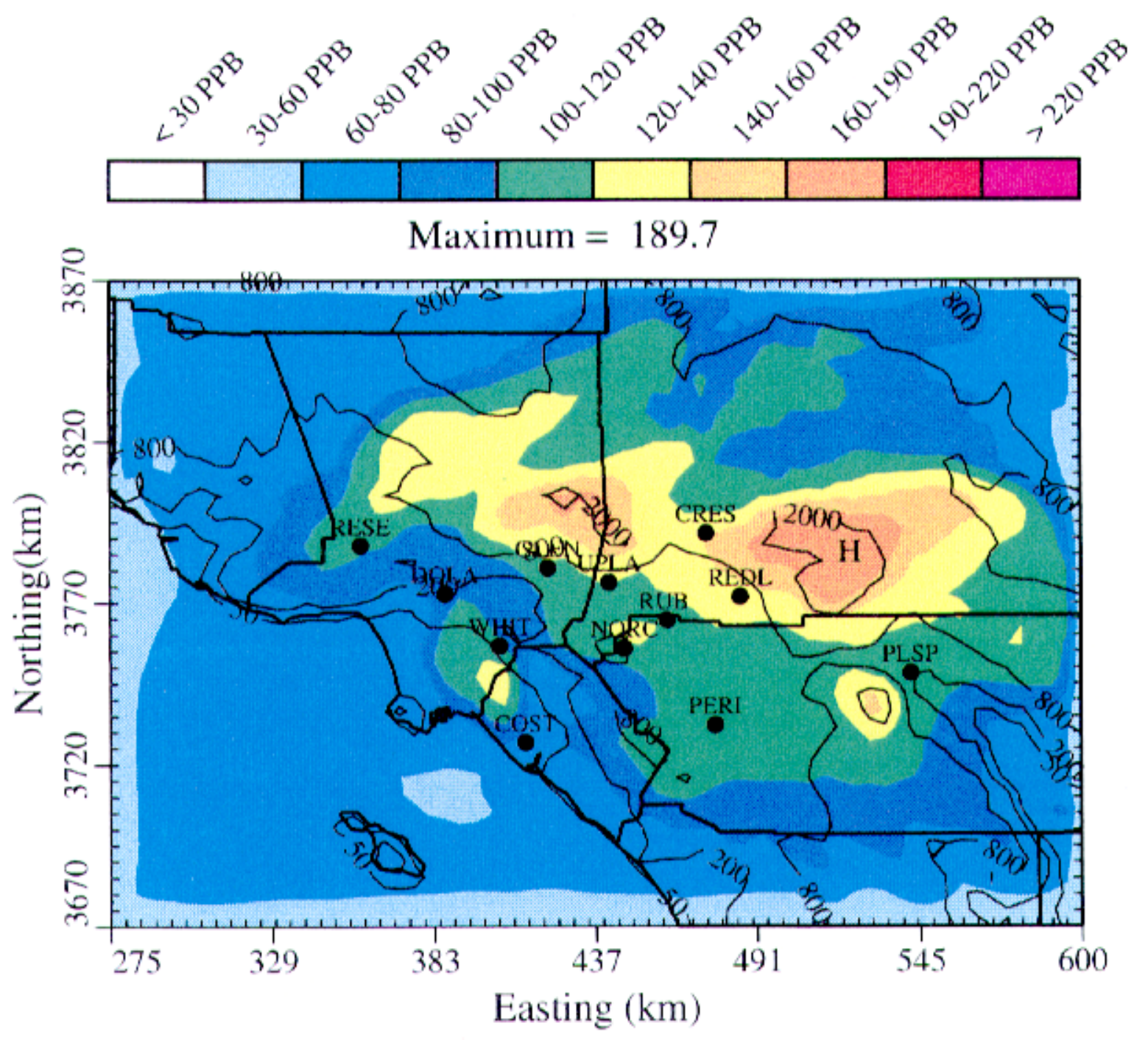

Figure 5-6a. Daily maximum hourly ozone predicted by CALGRID for 27 August 2007 - CNG fueled vehicle (RFG) scenario with SAPRC 90/93. 


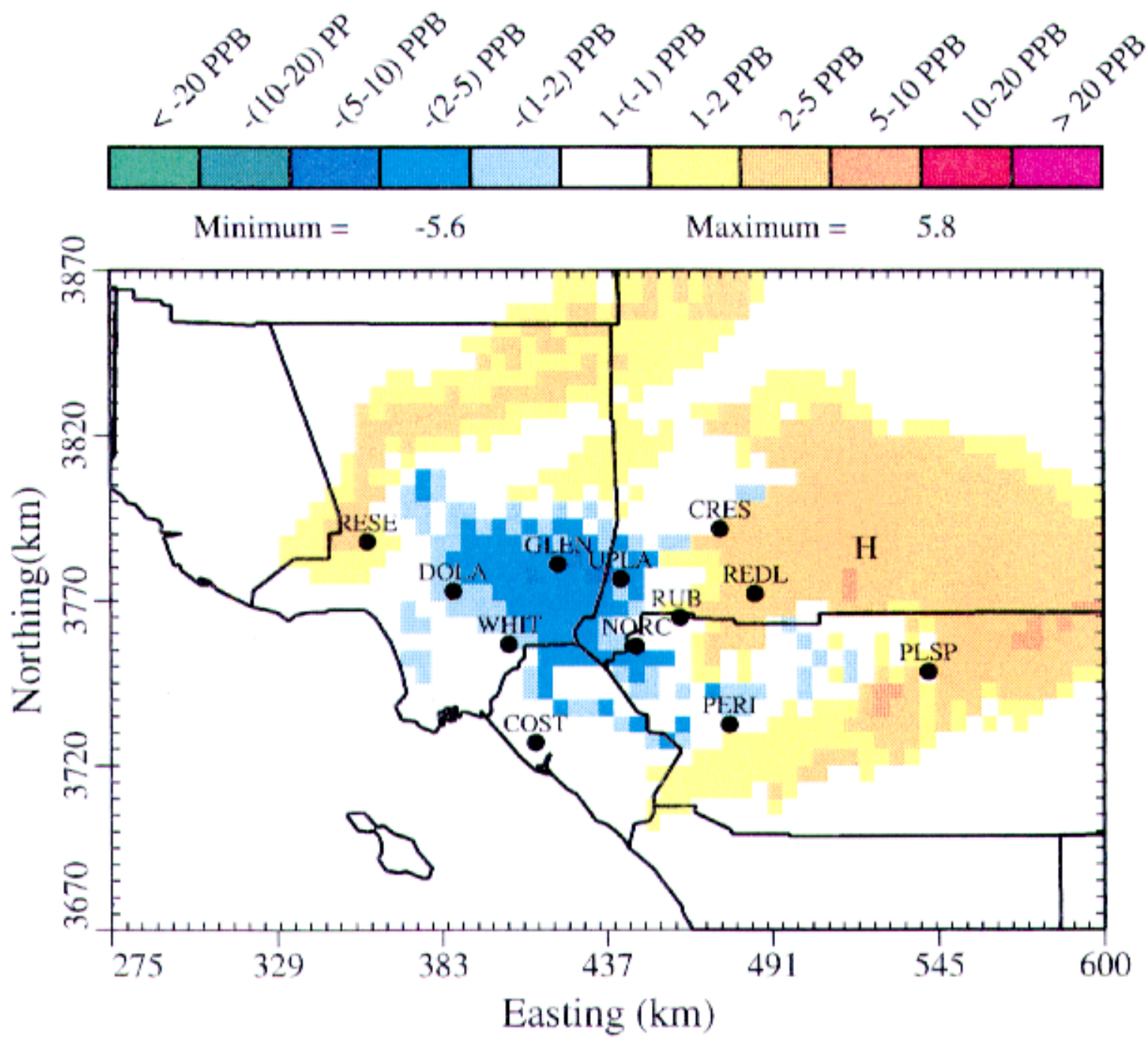

Figure 5-6b. Daily maximum 1-hr ozone during August 272007 - CNG w SAPRC90/93 minus S1 w SAPRC90/93. 


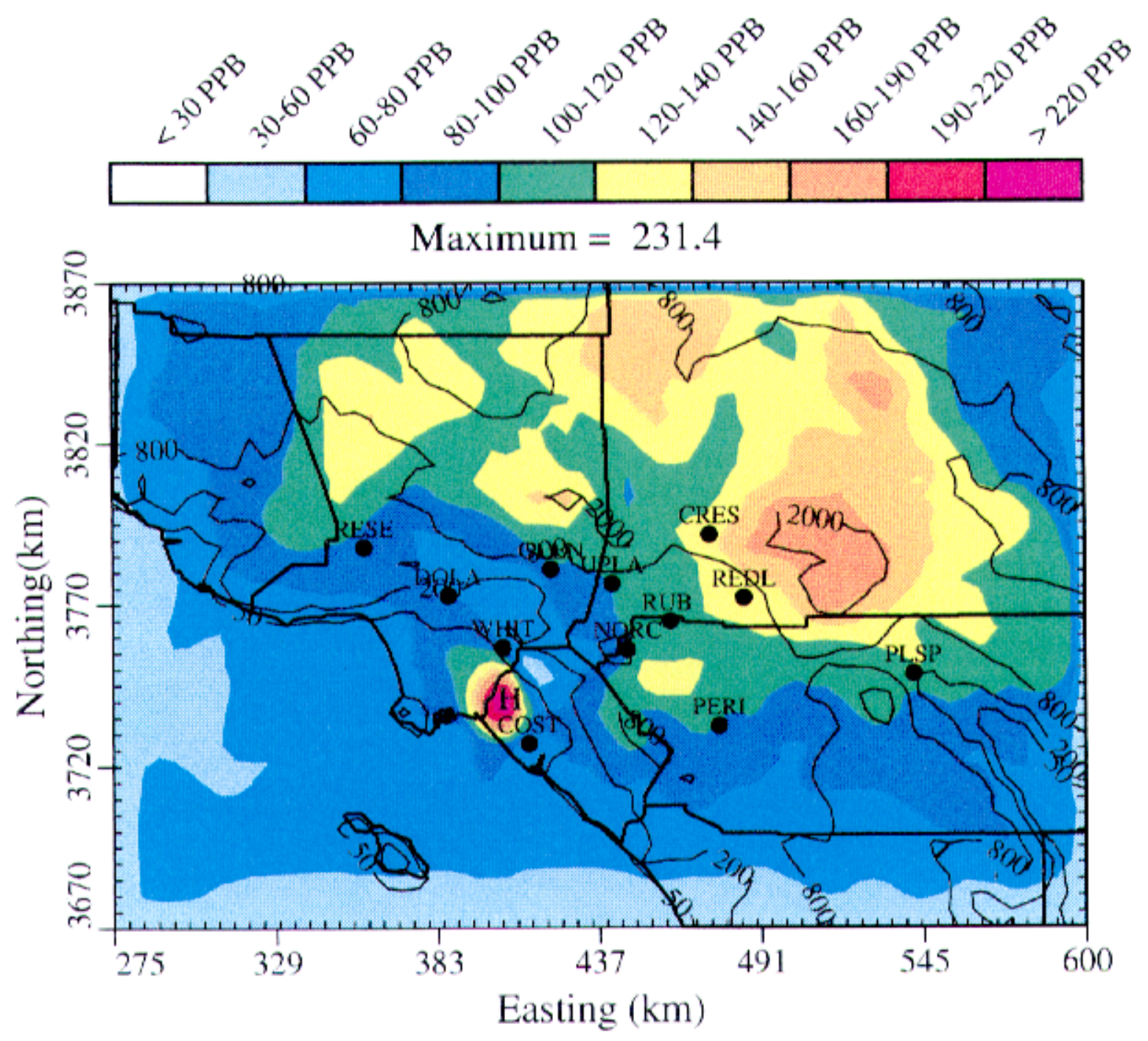

Figure $5-7$ a. Daily maximum hourly ozone predicted by CALGRID for 28 August 2007 - CNG fueled vehicle (RFG) scenario with SAPRC 90/93. 


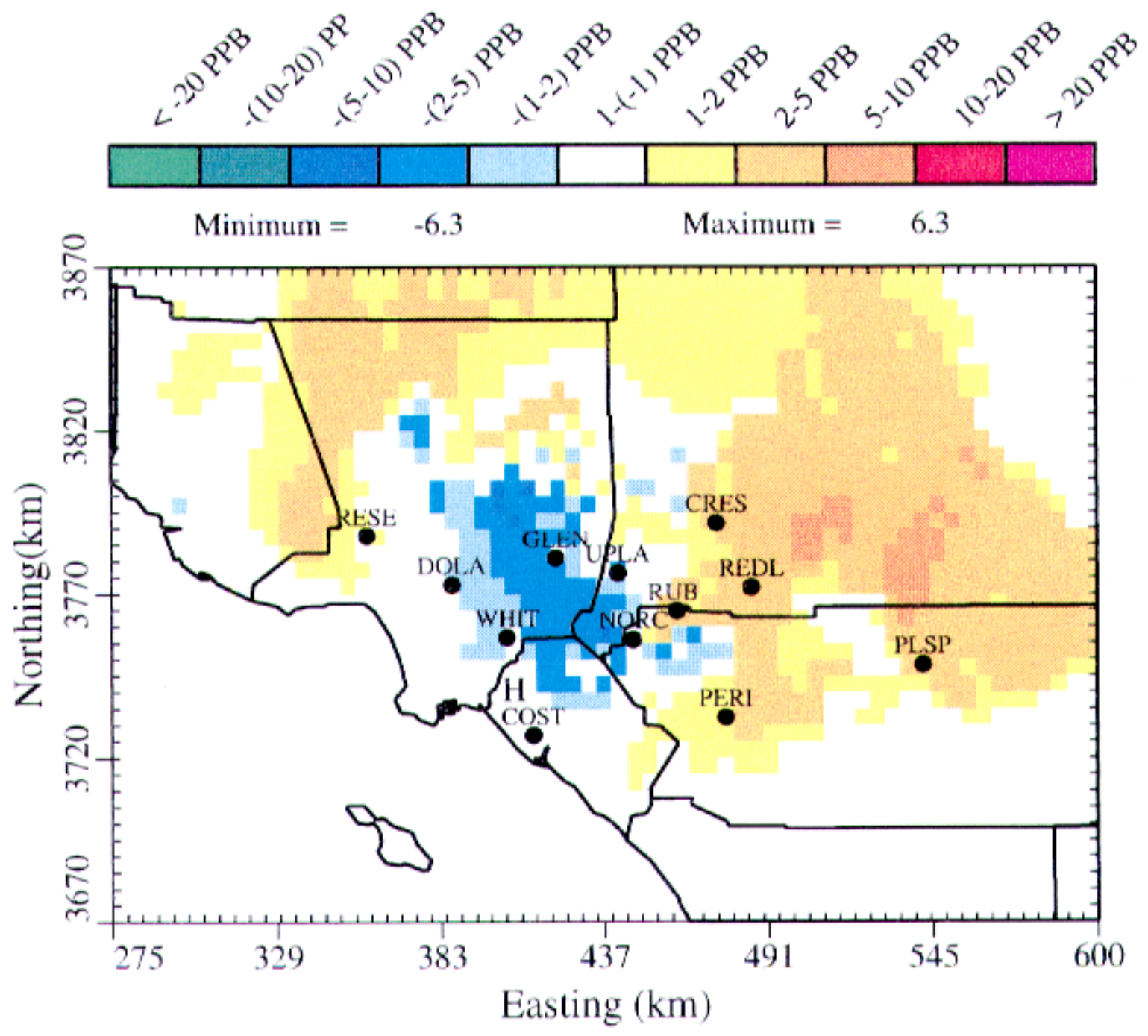

Figure 5-7b. Daily maximum 1-hr ozone during August 282007 - CNG w SAPRC90/93 minus S1 w SAPRC90/93. 


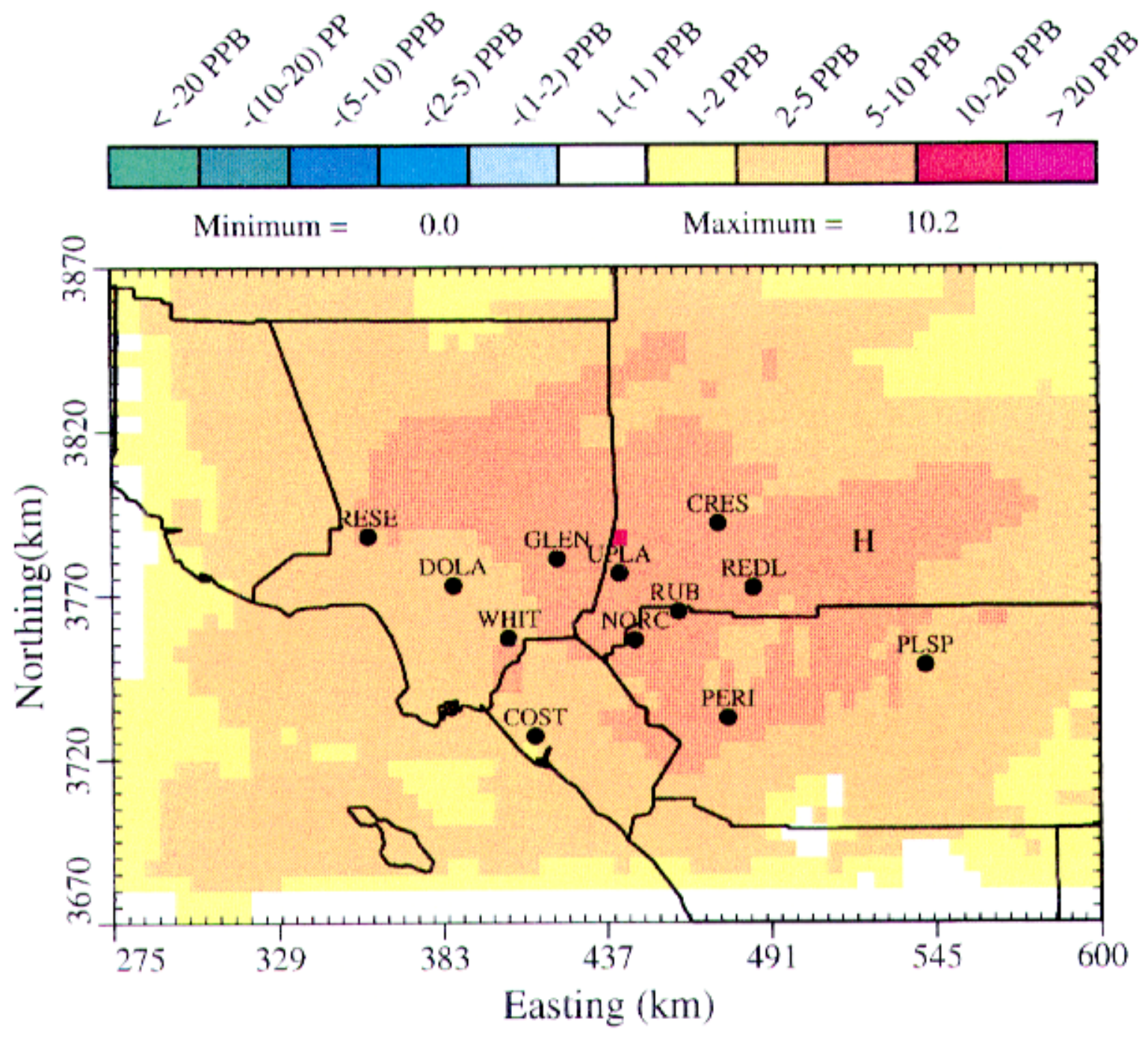

Figure 5-8a. Daily maximum 1-hr ozone during August 272007 - CNG w SAPRC90/93 minus CNG w SAPRC90. 


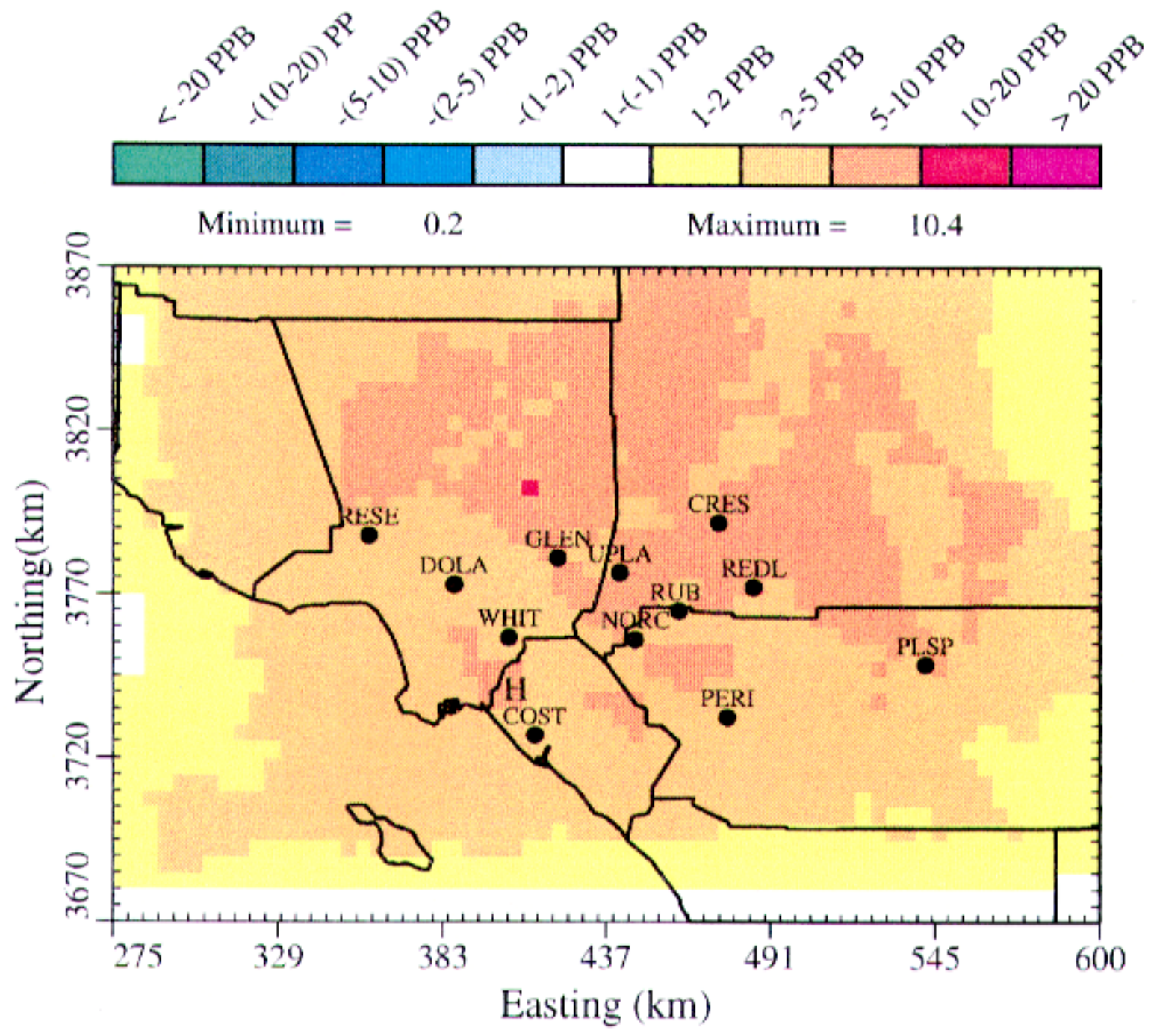

Figure 5-8b. Daily maximum 1-hr ozone during August 282007 - CNG w SAPRC90/93 minus CNG w SAPRC90. 


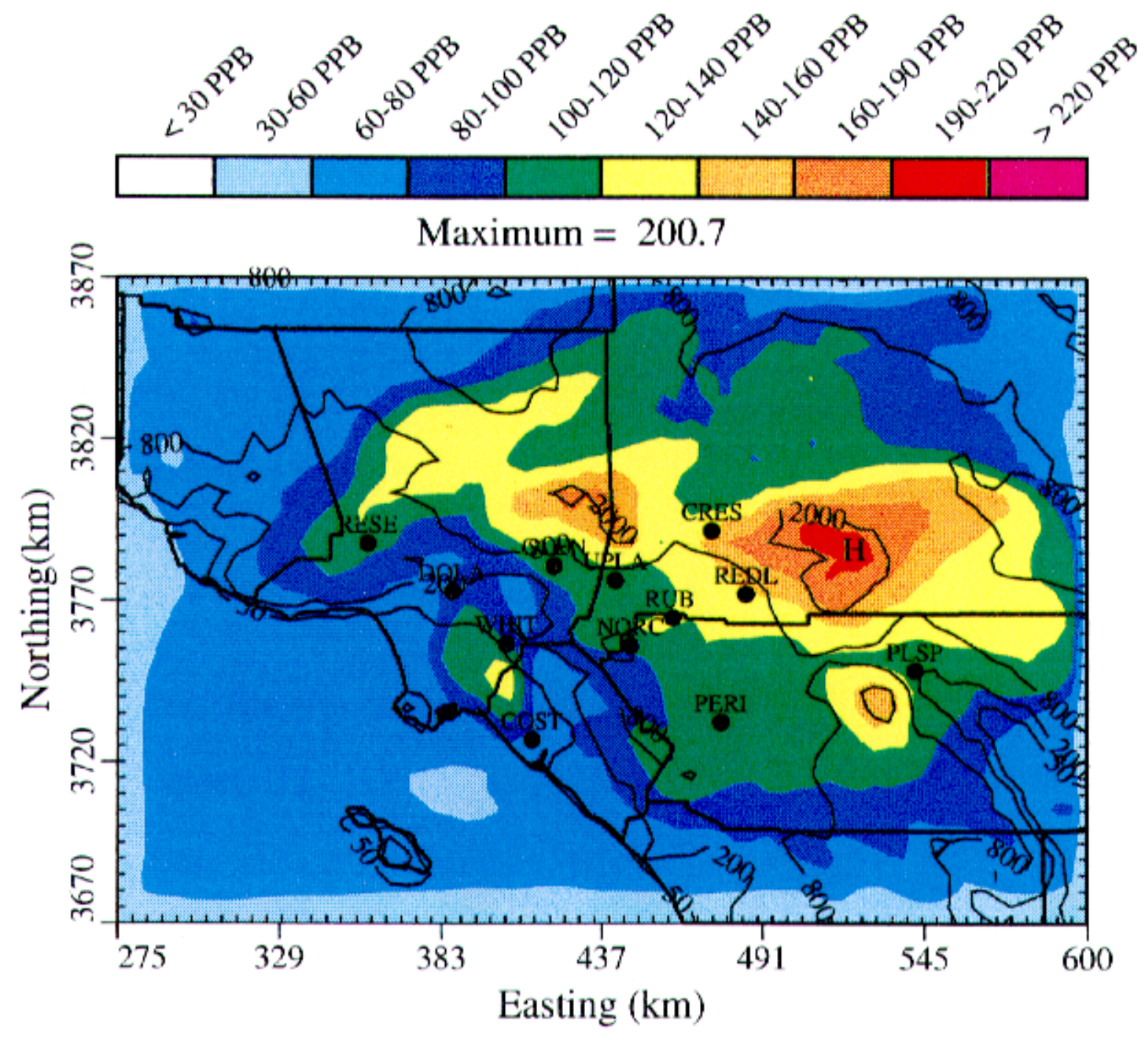

Figure 5-9a. Daily maximum hourly ozone predicted by CALGRID for 27 August 2007 - M85 fueled vehicle scenario with SAPRC 90/93. 


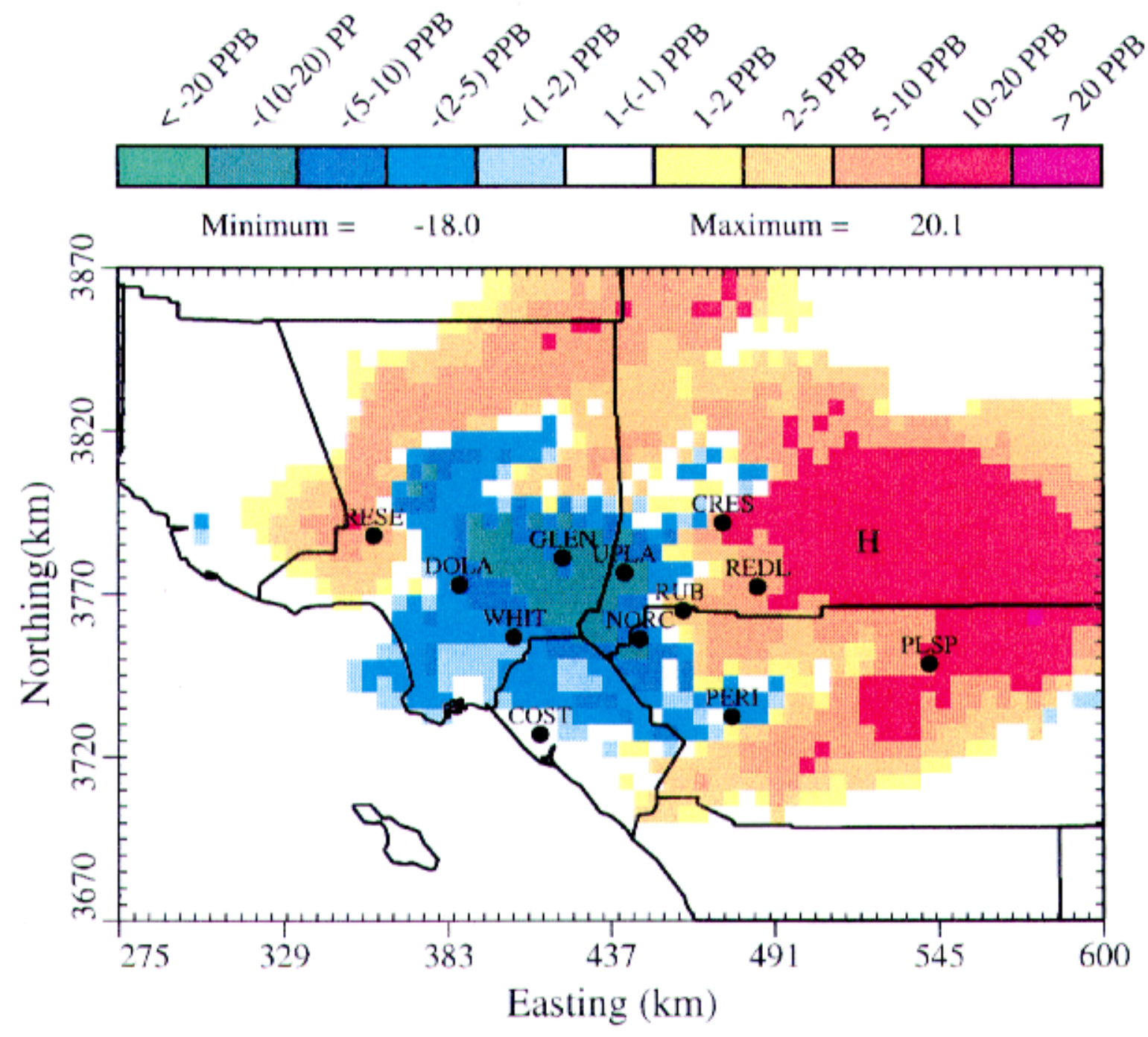

Figure 5-9b. Daily maximum 1-hr ozone during August 272007 - M85 w SAPRC90/93 minus S1 w SAPRC90/93. 


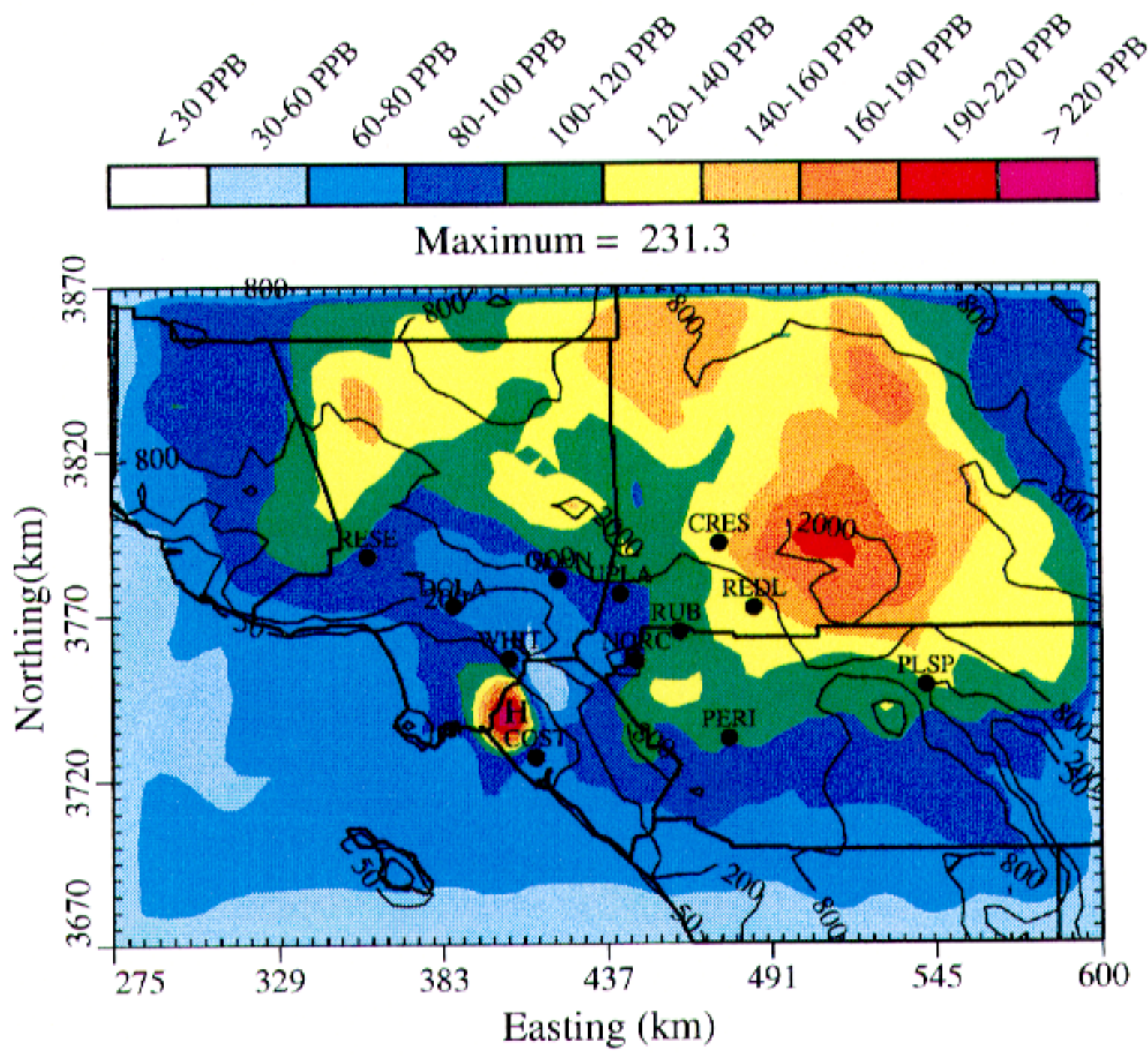

Figure 5-10a. Daily maximum hourly ozone predicted by CALGRID for 28 August 2007 - M85 fueled vehicle scenario with SAPRC 90/93. 


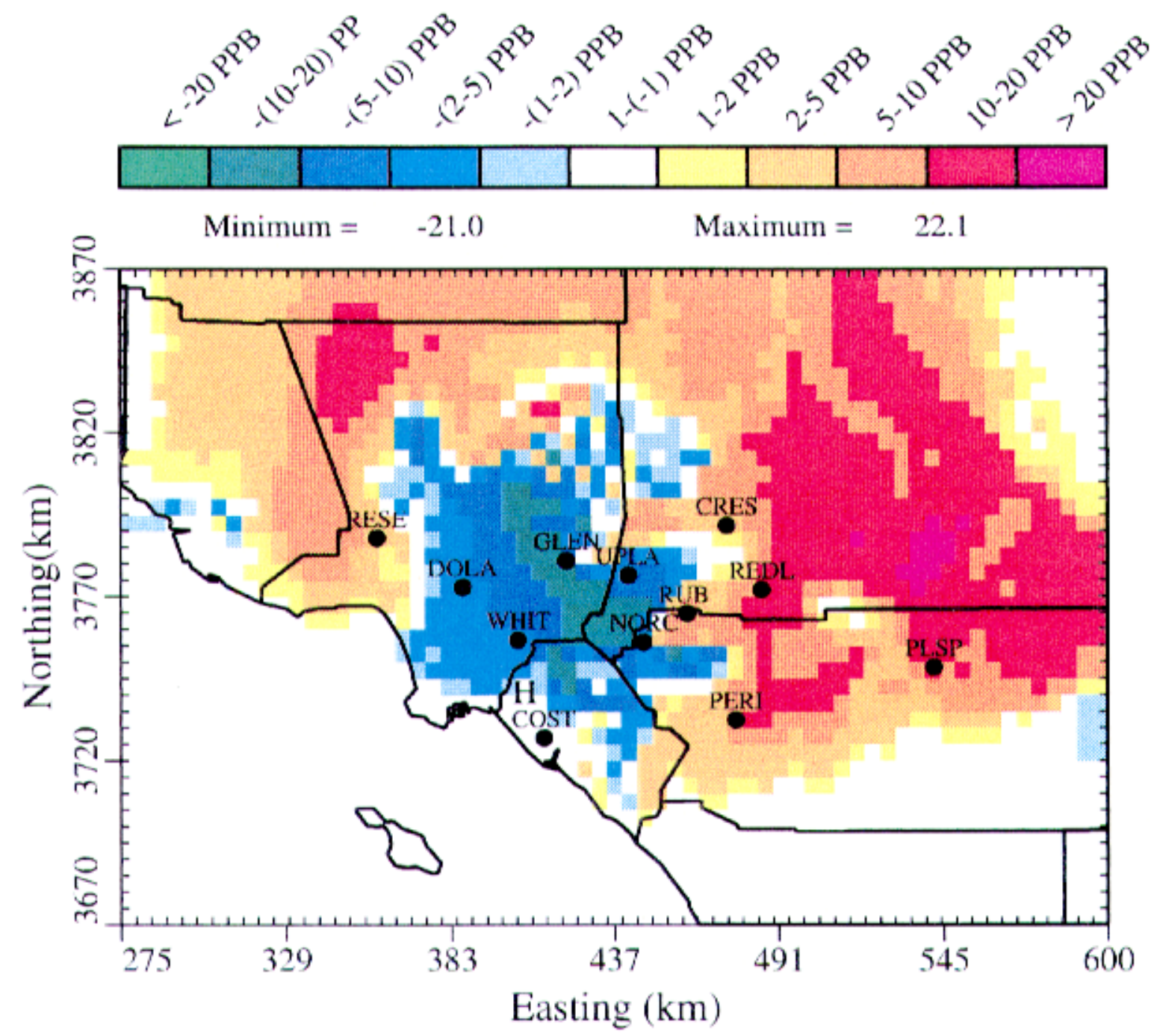

Figure 5-10b. Daily maximum 1-hr ozone during August 282007 - M85 w SAPRC90/93 minus S1 w SAPRC90/93. 


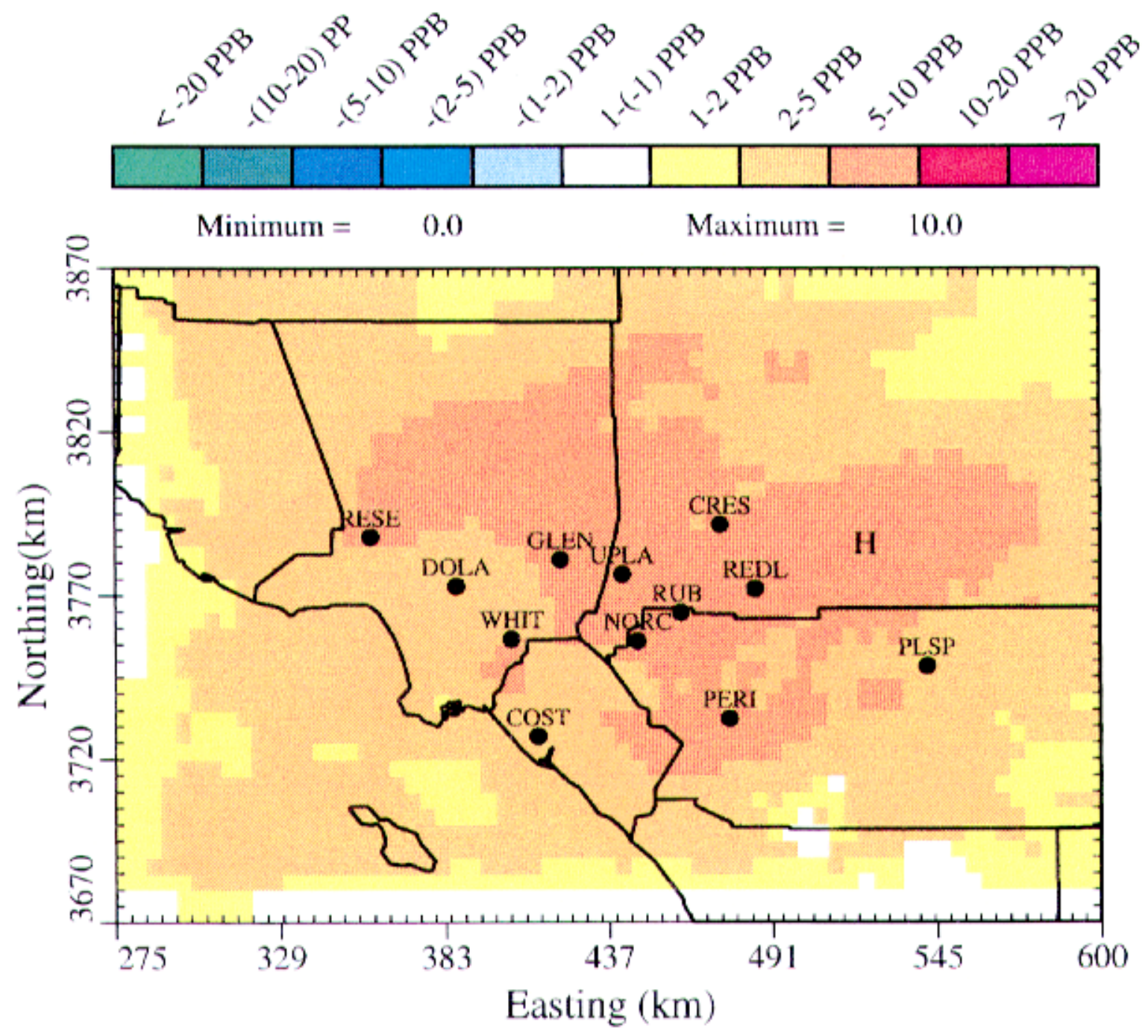

Figure 5-11a. Daily maximum 1-hr ozone during August 272007 - M85 w SAPRC90/93 minus m85 w SAPRC90. 


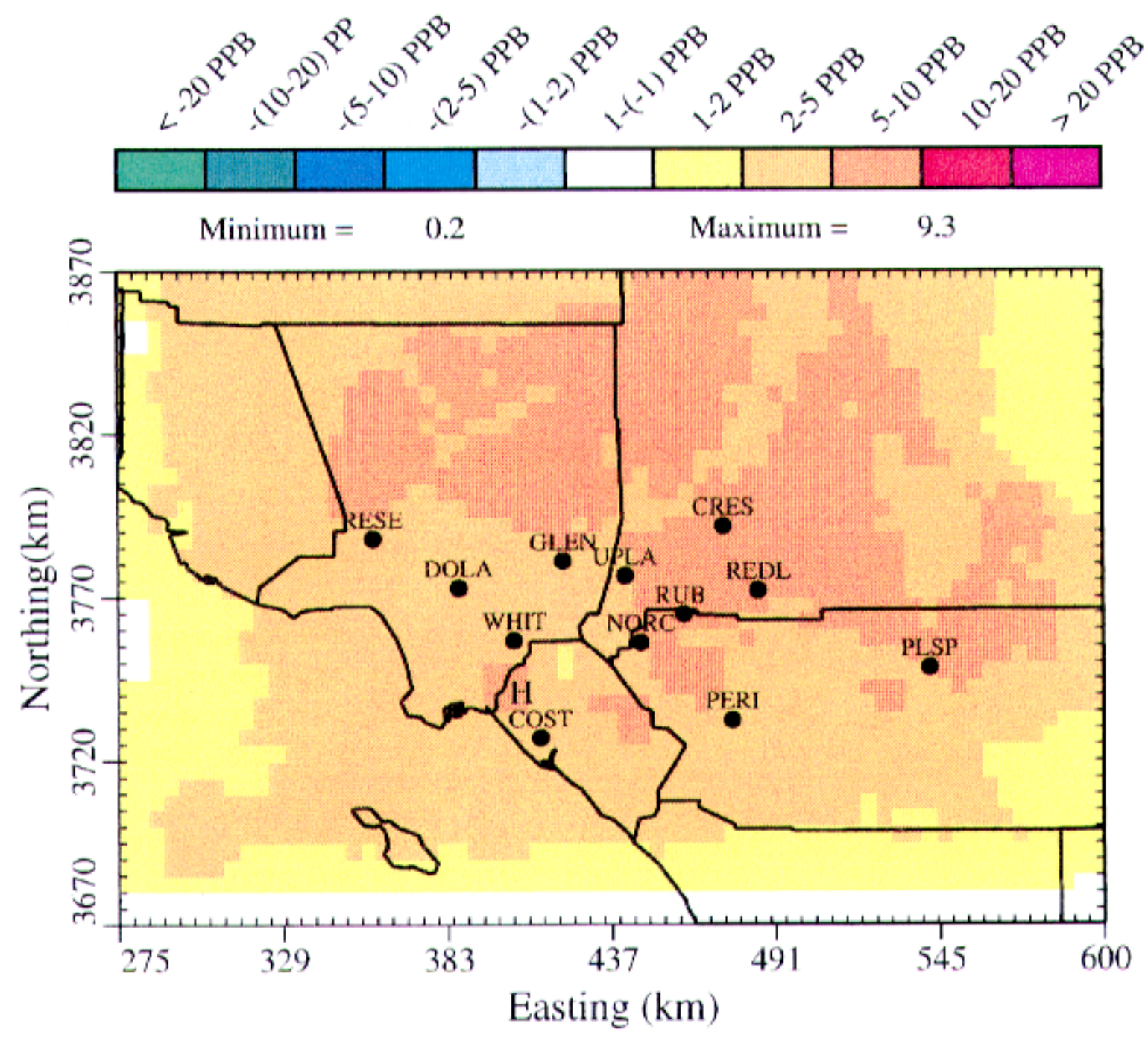

Figure 5-11b. Daily maximum 1-hr ozone during August 282007 - M85 w SAPRC90/93 minus M85 w SAPRC90. 


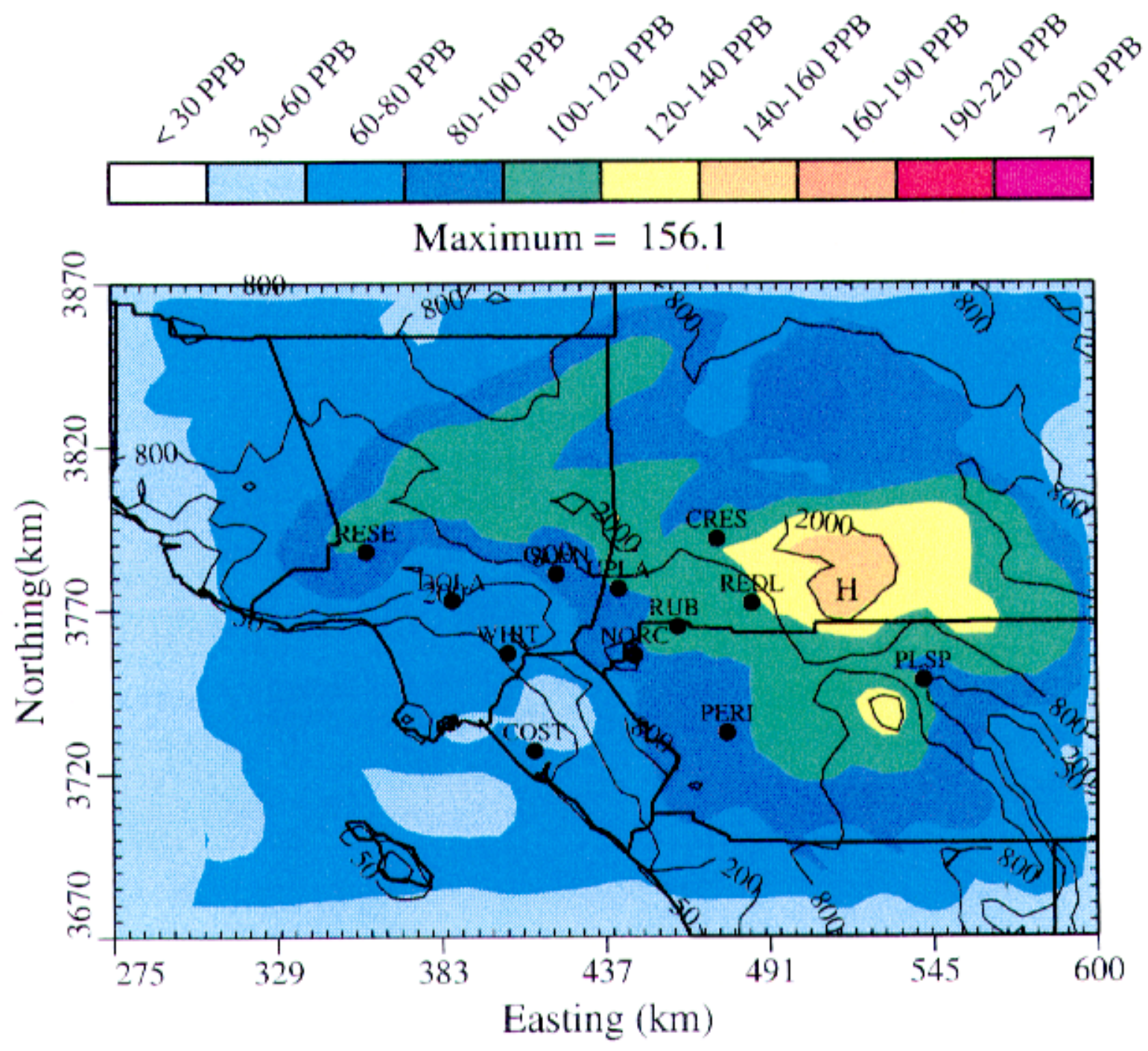

Figure 5-12a. Daily maximum 8-hr ozone predicted by CALGRID for 27 August 2007 - RFG fueled vehicle (RFG) scenario with SAPRC 90/93. 


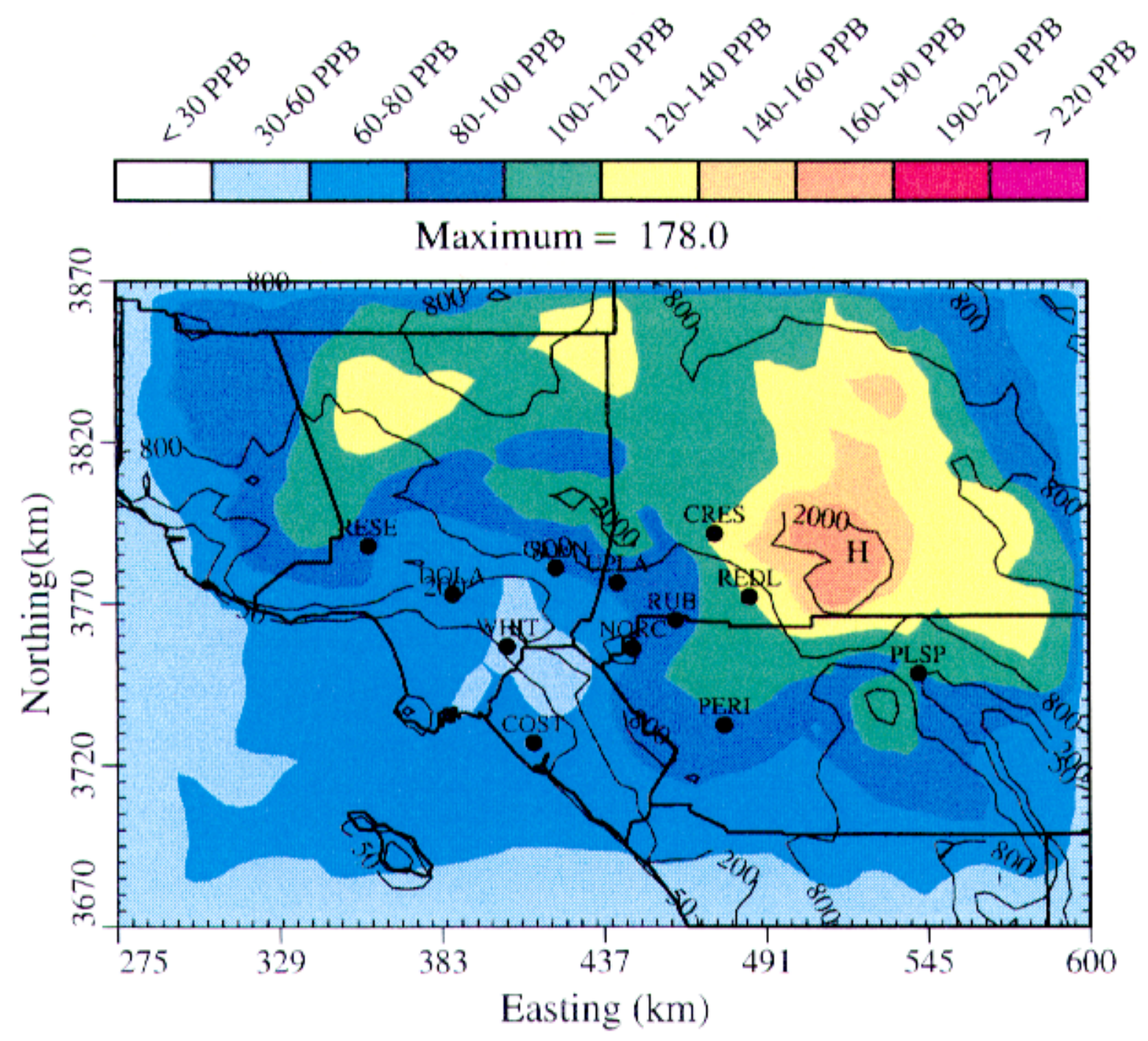

Figure 5-12b. Daily maximum 8-hr ozone predicted by CALGRID for 28 August 2007 - RFG fueled vehicle (RFG) scenario with SAPRC 90/93. 


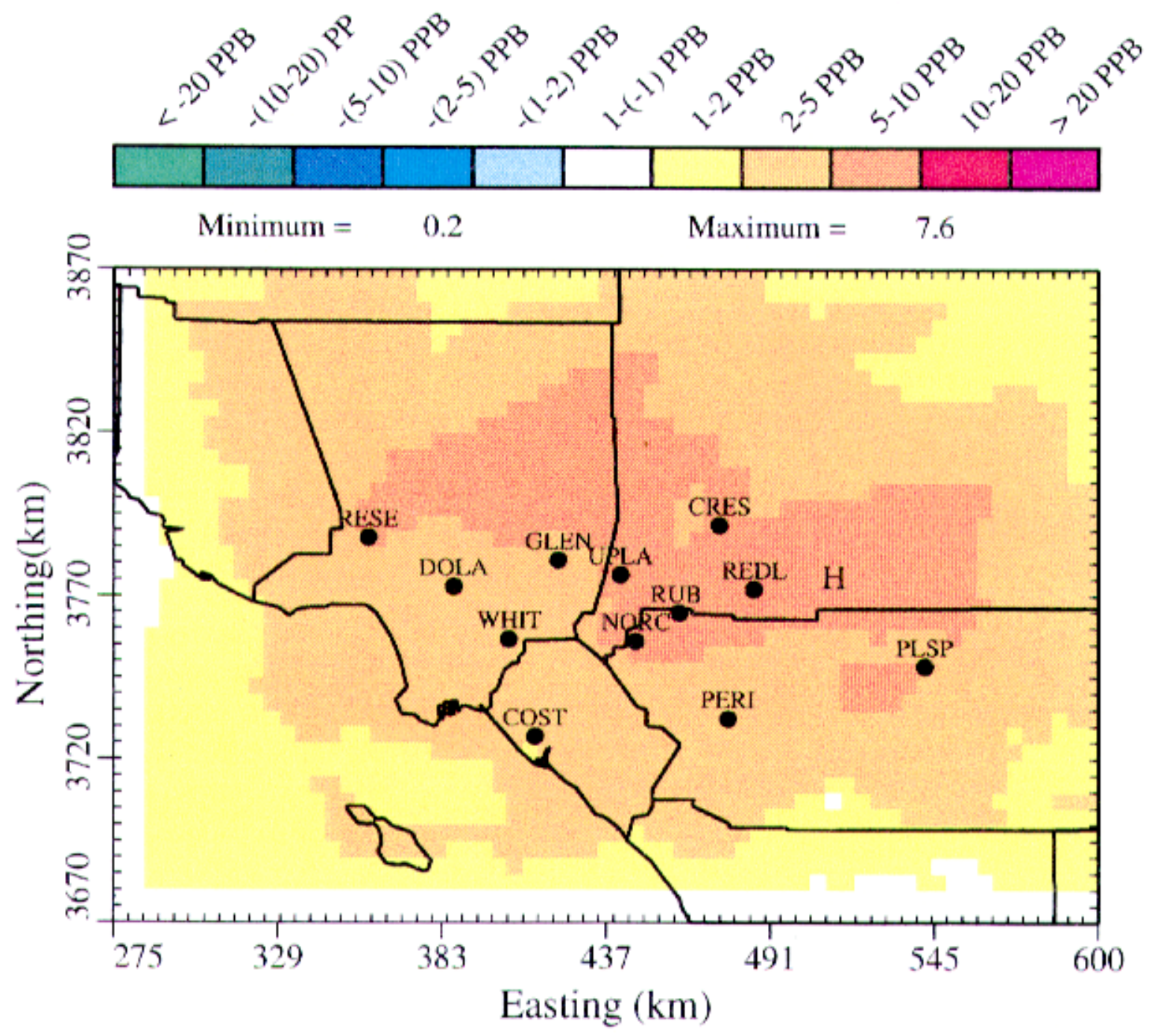

Figure 5-13a. Daily maximum 8-hr ozone during August 272007 - RFG w SAPRC90/93 minus RFG w SAPRC90. 


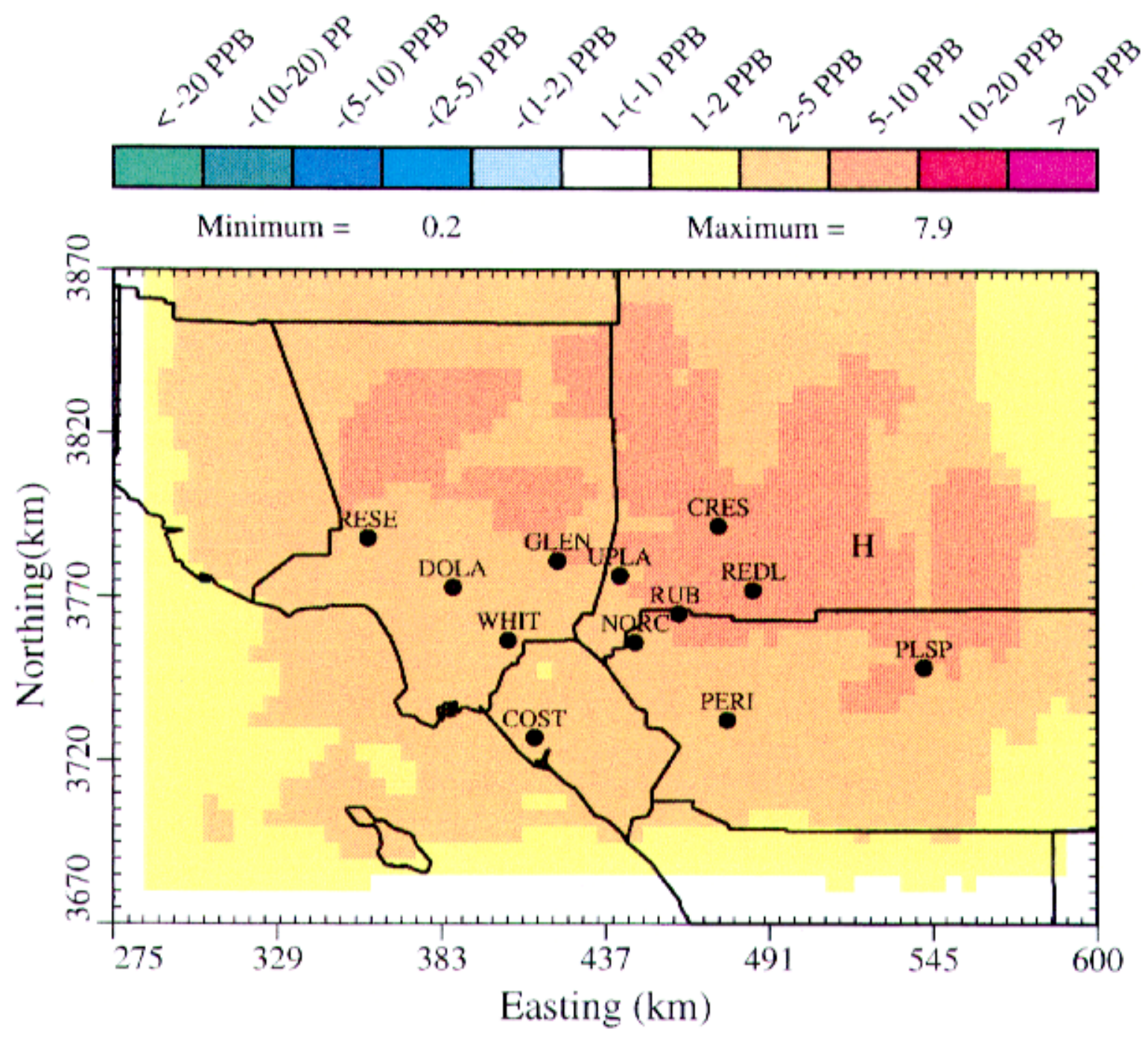

Figure 5-13b. Daily maximum 8-hr ozone during August 282007 - RFG w SAPRC90/93 minus RFG w SAPRC90. 


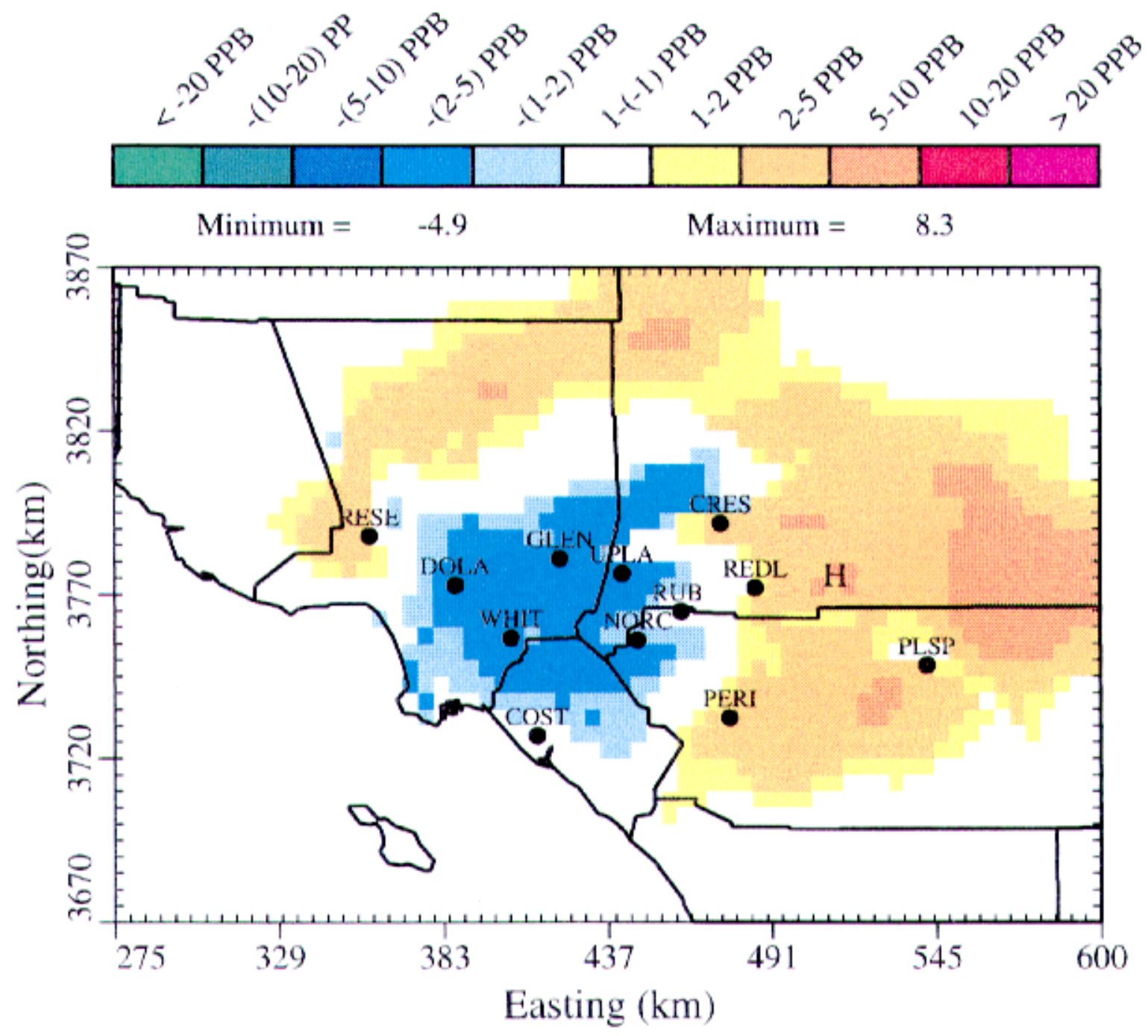

Figure 5-14a. Daily maximum 8-hr ozone during August 272007 - RFG w SAPRC90/93 minus CNG w SAPRC90/93 


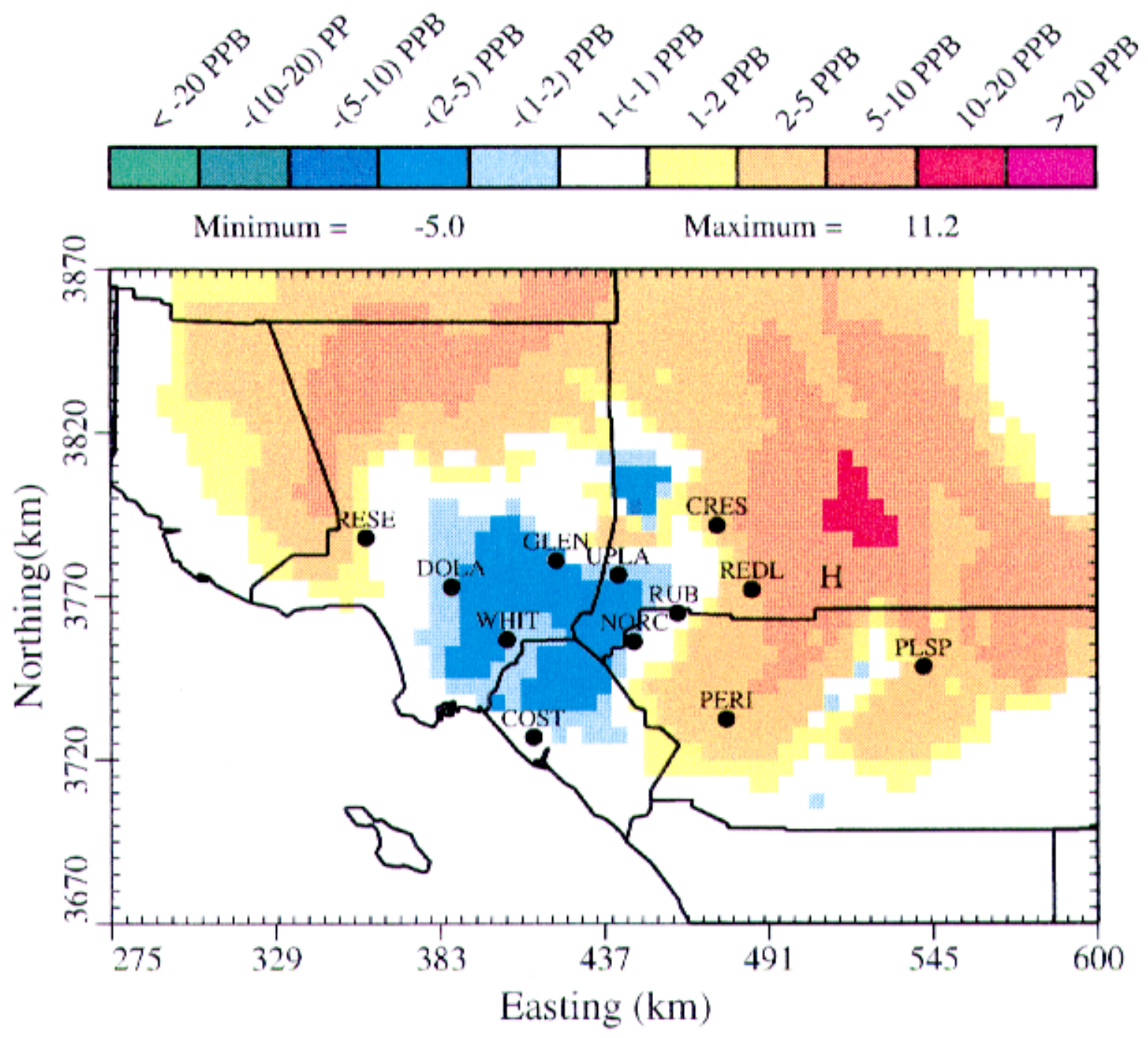

Figure 5-14b. Daily maximum 8-hr ozone during August 282007 - RFG w SAPRC90/93 minus CNG w SAPRC90/93 


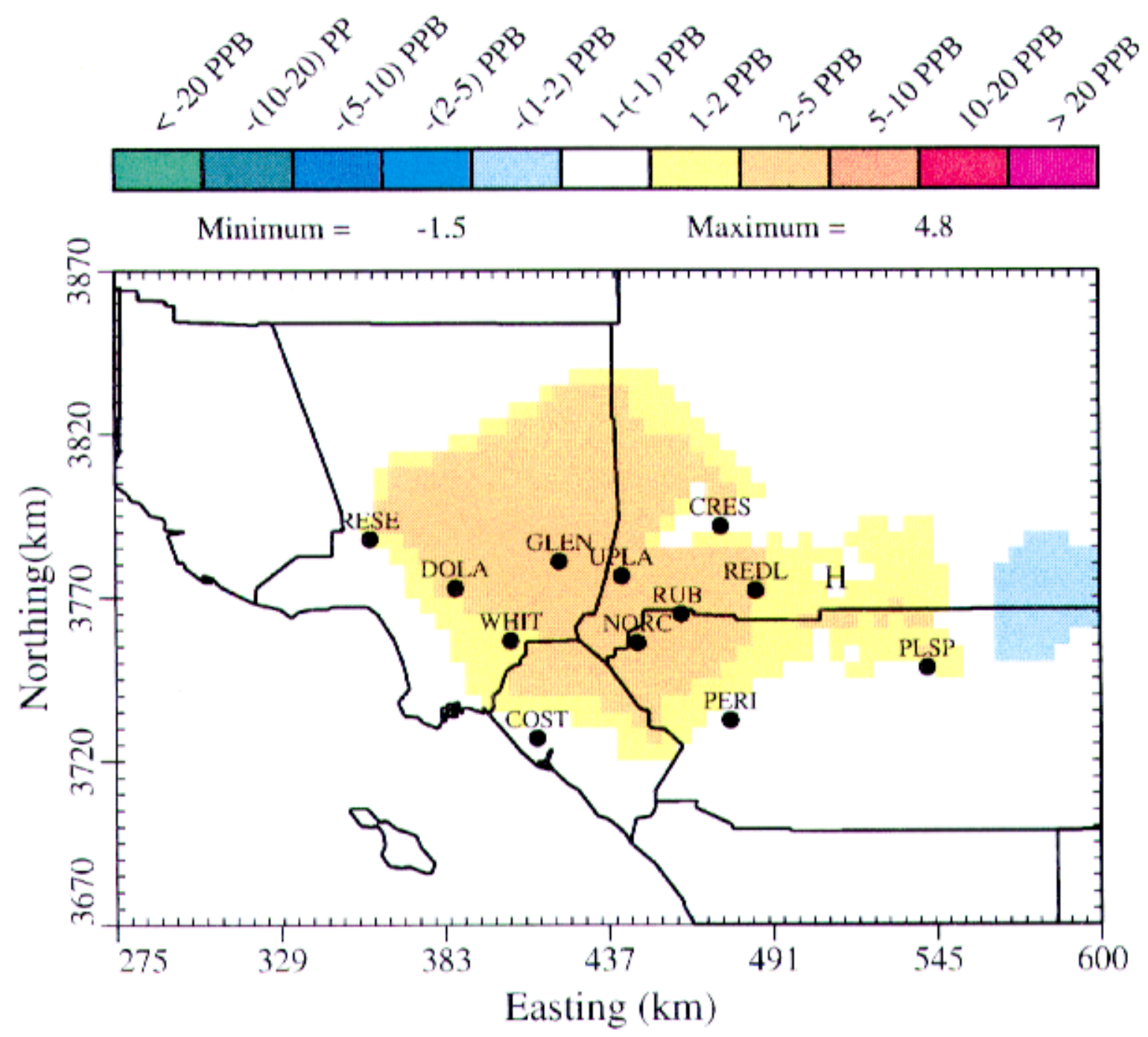

Figure 5-15a. Daily maximum 8-hr ozone during August 272007 - RFG w SAPRC90/93 minus M85 w SAPRC90/93. 


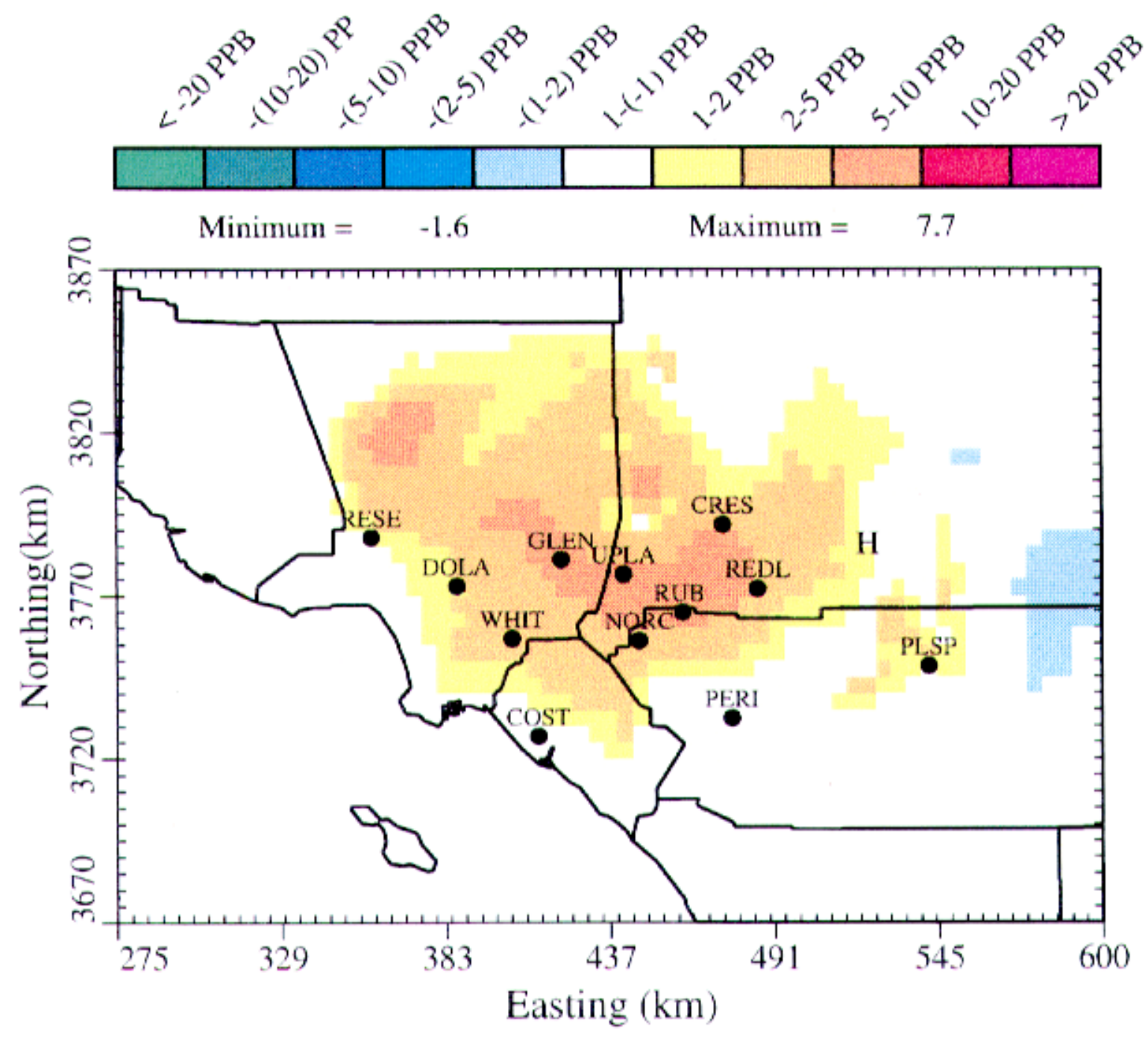

Figure 5-15b. Daily maximum 8-hr ozone during August 282007 - RFG w SAPRC90/93 minus M85 w SAPRC90/93. 


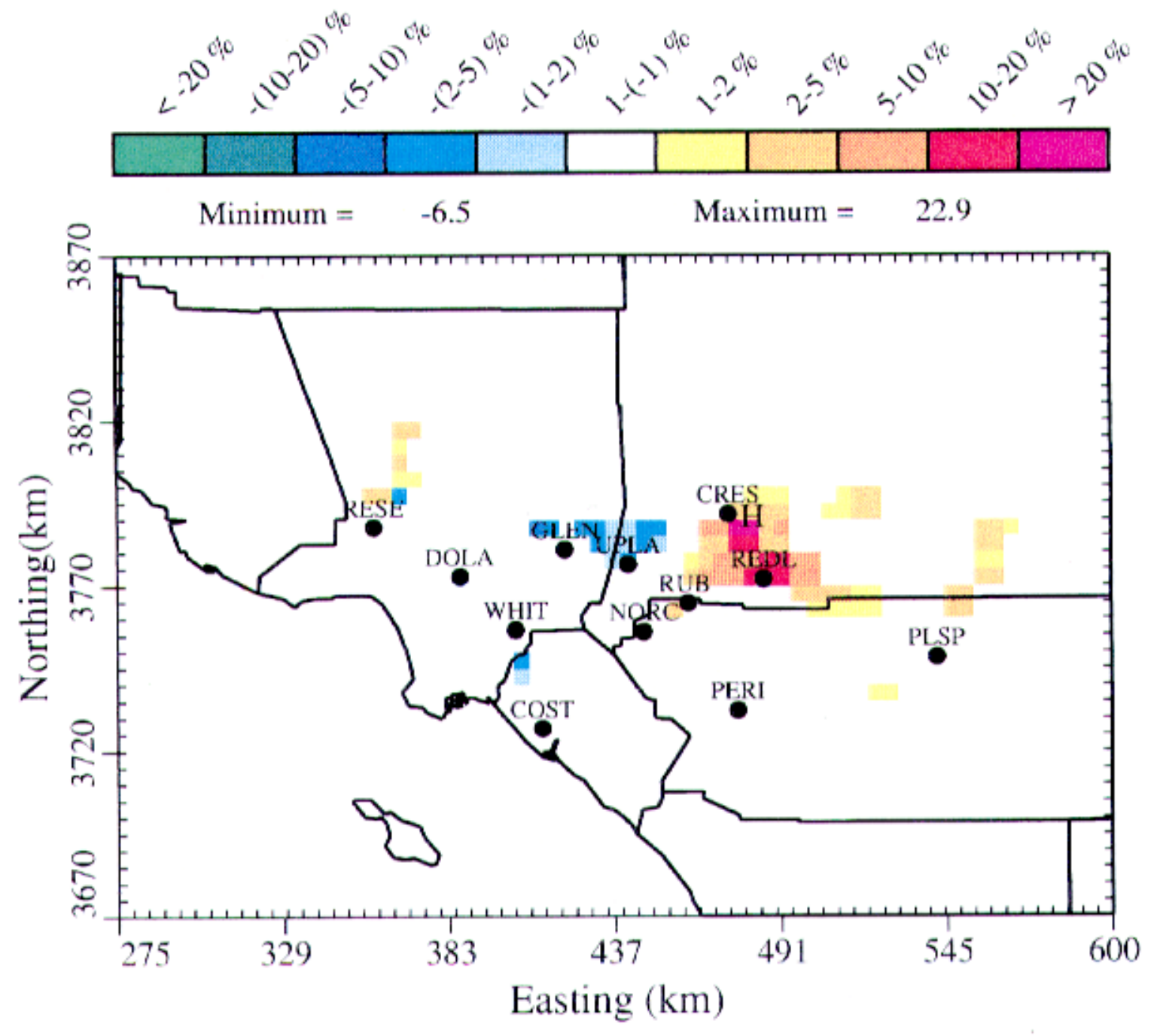

Figure 5-16a. Cumulative 1-hr ozone exposure (>120 ppb) percentile differences during August 272007. RFG w SAPRC90/93 minus CNG w SAPRC90/93. 


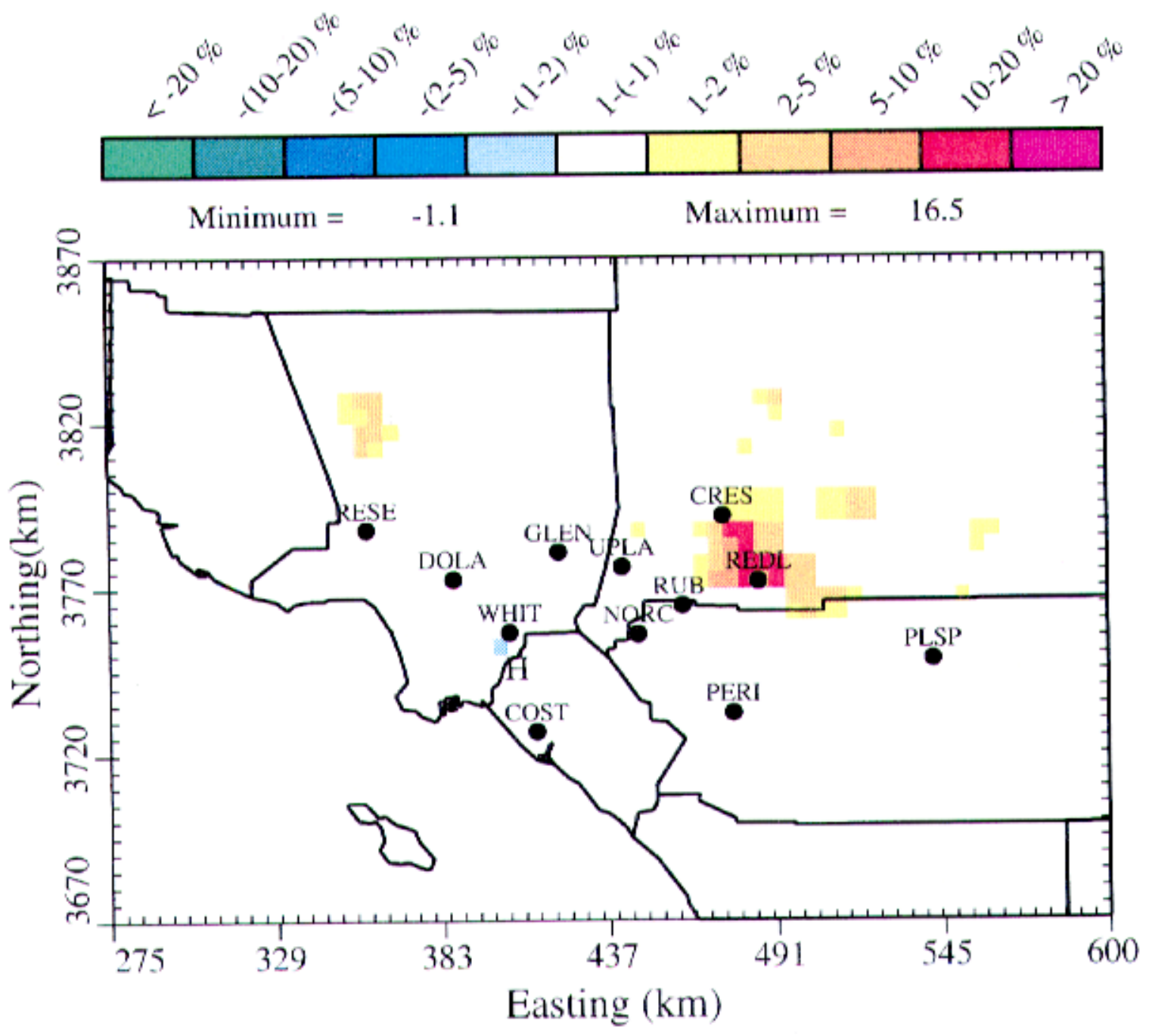

Figure 5-16b. Cumulative 1-hr ozone exposure ( $>120$ ppb) percentile differences during August 282007. RFG w SAPRC90/93 minus CNG w SAPRC90/93. 


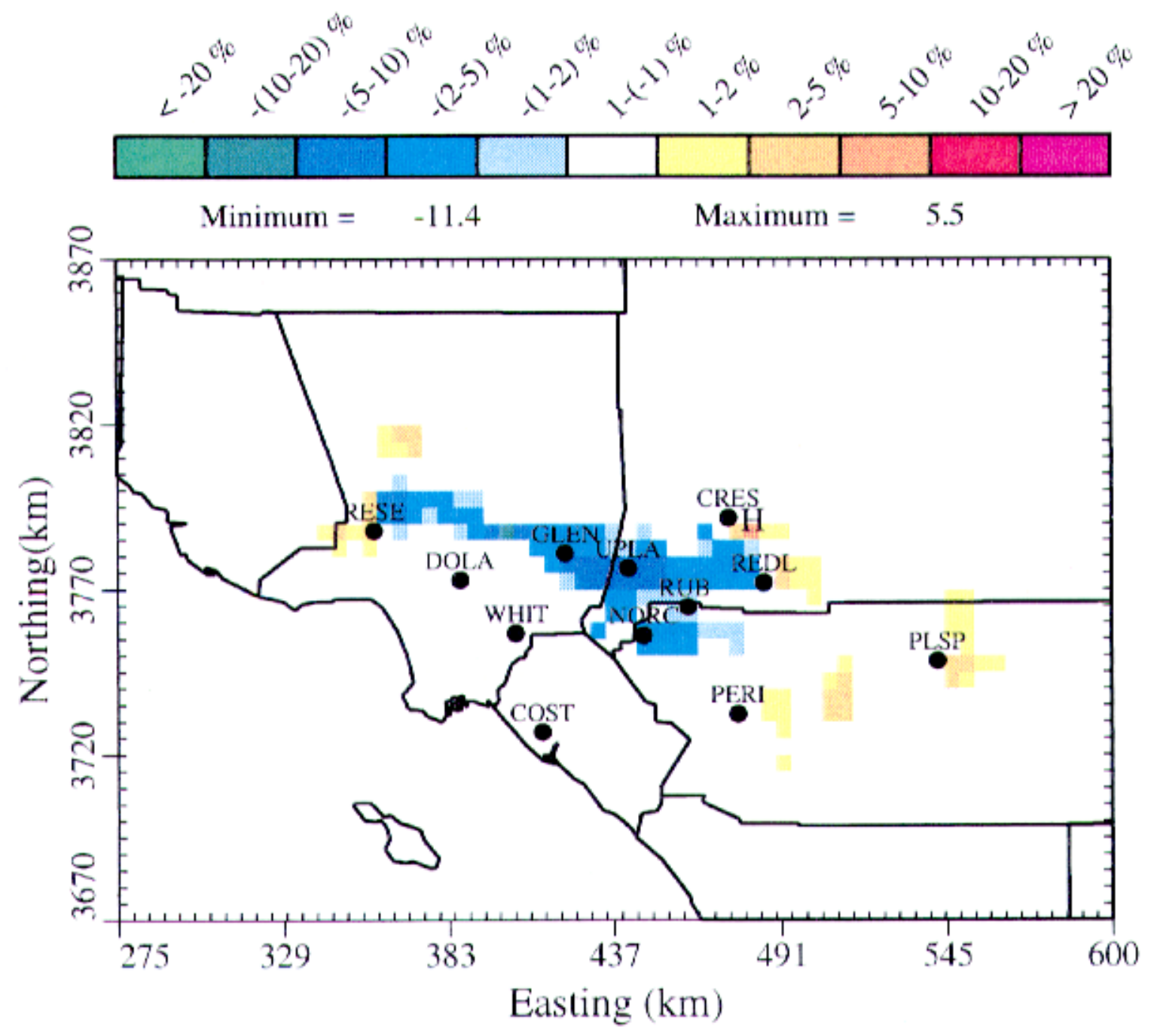

Figure 5-16c. Cumulative 8-hr ozone exposure ( $>80$ ppb) percentile differences during August 272007. RFG w SAPRC90/93 minus CNG w SAPRC90/93. 


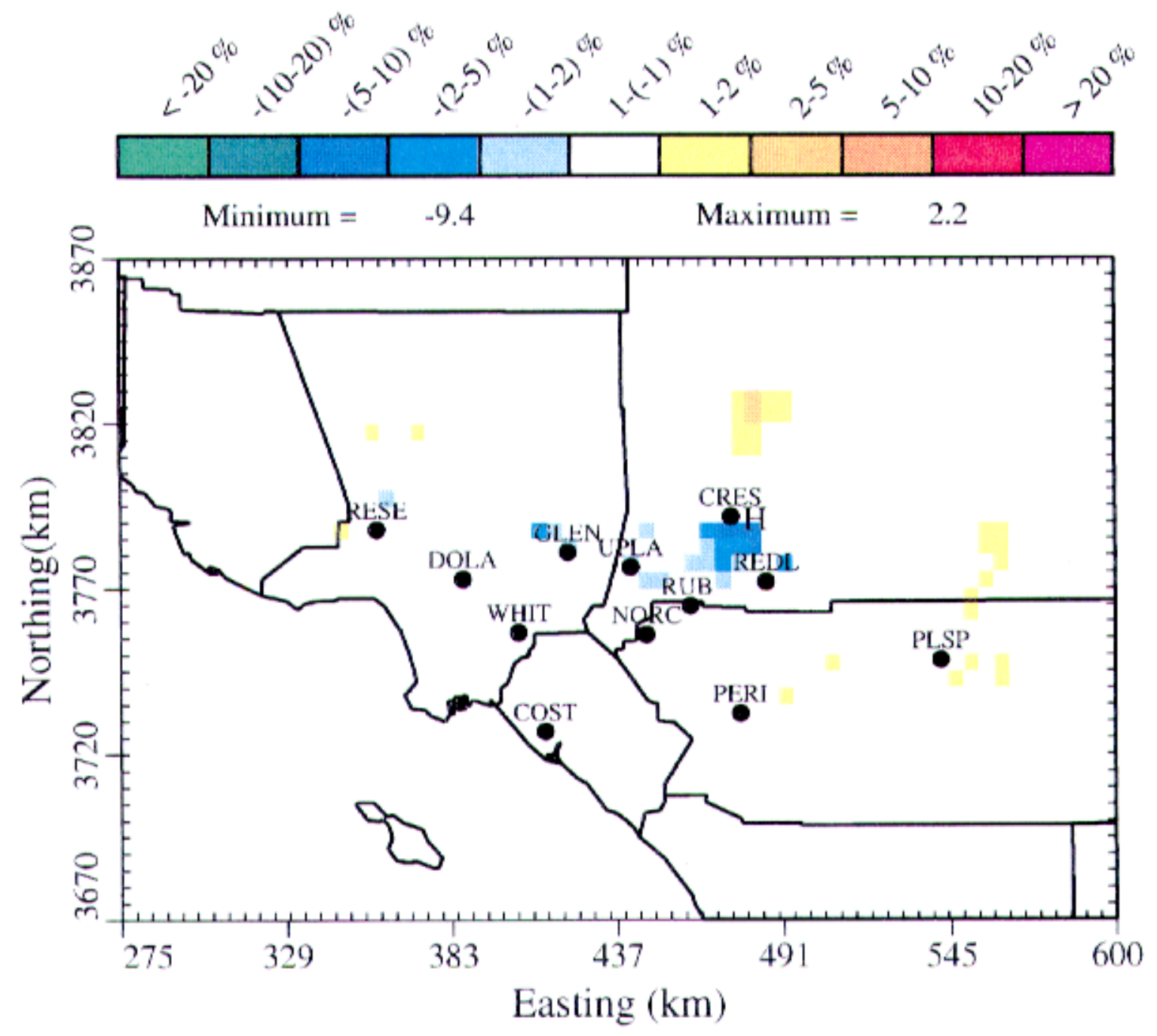

Figure 5-16d. Cumulative 8-hr ozone exposure ( $>80$ ppb) percentile differences during August 282007. RFG w SAPRC90/93 minus CNG w SAPRC90/93. 


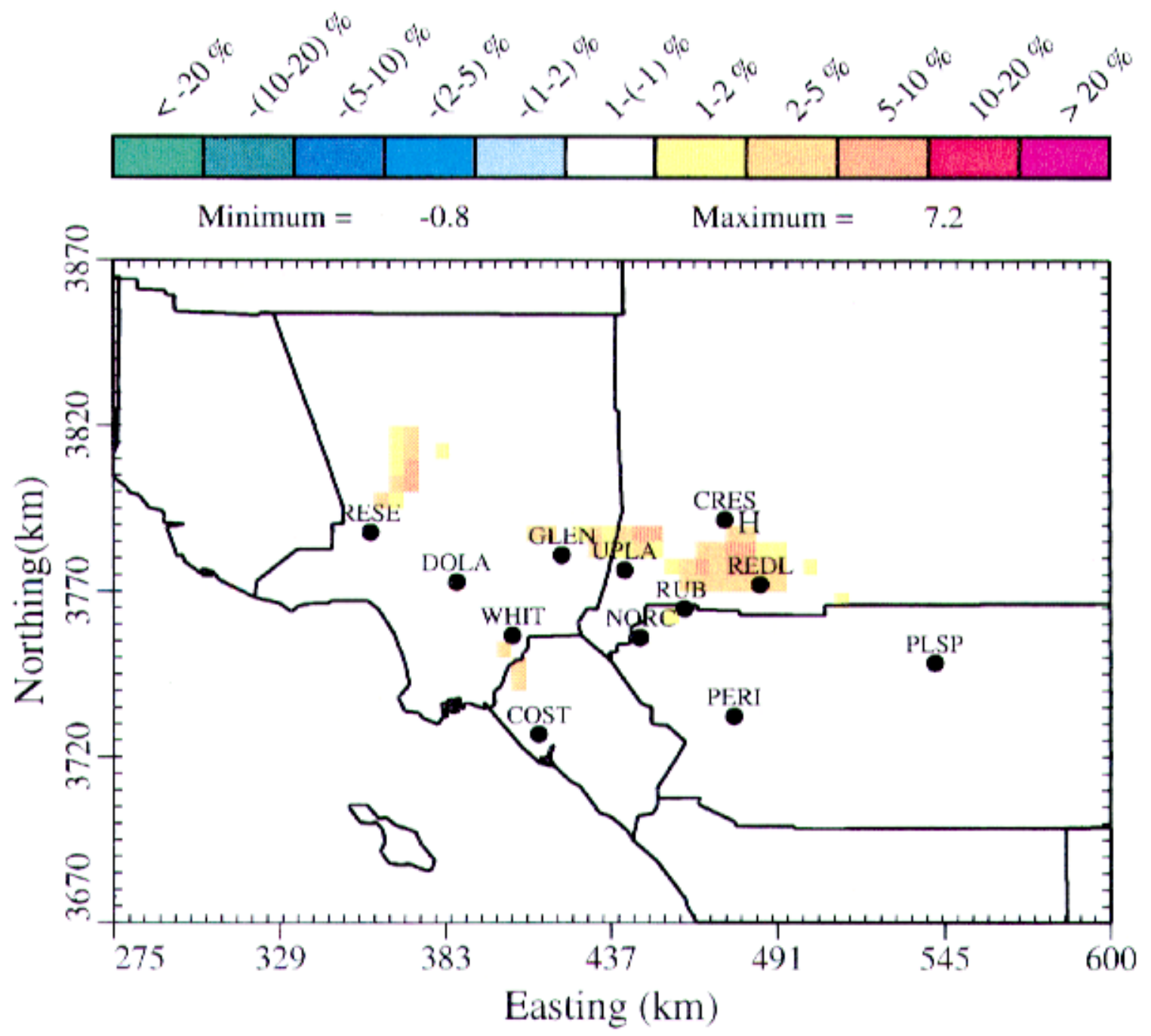

Figure 5-17a. Cumulative 1-hr ozone exposure ( $>120$ ppb) percentile differences during August 272007. RFG w SAPRC90/93 minus M85 w SAPRC90/93. 


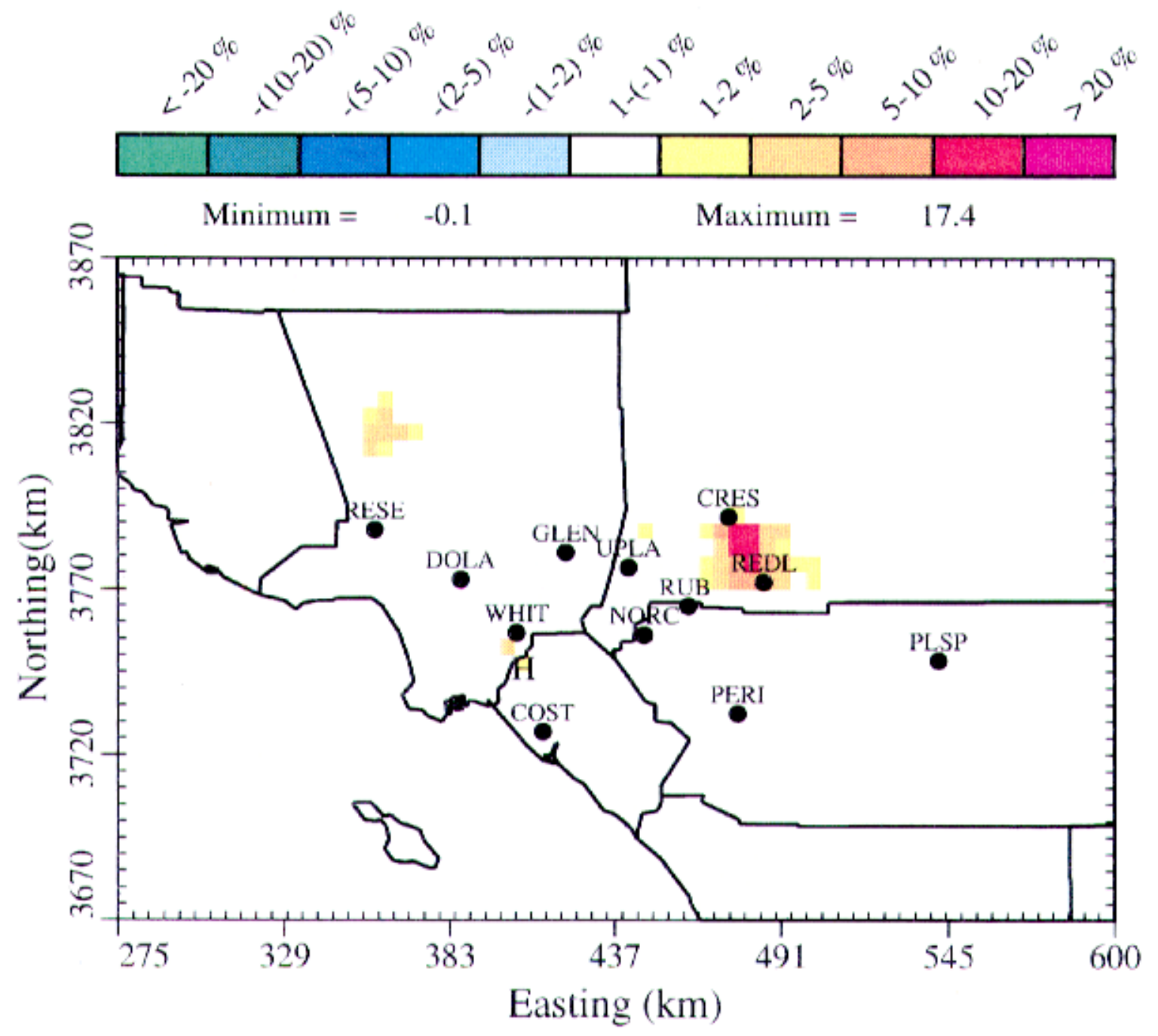

Figure 5-17b. Cumulative 1-hr ozone exposure ( $>120$ $\mathrm{ppb})$ percentile differences during August 282007. RFG w SAPRC90/93 minus M85 w SAPRC90/93. 


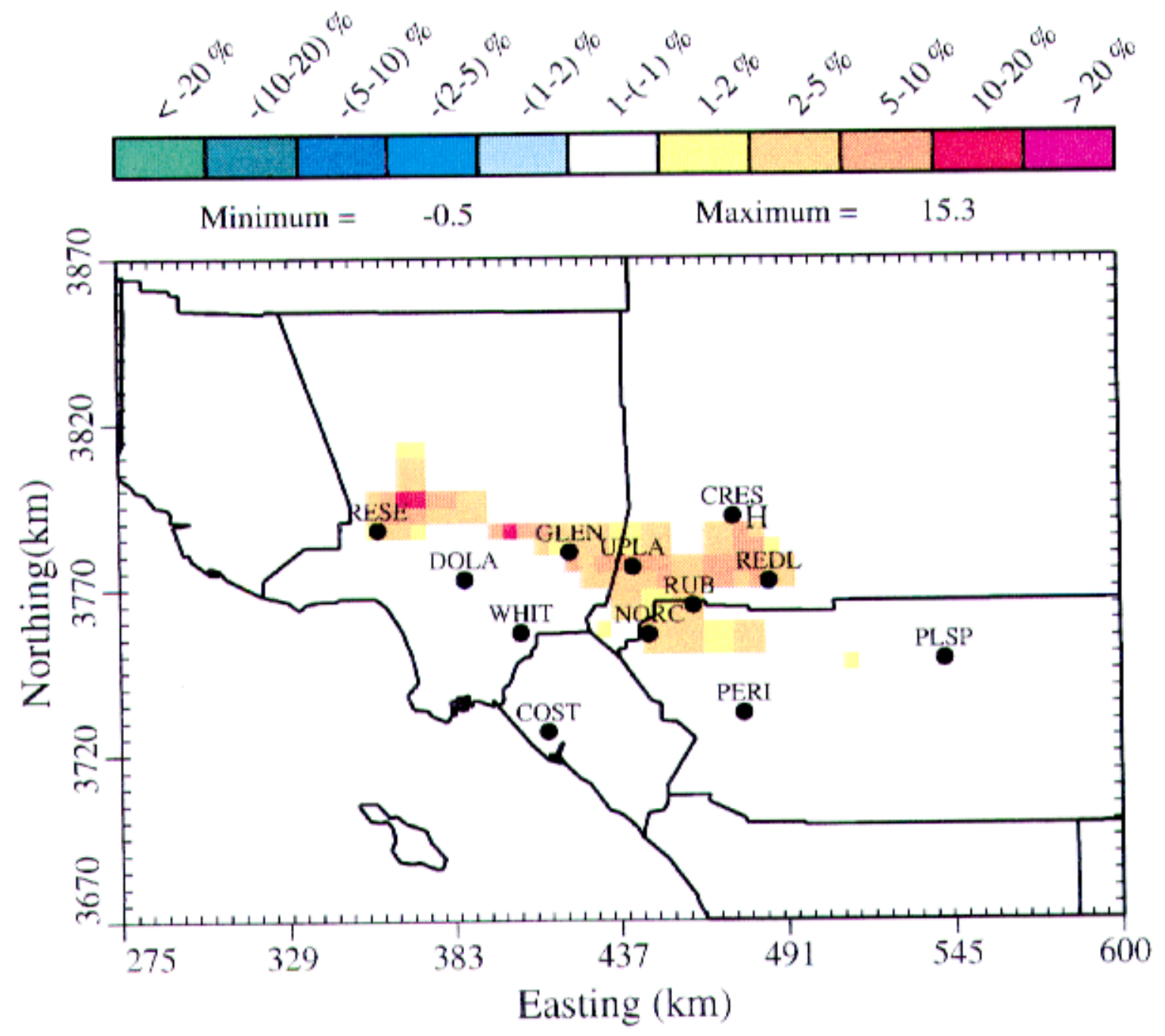

Figure 5-17c. Cumulative 8-hr ozone exposure $(<80$ ppb) percentile differences during August 272007. RFG w SAPRC90/93 minus M85 w SAPRC90/93. 


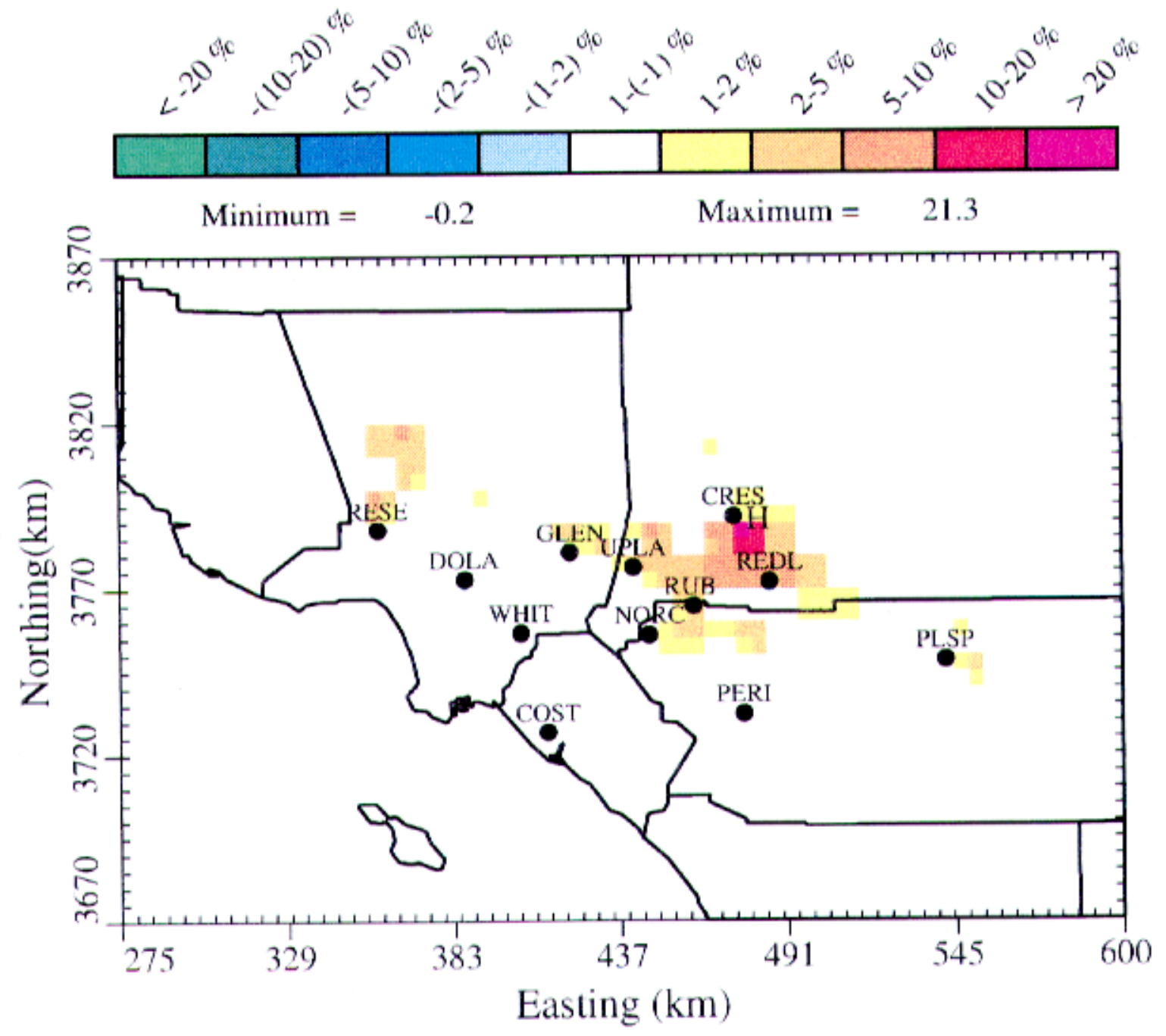

Figure 5-17d. Cumulative 8-hr ozone exposure ( $>80$ ppb) percentile differences during August 282007. RFG w SAPRC90/93 minus M85 w SAPRC90/93. 


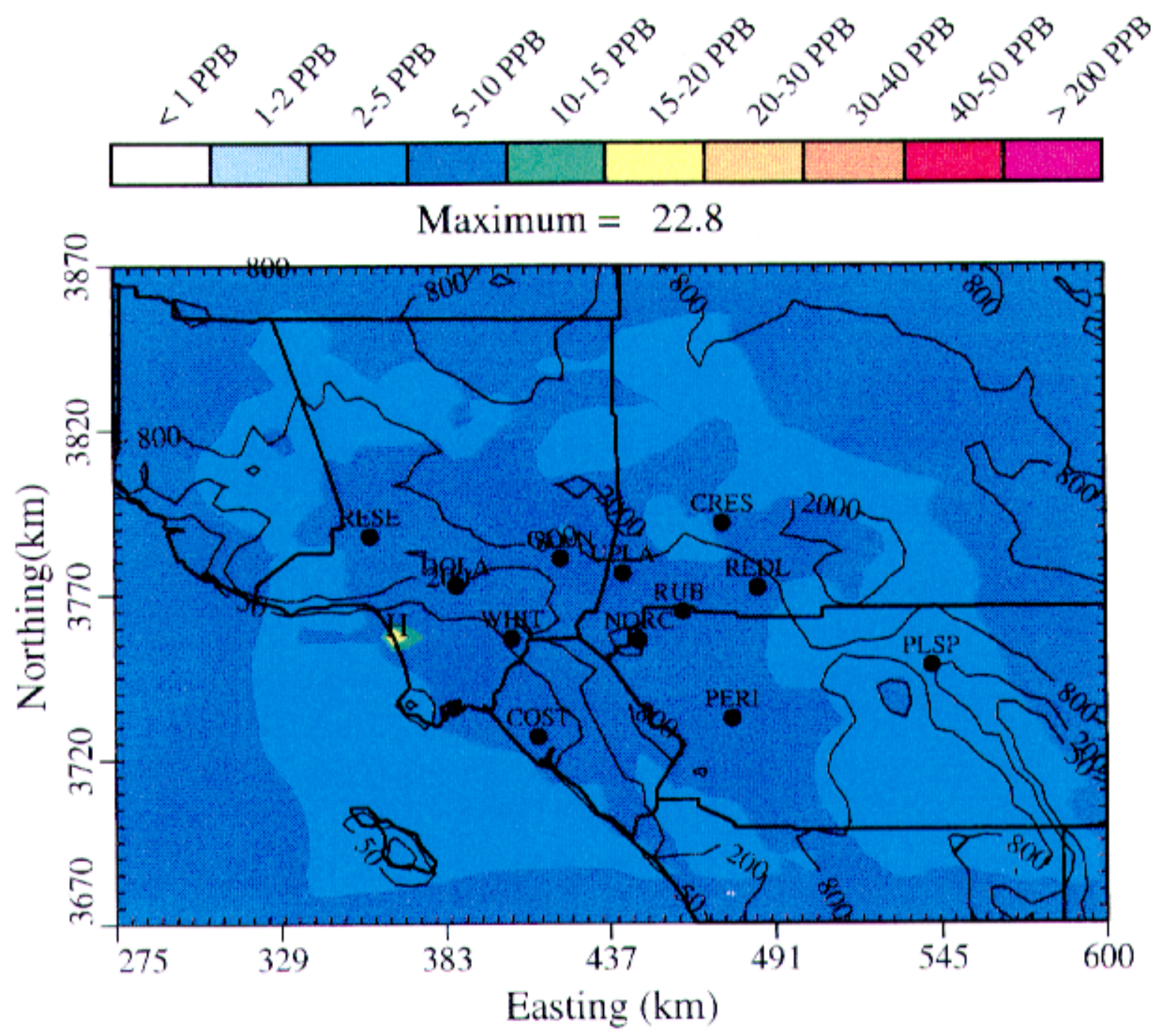

Figure 5-18a. Daily maximum hourly $\mathrm{HCHO}$ predicted by CALGRID for 27 August 2007 - RFG fueled vehicle (RFG) scenario with SAPRC 90/93. 


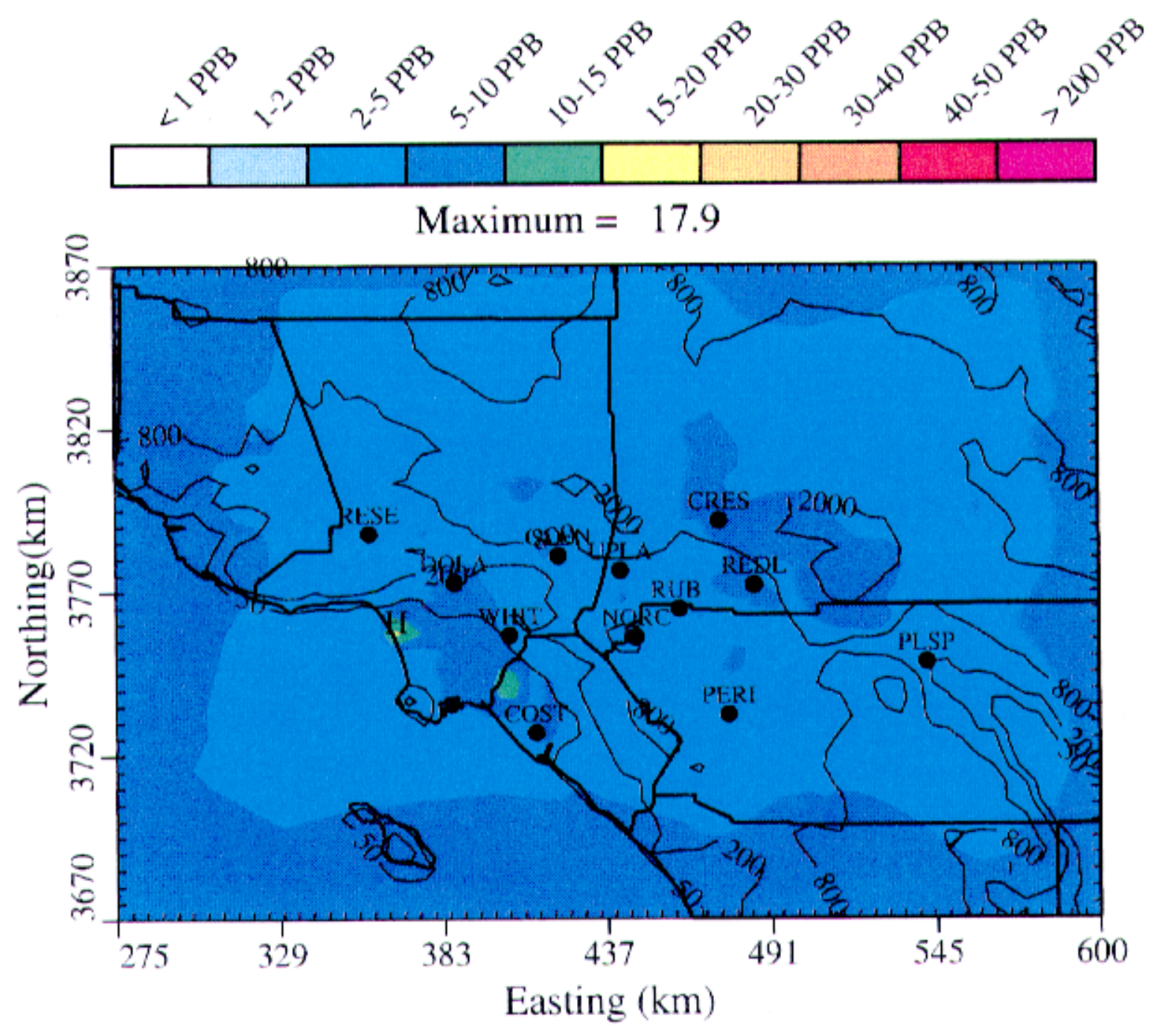

Figure 5-18b. Daily maximum hourly $\mathrm{HCHO}$ predicted by CALGRID for 28 August 2007 - RFG fueled vehicle (RFG) scenario with SAPRC 90/93. 


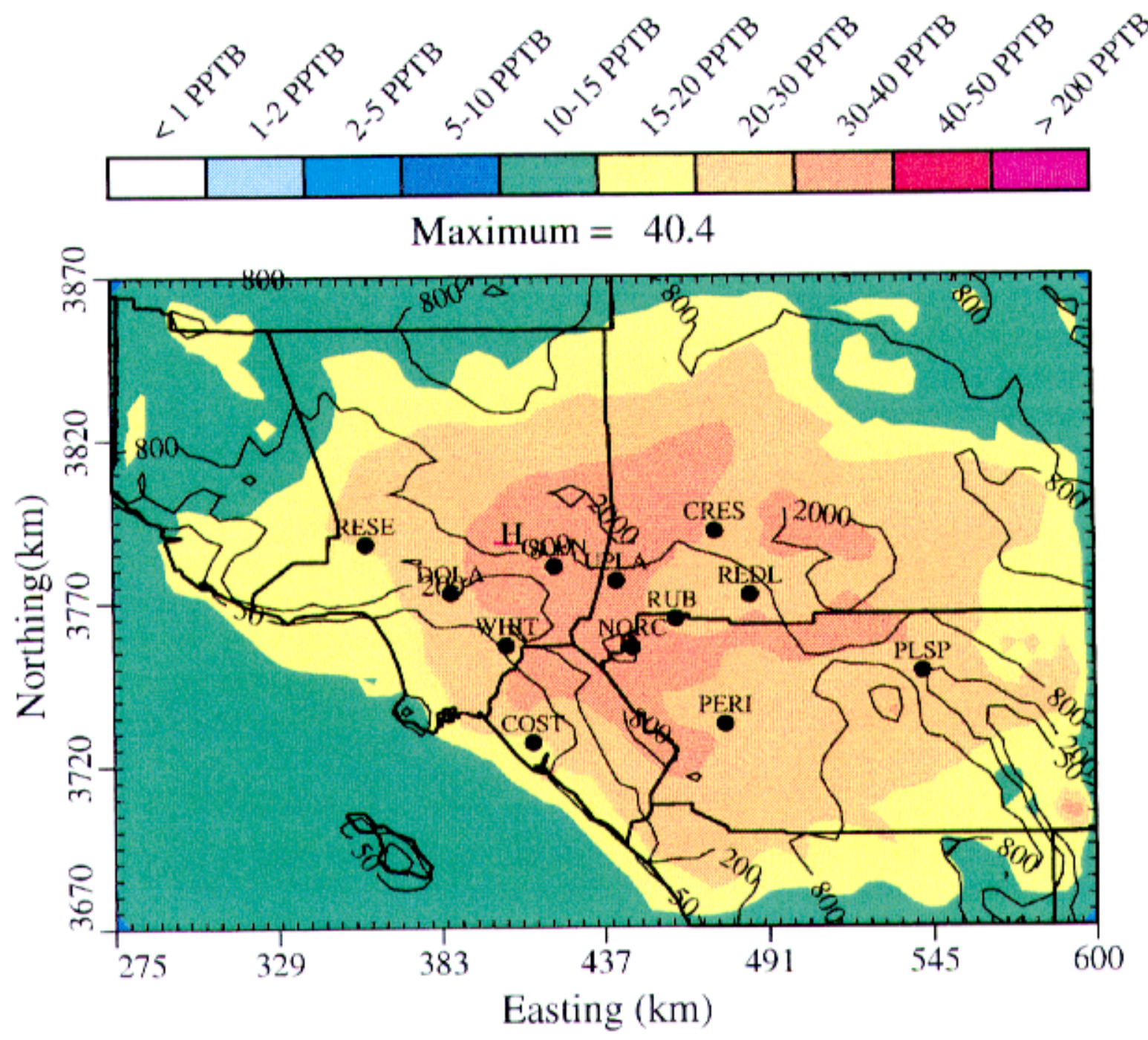

Figure 5-19a. Daily maximum hourly CCHO predicted by CALGRID for 27 August 2007 - RFG fueled vehicle (RFG) scenario with SAPRC 90/93. 


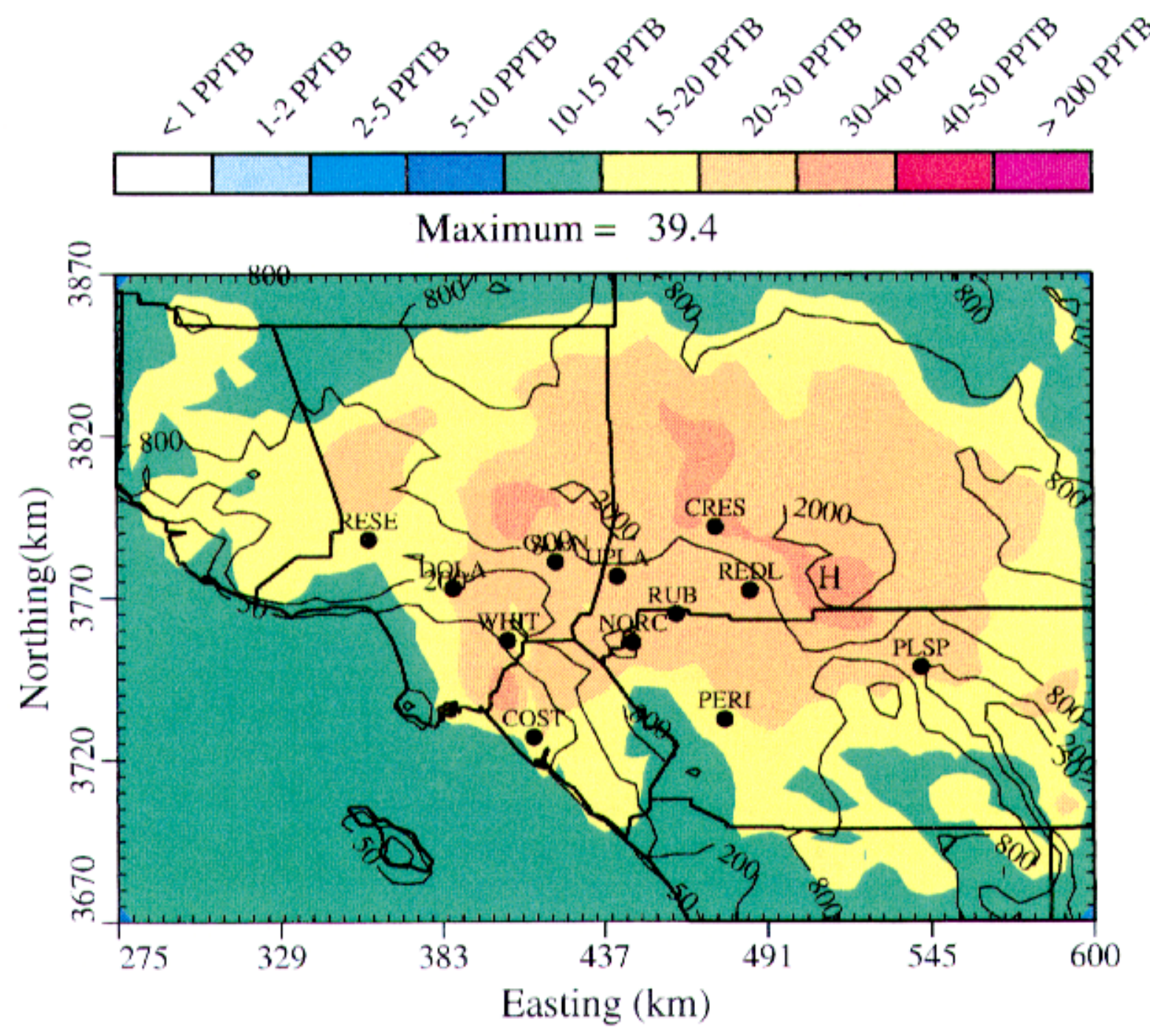

Figure $5-19 \mathrm{~b}$. Daily maximum hourly $\mathrm{CCHO}$ predicted by CALGRID for 28 August 2007 - RFG fueled vehicle (RFG) scenario with SAPRC 90/93. 


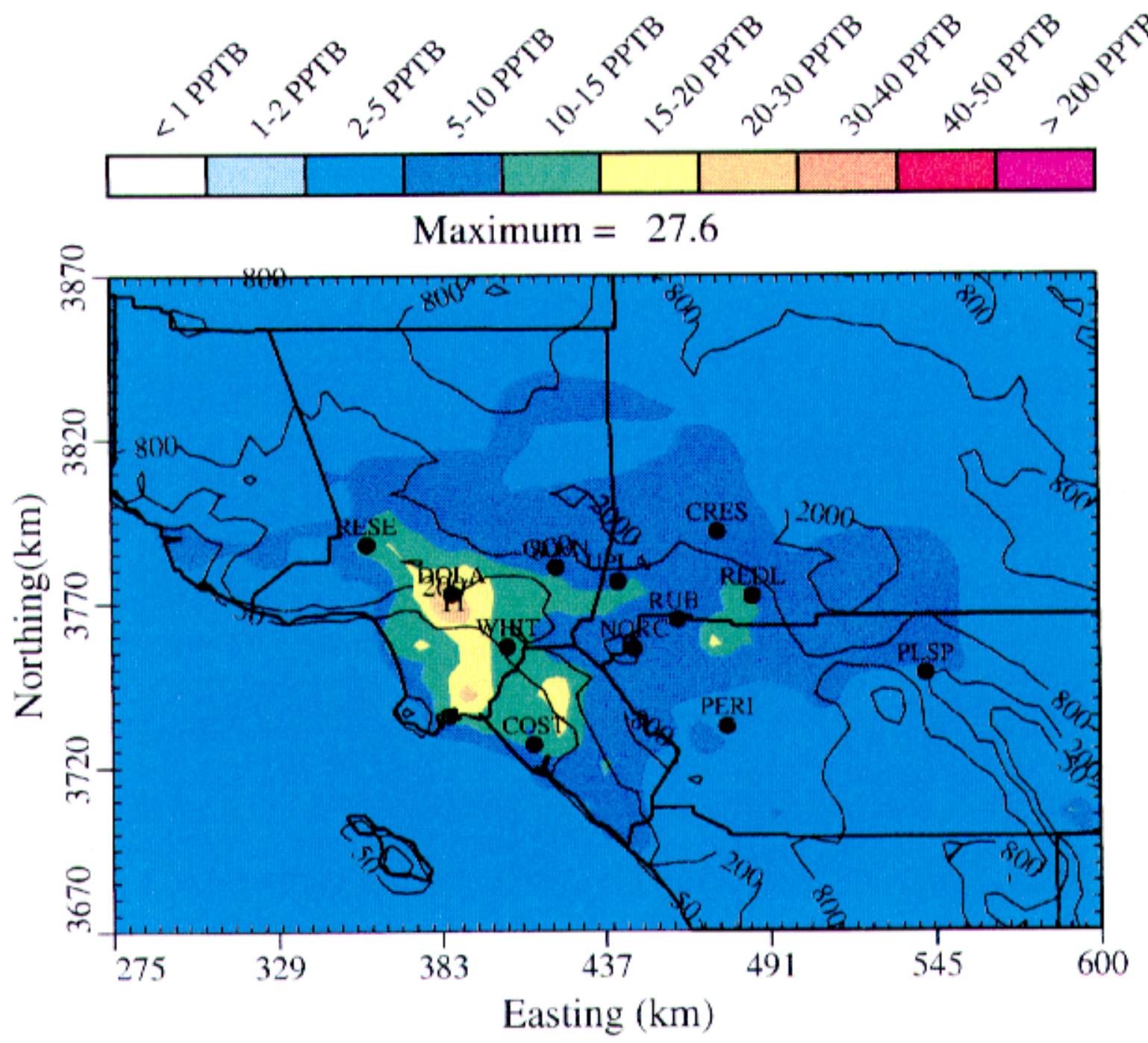

Figure 5-20a. Daily maximum hourly benzene predicted by CALGRID for 27 August 2007 - RFG fueled vehicle (RFG) scenario with SAPRC 90/93. 


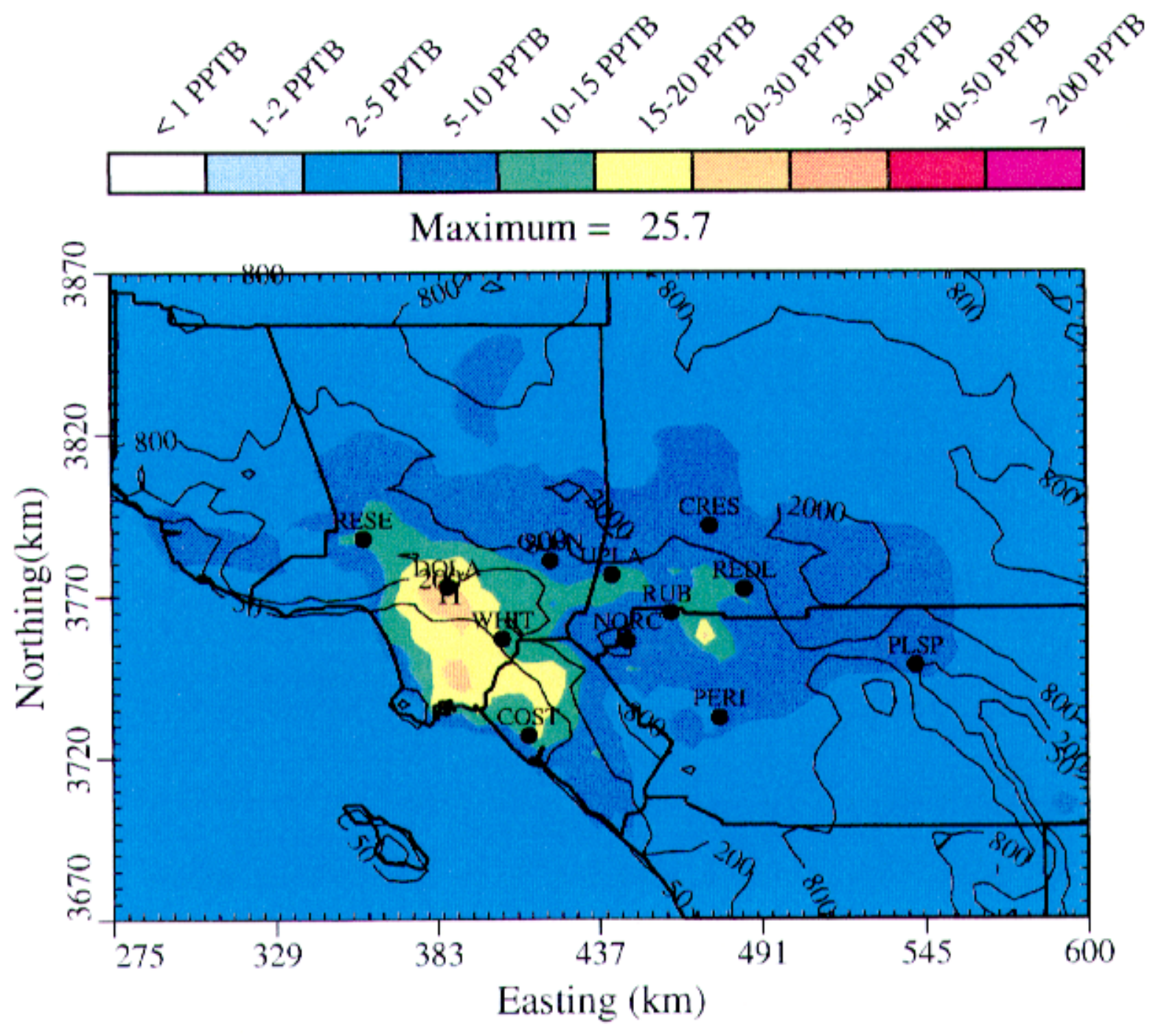

Figure 5-20b. Daily maximum hourly benzene predicted by CALGRID for 28 August 2007 - RFG fueled vehicle (RFG) scenario with SAPRC 90/93. 


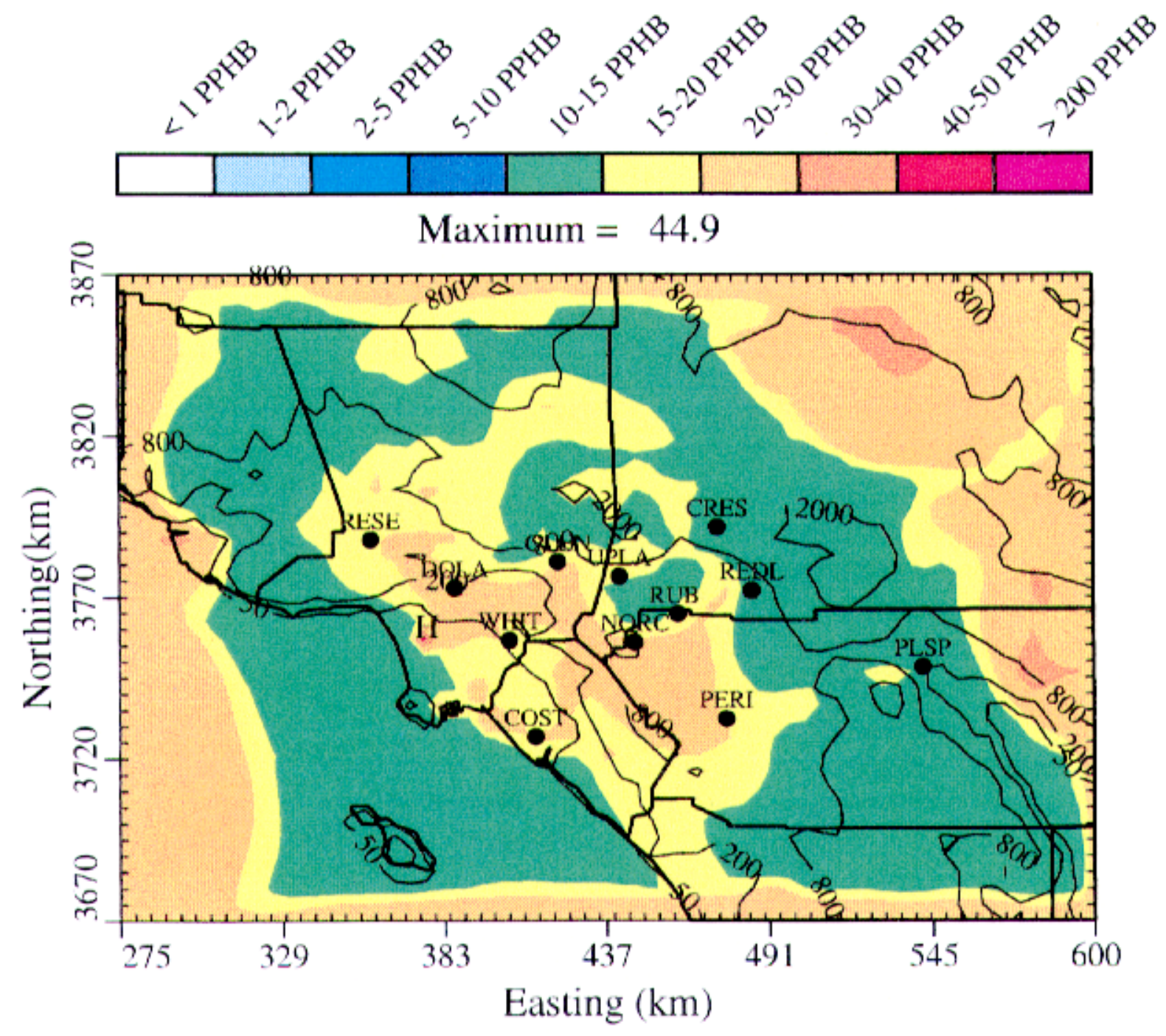

Figure 5-21a. Daily maximum hourly butadiene predicted by CALGRID for 27 August 2007 - RFG fueled vehicle (RFG) scenario with SAPRC 90/93. 


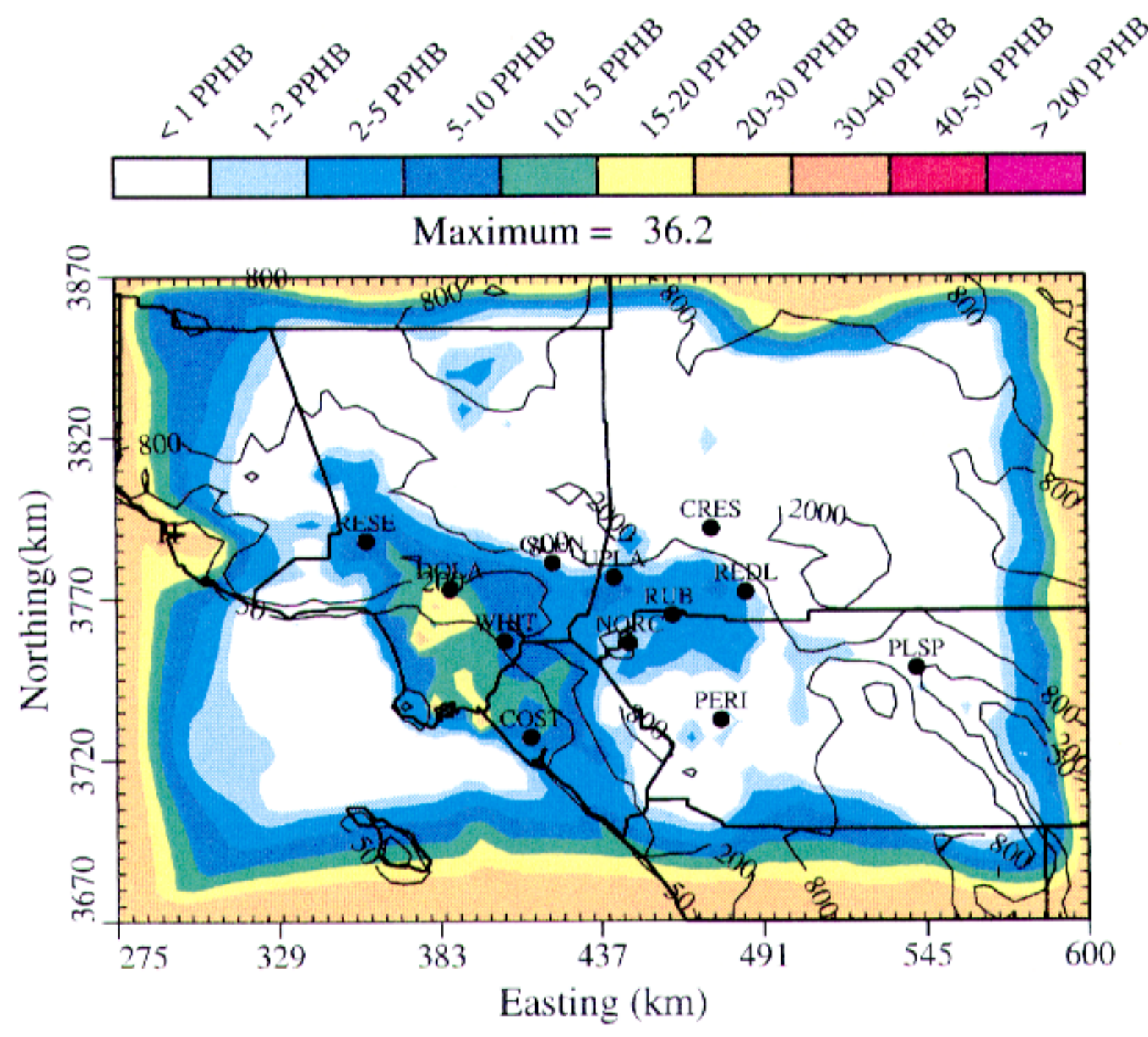

Figure $5-21$ b. Daily maximum hourly butadiene predicted by CALGRID for 28 August 2007 - RFG fueled vehicle (RFG) scenario with SAPRC 90/93. 


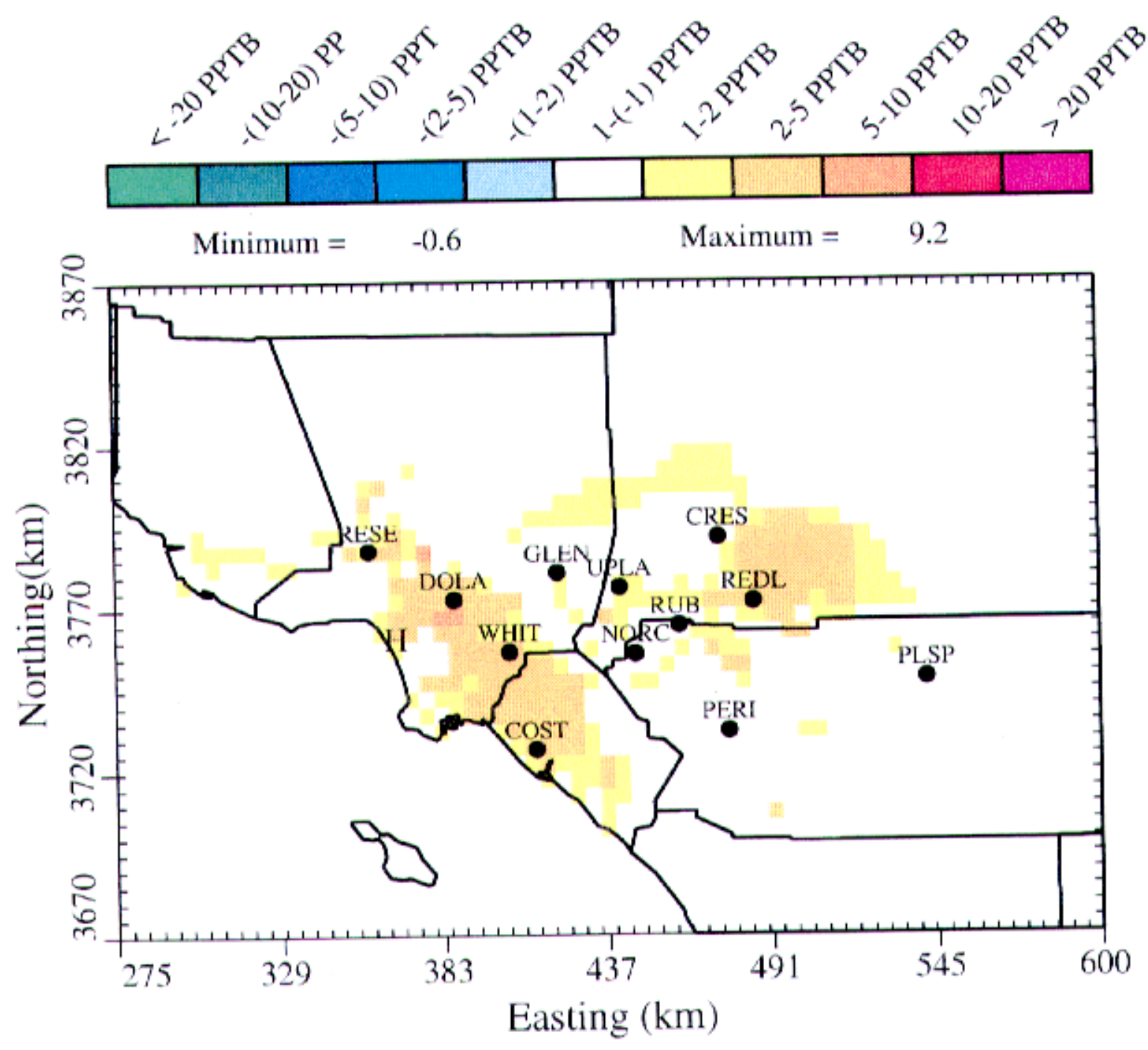

Figure 5-22a. Daily maximum 1-hr HCHO during August 272007 - RFG w SAPRC90/93 minus S1 w SAPRC90/93. 


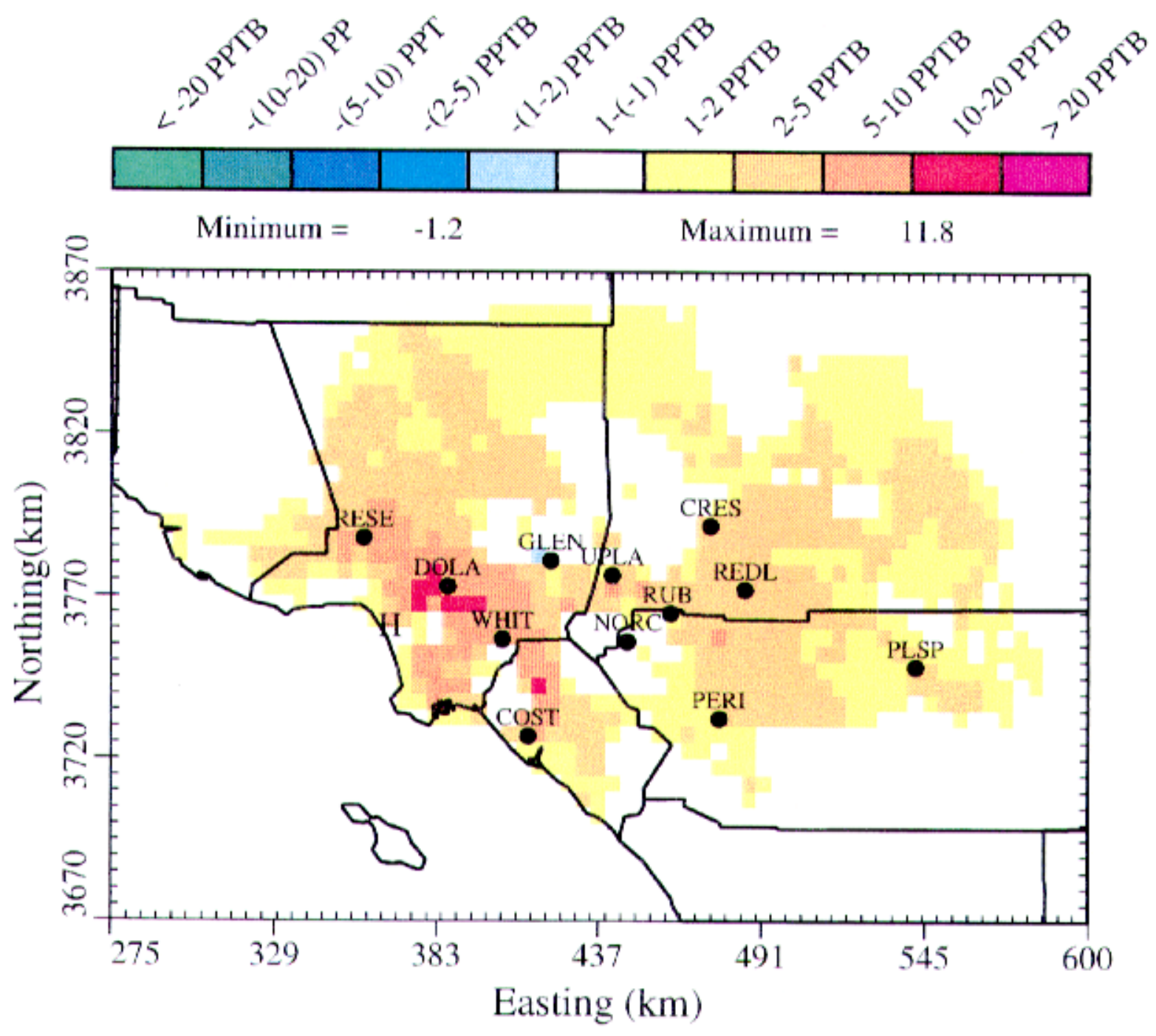

Figure 5-22b. Daily maximum 1-hr HCHO during August 282007 - RFG w SAPRC90/93 minus S1 w SAPRC90/93. 


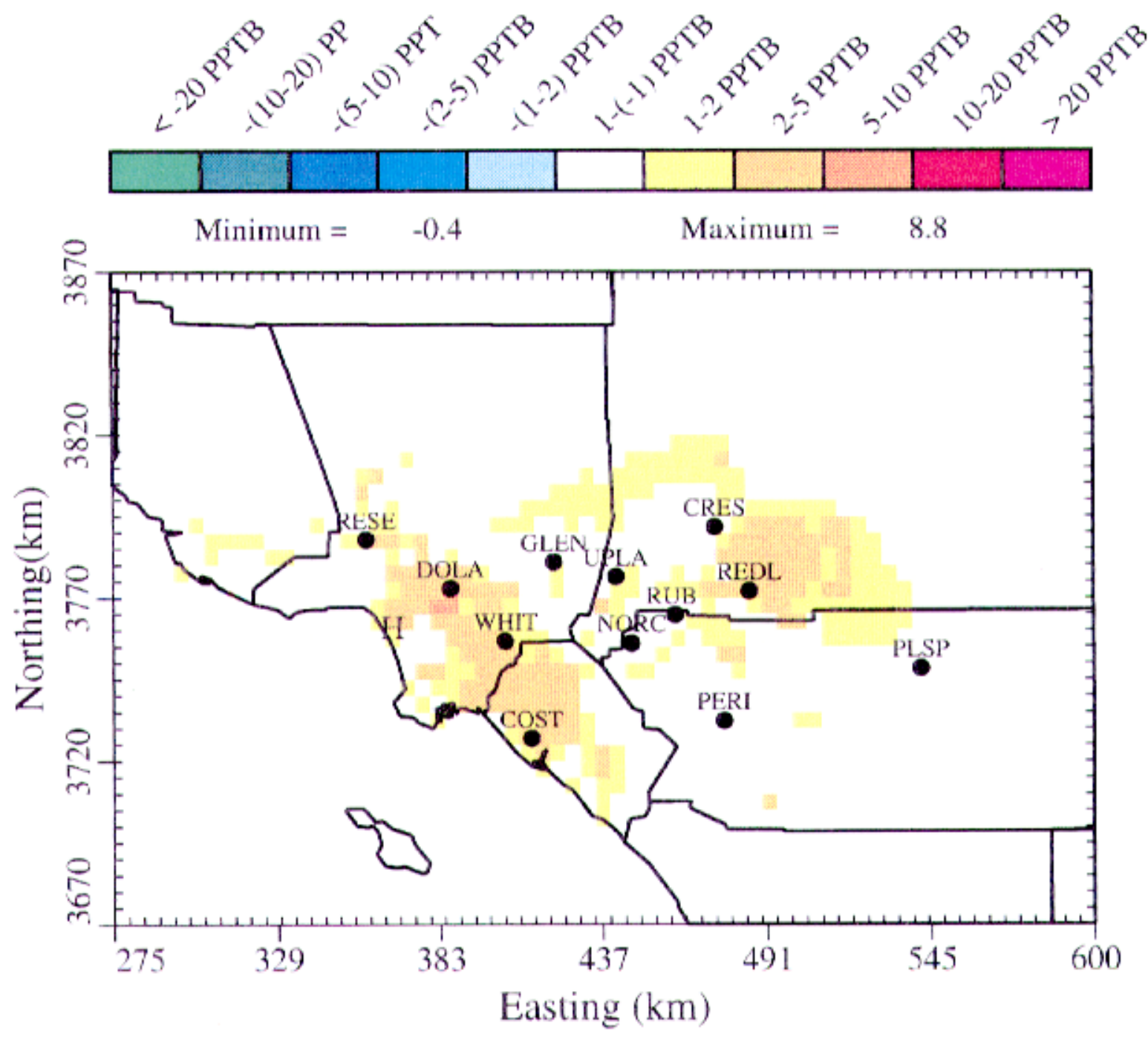

Figure 5-23a. Daily maximum 1-hr $\mathrm{HCHO}$ during August 272007 - RFG w SAPRC90/93 minus CNG w SAPRC90/93 


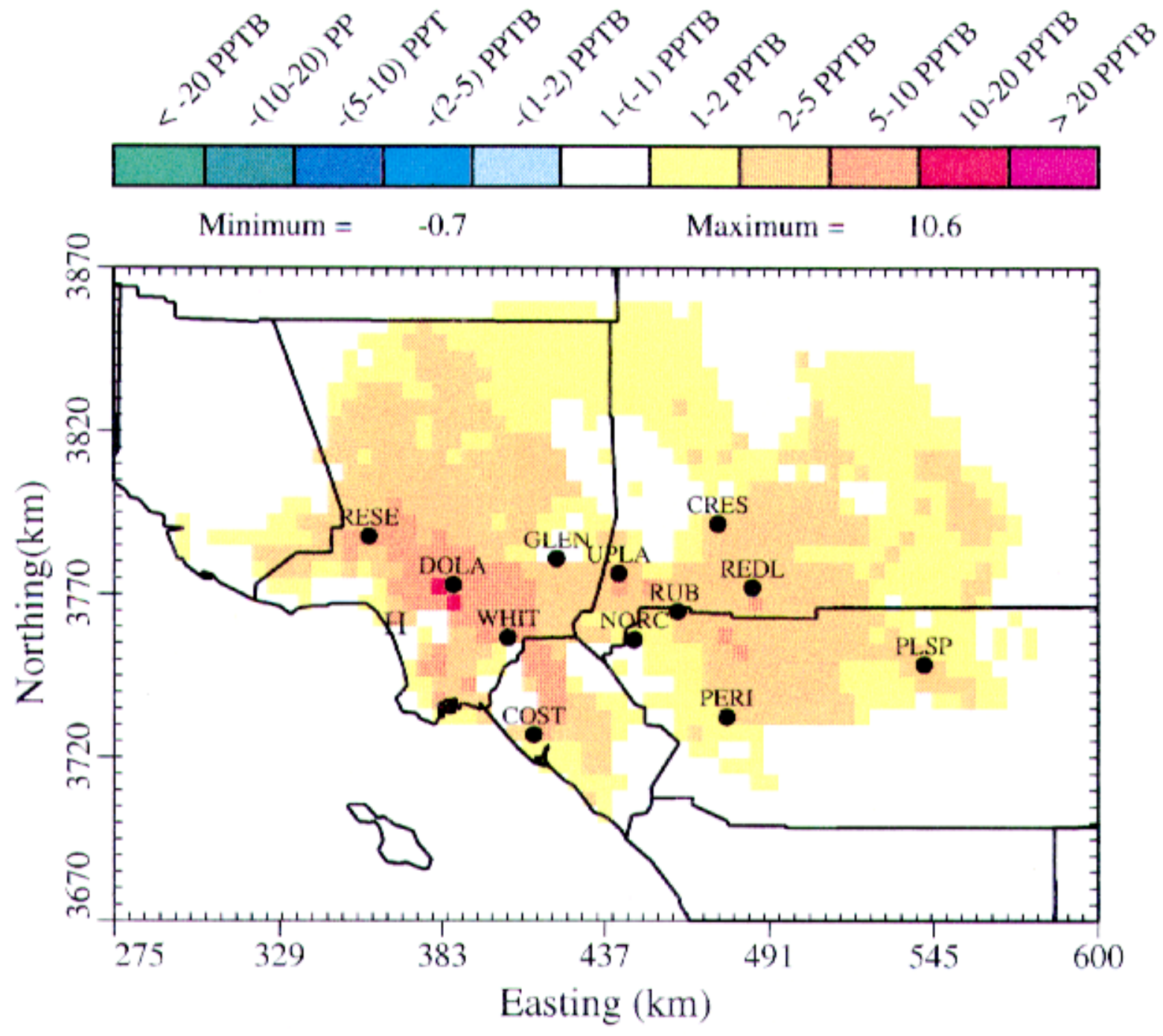

Figure 5-23b. Daily maximum 1-hr $\mathrm{HCHO}$ during August 282007 - RFG w SAPRC90/93 minus CNG w SAPRC90/93 


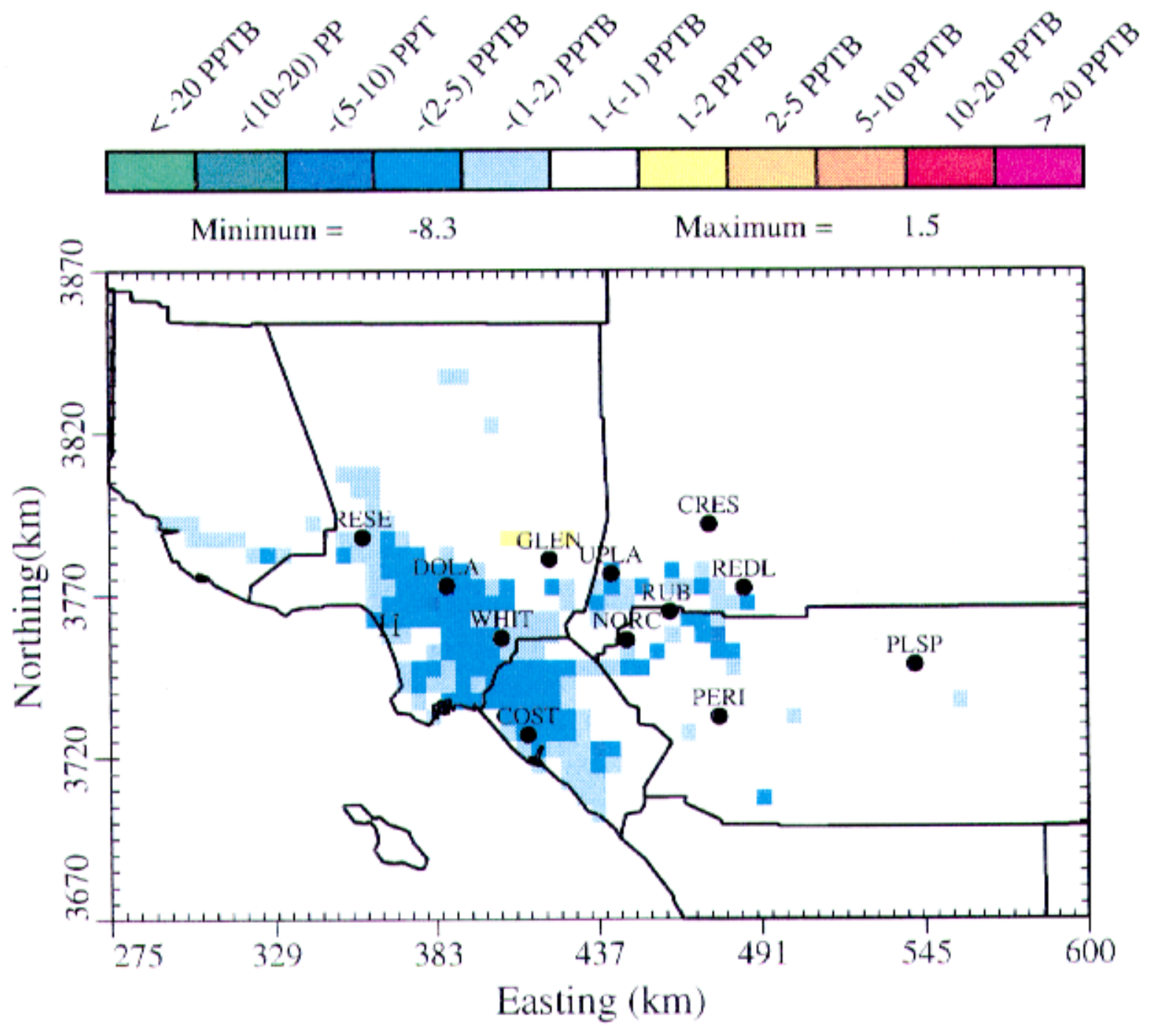

Figure 5-24a. Daily maximum 1-hr HCHO during August 272007 - RFG w SAPRC90/93 minus M85 w SAPRC90/93. 


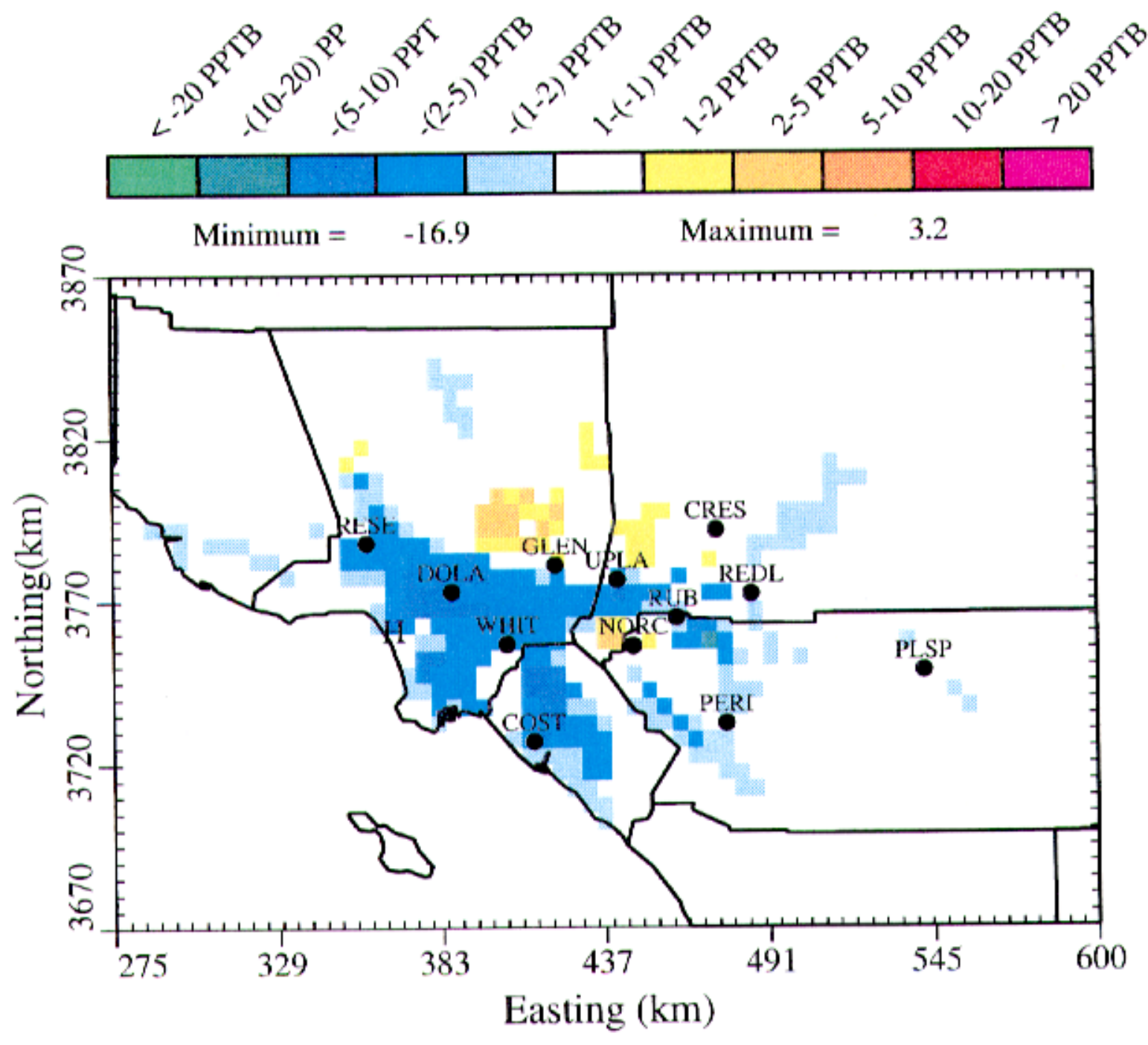

Figure 5-24b. Daily maximum 1-hr HCHO during August 282007 - RFG w SAPRC90/93 minus M85 w SAPRC90/93. 


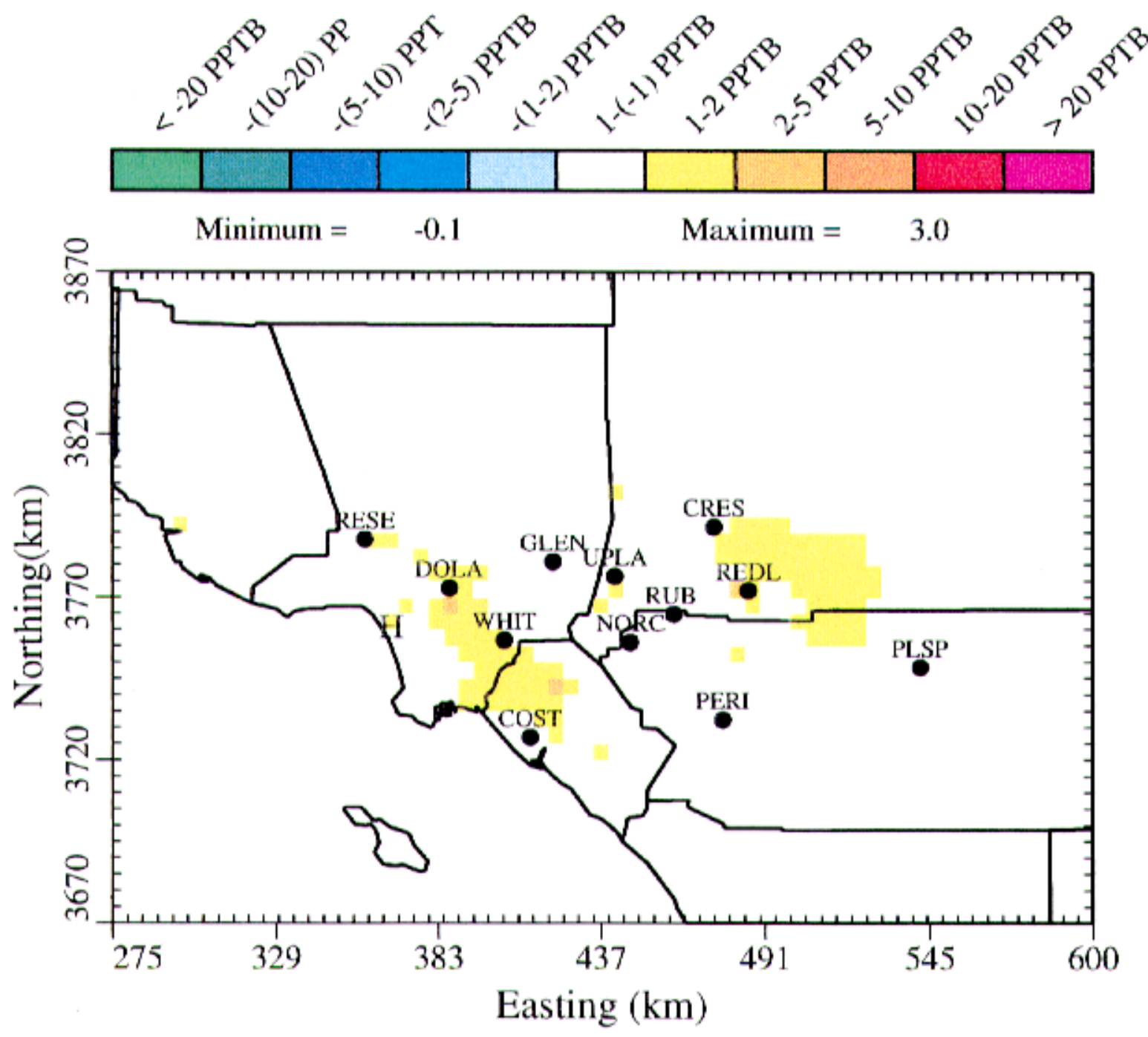

Figure 5-25a. Daily maximum 8-hr $\mathrm{HCHO}$ during August 272007 - RFG w SAPRC90/93 minus CNG w SAPRC90/93 


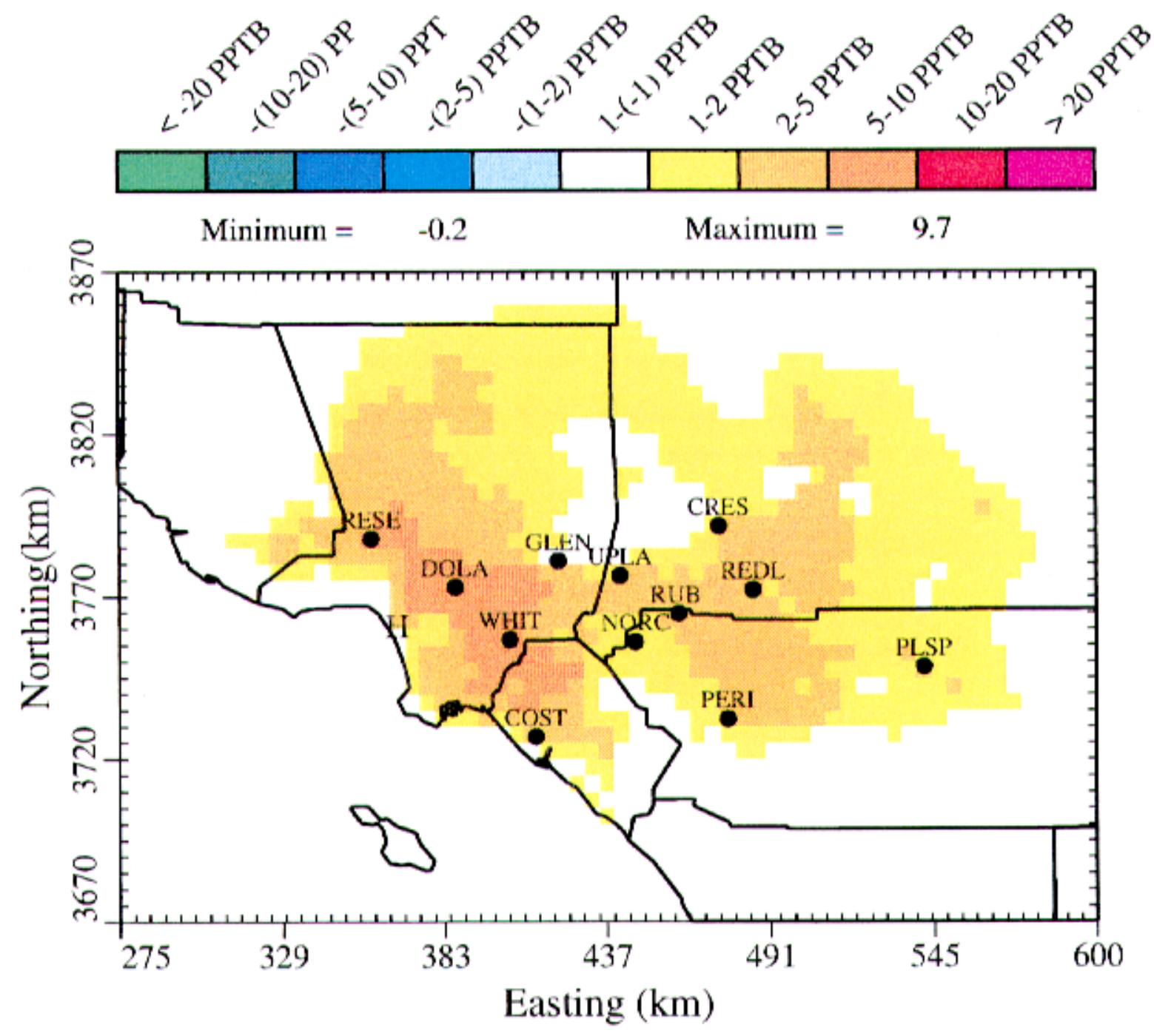

Figure 5-25b. Daily maximum 8-hr HCHO during August 282007 - RFG w SAPRC90/93 minus CNG w SAPRC90/93 


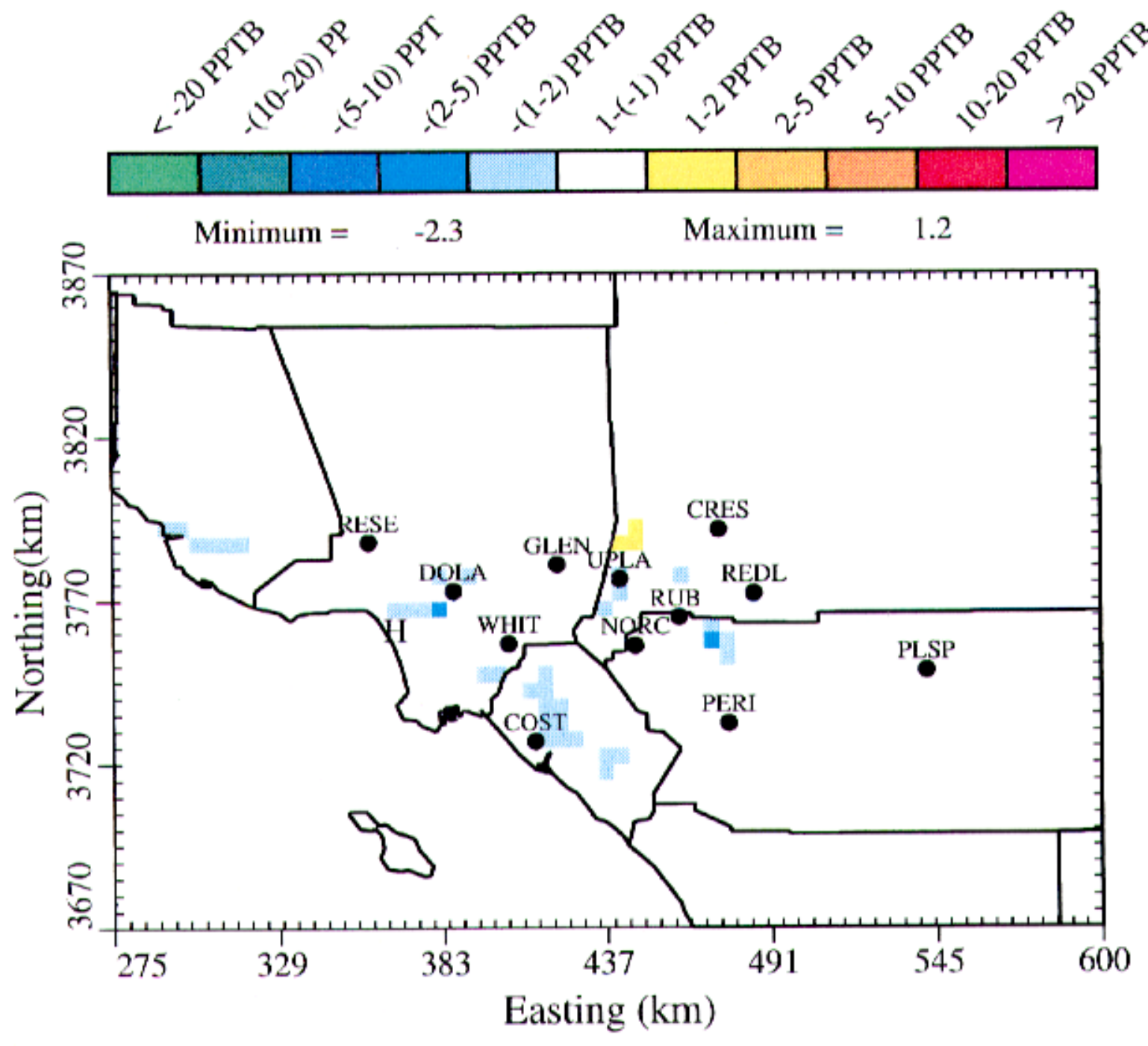

Figure 5-26a. Daily maximum 8-hr HCHO during August 272007 - RFG w SAPRC90/93 minus M85 w SAPRC90/93. 


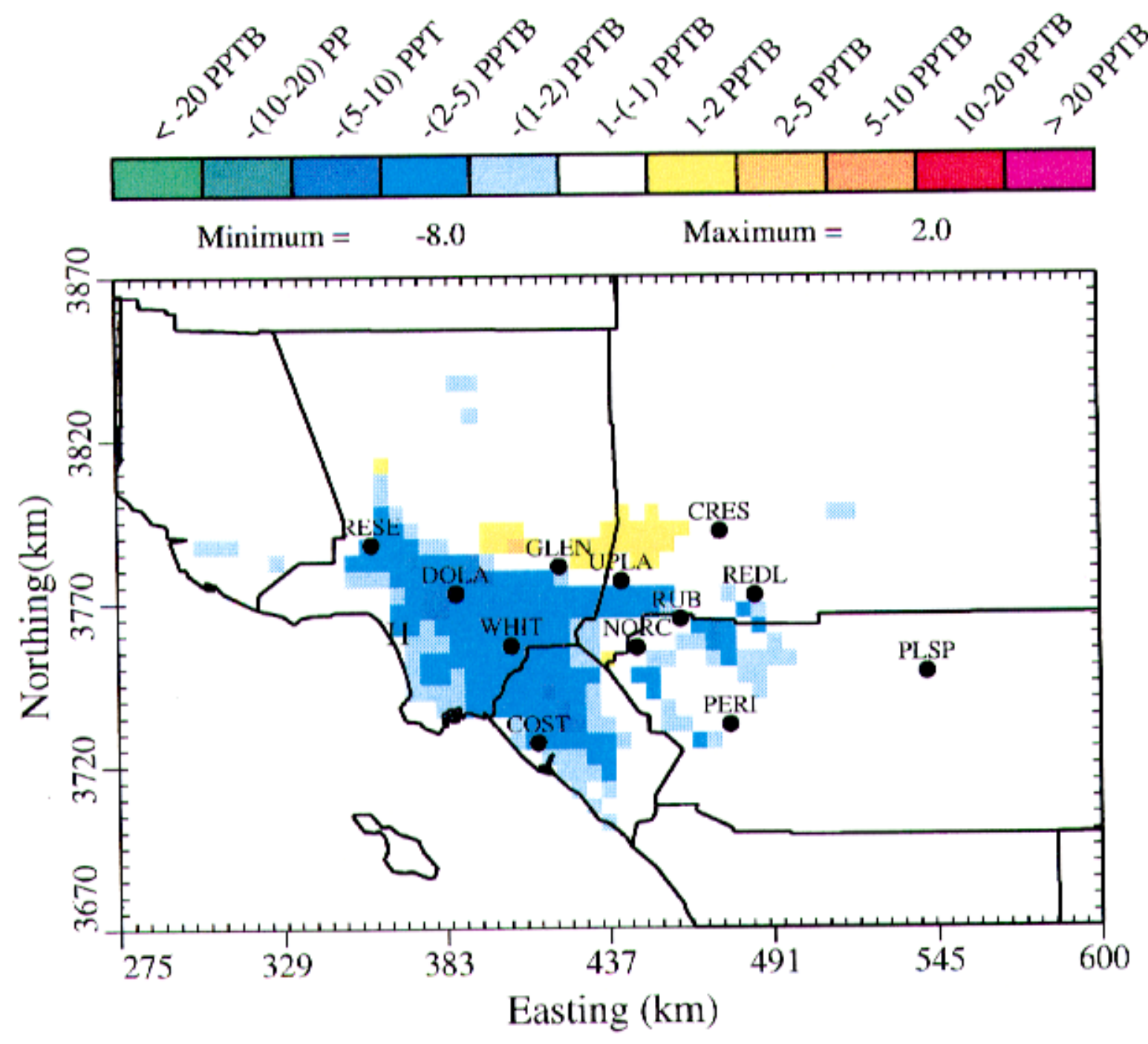

Figure 5-26b. Daily maximum 8-hr HCHO during August 282007 - RFG w SAPRC90/93 minus M85 w SAPRC90/93. 


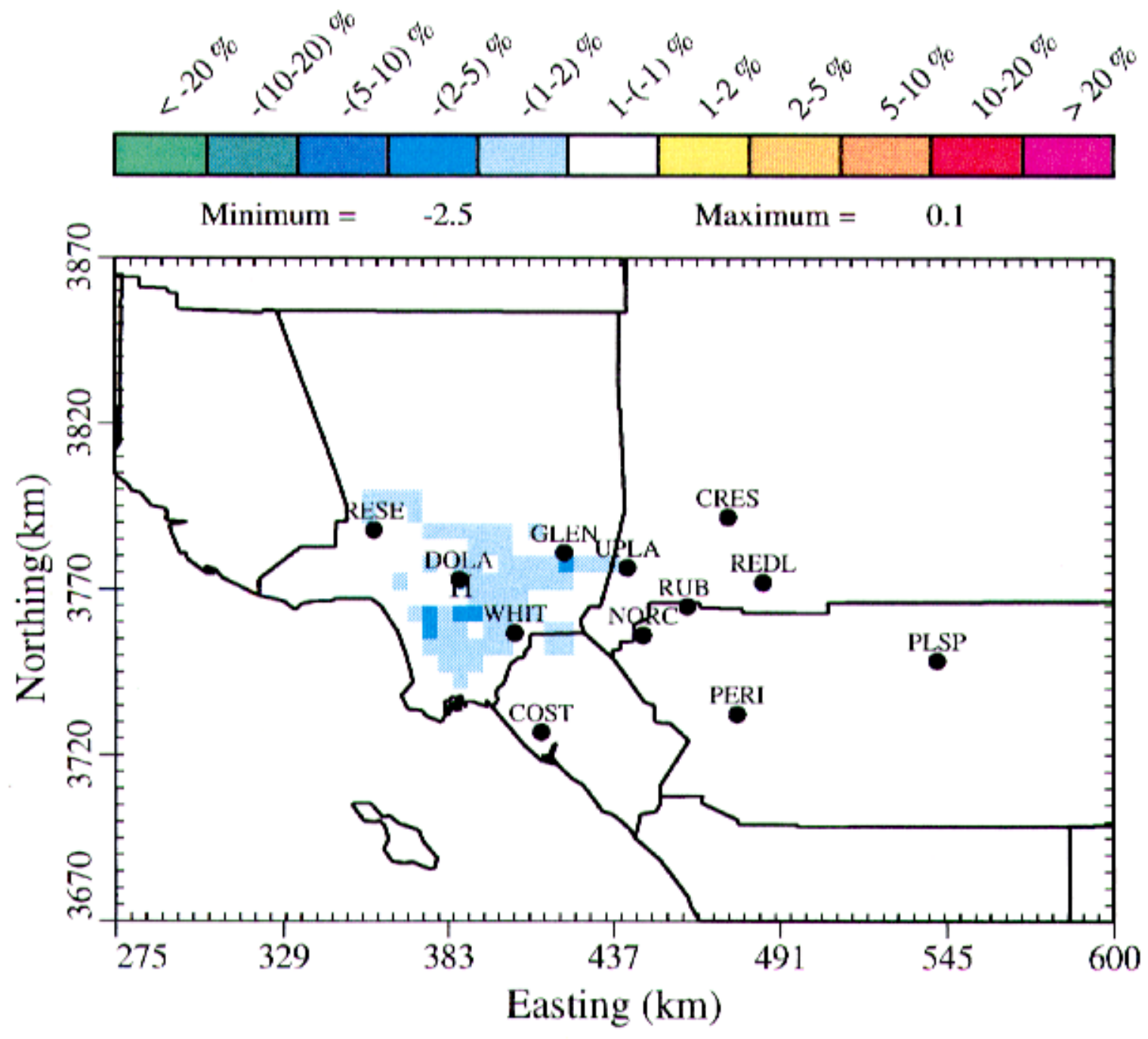

Figure 5-27a. Cumulative 1-hr HCHO exposure percentile differences during August 272007. RFG w SAPRC90/93 minus CNG w SAPRC90/93. 


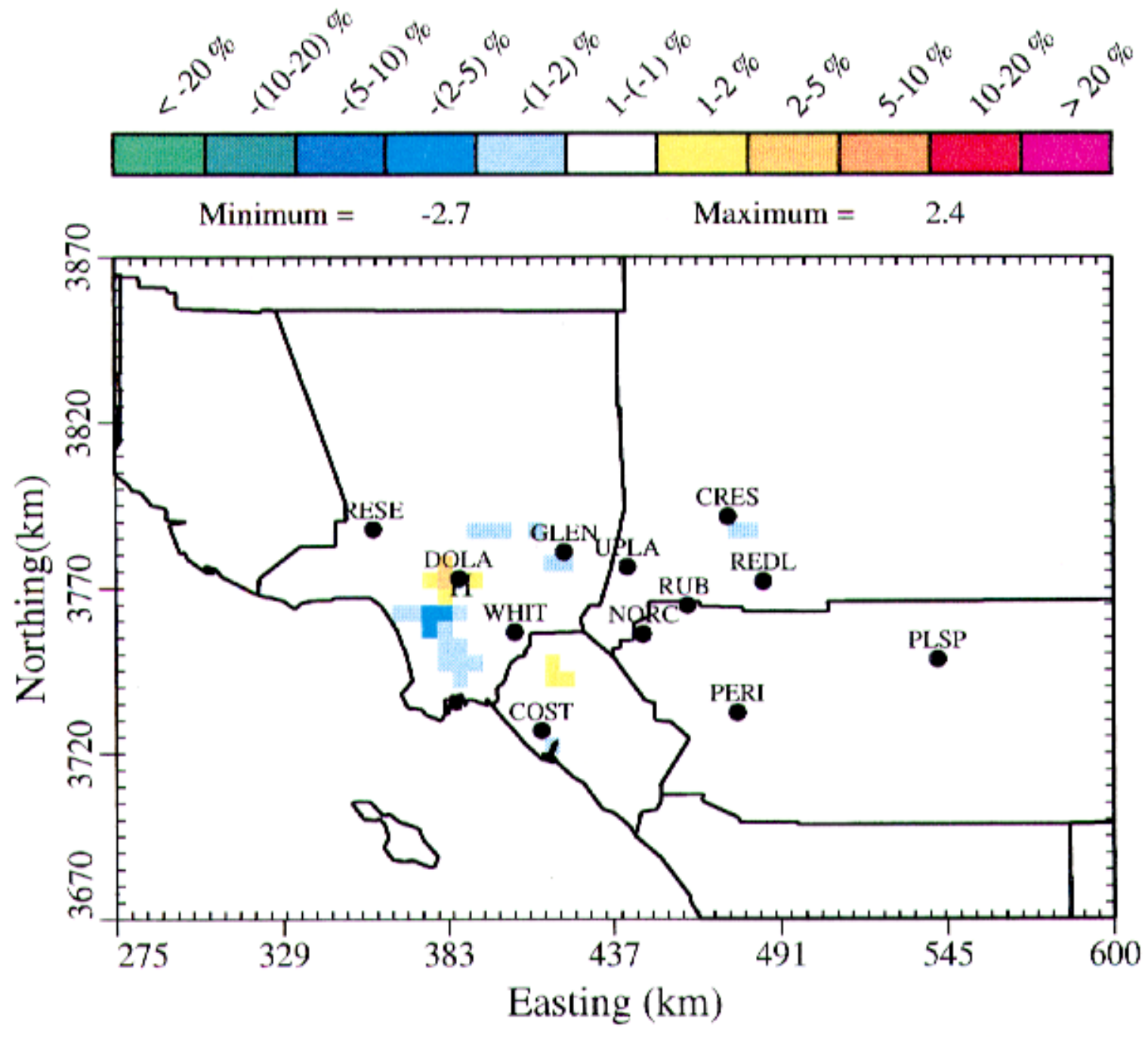

Figure 5-27b. Cumulative 1-hr HCHO exposure percentile differences during August 282007. RFG w SAPRC90/93 minus CNG w SAPRC90/93. 


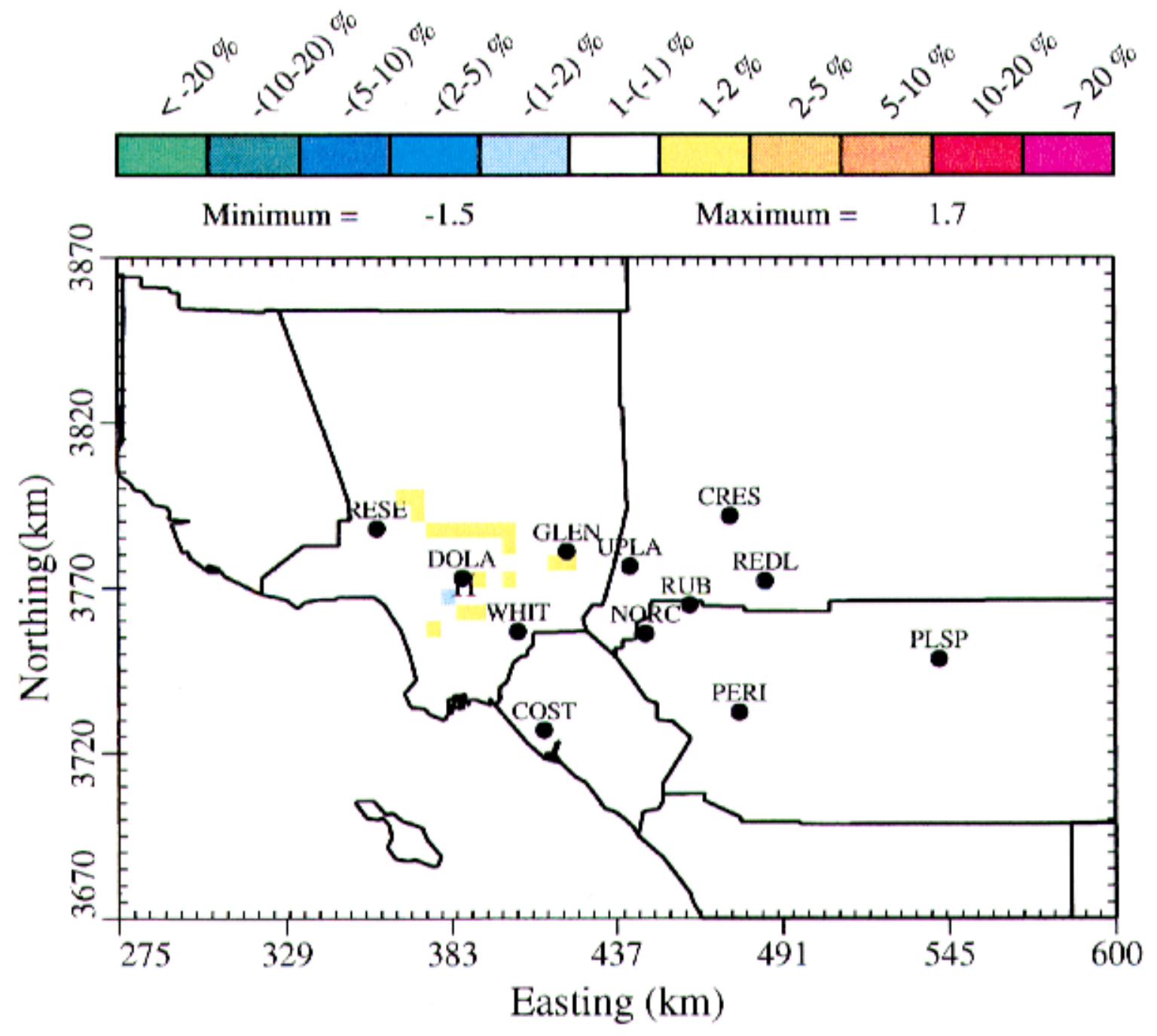

Figure 5-28a. Cumulative 1-hr HCHO exposure percentile differences during August 272007. RFG w SAPRC90/93 minus M85 w SAPRC90/93. 


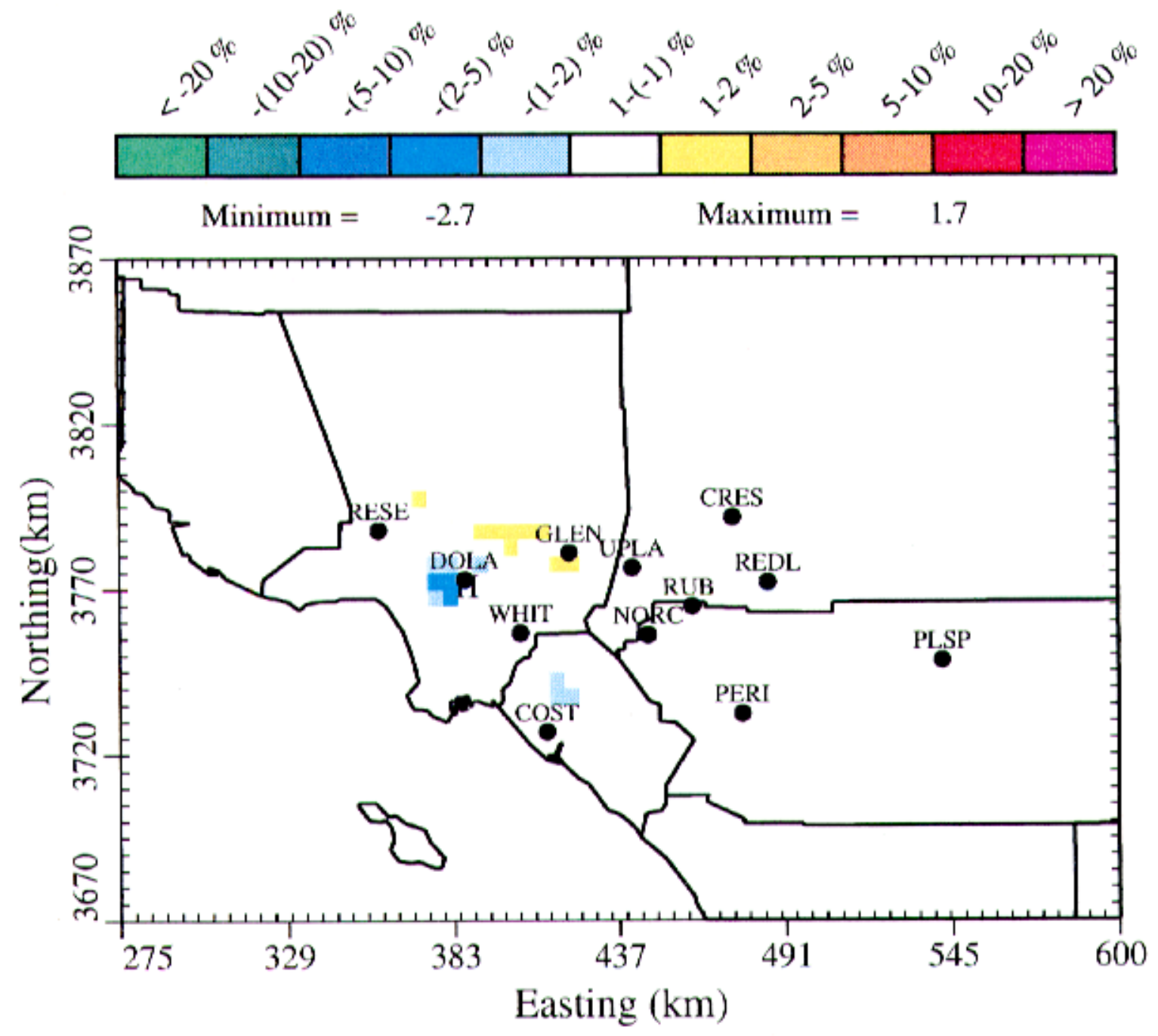

Figure 5-28b. Cumulative 1-hr HCHO exposure percentile differences during August 282007. RFG w SAPRC90/93 minus M85 w SAPRC90/93. 


\subsection{Summary and Conclusions}

The CALGRID photochemical modeling simulations for Los Angeles described in this report include results from the following technical tasks:

- Revision of the SAPRC90 chemistry to a version of the SAPRC93 chemistry plus the addition of toxic species BENZ and BUDI

- Development of a meteorological input data set sufficient to exercise the CALGRID model in the Los Angeles modeling domain

- Conversion of emission and initial and boundary condition files used for the UAM-IV CB-4 modeling exercises into suitable CALGRID SAPRC90 model input files

- CALGRID quality assurance model evaluation and comparison simulations for the 1987 base year using both CB-4 and SAPRC90 chemical mechanisms

- Exercise of CALGRID with both SAPRC90 and SAPRC90/93 chemical mechanisms for the four 2007 emission scenarios: no light- or medium-duty vehicle emissions; emissions from the use of RFG; emissions from the use of CNG; and emissions from the use of M85

- Analysis of the modeling results for (1) ozone peak ozone concentration impacts, (2) population exposures to exceedance concentrations, and (3) ozone sensitivity to emissions

- Analysis of the peak concentrations and exposures of the toxic compounds $\mathrm{HCHO}, \mathrm{CCHO}$, BENZ, and BUDI.

A variety of conclusions can be drawn from the results of the present study, including results from chemical mechanism testing; development of meteorological inputs; model evaluation and comparison; and the analyses of the impacts of the emission scenarios. The major findings of each type are next.

\subsection{Results of Modifications of the SAPRC Chemical Mechanism}

The SAPRC90 chemistry was upgraded to a preliminary version of SAPRC93 (denoted SAPRC90/93) and the toxic species BENZ and BUDI are added as "ghost" species which do not perturb the underlying chemical scheme. The results of testing indicate that the SAPRC90 chemistry destroys BENZ and BUD1 at a rate slower than CB-4. A side-by-side comparison of CB-4 and SAPRC90 chemistry indicates that CB-4 produces more ozone and $\mathrm{HCHO}$ but produces nearly equivalent maximum hydroxyl radical concentrations. The differences in the HO. destruction rate of VOC's lie in the fact that hydroxyl radical concentrations peak early with SAPRC90 and fall to lower values than with CB-4 during the remainder of each day (e.g., see Figure 2-3). The changes in the chemical input parameters for SAPRC90/93 included newer photolysis rates, newer rate constants for some reactions, and changes in the hydroxyl radical yield for ozone-olefin reactions. Numerical box model testing indicated that the resulting changes increased the amount of ozone and hydroxyl radical formation. Peak ozone concentrations increased by a few percent. 


\subsection{Results from CALGRID Model Input Preparation}

Conversion of the CB-4 species to SAPRC90/93 species was done according to a carbon mass conservative conversion scheme developed by Lurmann et al. (1991) for the two alkane, two aromatic, and three alkene lumping used in the present study. The largest model input preparation effort was in developing a suitable three-dimensional set of hourly meteorological fields. This was done using the CALMET diagnostic meteorological model (Scire et al. 1995) and the SCAQS database provided by CARB (Jackson 1998). The development of CALMET meteorological files for CALGRID required considerable adjustment of how meteorological data was processed (e.g., calms) and in the selection of parameters that represented the best "average" over the entire domain (e.g., the site for the domain mean wind).

The resulting meteorological fields indicate that (on both days) sites in the foothills received by late morning emissions that originated from nearby sources during mid-morning $(0700-0900$ LST). During the afternoon the trajectories indicated a more rapid transport of air out from the foothill sites into the mountains and down the passes into the desert than occurred earlier in the day. The shoreline sites are expected to remain rather clean because of the air trajectories coming in off the ocean. The strongest winds in the basin occur at the shoreline where a sea breeze was evident. The meteorology also indicated that within the Los Angeles basin, the wind speeds in the mixed layer did not increase systematically with height above the ground, requiring that mixed layer average wind speeds be reduced from surface values. The presence of an elevated subsidence inversion around $1250 \mathrm{~m}$ required an exploration of the maximum mixed layer height since convective mixing height algorithms produce estimates of over $2200 \mathrm{~m}$ over much of the eastern portion of the domain. A limitation of the mixing height to $1250 \mathrm{~m}$ represented a basinwide average compromise between the inversion intersection of terrain and the convective erosion and penetration of such an inversion. The limited mixing height contributed $20-40 \mathrm{ppb}$ to the relatively large ozone concentrations predicted by CALGRID around the highest terrain.

\subsection{Results from CALGRID Model Quality Assurance Evaluation Exercises}

For base year simulations, CALGRID was exercised without toxic species using the 1987 baseyear emissions developed by SCAQMD for the 1994 AQMP. CALGRID was exercised using the same input meteorological data using both CB-4 and SAPRC90. The predicted surface ozone and HCHO concentrations for the UAM-IV CB-4 exercise and the two CALGRID exercises were compared with observations at a number of sites throughout the modeling domain. The daily maximum concentrations predicted using CB-4 were examined, and CALGRID was found to produce significantly more ozone and higher peak ozone predictions ( $>50 \mathrm{ppb}$ higher $)$ than the UAM-IV for 27 - 28 August. The pattern of maximum concentrations, while similar in some features (e.g., low within basin predicted ozone concentrations), was significantly different in many other respects. For example, CALGRID predicted daily maximum concentrations which exceed the $120 \mathrm{ppb}$ standard over a much larger region to the east and north of the basin. The spatial pattern of exceedance concentrations followed the highest terrain in San Bernardino County.

The higher daily maximum ozone concentrations resulted in many stations having smaller ozone under-estimations for CALGRID than for UAM-IV. The basin-wide average ozone bias of CALGRID is of the order $30 \%$ lower on 27 August and 18\% lower on 28 August compared to UAM-IV. Time series of sites at several points in the basin demonstrated a better tracking of the daytime maximum concentrations by CALGRID than by UAM-IV predictions (which were coplotted). The use of SAPRC90 rather than CB-IV resulted in significantly lower peak 
concentrations. In many cases, CALGRID with SAPRC90 chemistry performed only marginally better than UAM-IV with CB-4 for predicting the daily maximum concentrations.

The differences in the predicted peak ozone concentrations between UAM-IV and CALGRID underscore the importance of the spatial characteristics of the wind fields and mixing heights in determining the pattern of peak daily maximum ozone. Even small, transient features such as the divergence-convergence pattern in the Los Angeles basin can have significant influence on predicted concentrations at some sites, as demonstrated by monitors near the Orange County boundary (Whittier and Anaheim sites).

The differences in peak ozone prediction for the base year due only to CB-4 versus SAPRC90 chemistry differences are of the same order as those arising from the use of UAM-IV versus CALGRID. What fraction of the UAM-IV versus CALGRID differences can be attributed to the different input meteorological fields remains unknown and cannot as a practical matter be separated from basic differences in model design (i.e., variable layer versus fixed layer heights).

\subsection{Results from Comparisons of CALGRID Predicted Future Year Ozone and Toxic Compound Concentrations}

The CALGRID modeling results show that for ozone, all fuels produce an incremental ozone field that is similar, with a pattern of two areas of peak ozone increment: one over the eastern portion of the basin and foothills, and another farther from the basin in the mountainous areas of San Bernardino County. The peak over the basin is an area of ozone "benefit" for all fuels, with motor vehicle emissions producing reductions in ozone. All fuels produce ozone increases in the second area farther downwind in San Bernardino County. The CNG scenario produces the smallest increases of ozone in the San Bernardino County area, but also produces the smallest reduction of ozone in the eastern portion of the basin. The M85 scenario produces the largest reductions of ozone in the eastern portion of the basin and somewhat smaller increases in the San Bernardino County area than the RFG scenario. The spatial pattern and the relative impacts of each fuel remain the same when 8 -hr averages are examined.

The CNG scenario produces the highest peak ozone sensitivities of the three fuels examined. The $\mathrm{CNG}$ scenario has an emission $\mathrm{VOC} / \mathrm{NO}_{\mathrm{X}}$ ratio of 7:54 by tonnage. The domination of the emissions by $\mathrm{NO}_{\mathrm{X}}$ on a per ton basis is a likely explanation for the larger peak ozone sensitivity. Both M85 and RFG have the same overall peak ozone sensitivity, however, when the metric was changed to examine the peak increase and decrease (incremental change), it was found that M85 scenario emissions produced significantly greater ozone decreases.

Relative to RFG, the use of CNG produces net ozone exposure benefits (decreases) for 1-hr average concentrations, but net detriments for 8-hr average concentrations. The use of M85 as an alternative fuel results in net ozone exposure benefits relative to RFG for both 1-hr and 8-hr average concentrations.

For all four toxic compounds, the CNG scenario produces the smallest incremental increases in daily maximum concentrations. For three compounds (CCHO, BENZ, and BUDI), the RFG scenario produces the largest incremental increases. The 8-hr average concentration increments are consistent with those of the 1-hr averages. The concentration increment of HCHO varies in a different manner from the other toxic species. The largest concentration increases are associated with the use of M85, because the emissions of MEOH from M85 fueled vehicles can be 
converted to HCHO. The largest $\mathrm{HCHO}$ increases are found across the Los Angeles basin, especially in the vicinity of DOLA.

Relative to RFG, the use of M85 does not produce significantly larger HCHO exposures.

Significant changes occur in only a few cells. Increases in some area are offset by decreases in others. Relative to RFG, the CNG fuel scenario generally produces benefits (decreases) in the exposure to toxic chemicals. The degree of net benefit is rather small (a few percent), reflecting the dominant contribution of non-mobile emission sources. 


\subsection{REFERENCES}

Balentine, H., N. Dickson, M.E. Fernau, J. Killus, G. Moore, W.R. Oliver, and V. Sadeghi (1997a). Urban Airshed Modeling of Air Quality Impacts of Alternative Transportation Fuel Use in Los Angeles and Atlanta. NREL/TP-YCC-05-14072. National Renewable Energy Laboratory, Golden, CO. Work performed by Radian Corporation, Sacramento, CA and Earth Tech, Inc., Concord, MA.

Balentine, H., M.E. Fernau, J. Killus, G. Moore, and V. Sadeghi (1997b). Urban Airshed Modeling of Air Quality Impacts of Alternative Transportation Fuel Use in Los Angeles and Atlanta. Appendix C: Emission Modeling Document. NREL/TP-YCC-05-14072. National Renewable Energy Laboratory, Golden, CO. Work performed by Radian Corporation, Sacramento, CA and Earth Tech, Inc., Concord, MA.

Balentine, H., M.E. Fernau, J. Killus, G. Moore, and V. Sadeghi (1997c). Urban Airshed Modeling of Air Quality Impacts of Alternative Transportation Fuel Use in Los Angeles and Atlanta. Appendix B: Photochemical Modeling Protocol. NREL/TP-YCC-05-14072. National Renewable Energy Laboratory, Golden, CO. Work performed by Radian Corporation, Sacramento, CA and Earth Tech, Inc., Concord, MA.

Brocchini, M., M. Wurtele, G. Umgiesser, and S. Zecchetto (1995). "Calculation of a MassConsistent Two-Dimensional Wind Field with Divergence Control." J. of Applied. Meteor. 34(11): 2543-2555.

Cantrell C.A., J.A. Davidson, A.H. McDaniel, R.E.Shetter, and J.G. Calvert (1990).

"Temperature - Dependent Formaldehyde Cross Sections in the Near Ultraviolet Spectral Region.” J. Phys. Chem. 94, 3902-3908.

CARB (1992). Technical Guidance Document: Photochemical Modeling. California Resources Board, Sacramento, CA.

Carter, W. (1996). “Condensed Atmospheric Photooxidation Mechanism for Isoprene.” Atmos. Environ. 30(24):4275-4290.

Carter, W. (1995). "Computer Modeling of Environmental Chamber Measurements of Maximum Incremental Reactivities of Volatile Organic Compounds.” Atmos. Environ. 29 (18):2513-2527.

Carter, W. (1994). "Development of Ozone Reactivity Scales for Volatile Organic Compounds." J. Air \& Waste Manage. Assoc. 44: 881-889.

Carter, W. (1990). “A Detailed Mechanism for the Gas-Phase Atmospheric Reactions of Organic Compounds." Atmos. Environ. 24a:481-518. 


\subsection{REFERENCES}

Eisele, F., G. Mount, D. Tanner, A. Jefferson, R. Shetter, J. Harder, and E. Williams (1997). "Understanding the Production and Interconversion of the Hydroxl Radical During the Tropospheric OH Photochemistry Experiment.” J. of Geophys. Res., 102(D5):64576465.

Jackson, B. (1998). Personal communication. California Air Resources Board, Sacramento, CA.

Killus , J. (1996). Development and Testing of a Toxics Version of the CB-4 Mechanism. Technical Memorandum to Radian Corporation under contract NREL/TP-YCC-0514072. National Renewable Energy Laboratory, Golden, CO.

Kumar, N., and F.W. Lurmann (1995). Development of the Flexible Chemical Mechanism Version of the Urban Airshed Model. Sonoma Technology, Inc. Santa Rosa, CA.

Kumar, N.; A.G. Russell, T.W. Tesche, and D.E McNally (1994). "Evaluation of CALGRID Using Two Different Ozone Episodes and Comparison to UAM Results." Atmos. Environ. 28(17):2823-2845.

Lurmann F., M. Gery, and W. Carter (1991). Implementation of the 1990 SAPRC Chemical Mechanism in the Urban Airshed Model. STI-99290-1164-FR. Sonoma Technology, Inc., Santa Rosa, CA.

Moore, G., M. Fernau, and R. Londergan (1998). Urban Airshed Modeling of Air Quality Impacts of Alternative Transportation Fuel Use in Los Angeles and Atlanta - M85 Fuel Use. Final Report to the National Renewable Energy. Laboratory (NREL), Contract YCC-05-14072-01. Golden, CO 80401.

Rogers, J.D. (1990). "Ultraviolet Absorption Cross Sections and Atmospheric Photodissociation Rate Constants of Formaldehyde." J. Phys. Chem. 90, 4011-4015.

SCAQMD (1994). 1994 Air Quality Management Plan: Meeting the Clean Air Challenge. South Coast Air Quality Management District, Diamond Bar, CA.

Scire, J.S., E.M. Insley, R.J.; Yamartino, and M.E. Fernau (1995). A User's Guide for the CALMET Meteorological Model. Doc. No. 1406. Earth Tech, Inc., Concord, MA.

Scire, J.S., and R.J. Yarmartino (1989). CALGRID: A Photochemical Grid Model Volume II: User's Guide. Sigma Research Corporation, Concord, MA.

van Ulden, A.P., and A.A.M. Holtslag (1985). "Estimation of Atmospheric Boundary Layer Parameters for Diffusion Applications.” J. Clim. and App. Meteor., 24:1196-1207.

Yamartino, R.J., J.S., Scire, G.R., Carmichael, and Y.S Chang (1992). "The CALGRID Mesoscale Photochemical Grid Model -- I. Model Formulation." Atmos. Environ., 26A:1493-1512. 


\subsection{REFERENCES}

Yamartino, R.J., J. Scire, G. Moore, D. McNaughton, M. Fernau (1996) "Development of the Regional CALGRID Ozone Model." AWMA Presentation, $89^{\text {th }}$ Annual Meeting, June 23028, 1996, Earth Tech, Inc. Concord, MA. 
Appendix A

Listing of CALMET Input File 
NREL: LOS ANGELES CALMET RUN -- 27-28 August 1987; SCAQS Study data $65 \times 405 \mathrm{~km}$ meteorological grid -- orginal calmetup with reduced winds corrected wind speeds - terrain tracking isentropes

Met. stations used: 47 surface, 4 upper air, 0 precip., 1 overwater

- Run title (3 lines) -..--

CALMET MODEL CONTROL FILE

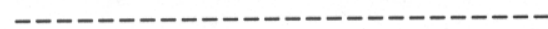

INPUT GROUP: 0 -- Input and Output File Names

\begin{tabular}{|c|c|c|c|}
\hline Default Name & $\begin{array}{l}\text { Type } \\
----\end{array}$ & File Name & \\
\hline GEO.DAT & input & $!$ GEODAT $=$ GEO. $\mathrm{DAT}$ & $!$ \\
\hline SURF.DAT & input & ! SRFDAT=SURF.OUT & $!$ \\
\hline PRECIP.DAT & input & * $\mathrm{PRCDAT}=$ & * \\
\hline MM4 . DAT & input & * $\mathrm{MM} 4 \mathrm{DAT}=$ & * \\
\hline WT.DAT & input & * WTDAT $=$ & * \\
\hline CALMET.LST & output & ! METLST=C28CX16.LST & $!$ \\
\hline CALMET. DAT & output & $!$ METDAT $=\mathrm{C} 28 \mathrm{CX} 16 . \mathrm{DAT}$ & $!$ \\
\hline CLOUD.DAT & output & $! \quad$ CLDDAT $=C D 28 C X 16 . \mathrm{DAT}$ & $!$ \\
\hline PACOUT. DAT & output & * $\mathrm{PACDAT}=$ * & * \\
\hline
\end{tabular}

NUMBER OF UPPER AIR \& OVERWATER STATIONS:

Number of upper air stations (NUSTA) No default ! NUSTA $=4$ ! Number of overwater met stations

(NOWSTA) No default ! NOWSTA $=1$ !

! END!

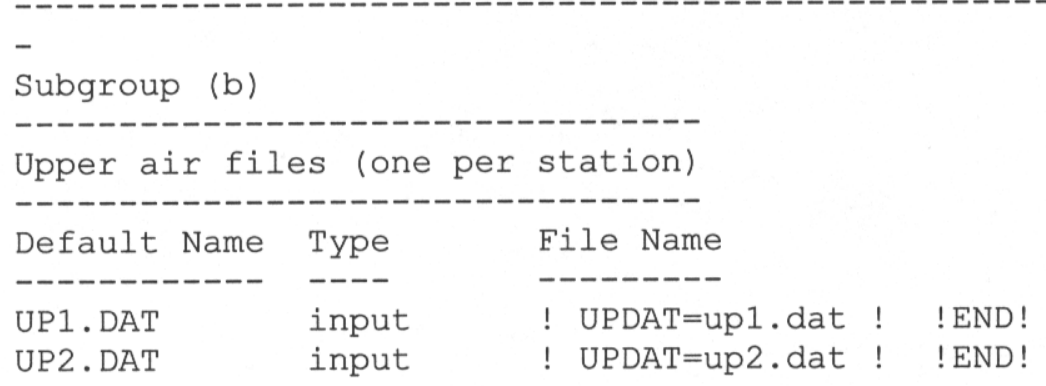




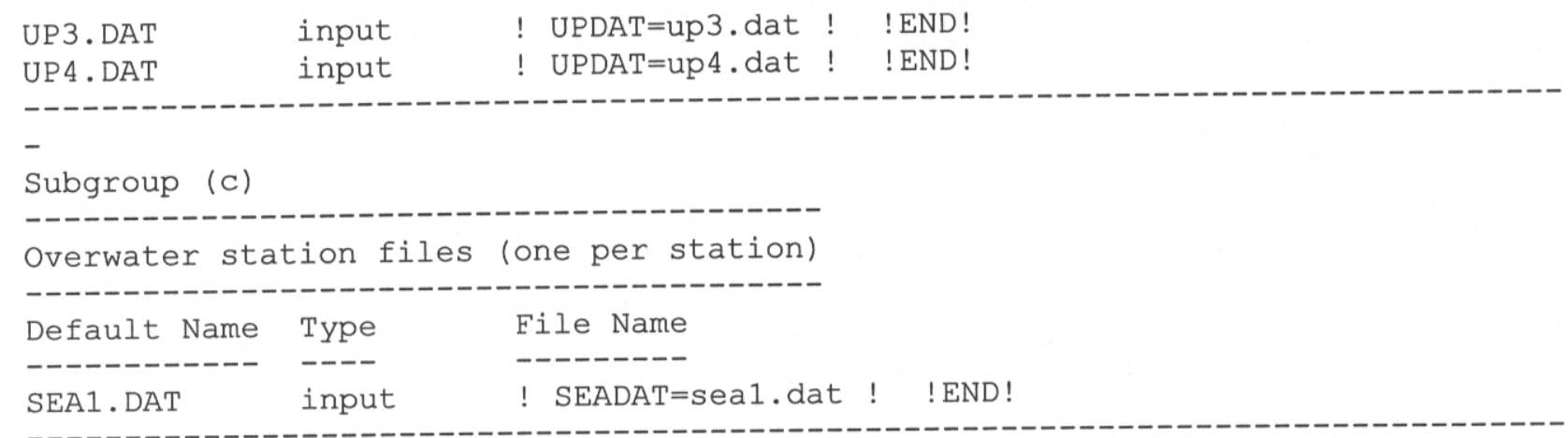

Subgroup (d)

---------------

Other file names

----------------

\begin{tabular}{|c|c|c|}
\hline Default Name & Type & File Name \\
\hline ----ー-ー-ー-ー- & ---- & --------- \\
\hline DIAG.DAT & input & ! DIADAT = diag.dat! \\
\hline PROG.DAT & input & * $\mathrm{PRGDAT}=$ \\
\hline TEST.PRT & output & * TSTPRT $=$ \\
\hline TEST.OUT & output & * TSTOUT $=$ \\
\hline TEST.KIN & output & * TSTKIN $=$ \\
\hline TEST. FRD & output & * TSTFRD $=$ \\
\hline TEST.SLP & output & * TSTSLP $=$ \\
\hline
\end{tabular}

NOTES: (1) File/path names can be up to 70 characters in length

(2) Subgroups (a) and (d) must have ONE "END" (surrounded by delimiters) at the end of the group

(3) Subgroups (b) and (c) must have an "END" (surrounded by delimiters) at the end of EACH LINE

! END!

INPUT GROUP: 1 -- General run control parameters

\begin{tabular}{|c|c|c|c|c|c|c|}
\hline \multirow{4}{*}{ Starting date: } & Year & (IBYR) & -- No default & $!$ & IBYR $=$ & 87 \\
\hline & Month & ( IBMO) & -- No default & $!$ & $\mathrm{IBMO}=$ & 8 \\
\hline & Day & ( IBDY) & -- No default & $!$ & IBDY $=$ & 28 \\
\hline & Hour & (IBHR) & -- No default & ! & IBHR $=$ & 0 \\
\hline Base time zone & & (IBTZ) & -- No default & $!$ & IBTZ= & 8 \\
\hline $\mathrm{PST}=08, \mathrm{MST}$ & $\Gamma=07$ & & & & & \\
\hline $\mathrm{CST}=06, \mathrm{EST}$ & $\Gamma=05$ & & & & & \\
\hline
\end{tabular}




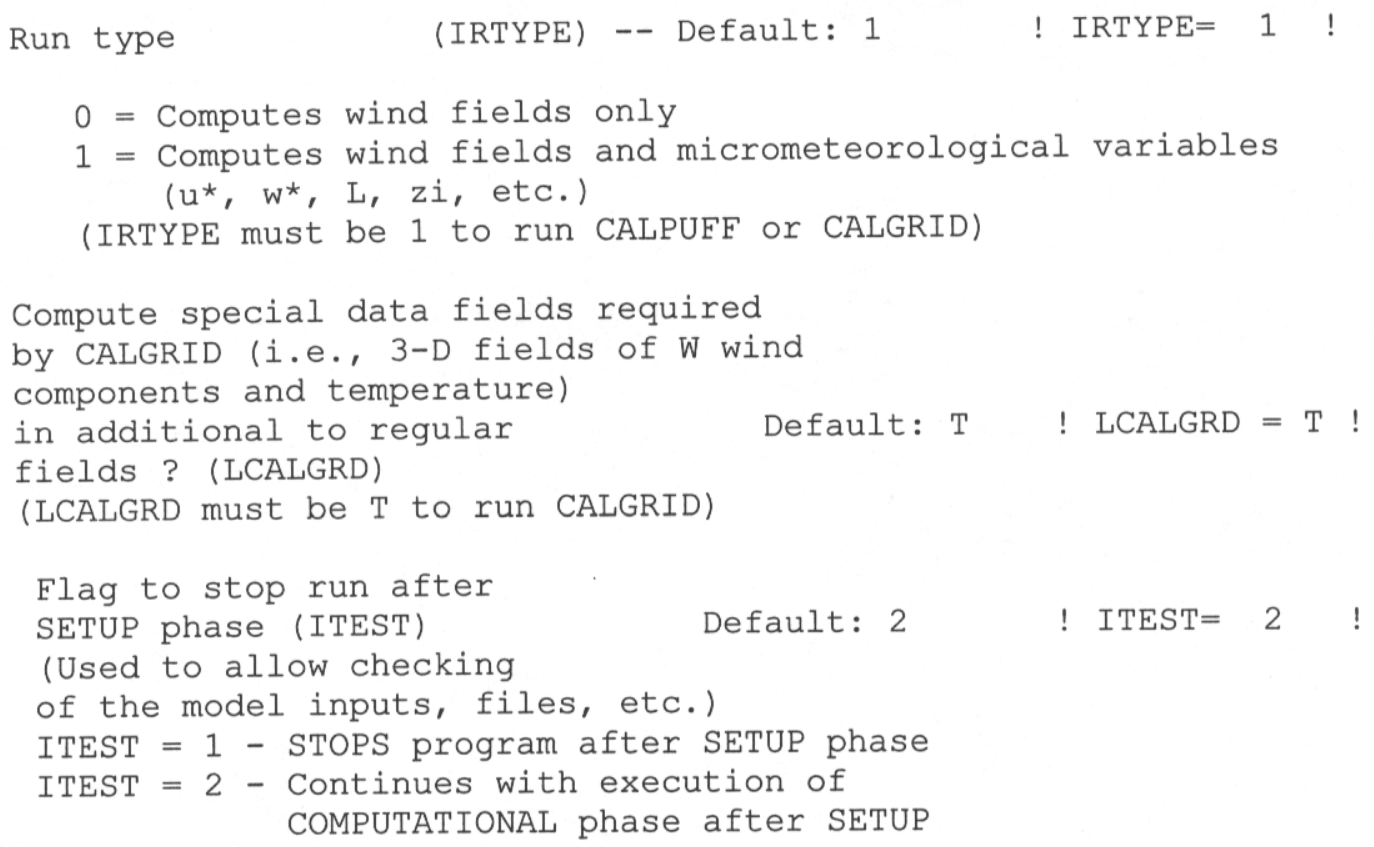

HORIZONTAL GRID DEFINITION:

No. $X$ grid cells (NX)

No. Y grid cells (NY)

GRID SPACING (DGRIDKM)

REFERENCE COORDINATES

of SOUTHWEST corner of grid point $(1,1)$

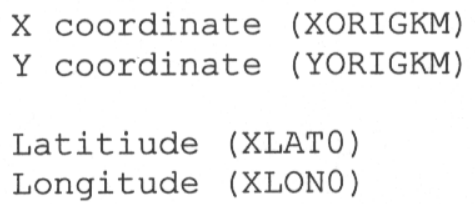

UTM ZONE (IUTMZN)

Rotate input winds from true north to map north using a Lambert conformal projection? (LLCONF)

Latitude of 1 st standard parallel Latitude of 2nd standard parallel No default No default Units: $\mathrm{km}$ No default No default No default

$\begin{array}{ll}\text { No default } & ! \text { NX }=65 ! \\ \text { No default } & ! \text { NY }=40 ! \\ \text { No default } & ! \text { DGRIDKM= 5. } \\ \text { Units: km } & \end{array}$

(XLAT1 and XLAT2; + in $\mathrm{NH,} \mathrm{-} \mathrm{in} \mathrm{SH}$ ) 


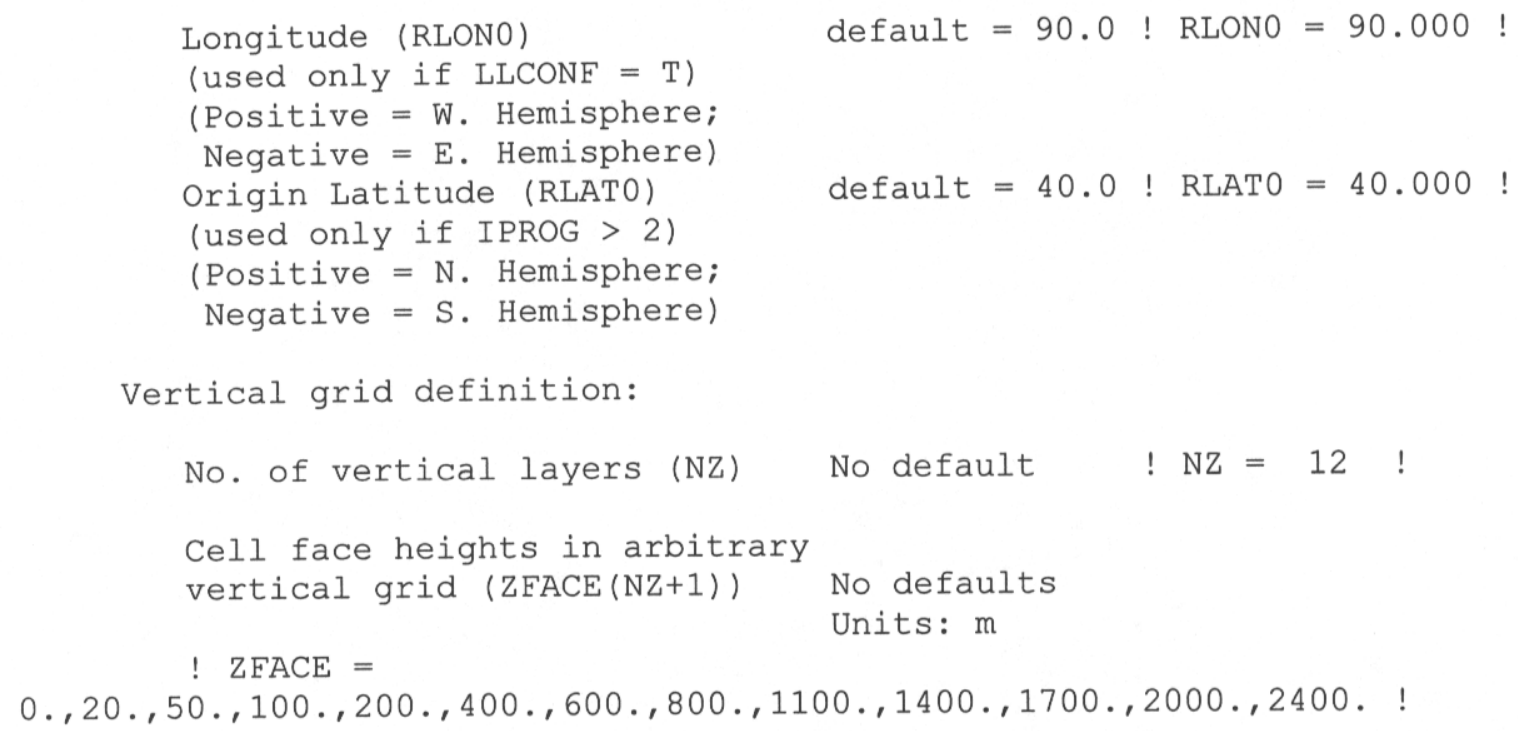

LINE PRINTER OUTPUT OPTIONS:

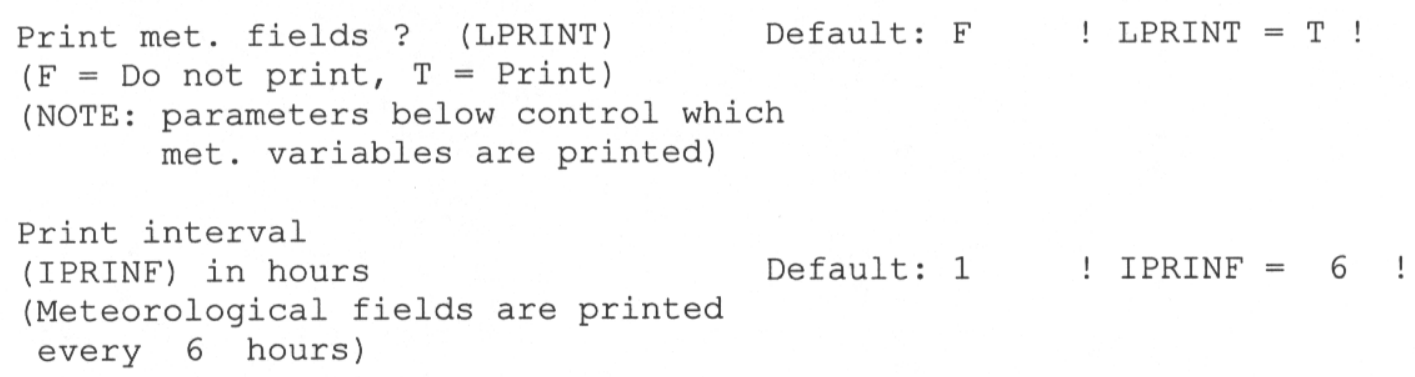


Specify which layers of $U, V$ wind component

to print (IUVOUT(NZ)) -- NOTE: NZ values must be entered

( 0 =Do not print, $1=$ Print)

(used only if LPRINT $=\mathrm{T}$ ) Defaults: $\mathrm{NZ}$ ) 0

! IUVOUT $=1,0,0,0,0,0,0,0,0,0,0,0$ !

Specify which levels of the $\mathrm{W}$ wind component to print

(NOTE: $W$ defined at TOP cell face -- 14 values)

(IWOUT(NZ)) -- NOTE: NZ values must be entered

( $0=$ Do not print, $1=$ =Print)

(used only if LPRINT $=\mathrm{T}$ \& LCALGRD $=\mathrm{T}$ )

! IWOUT $=0,0,0,0,0,0,0,0,0,0,0,0$ !

Specify which levels of the 3-D temperature field to print

(ITOUT(NZ)) -- NOTE: NZ values must be entered

( $0=$ Do not print, $1=$ Print)

(used only if LPRINT $=T$ \& LCALGRD $=T$ )

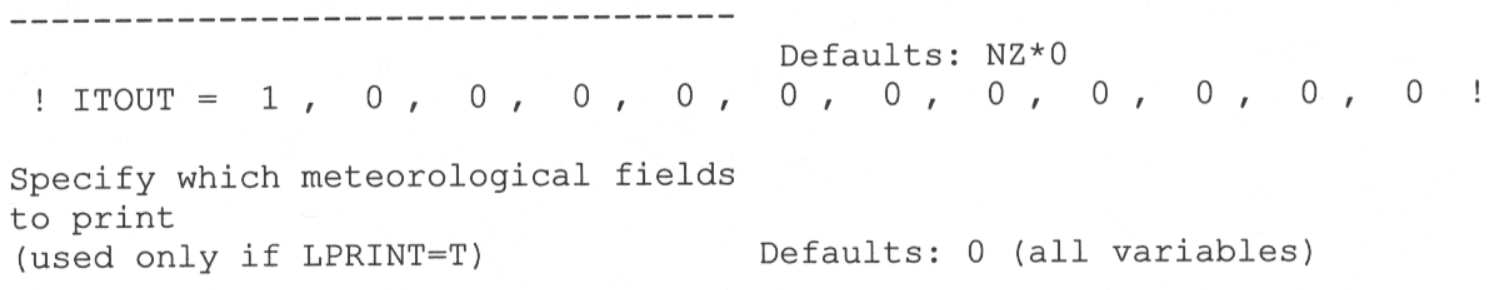

Variable

Print ?

$10=$ do not print,

1 = print)

$(------1$

- - - - - - - - - - - - - -

! STABILITY $=$

USTAR =

MONIN $=$

MIXHT =

! WSTAR =

PRECIP $=$

$\begin{array}{ll}! & \text { SENSHEAT } \\ \operatorname{CONVZI}=\end{array}$

Testing and debug print options for micrometeorological module

Print input meteorological data and

internal variables (LDB)
( $\mathrm{F}=$ Do not print, $\mathrm{T}=$ print)

! - PGT stability class

! - Friction velocity

! - Monin-Obukhov length

! - Mixing height

! - Convective velocity scale

! - Precipitation rate

$\begin{array}{ll}1 & ! \text { - Sensible heat flux } \\ 1 & ! \text { - Convective mixing ht. }\end{array}$

(NOTE: this option produces large amounts of output)

First time step for which debug data 
are printed (NN1) Default: $1 \quad$ nN1 1 !

Last time step for which debug data

are printed (NN1)

Default: $1 \quad$ ! NN2 $=1$ !

Testing and debug print options for wind field module (all of the following print options control output to wind field module's output files: TEST.PRT, TEST.OUT, TEST.KIN, TEST.FRD, and TEST.SLP)

Control variable for writing the test/debug wind fields to disk files (IOUTD)

( $0=$ Do not write, 1 =write)

! IOUTD $=0 \quad$ !

Number of levels, starting at the surface,

to print (NZPRN2)

Default: 1

! NZPRN2 $=0$ !

Print the INTERPOLATED wind components ?

( IPRO ) $(0=$ no, 1 =yes $)$

Default: 0

! $\quad$ IPRO $=0 \quad$ !

Print the TERRAIN ADJUSTED surface wind

components ?

(IPR 1$) \quad(0=$ no, 1 =yes $)$

Default: 0

! $\quad$ IPR1 $=0 \quad$ !

Print the SMOOTHED wind components and the INITIAL DIVERGENCE fields ?
(IPR2) $\quad(0=$ no, 1=yes )
Default: 0
! $\quad$ IPR2 $=0 \quad$ !

Print the FINAL wind speed and direction

fields ?

(IPR3) (0=no, 1=yes)

Default: 0

! $\quad$ IPR3 $=0 \quad$ !

Print the FINAL DIVERGENCE fields ?

(IPR4) $(0=$ no, 1 =yes $) \quad$ Default: $0 \quad$ IPR4 0 !

Print the winds after KINEMATIC effects

are added ?

(IPR5) $(0=$ no, 1 =yes $)$

Default: 0

! $\quad$ IPR5 $=0 \quad$ !

Print the winds after the FROUDE NUMBER

adjustment is made?

(IPR6) $\quad(0=$ no, 1 =yes )

Default: 0

! IPR6 $=0 \quad$ !

Print the winds after SLOPE FLOWS

are added ?

Default: 0

! $\quad$ IPR7 $=0 \quad$ !

Print the FINAL wind field components ?

(IPR8) ( 0 =no, 1=yes)

Default: 0

! IPR8 $=0$ !

! END! 
INPUT GROUP: 4 -- Meteorological data options

\section{--D-D---D---}

NUMBER OF SURFACE \& PRECIP. METEOROLOGICAL STATION

Number of surface stations (NSSTA) No default $\quad$ NSSTA $=47$ !

Number of precipitation stations

(NPSTA) No default $!$ NPSTA $=0 \quad !$

CLOUD DATA OPTIONS

Griddid cloud fields:

(ICLOUD) Default: $0 \quad$ ! ICLOUD $=1$ !

ICLOUD $=0-$ Gridded clouds not used

ICLOUD $=1$ - Gridded CLOUD. DAT generated as OUTPUT

ICLOUD $=2-$ Gridded CLOUD. DAT read as INPUT

FILE FORMATS

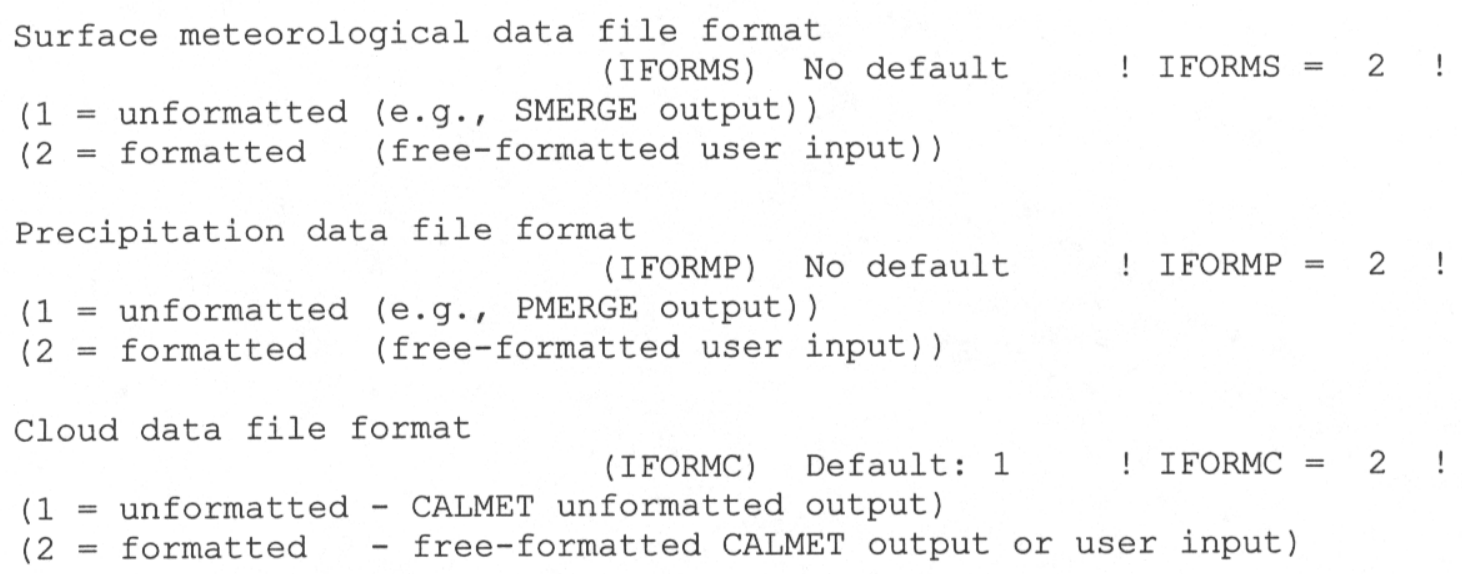

INPUT GROUP: 5 -- Wind Field Options and Parameters

WIND FIELD MODEL OPTIONS

Model selection variable (IWFCOD)

0 = Objective analysis only

1 = Diagnostic wind module

Compute Froude number adjustment

effects ? (IFRADJ)

$(0=\mathrm{NO}, 1=\mathrm{YES})$

Compute kinematic effects ? (IKINE)

$(0=$ NO, 1 = YES $)$

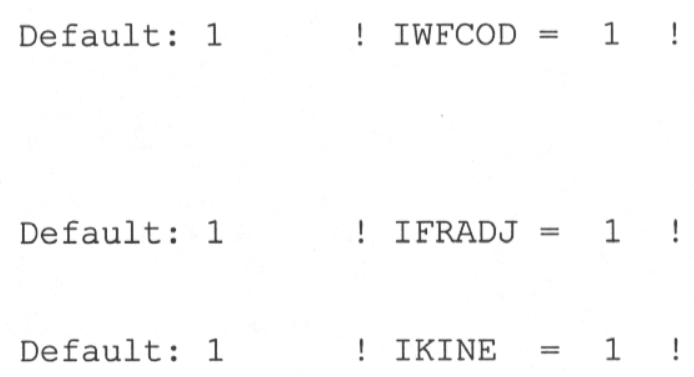




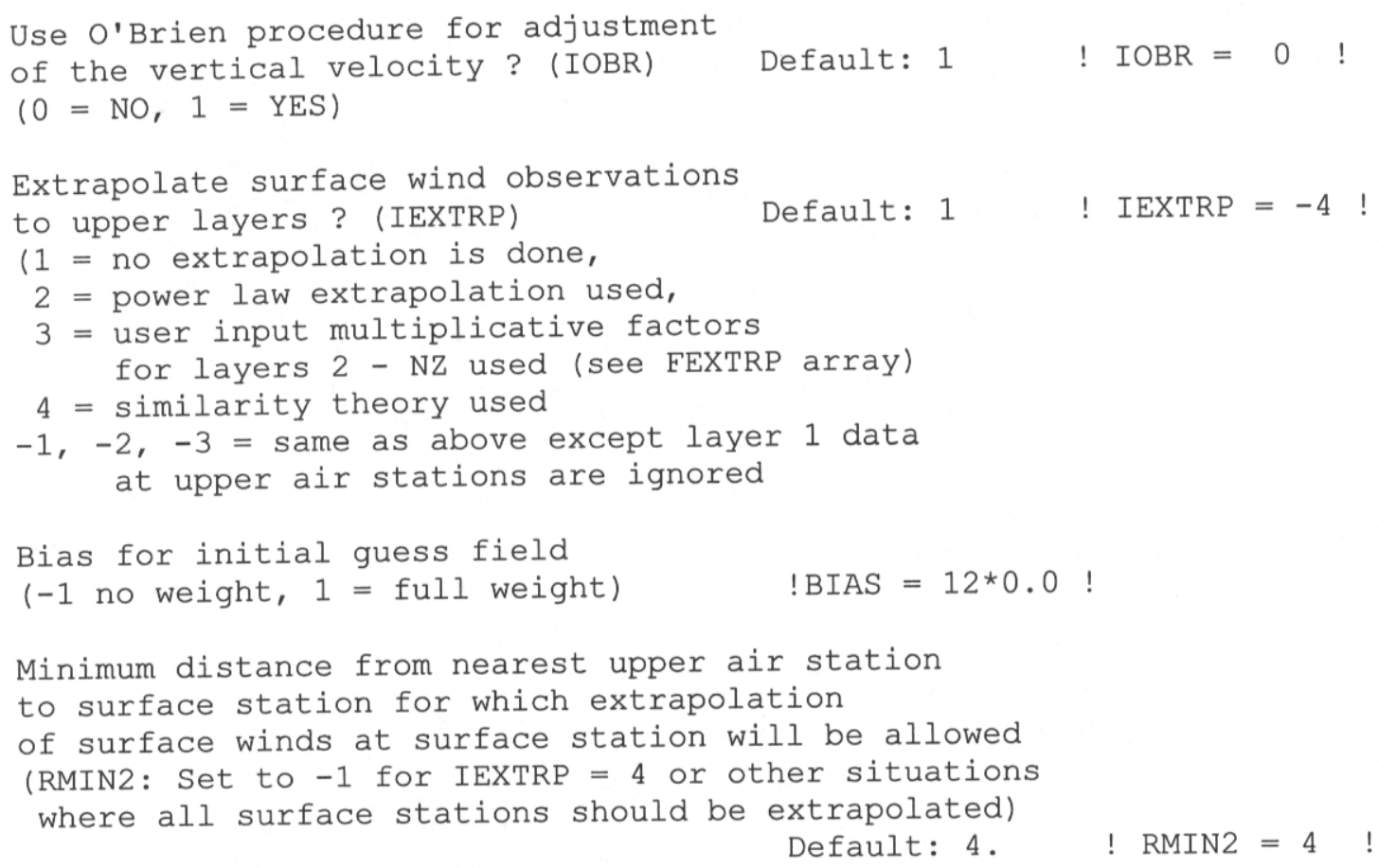




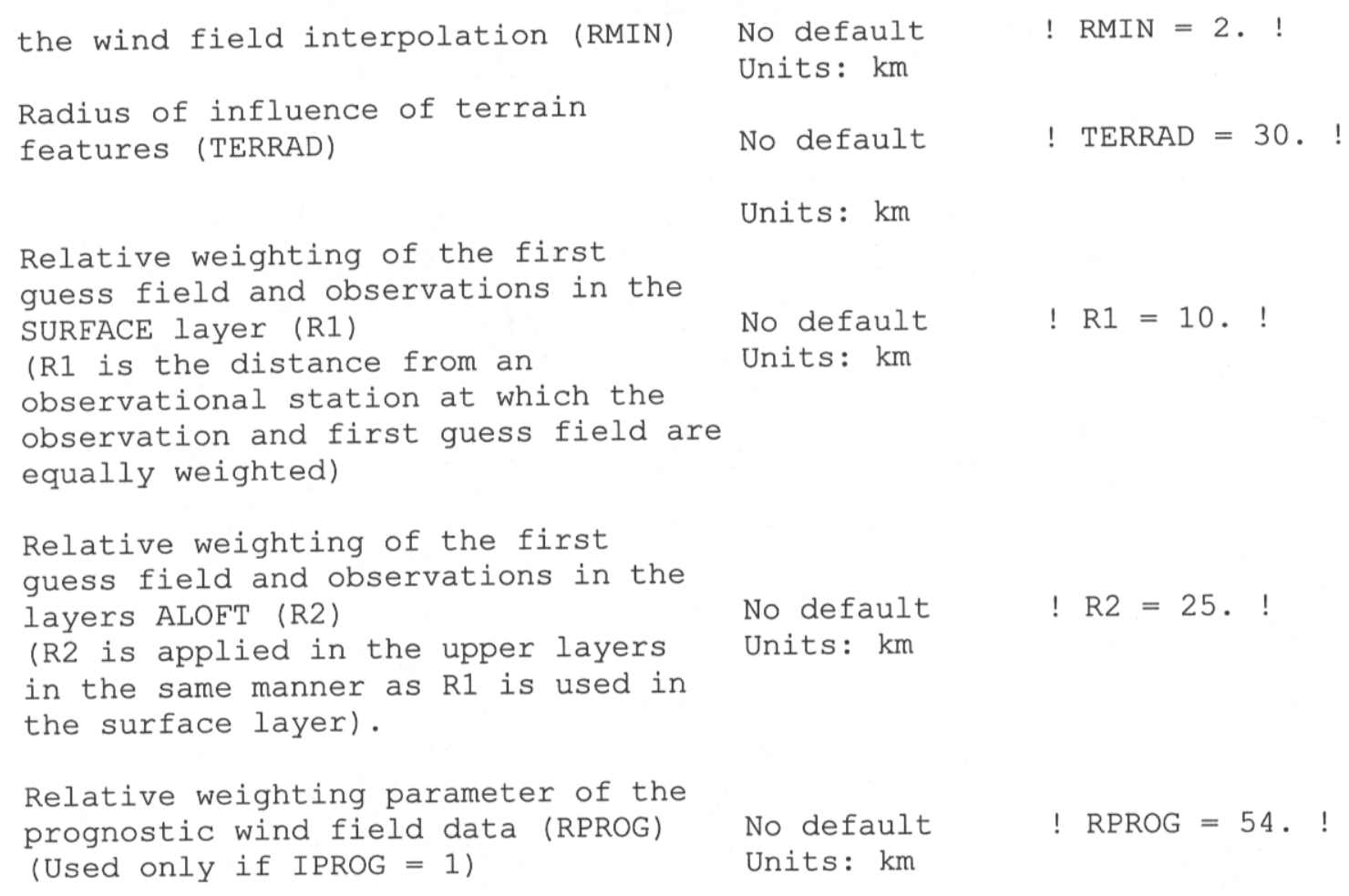

Maximum acceptable divergence in the divergence minimization procedure (DIVLIM)

Default: $5 . E-6$ ! DIVLIM $=5.0 \mathrm{E}-06$

Maximum number of iterations in the divergence min. procedure (NITER)

Default: 50 ! NITER $=50$ !

Number of passes in the smoothing

procedure (NSMTH(NZ))

NOTE: NZ values must be entered Default: $2,(\operatorname{mxnz}-1) * 4$ ! NSMTH $=$

$5,5,5,5,5,16,16,16,16,16,32,32, !$

Maximum number of stations used in each layer for the interpolation of data to a grid point (NINTR2(NZ)) NOTE: NZ values must be entered

$9,9,9,9,9,9,9,9,9,9,9,9$ !

Critical Froude number (CRITFN)

Default: 1.0 ! CRITFN $=1$. !

Empirical factor controlling the influence of kinematic effects (ALPHA)

Default: $0.1 \quad$ ! ALPHA $=0.1$ !

Multiplicative scaling factor for extrapolation of surface observations to upper layers (FEXTR2(NZ))

Default: $N Z * 0.0$ 
! $\operatorname{EEXTR2}=0 ., 0 ., 0 ., 0 ., 0 ., 0 ., 0 ., 0 ., 0 ., 0 ., 0 ., 0.4$

(Used only if IEXTRP $=3$ or -3 )

BARRIER INFORMATION

Number of barriers to interpolation

of the wind fields (NBAR)

Default: $0 \quad$ ! NBAR $=0 \quad$ !

THE FOLLOWING 4 VARIABLES ARE INCLUDED

ONLY IF NBAR > 0

NOTE: NBAR values must be entered

for each variable

No defaults

Units: $\mathrm{km}$

$X$ coordinate of BEGINNING

of each barrier $(\mathrm{XBBAR}(\mathrm{NBAR})) \quad$ ! $\mathrm{XBBAR}=0$. !

$Y$ coordinate of BEGINNING

of each barrier (YBBAR(NBAR)) ! YBBAR $=0$. !

$X$ coordinate of ENDING

of each barrier $(\mathrm{XEBAR}(\mathrm{NBAR})) \quad$ ! XEBAR $=0$. !

$Y$ coordinate of ENDING

of each barrier (YEBAR(NBAR)) ! YEBAR $=0$. !

DIAGNOSTIC MODULE DATA INPUT OPTIONS

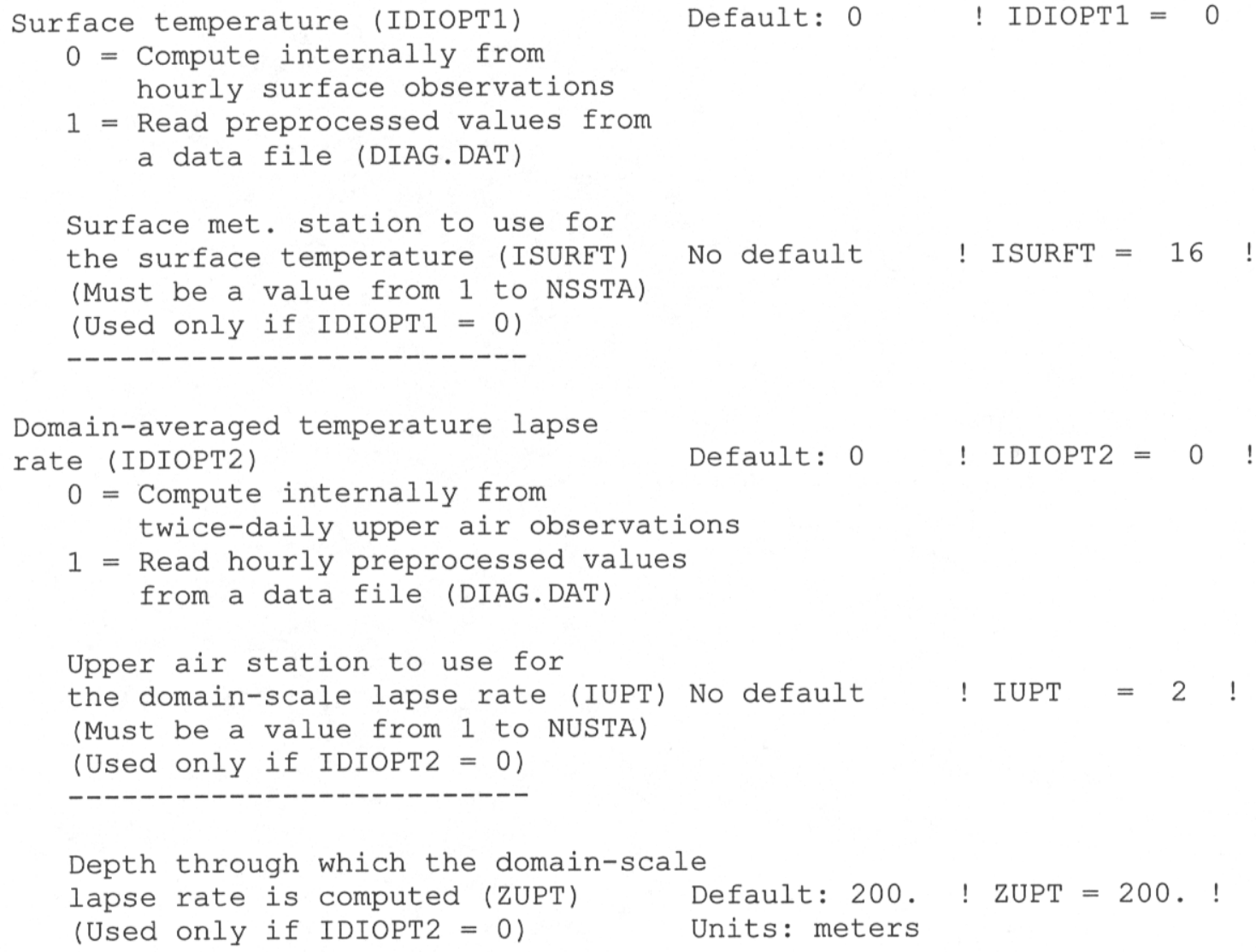


Domain-averaged wind components (IDIOPT3)

$0=$ Compute internally from twice-daily upper air observations

1 = Read hourly preprocessed values a data file (DIAG.DAT)

Upper air station to use for the domain-scale winds (IUPWND) No default ! IUPWND $=2$ ! (Must be a value from -1 to NUSTA) (Used only if IDIOPT3 = 0 )

Default: $0 \quad$ ! IDIOPT3 $3=0$ ! --------------------------

Bottom and top of layer through which the domain-scale winds are computed (ZUPWND (1), ZUPWND (2)) Defaults: 1., 2500. ! ZUPWND= 1., 2000. (Used only if IDIOPT3 = 0) Units: meters

Observed surface wind components

for wind field module (IDIOPT4)

$0=$ Read WS, WD from a surface data file (SURF.DAT)

1 = Read hourly preprocessed U, V from a data file (DIAG.DAT)

Observed upper air wind components

for wind field module (IDIOPT5) Default: $0 \quad$ IDIOPT5 $=0$ !

$0=$ Read WS, WD from an upper air data file (UP1.DAT, UP2.DAT, etc.)

1 = Read hourly preprocessed U, V from a data file (DIAG.DAT)

LAKE BREEZE INFORMATION

Use Lake Breeze Module (LLBREZE) Default: $\mathrm{F} \quad$ ! LLBREZE $=\mathrm{F}$ !

Number of lake breeze regions (NBOX)

! $\mathrm{NBOX}=0 \quad !$

$\mathrm{x}$ Grid line 1 defining the region of interest

$x$ Grid line 2 defining the region of interest

Y Grid line 1 defining the region of interest

Y Grid line 2 defining the region of interest

$$
\begin{aligned}
& ! \mathrm{XG1}=0 . ! \\
& ! \mathrm{XG} 2=0 . ! \\
& ! \mathrm{YG1}=0 . ! \\
& ! \mathrm{YG} 2=0 . !
\end{aligned}
$$

$\mathrm{X}$ Point defining the coastline (Straight line)
(XBCST)
$(\mathrm{KM})$
Default: none
! $\mathrm{XBCST}=0 . !$ 


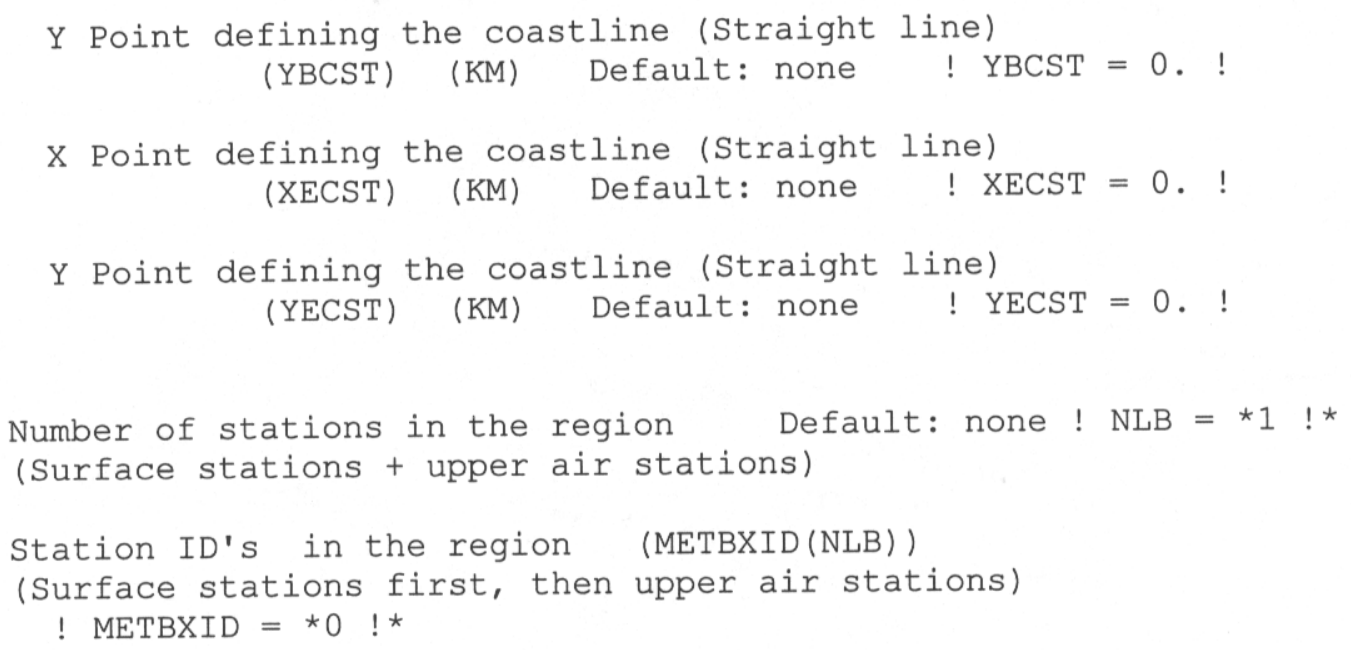

Neutral, mechanical equation (CONSTB)

Convective mixing ht. equation (CONSTE)

Stable mixing ht. equation (CONSTN)

Overwater mixing ht. equation (CONSTW)

Absolute value of Coriolis

parameter (FCORIOL)

04 !

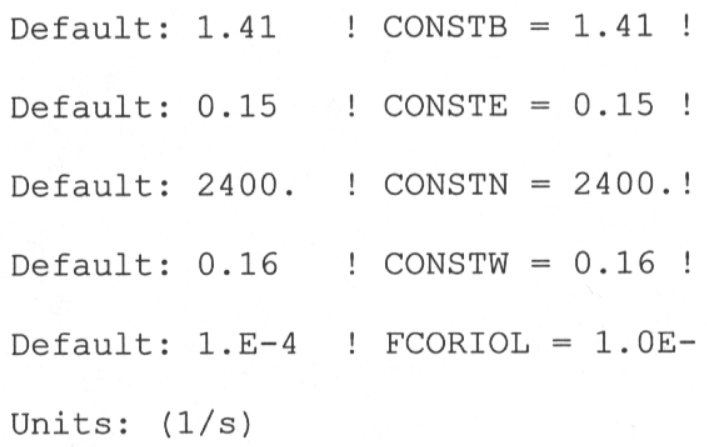

SPATIAL AVERAGING OF MIXING HEIGHTS

Conduct spatial averaging

(IAVEZI) ( $0=$ no, 1 =yes )

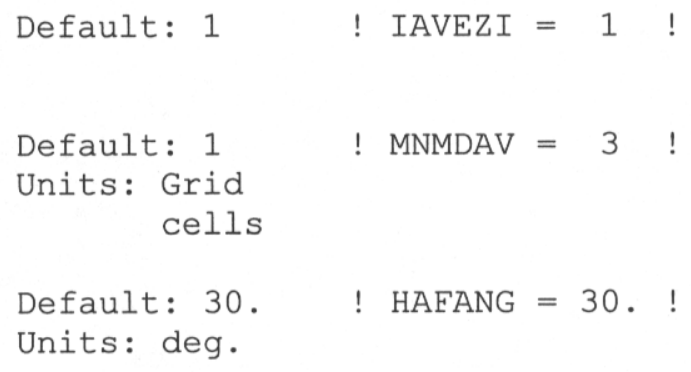

Units: deg.

Max. search radius in averaging process (MNMDAV)

Half-angle of upwind looking cone for averaging (HAFANG)

Layer of winds used in upwind 
averaging (ILEVZI)

(must be between 1 and $\mathrm{NZ}$ )

OTHER MIXING HEIGHT VARIABLES

Minimum potential temperature lapse rate in the stable layer above the current convective mixing ht. (DPTMIN)

Depth of layer above current conv. mixing height through which lapse rate is computed (DZZI)

Minimum overland mixing height (ZIMIN)

Maximum overland mixing height (ZIMAX)

Minimum overwater mixing height (ZIMINW) -- (Not used if observed overwater mixing hts. are used) Maximum overwater mixing height (ZIMAXW) -- (Not used if observed overwater mixing hts. are used)
No default ! ILEVZI $=1$ !

TEMPERATURE PARAMETERS

Interpolation type

$(1=1 / R ; 2=1 / R * * 2)$

Default: 1

! IRAD $=1$ !

Radius of influence for temperature

interpolation (TRADKM) Default: $100 \mathrm{~km}$

Default : 5

! NUMTS $=4$ !

Maximum Number of stations to include

in temperature interpolation (NUMTS)

Conduct spatial averaging of temp-

eratures (IAVET) $(0=$ no, $1=y e s)$

Default: 1 ! IAVET $=1$ !

(will use mixing ht MNMDAV, HAFANG

so make sure they are correct)

Default temperature gradient

Default: -.0098 ! TGDEFB $=-0.0065 !$

below the mixing height over

water $(\mathrm{K} / \mathrm{m})$ (TGDEFB)

Default temperature gradient

Default: -.0045 ! TGDEFA $=-0.0025$ ! above the mixing height over water $(\mathrm{K} / \mathrm{m})$ (TGDEFA)

Beginning (JWAT1) and ending (JWAT2)

land use categories for temperature

interpolation over water -- Make

! JWAT1 $=99$ !

bigger than largest land use to disable

! JWAT2 $=99$ !

PRECIP INTERPOLATION PARAMETERS 
Method of interpolation (NFLAGP) $(1=1 / R, 2=1 / R \star \star 2,3=E X P / R \star \star 2)$

Radius of Influence (km) (SIGMAP) $(0.0 \Rightarrow$ use half dist. btwn nearest stns $\mathrm{w} \& \mathrm{w} /$ out precip when NFLAGP $=3$ )

Minimum Precip. Rate Cutoff $(\mathrm{mm} / \mathrm{hr})$ Default $=0.01 \quad$ CUTP $=0.01$ !
Default $=2 \quad !$ NFLAGP $=2 \quad !$
Default $=100.0 \quad !$ SIGMAP $=100 . \quad !$

!END!

INPUT GROUP: 7 -- Surface meteorological station parameters

SURFACE STATION VARIABLES

(One record per station -- 12 records in all)

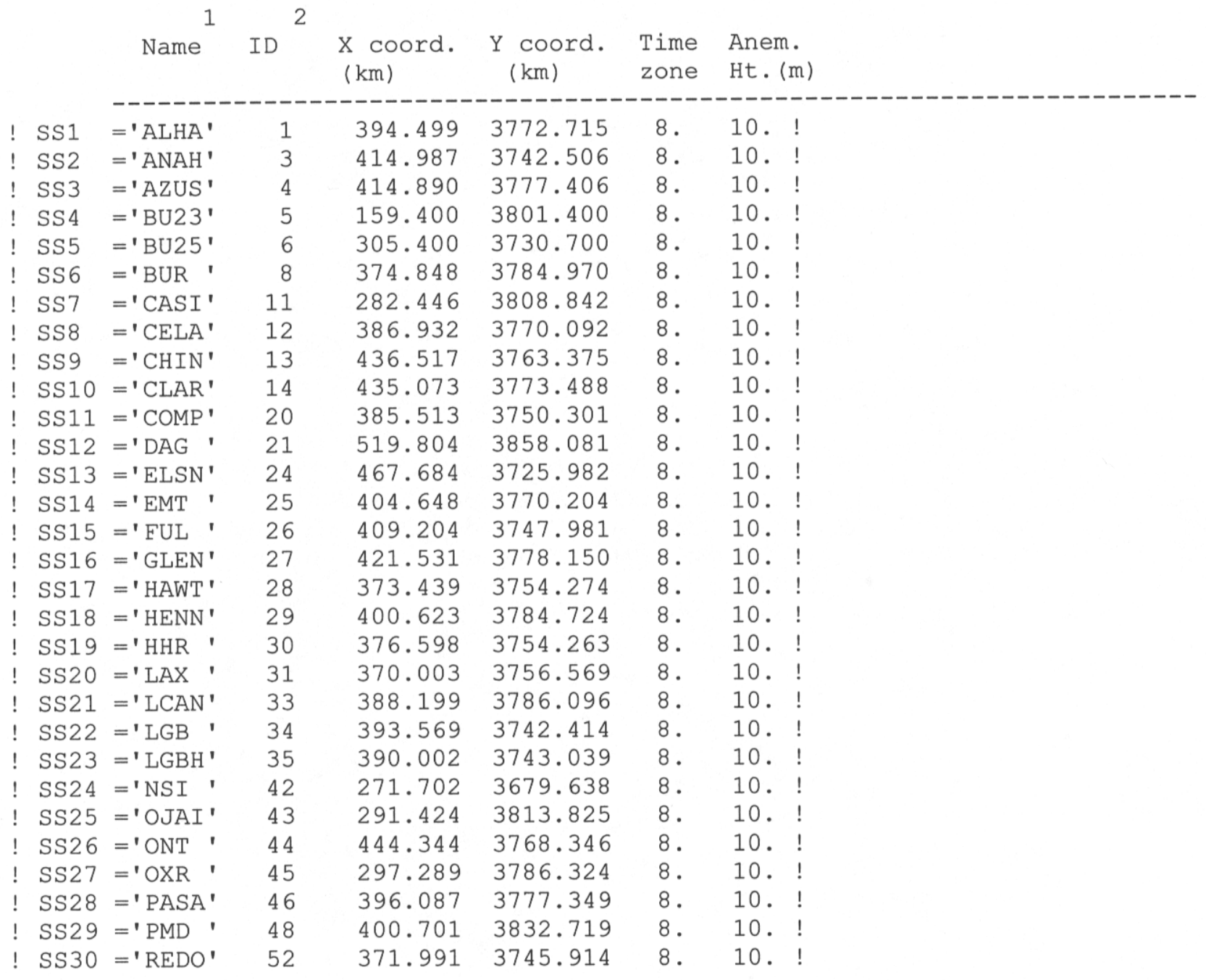




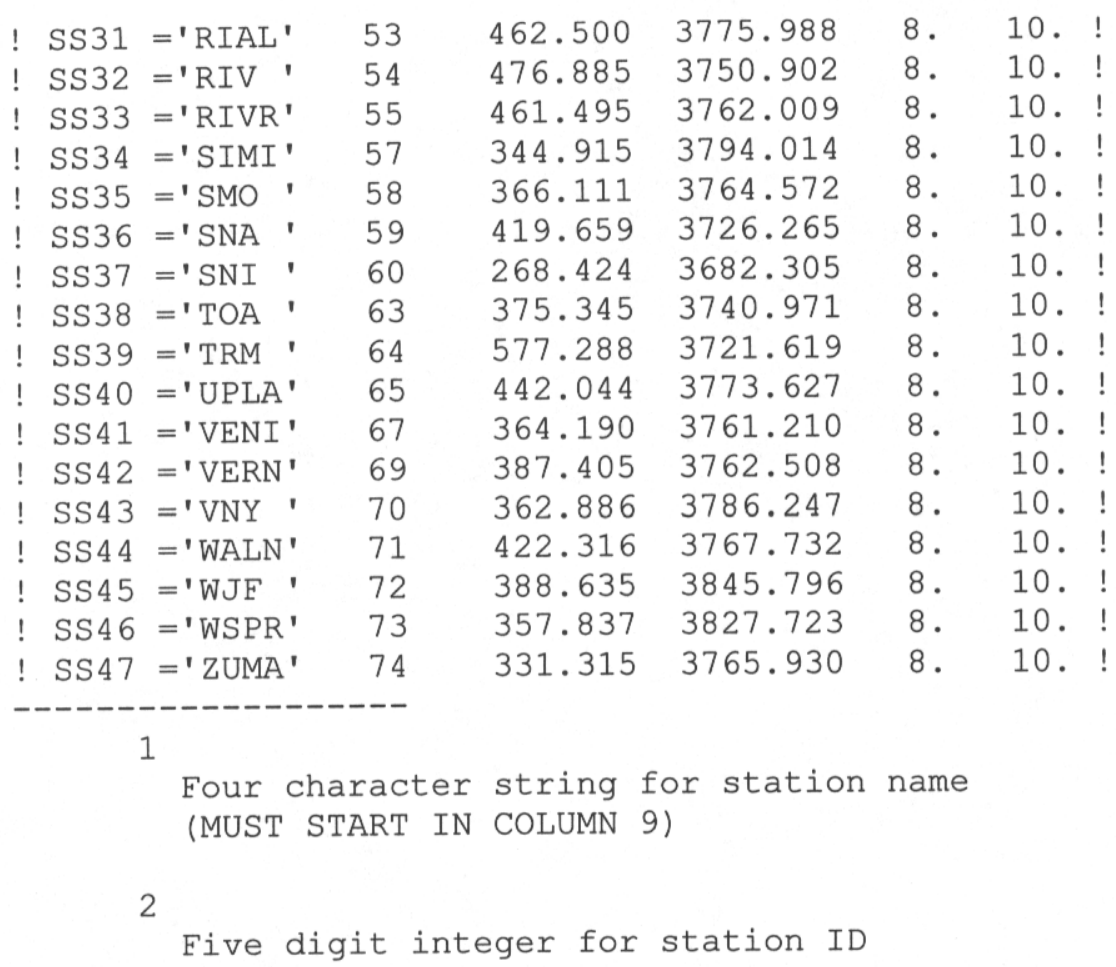

!END!

INPUT GROUP: 8 -- Upper air meteorological station parameters

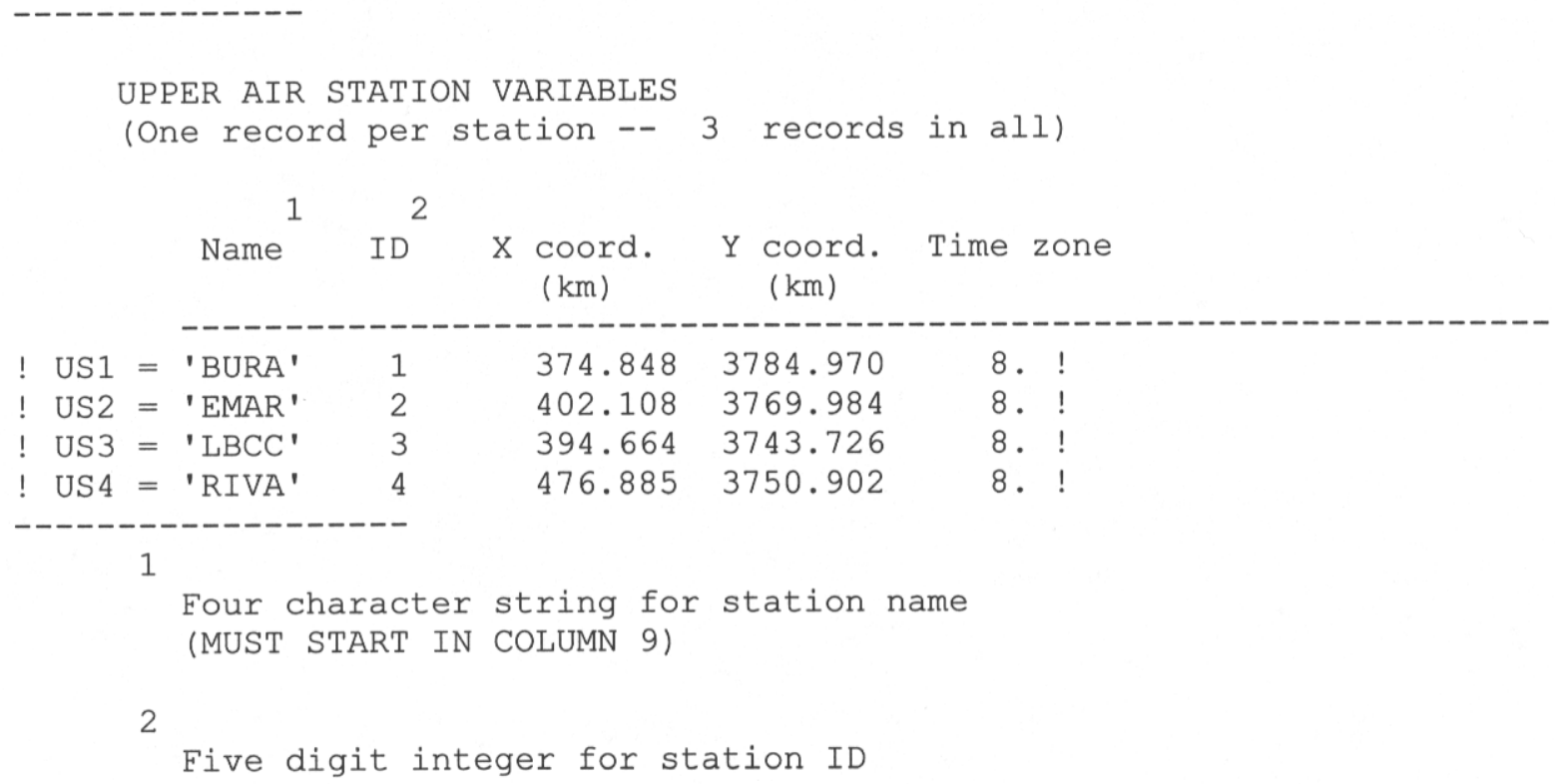

! END! 
INPUT GROUP: 9 -- Precipitation station parameters

\begin{tabular}{|c|c|c|}
\hline \multicolumn{3}{|c|}{$\begin{array}{l}\text { PRECIPITATION STATION VARIABLES } \\
\text { (One record per station -- } 0 \text { records in } \\
(\text { NOT INCLUDED IF NPSTA }=0 \text { ) }\end{array}$} \\
\hline 1 & 2 & \\
\hline Name & $\begin{array}{c}x \text { coord. } \\
(\mathrm{km})\end{array}$ & $\begin{array}{c}\text { Y coord. } \\
(\mathrm{km})\end{array}$ \\
\hline
\end{tabular}

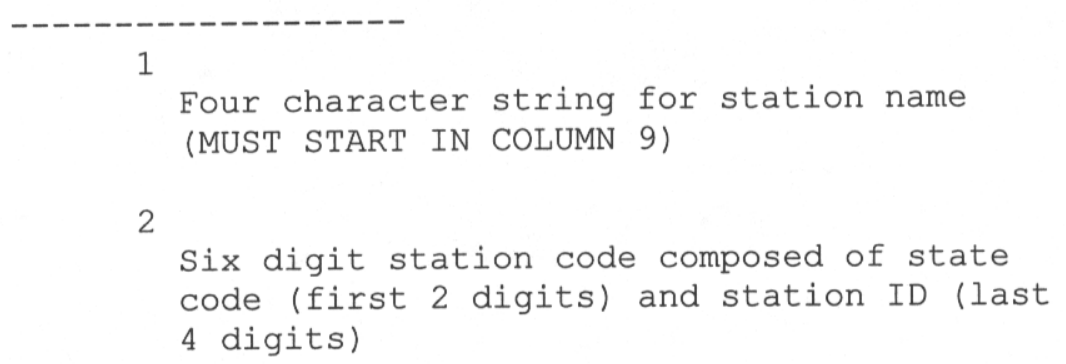


Appendix B

Listing of CALGRID input file (CB-4 case) 
CALGRID CB4 VERSION; REGIONAL RUN ON LA SIP DOMAIN AT 5 KM

USES REGIONAL VERSION 1.8 WITH 12 LAYERS - OLD PHOTOLYSIS - NEW O1D RATES

AUGUST 27, 1987 - WITH 1987 BASE EMISSIONS - CALMET X17 FILE

RUN TITLE (3 LINES)

CALGRID MODEL CONTROL FILE

ADDITIONAL USER COMMENTS

Uses Hourly CALMETUP meteorology, no calms, and no pseudosoundings

EMISSIONS are from SCAQMD SIP (Rsurf $=2.0$, new Kzmin scheme)

BOUNDARY, TOP, and INITIAL CONDITIONS ARE TAKEN FROM LA UAM-IV PREDICTIONS

REVISED BEIS2 CB-IV CHEMISTRY AND A 320 DU COLUMNAR OZONE

INPUT GROUP: 0 -- Input and Output File Names

Subgroup (a)

\begin{tabular}{|c|c|c|c|}
\hline Default Name & Type & & File Name \\
\hline-------- & --- & & ------- \\
\hline CALMET.DAT & input & ! & CALMET $=\mathrm{h}: \backslash$ nrel $\backslash$ calgrid $\backslash$ met $\backslash \mathrm{c} 27 \mathrm{cx} 17$. dat \\
\hline ICON.DAT & input & $!$ & ICONFL $=h: \backslash n r e l \backslash c a l g r i d \backslash i c b c \backslash a q l b a s 27 . c g$ \\
\hline CON.DAT & input & $!$ & BCONFL $=h: \backslash$ nrel $\backslash c a l g r i d \backslash i c b c \backslash b n d b a s 27 . c g$ \\
\hline CON.DAT & input & ! & $\mathrm{TCONFL}=\mathrm{h}: \backslash$ nrel $\backslash$ calgrid $\backslash i \mathrm{cbc} \backslash$ topbas $27 . \mathrm{cg}$ \\
\hline PTECYC.DAT & input & ! & PTECYC $=$ caldum 1 \\
\hline PTEMRB. DAT & input & ! & PTEMRB $=h: \backslash$ nrel $\backslash$ calgrid $\backslash$ emiss $\backslash$ ptsbas $27 . \mathrm{cg}$ \\
\hline PTEMOB. DAT & input & ! & PTEMOB $=$ caldum2 \\
\hline AREM. DAT & input & ! & AREMFL $=h: \backslash$ nrel $\backslash$ calgrid $\backslash$ emiss $\backslash$ emsbas $27 . \mathrm{cg}$ \\
\hline VD. DAT & input & ! & VDEPFL $=$ vdcarb. dat \\
\hline CLDDAT. DAT & input & ! & CLDDAT $=\mathrm{h}: \backslash$ nrel $\backslash$ calgrid $\backslash$ met $\backslash$ cld 27 ala.bin \\
\hline CALGRD. LST & output & ! & GRDLST $=\mathrm{cga} 18 \mathrm{c} 27.1 \mathrm{st}$ \\
\hline CALGRD. DAT & output & ! & $\mathrm{CNCDAT}=\mathrm{h}: \backslash$ nrel $\backslash$ calgrid $\backslash$ outputs $\backslash$ cna18c27. bin \\
\hline DEPCNC.DAT & output & ! & DEPDAT $=h: \backslash$ nrel $\backslash$ calgrid $\backslash$ outputs $\backslash$ dpa $18 c 27$. bin \\
\hline ICONST. DAT & output & ! & RESTRT $=h: \backslash$ nrel $\backslash$ calgrid $\backslash$ outputs $\backslash$ ica $18 c 27$.bin \\
\hline NEST.DAT & output & $!$ & BNEST $=$ caldum 4 \\
\hline
\end{tabular}

All file names will be converted to lower case if LCFILES $=\mathrm{T}$

Otherwise, if LCFILES $=F$, file names will be converted to UPPER CASE

$\mathrm{T}=$ lower case $!$ LCFILES $=\mathrm{T} !$

$\mathrm{F}=$ UPPER CASE

NOTES: (1) File/path names can be up to 70 characters in length

(2) Subgroups (a) and (d) must have ONE "END" (surrounded by delimiters) at the end of the group

(3) Subgroups (b) and (c) must have an "END" (surrounded by delimiters) at the end of EACH LINE

!END!

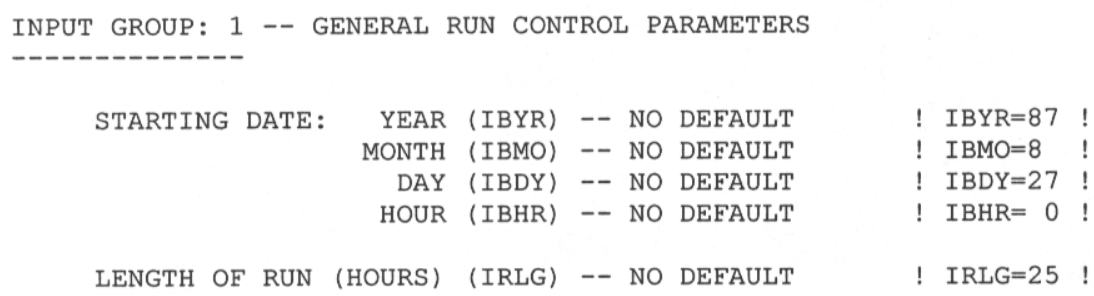




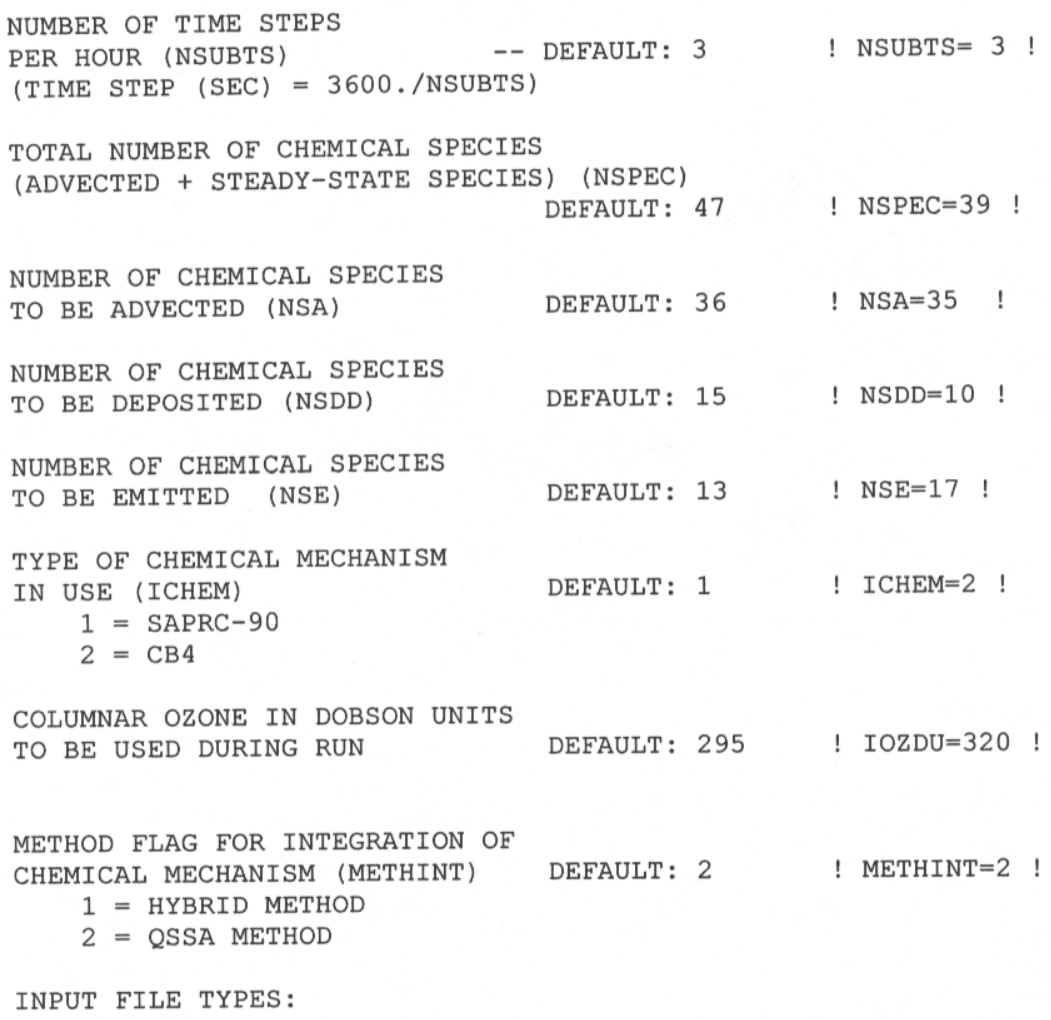

INPUT FILE TYPES:

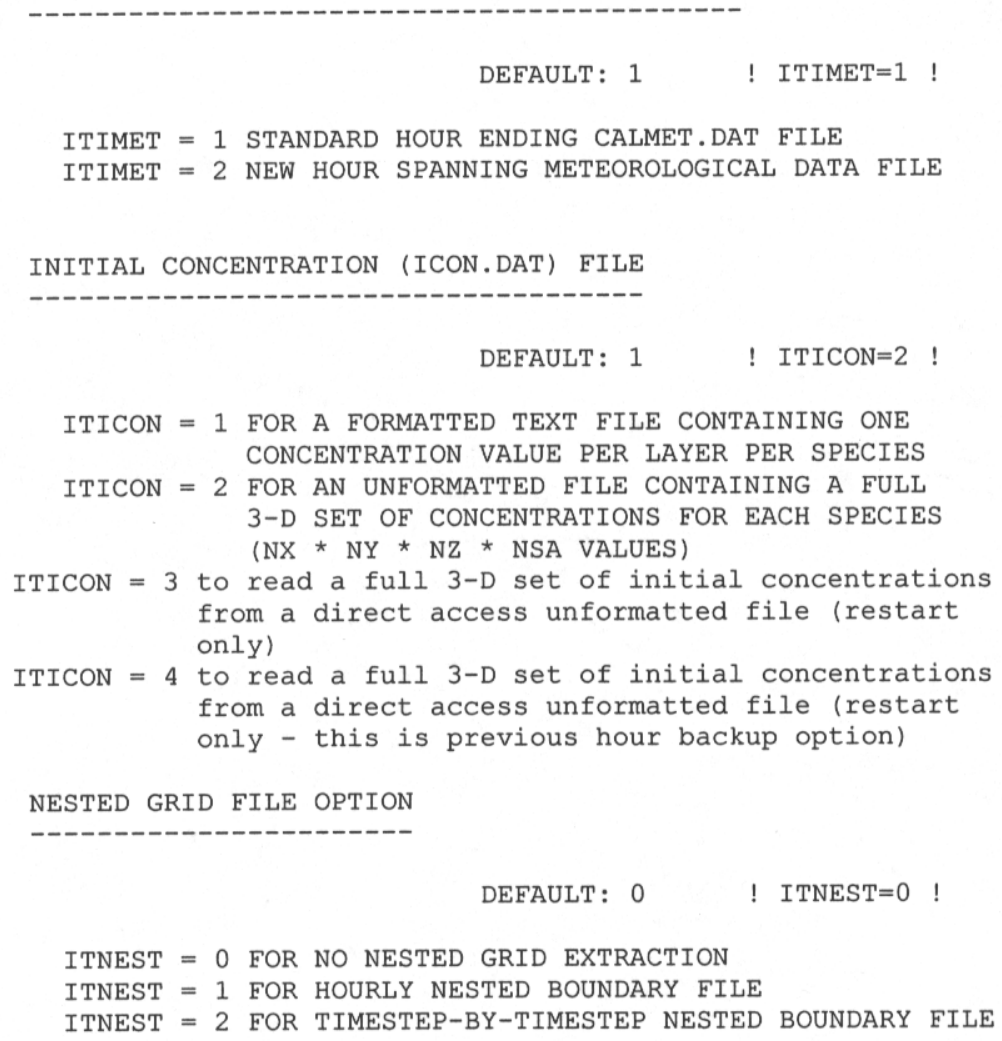




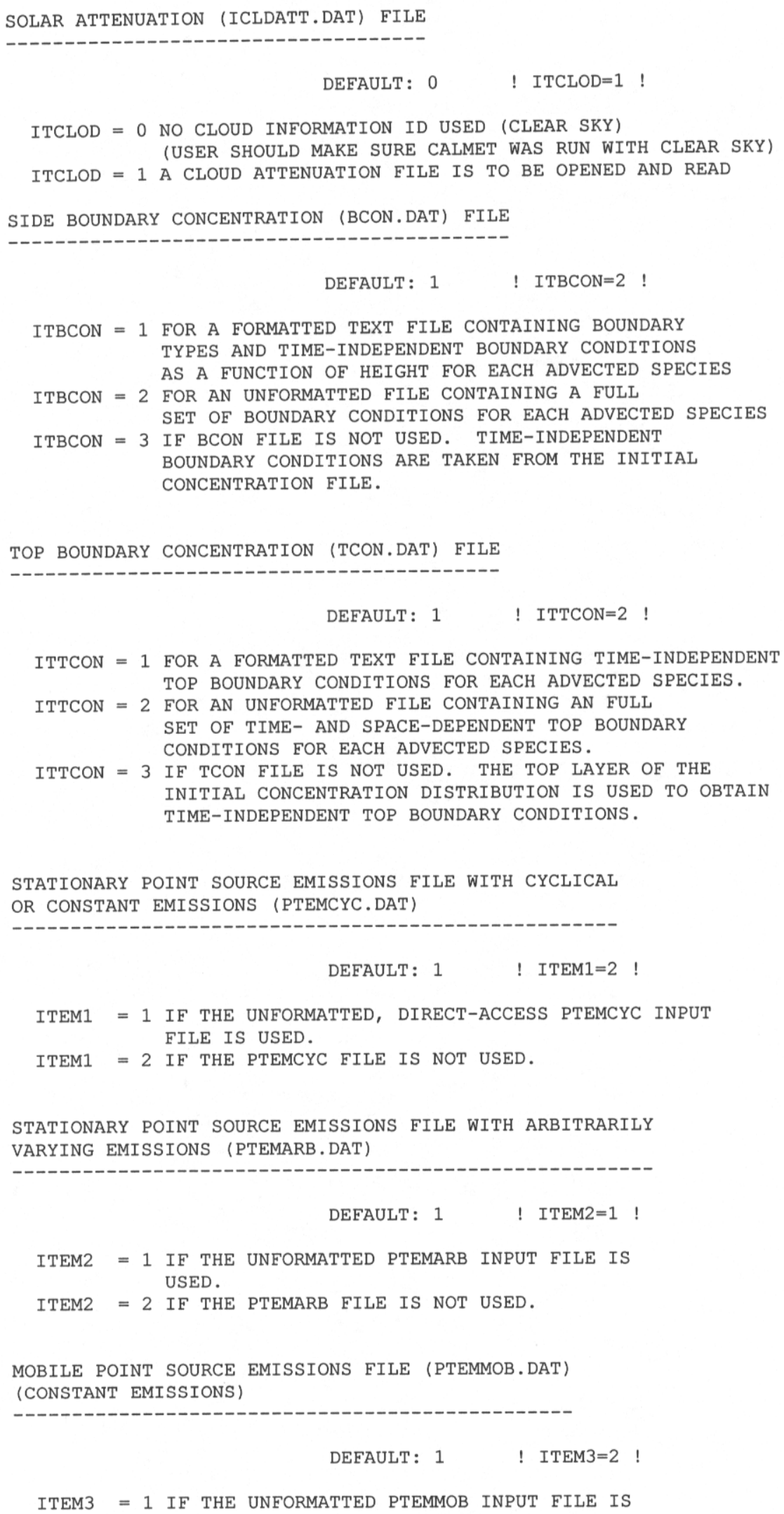


USED.

ITEM3 $=2$ IF THE PTEMMOB FILE IS NOT USED.

AREA SOURCE EMISSIONS FILE (AREM.DAT)

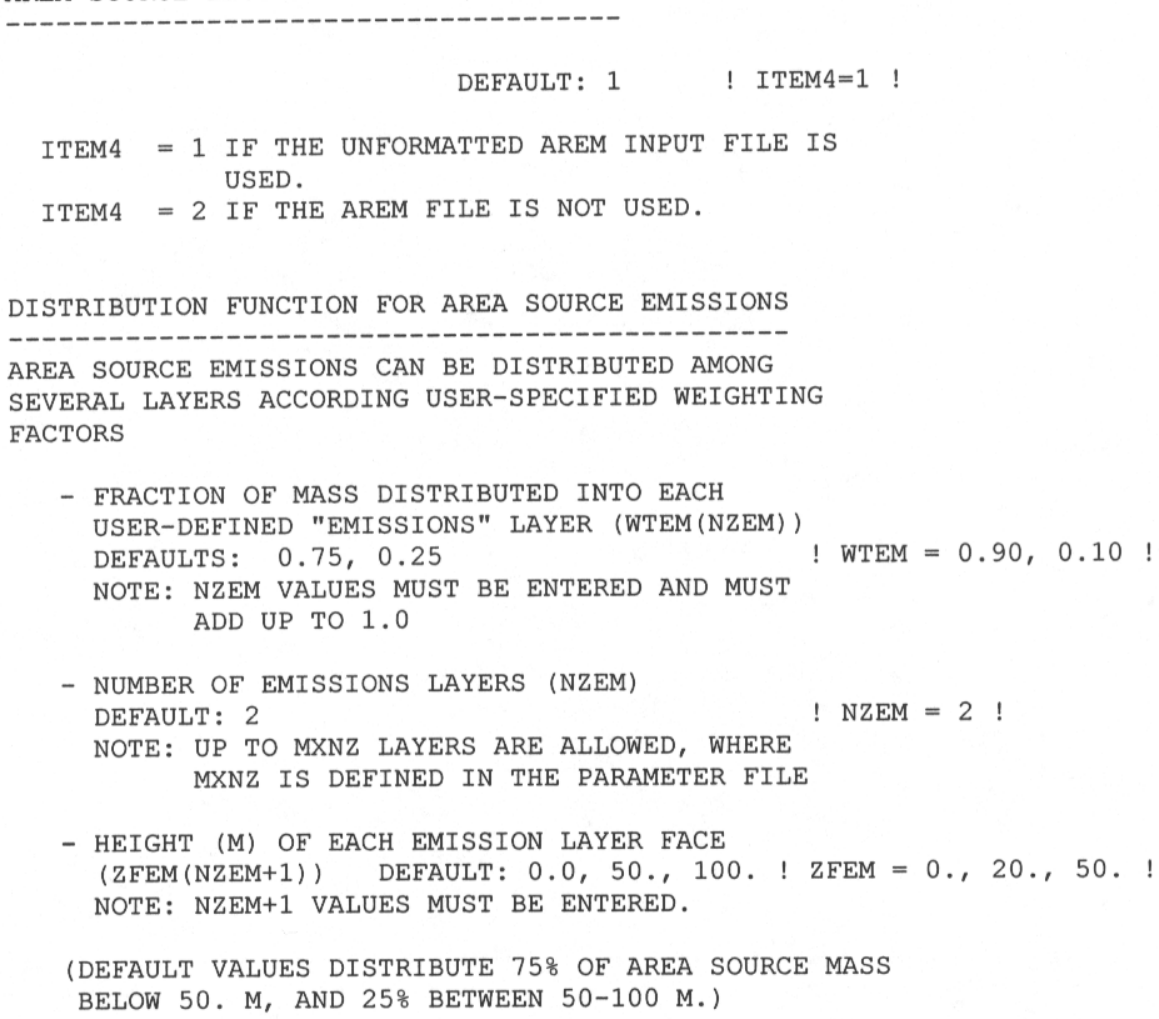

! IEM1REC $=39$ !

! END!

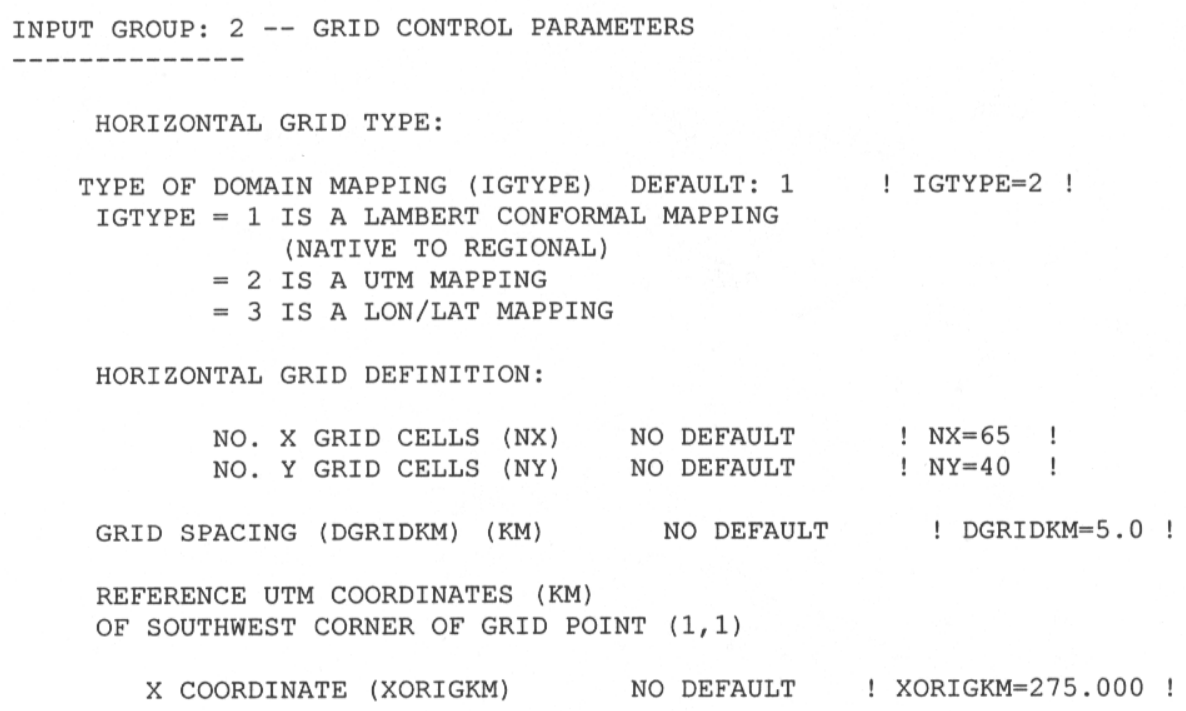

HORIZONTAL GRID DEFINITION:

NO. $X$ GRID CELLS (NX)

GRID SPACING (DGRIDKM) (KM)

REFERENCE UTM COORDINATES (KM)

OF SOUTHWEST CORNER OF GRID POINT $(1,1)$
X COORDINATE (XORIGKM)
NO DEFAULT
! XORIGKM $=275.000 \quad$ ! 

Y COORDINATE (YORIGKM)
NO DEFAULT
! YORIGKM $=3670.000 \quad$ !
UTM ZONE (IUTMZN)
NO DEFAULT
! IUTMZN= 11 !

REFERENCE COORDINATES OF CENTER

OF THE DOMAIN (USED IN THE

CALCULATION OF SOLAR ELEVATION ANGLES)

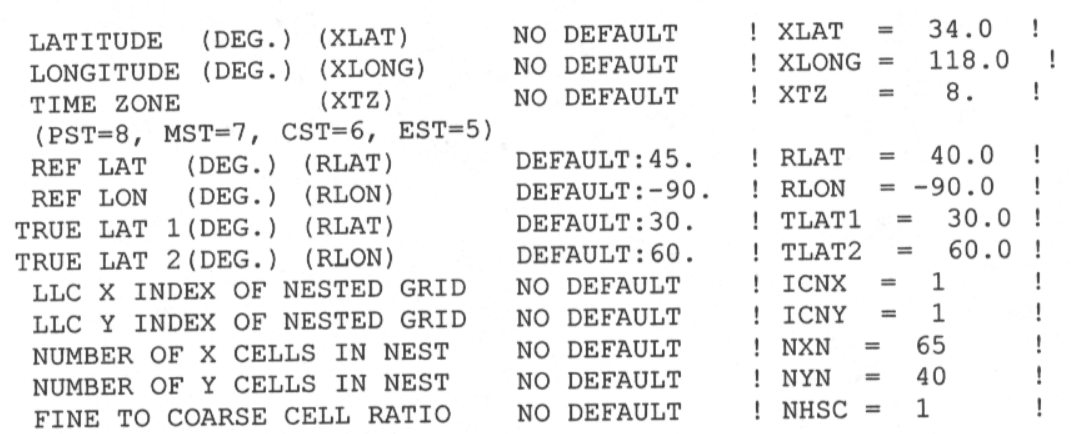

VERTICAL GRID DEFINITION:

NO. OF VERTICAL LAYERS IN THE

CALMET METEOROLOGICAL GRID (NZM) NO DEFAULT ! NZM $=12$ !

VERTICAL CALGRID GRID TYPE (IVGTYP) DEFAULT: 2 ! IVGTYP=2 ! IVGTYP $=0$ UNIFORM THICKNESS ABOVE AND BELOW DIFFBREAK

IVGTYP $=1$ DYNAMICALLY VARYING LAYERS

IVGTYP $=2$ FOR ARBITRARY FIXED GRID

ENTER VALUES FOR THE FOLLOWING VARIABLES BASED ON IVGTYP

\begin{tabular}{c} 
IVGTYP \\
\hdashline 0 \\
1 \\
2
\end{tabular}
REQUIRED VARIABLES

NZ, NZL, ZMINB, ZMAXB, ZMINA, ZMAXA, ZTOP

NZ, NZL, DZMIN, ZTOP

$\mathrm{NZ}$, ZFACE $(\mathrm{NZ}+1)$

IVGTYP

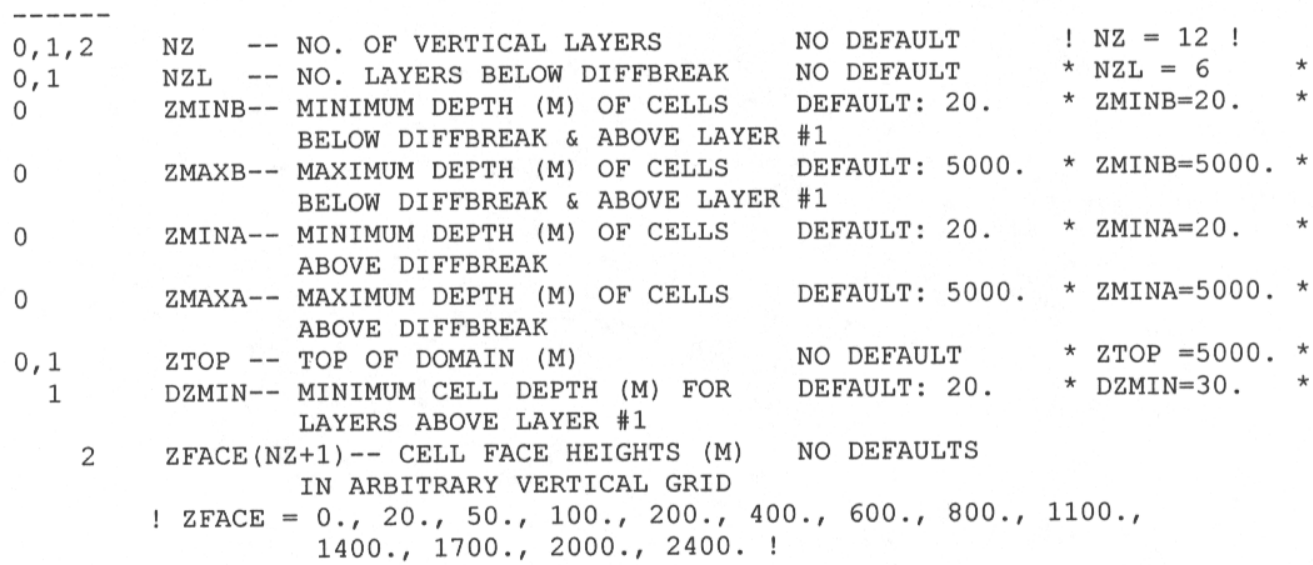

!END!

INPUT GROUP: 3 -- SPECIES LIST

SPECIES MODELED ADVECTED DMITTED DRY DEPITED 
NAME

$(0=\mathrm{NO}, 1=\mathrm{YES}) \quad(0=\mathrm{NO}, 1=\mathrm{YES})$

$(0=\mathrm{NO}, 1=\mathrm{YES})$

$(0=\mathrm{NO}$,

$1=$ COMPUTED - GAS

$2=$ COMPUTED-PARTICLE

$3=$ USER-SPECIFIED)

BUILD-UP SPECIES

ACTIVE SPECIES

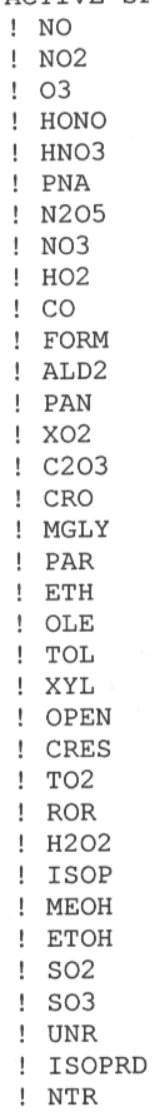

$\begin{array}{ll}= & 1 \\ = & 1\end{array}$

$\begin{array}{ll}= & 1 \\ = & 1\end{array}$

$=1$

$=1$

$=1$

$=1$

$=1$

$=1$

$=1$

$=1$

$=1$

$=1$

$=1$

$=1$

$=1$

$=1$

$=1$

$=1$

$=1$

$\begin{array}{ll}= & 1 \\ & \end{array}$

$=1$

$\begin{array}{ll}= & 1 \\ = & 1\end{array}$

$=1$

$=1$

$=1$

$=1$

$\begin{array}{ll}= & 1 \\ = & 1\end{array}$

$\begin{array}{ll}= & 1 \\ = & 1\end{array}$

$$
\begin{array}{ll}
= & 1 \\
= & 1 \\
= & 1
\end{array}
$$

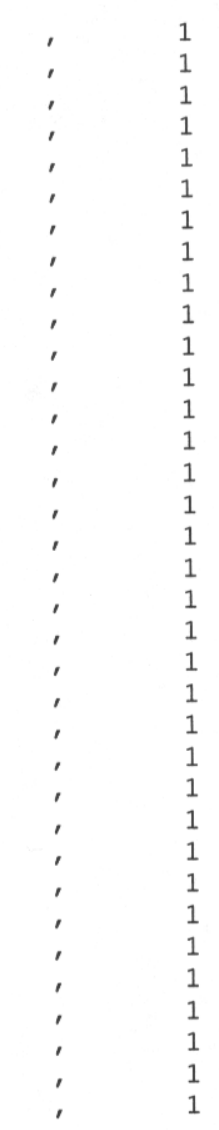

STEADY-STATE SPECIES
! $\mathrm{OH}$
! 0
! O1D
! $\mathrm{XO} 2 \mathrm{~N}$
! $\mathrm{H} 2 \mathrm{O}$

$$
\begin{array}{ll}
= & 1 \\
= & 1 \\
= & 1 \\
= & 1 \\
= & 1
\end{array}
$$

! END!

INPUT GROUP: 4 -- CHEMICAL PARAMETERS FOR DRY DEPOSITION OF GASES

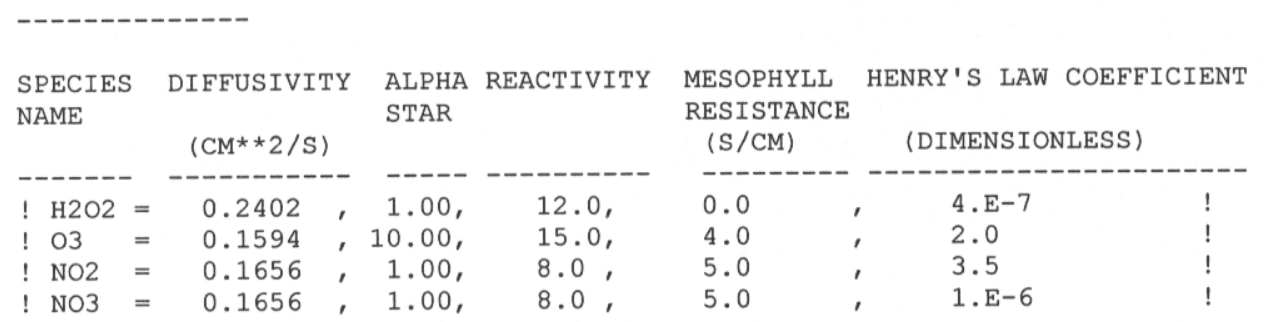




\begin{tabular}{|c|c|c|c|c|c|c|c|c|c|c|}
\hline * & HNO3 & $=$ & 0.1628 & ' & 1.00, & 18.0 & 0.0 & , & $4 \cdot E-2$ & * \\
\hline ! & HONO & $=$ & 0.1100 & , & 1.00, & 4.0 & 2.0 & ， & $4.3 E-4$ & $!$ \\
\hline ! & $\mathrm{HO} 2$ & $=$ & 0.2402 & ， & 1.00 & 12.0 & 0.0 & ， & 1. $E-6$ & $!$ \\
\hline$!$ & PAN & $=$ & 0.1050 & , & 1.00, & 4.0 & 1.0 & , & 1. $E-2$ & $!$ \\
\hline ! & FORM & $=$ & 0.2336 & ' & 1.00, & 4.0 , & 0.0 & , & 4. $E-6$ & ! \\
\hline * & $\mathrm{SO} 2$ & $=$ & 0.1509 & ， & 1.00E3, & 8.0 , & 0.0 & ' & 4. $E-2$ & * \\
\hline
\end{tabular}

!END!

INPUT GROUP: 5 -- SIZE PARAMETERS FOR DRY DEPOSITION OF PARTICLES

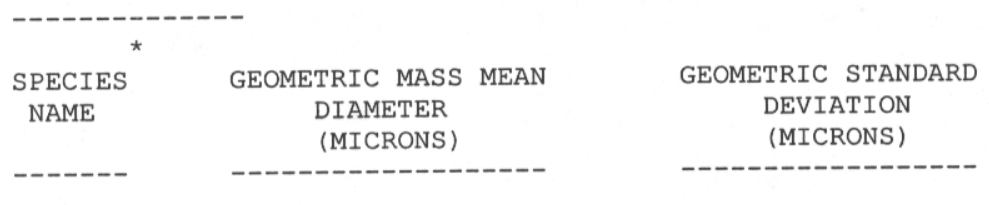

!END!

INPUT GROUP: 6 -- MISCELLANEOUS DRY DEPOSITION PARAMETERS

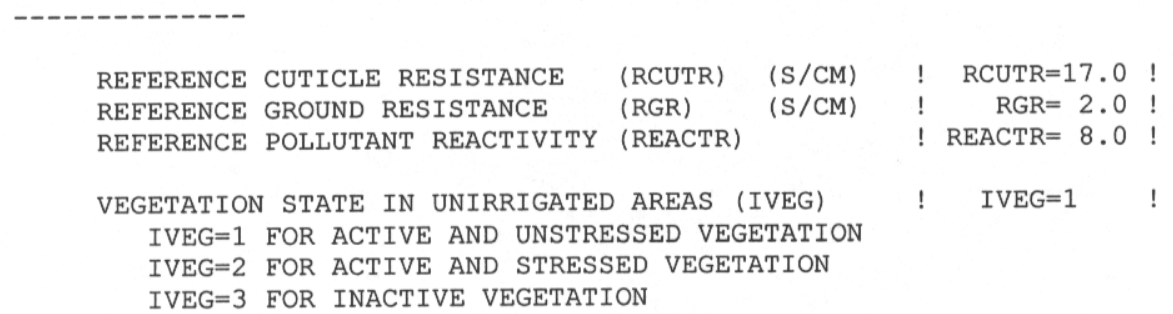

! END!

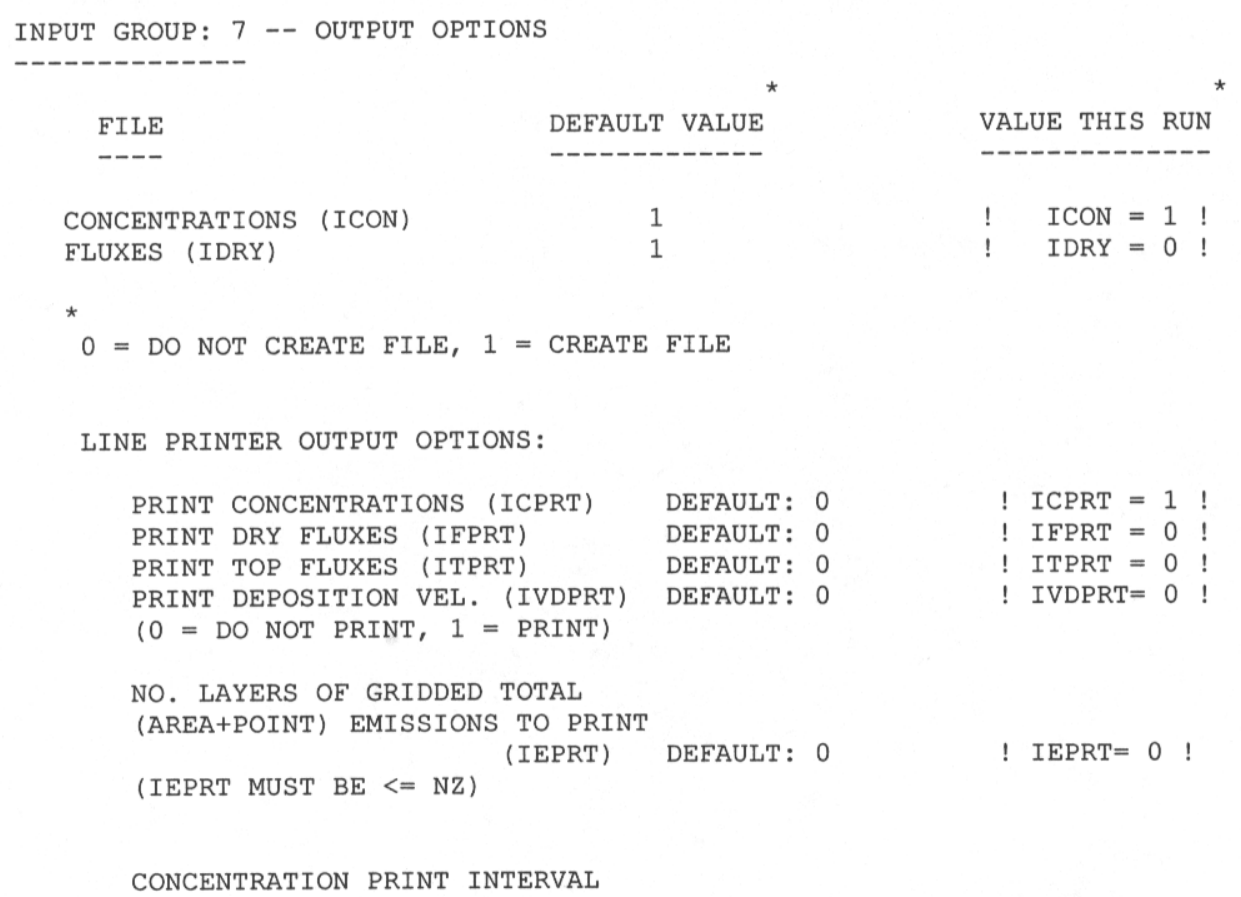


(ICFRQ) IN HOURS

DRY FLUX PRINT INTERVAL

(IFFRQ) IN HOURS

TOP FLUX PRINT INTERVAL

(ITFRQ) IN HOURS

DEPOSITION VEL. PRINT INTERVAL

(IVDFRQ) IN HOURS

EMISSIONS PRINT INTERVAL

(IEFRQ) IN HOURS
DEFAULT: 1
! ICFRQ $=1 !$
DEFAULT: 1
! IFFRQ $=0$ !
DEFAULT: 1
! ITFRQ $=0$ !
DEFAULT: 1
! IVDFRQ $=0$ !
DEFAULT: 1
! IEFRQ $=0$ !

SPECIES LIST FOR OUTPUT OPTIONS

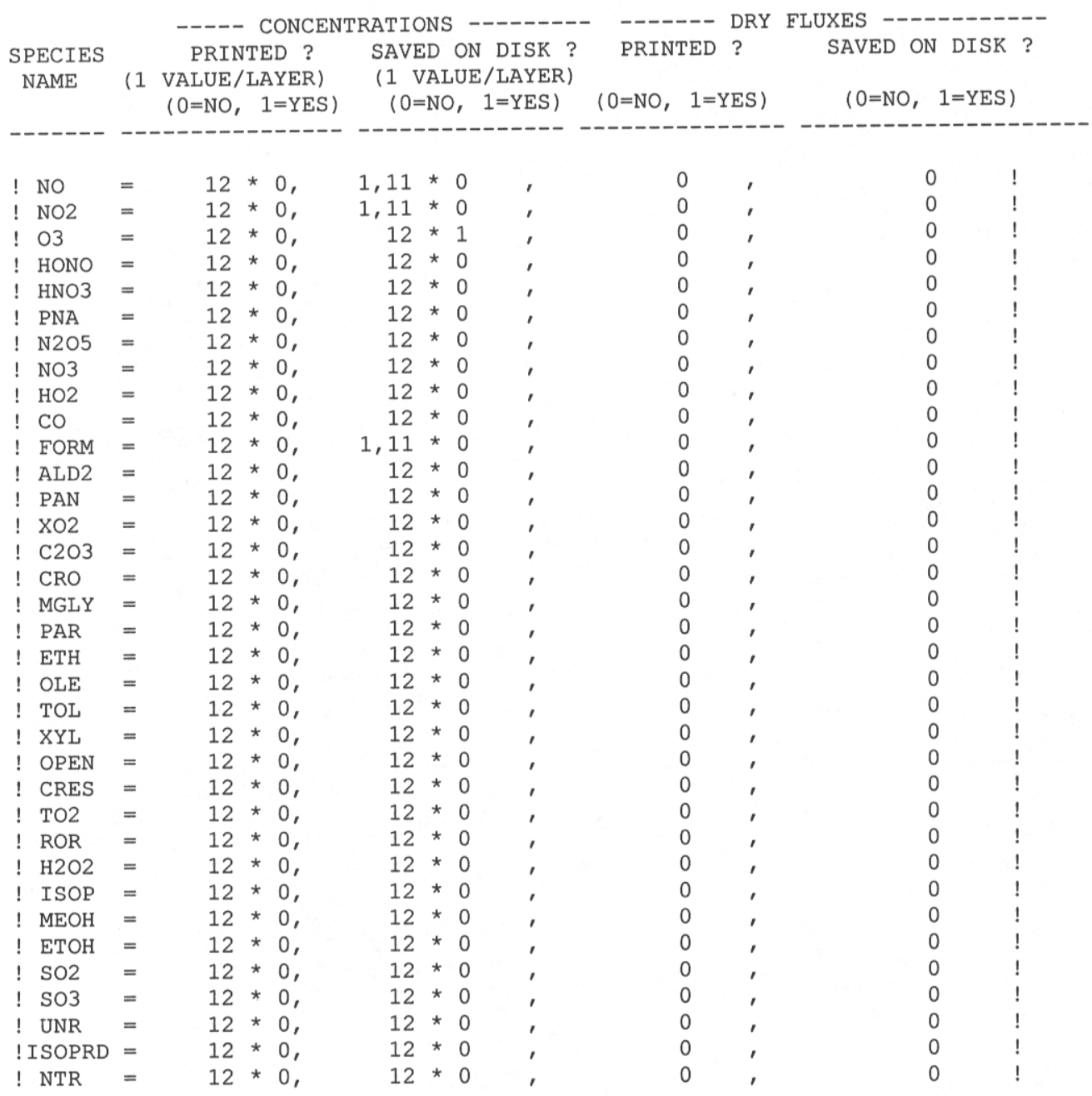

!END!

INPUT GROUP: 8 -- VERTICAL AND HORIZONTAL DIFFUSIVITY PARAMETERS

HORIZONTAL DIFFUSIVITY:

METHOD FLAG (KHMODE) KHMODE $=0-$ PBL DIFFUSIVITIES ARE 


$\begin{array}{ll} & \begin{array}{l}\text { DETERMINED BASED ON STABILITY } \\ \text { CLASS (SEE DKHSTB ARRAY) }\end{array} \\ \text { KHMODE = } 1- & \begin{array}{l}\text { SAME AS ABOVE EXCEPT DIFFUSIVITIES } \\ \text { ARE ADJUSTED FOR WIND SPEED }\end{array} \\ \text { KHMODE = } 2-\text { USES SMAGORINSKY METHOD } & \\ \text { KHMODE }=3-\text { ADDS THE RESULTS OF METHODS } 1 \text { AND } 2\end{array}$

HORIZONTAL DIFFUSIVITY $(M * * 2 / S)$ ABOVE

THE DIFFBREAK HEIGHT (DKHUP)
(USED ONLY IF KHMODE $=0,1$, OR 3 )

HORIZONTAL DIFFUSIVITY $(M * * 2 / S)$ BELOW

THE DIFFBREAK HEIGHT (DKHSTB(6)) DEFAULTS: $224 ., 96 ., 32 ., 0 ., 0 ., 0$. (USED ONLY IF KHMODE $=0,1$, OR 3) ! DKHSTB $=224 ., 96 ., 32 ., 0 ., 0 ., 0$. !

(NOTE: IF KHMODE $=1$ OR 3, THESE

DKHSTB VALUES ARE SCALED BY WIND SPEED)

VERTICAL DIFFUSIVITY:

MINIMUM VERTICAL DIFFUSIVITY $\left(M^{\star *} 2 / \mathrm{S}\right)$ (DKZMIN)

DEFAULT: 1.0 ! DKZMIN $=0.05 !$

VERTICAL DIFFUSIVITY $(M * * 2 / S)$ AT THE MODEL TOP (DKZTOP)

DEFAULT: 0.0 ! DKZTOP $=0.0$ !

!END! 
Listing of CALGRID input file (SAPRC90 case) 
CALGRID SAPRC90 VERSION; REGIONAL RUN ON LA SIP DOMAIN AT 5 KM USES REGIONAL VERSION 1.8 WITH 12 LAYERS - OLD PHOTOLYSIS

AUGUST 27, 1987 - WITH 1987 BASE EMISSIONS

-

CALGRID MODEL CONTROL FILE

ADDITIONAL USER COMMENTS

Uses Hourly CALMETUP meteorology, no calms, and no pseudosoundings

EMISSIONS are from SCAQMD SIP (Rsurf $=2.0$, new Kzmin scheme)

BOUNDARY, TOP, and INITIAL CONDITIONS ARE TAKEN FROM LA UAM-IV PREDICTIONS

STANDARD SAPRC90 CHEMISTRY AND A 320 DU COLUMNAR OZONE

USES CALMET FILE X16 (run17 with all observed data)

INPUT GROUP: 0 -- Input and Output File Names

Subgroup (a)

Default Name

File Name

CALMET . DAT

ICON. DAT

BCON. DAT

--- -

input ! CALMET=h: \nrel \calgrid \met \c27cx16. dat

input ! ICONFL=h: \nrel\calgrid \icbc $\backslash a q l b a s 27 . s 90$

input ! BCONFL $=\mathrm{h}$ : \nrel \calgrid $\backslash$ icbc $\backslash$ bndbas 27.s90

TCON.DAT input

PTECYC.DAT input

PTEMRB.DAT input

PTEMOB.DAT input

AREM. DAT input

VD. DAT

CLDDAT . DAT

CALGRD.LST

CALGRD. DAT

DEPCNC. DAT

ICONST.DAT

BNEST . DAT

input

(a)

output ! GRDLST=Cgb17c27.1st

output ! CNCDAT=h:\nrel\calgrid \outputs\cnb17c27.bin

output ! DEPDAT=h: \nrel\calgrid \outputs \dpb17c27.bin

output ! RESTRT=h: \nrel\calgrid\outputs \icb17c27.bin

output ! BNEST=caldum4

All file names will be converted to lower case if LCFILES $=\mathrm{T}$

Otherwise, if LCFILES = F, file names will be converted to UPPER CASE

$\mathrm{T}=$ lower case

$\mathrm{F}=$ UPPER CASE

NOTES: (1) File/path names can be up to 70 characters in length

(2) Subgroups (a) and (d) must have ONE "END" (surrounded by delimiters) at the end of the group

(3) Subgroups (b) and (c) must have an "END" (surrounded by delimiters) at the end of EACH LINE

! END!

INPUT GROUP: 1 -- GENERAL RUN CONTROL PARAMETERS

-----------

STARTING DATE:

$$
\begin{array}{rllll}
\text { YEAR } & \text { (IBYR) } & -- & \text { NO } & \text { DEFAULT } \\
\text { MONTH } & \text { (IBMO) } & -- & \text { NO DEFAULT } \\
\text { DAY } & \text { (IBDY) } & -- & \text { NO DEFAULT } \\
\text { HOUR } & \text { (IBHR) } & -- & \text { NO DEFAULT }
\end{array}
$$

IBMO $=8$ !

! IBDY $=27$ !

LENGTH OF RUN (HOURS) (IRLG) -- NO DEFAULT

! IRLG=25 !

NUMBER OF TIME STEPS

PER HOUR (NSUBTS)

(TIME STEP $($ SEC $)=3600 . /$ NSUBTS

- DEFAULT: 3 ! NSUBTS $=3 !$


TOTAL NUMBER OF CHEMICAL SPECIES

(ADVECTED + STEADY-STATE SPECIES) (NSPEC)

DEFAULT : $47 \quad$ NSPEC $=50$ !

NUMBER OF CHEMICAL SPECIES

TO BE ADVECTED (NSA)

DEFAULT: $36 \quad$ NSA $=40$ !

NUMBER OF CHEMICAL SPECIES

TO BE DEPOSITED (NSDD)

DEFAULT $: 15 \quad !$ NSDD $=16 !$

NUMBER OF CHEMICAL SPECIES

TO BE EMITTED (NSE)

DEFAULT : 13 ! NSE $=25$ !

TYPE OF CHEMICAL MECHANISM

IN USE (ICHEM)

$1=$ SAPRC -90

$2=\mathrm{CB} 4$

DEFAULT: 1 I ICHEM=1 !

COLUMNAR OZONE IN DOBSON UNITS

TO BE USED DURING RUN

DEFAULT : 295 ! IOZDU $=320 !$

METHOD FLAG FOR INTEGRATION OF CHEMICAL MECHANISM (METHINT)

$1=$ HYBRID METHOD

$2=$ QSSA METHOD

DEFAULT: 2

! METHINT $=2$ !

INPUT FILE TYPES:

METEOROLOGICAL VARIABLES

(CALMET.DAT) FILE

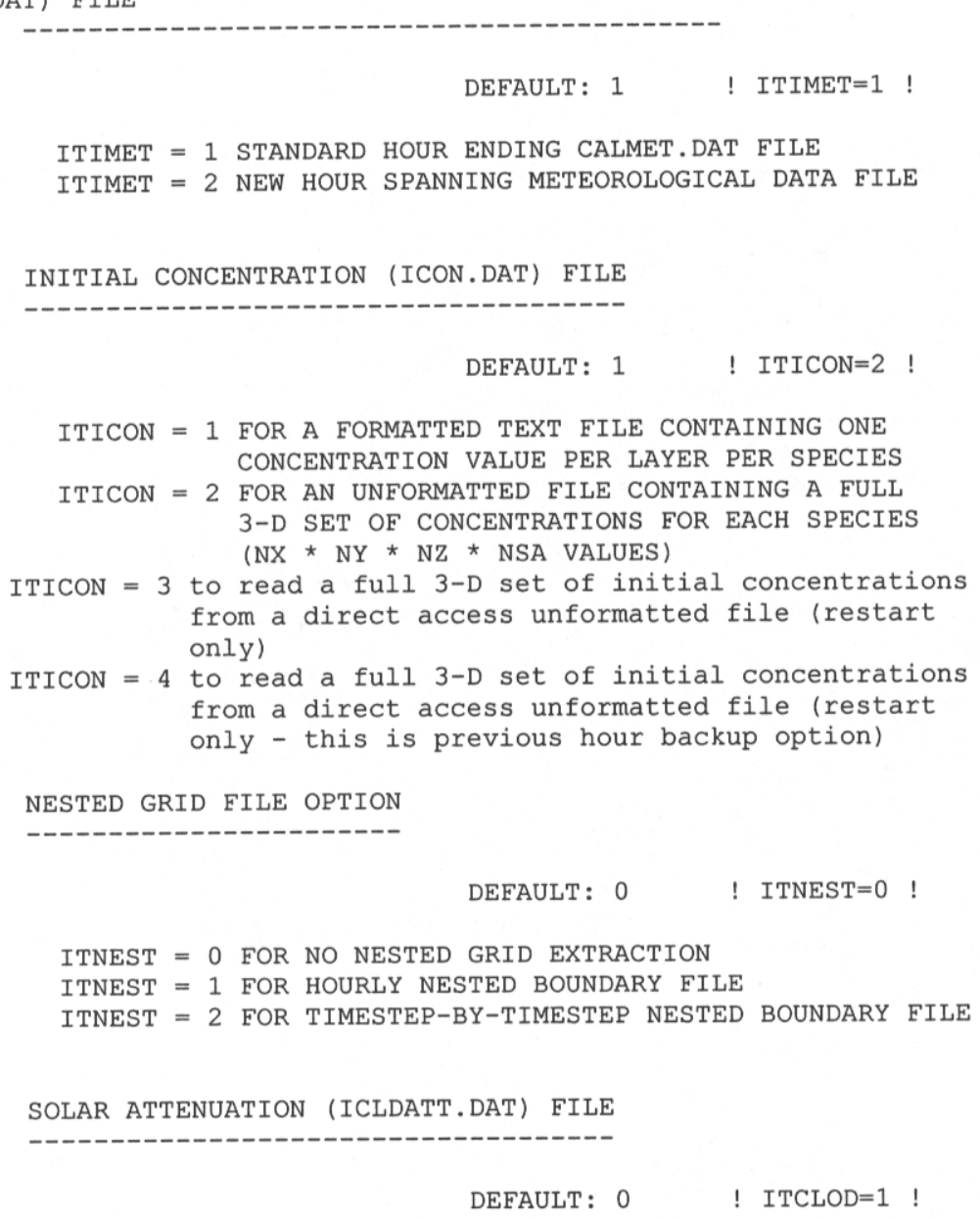




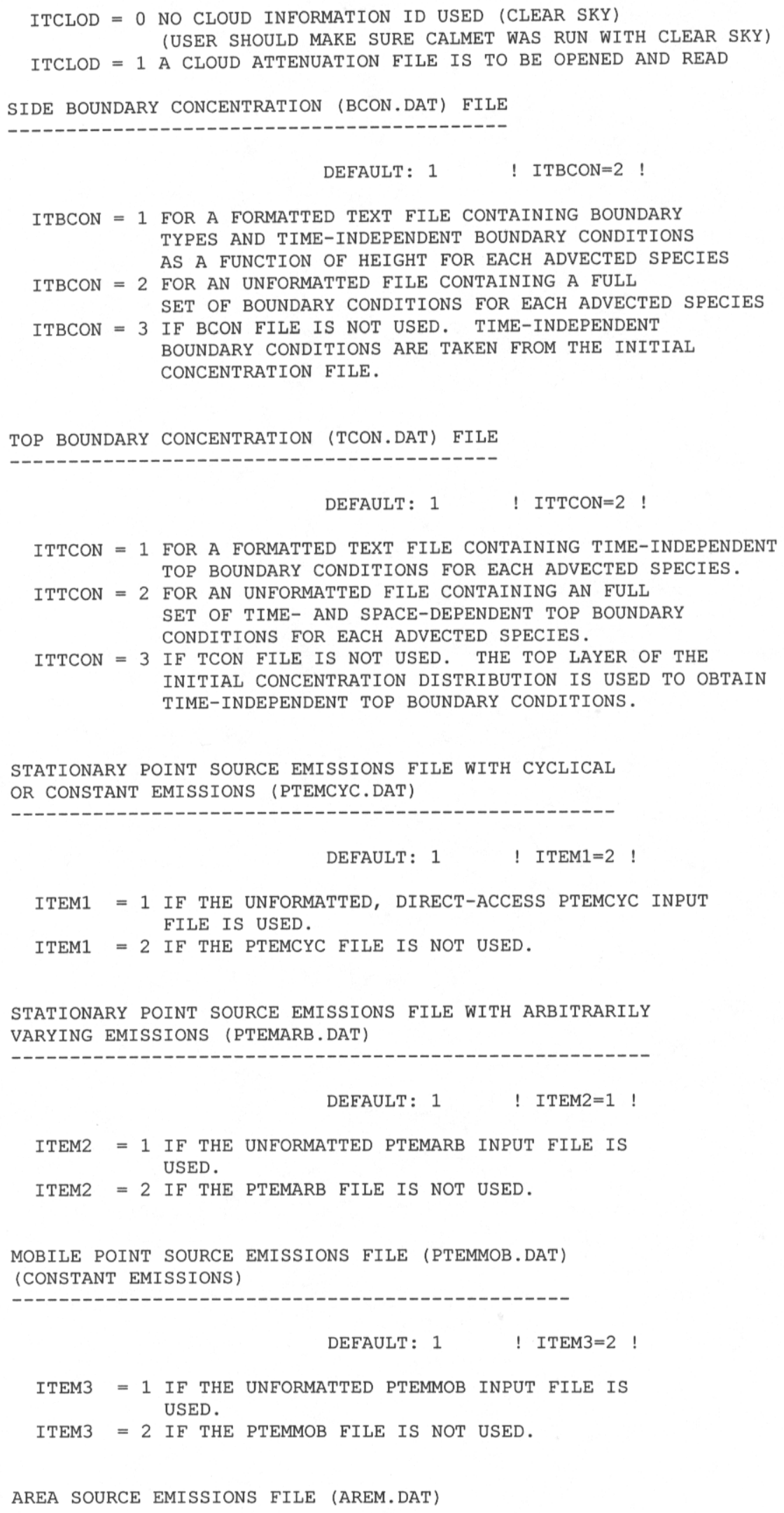




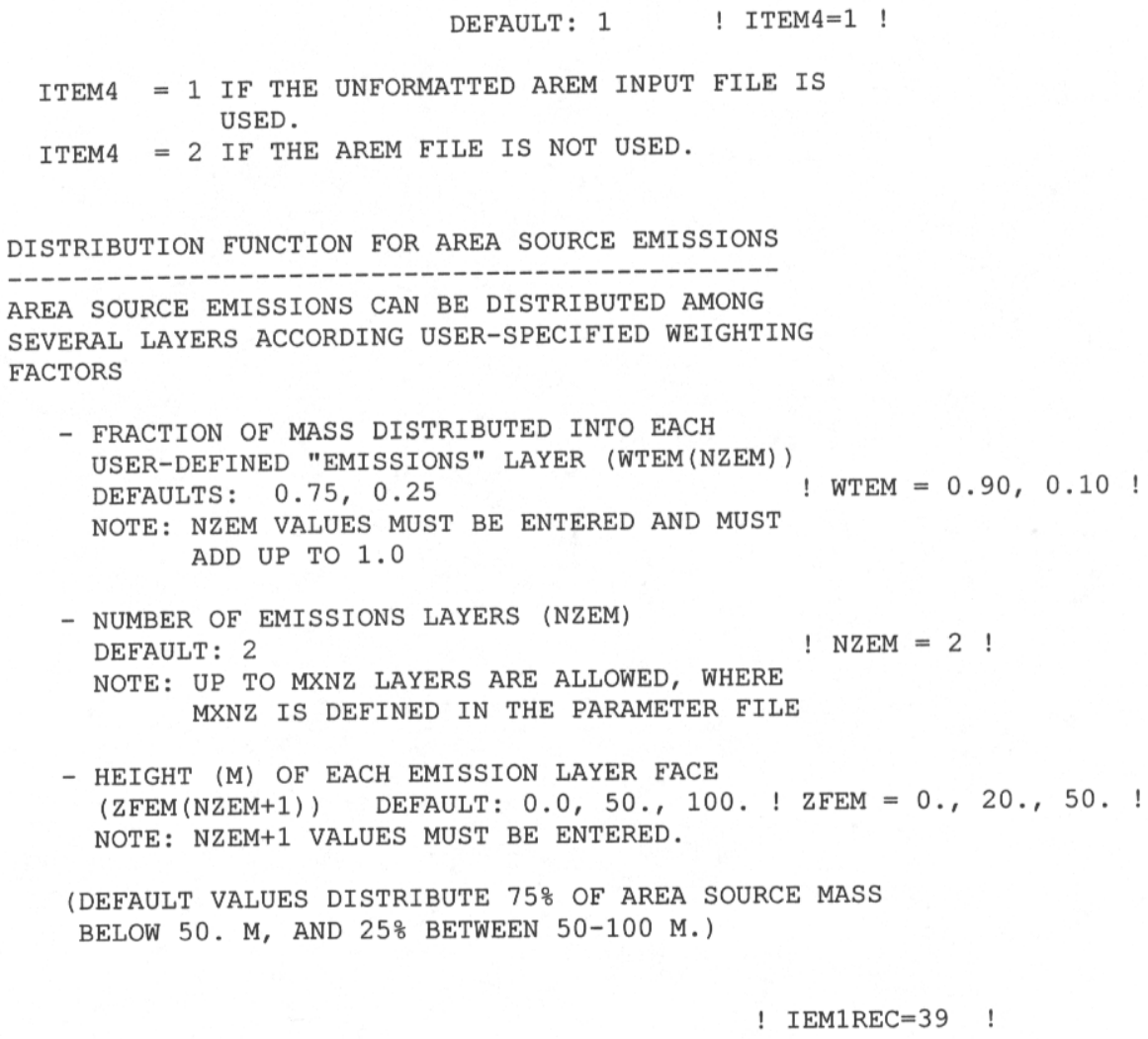

! IEM1REC $=39$ !

!END!

INPUT GROUP: 2 -- GRID CONTROL PARAMETERS

HORIZONTAL GRID TYPE:

TYPE OF DOMAIN MAPPING (IGTYPE) DEFAULT: 1 ! IGTYPE=2 ! IGTYPE $=1$ IS A LAMBERT CONFORMAL MAPPING (NATIVE TO REGIONAL)

$=2$ IS A UTM MAPPING

$=3$ IS A LON/LAT MAPPING

HORIZONTAL GRID DEFINITION:

NO. X GRID CELLS (NX) NO DEFAULT ! NX=65 !

NO. Y GRID CELLS (NY) NO DEFAULT ! NY=40

GRID SPACING (DGRIDKM) (KM) NO DEFAULT ! DGRIDKM=5.0 !

REFERENCE UTM COORDINATES (KM)

OF SOUTHWEST CORNER OF GRID POINT $(1,1)$

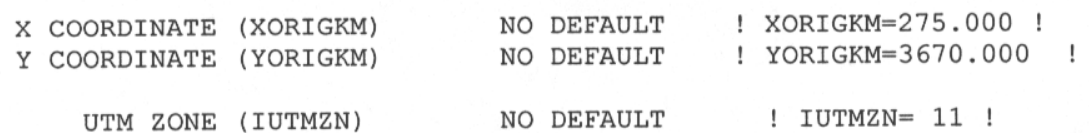

REFERENCE COORDINATES OF CENTER 
OF THE DOMAIN (USED IN THE

CALCULATION OF SOLAR ELEVATION ANGLES)

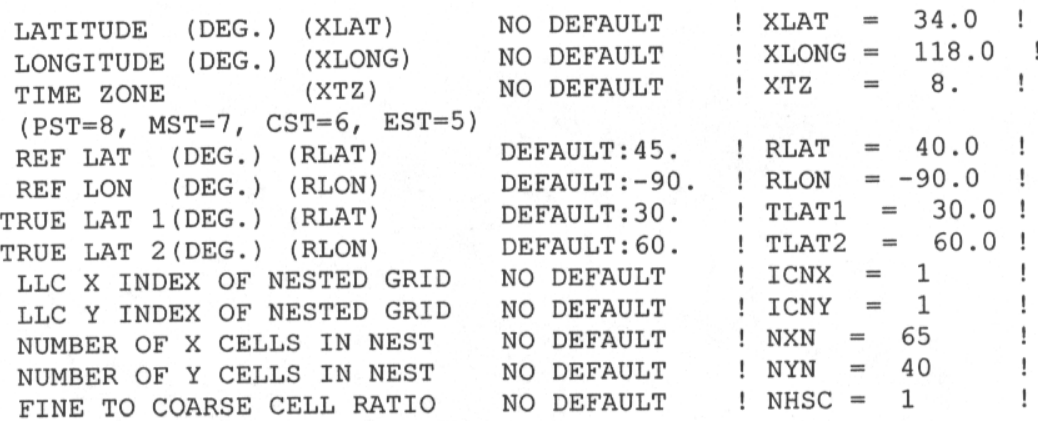

VERTICAL GRID DEFINITION:

NO. OF VERTICAL LAYERS IN THE

CALMET METEOROLOGICAL GRID (NZM) NO DEFAULT ! NZM $=12$ !

VERTICAL CALGRID GRID TYPE (IVGTYP) DEFAULT: 2 ! IVGTYP=2 ! IVGTYP $=0$ UNIFORM THICKNESS ABOVE AND BELOW DIFFBREAK

IVGTYP $=1$ DYNAMICALLY VARYING LAYERS

IVGTYP $=2$ FOR ARBITRARY FIXED GRID

ENTER VALUES FOR THE FOLLOWING VARIABLES BASED ON IVGTYP IVGTYP REQUIRED VARIABLES

$\begin{array}{ll}0 & \text { NZ, NZL, ZMINB, ZMAXB, ZMINA, ZMAXA, ZTOP } \\ 1 & \text { NZ, NZL, DZMIN, ZTOP }\end{array}$

IVGTYP

$2 \quad \mathrm{NZ}, \mathrm{ZFACE}(\mathrm{NZ}+1)$

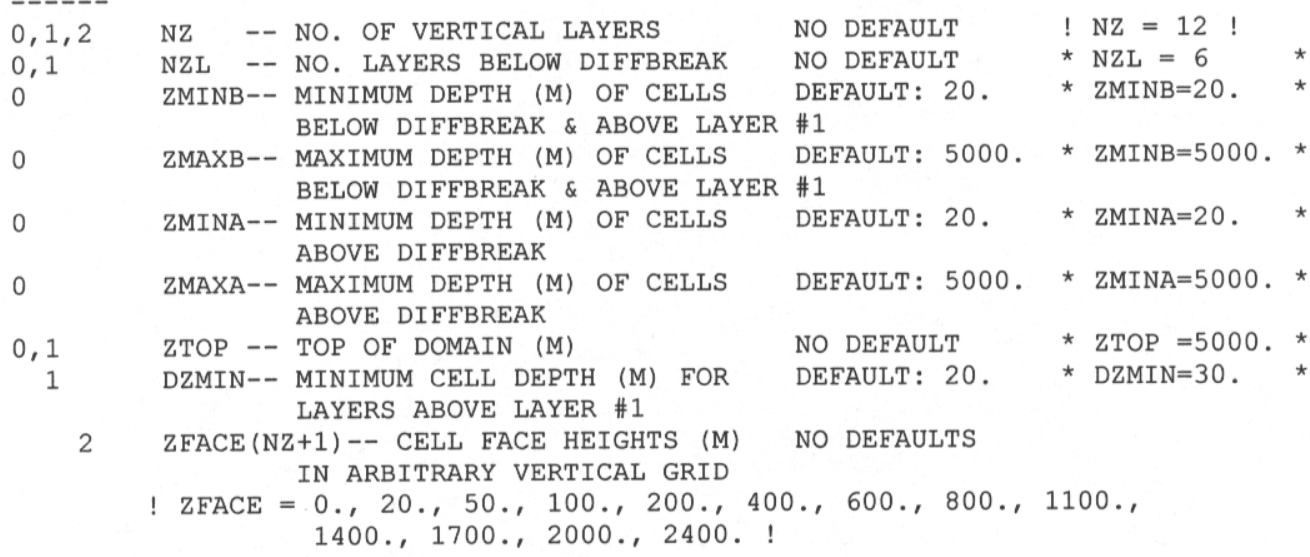

!END!

INPUT GROUP: 3 -- Species list

$\begin{array}{lcccc} & & & \text { DRY } \\ \text { SPECIES } & \text { MODELED } & \text { ADVECTED } & \text { EMITTED } & \text { DEPOSITED } \\ \text { NAME } & (0=\mathrm{NO}, 1=\mathrm{YES}) & (0=\mathrm{NO}, 1=\mathrm{YES}) & (0=\mathrm{NO}, 1=\mathrm{YES}) & (0=\mathrm{NO}, \\ & & & 1=\text { COMPUTED-GAS } \\ & & & 2=\text { COMPUTED-PARTICLE } \\ & & & 3=\text { USER-SPECIFIED })\end{array}$


BUILD-UP SPECIES

\begin{tabular}{|c|c|c|c|c|c|c|c|c|}
\hline ! $\mathrm{CO} 2$ & $=$ & 1 & , & 1 & , & 0 &, & 0 \\
\hline ! SULF & $=$ & 1 & , & 1 & , & 0 & , & 2 \\
\hline$!-\mathrm{C}$ & $=$ & 1 & ， & 1 & , & 0 & , & 0 \\
\hline
\end{tabular}

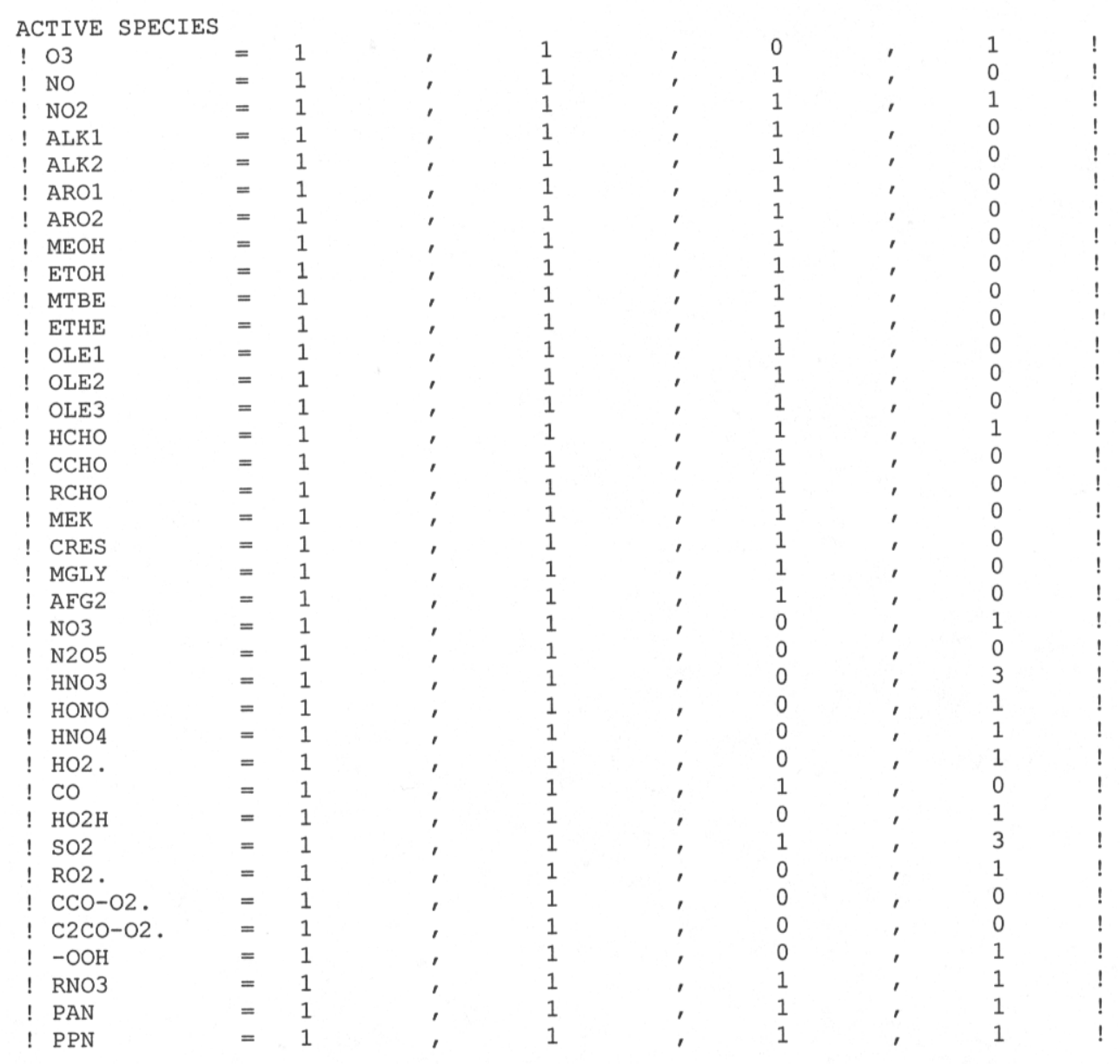

STEADY-STATE SPECIES

$\begin{array}{lll}\text { ! HO. } & = & 1 \\ \text { ! O } & = & 1 \\ ! \text { O*1D2 } & = & 1 \\ \text { ! O3OL-SB } & = & 1 \\ \text { ! RO2-R. } & = & 1 \\ \text { ! RO2-N. } & = & 1 \\ \text { ! R2O2. } & = & 1 \\ \text { ! HOCOO. } & = & 1 \\ \text { ! BZ-O. } & = & 1\end{array}$

CONSTANT SPECIES

! $\mathrm{H} 2 \mathrm{O}$

$=1$

!END!

INPUT GROUP: 4 -- Chemical parameters for dry deposition of gases

$\begin{array}{lll}\text { SPECIES DIFFUSIVITY ALPHA STAR REACTIVITY MESOPHYLL RESISTANCE } & \text { HENRY'S LAW }\end{array}$ 


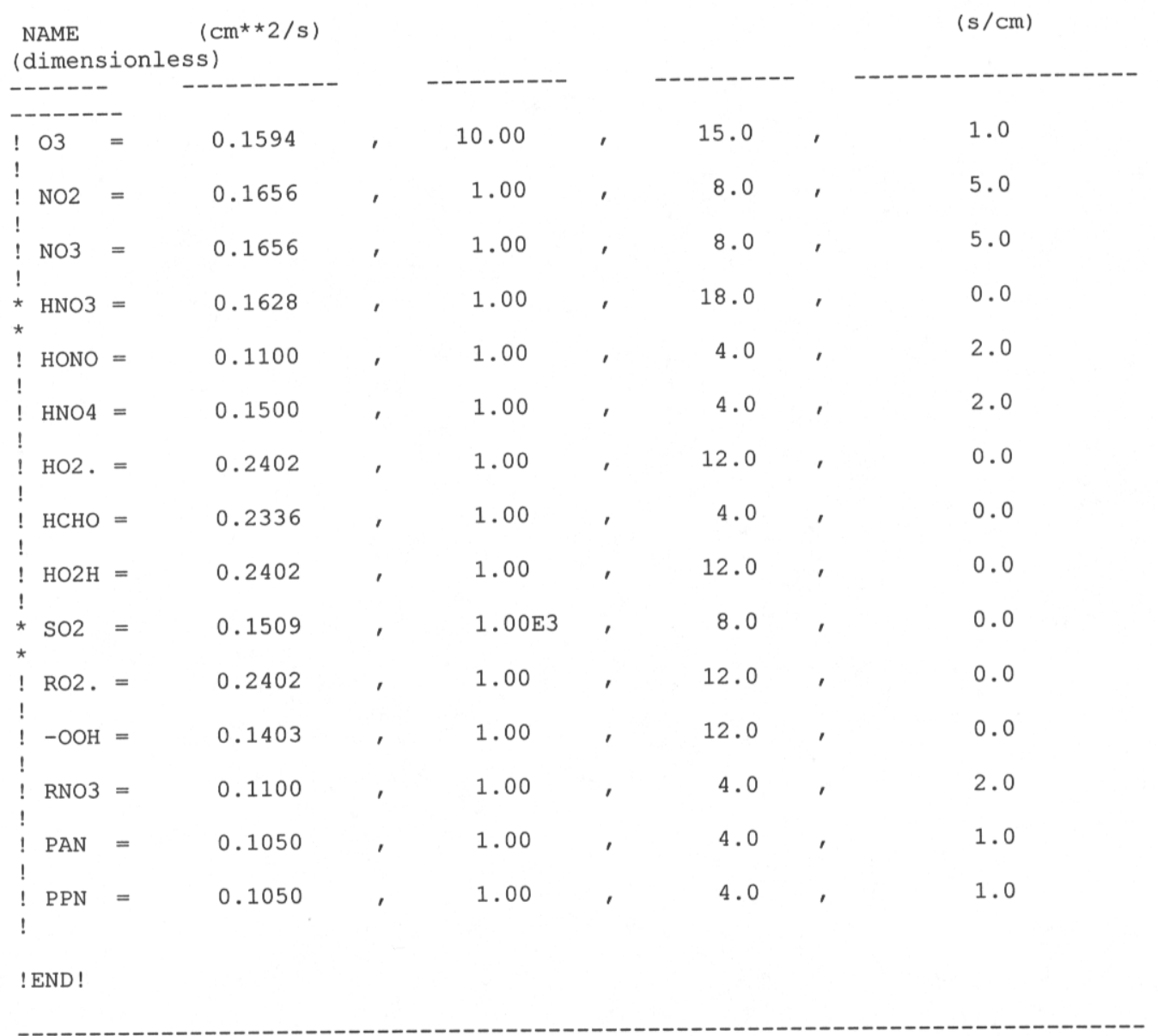

INPUT GROUP: 5 -- Size parameters for dry deposition of particles

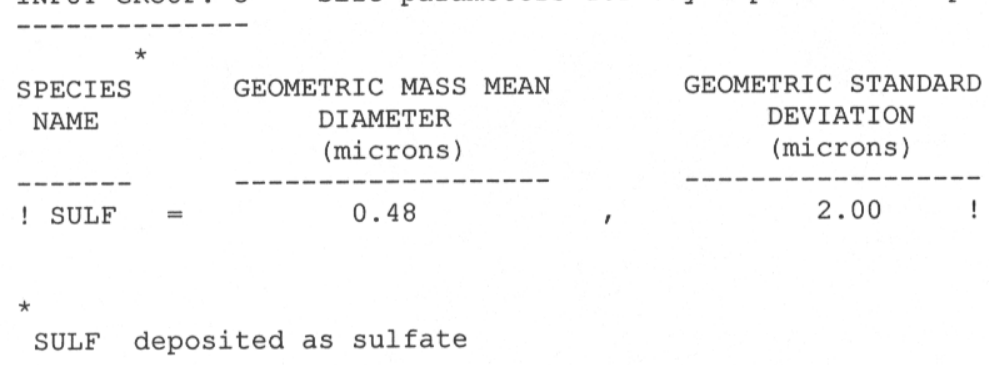

! END!

INPUT GROUP: 6 -- Miscellaneous dry deposition parameters

\begin{tabular}{|c|c|c|c|c|}
\hline Reference cuticle resistance & (RCUTR) & $(\mathrm{s} / \mathrm{cm})$ & $!$ & RCUTR $=17.0$ \\
\hline Reference ground resistance & (RGR) & $(\mathrm{s} / \mathrm{cm})$ & $!$ & $\mathrm{RGR}=2.0$ \\
\hline Reference pollutant reactivity & (REACTR) & & $!$ & REACTR $=8.0$ \\
\hline
\end{tabular}


IVEG $=1$ for active and unstressed vegetation

IVEG=2 for active and stressed vegetation

$I V E G=3$ for inactive vegetation

! END!

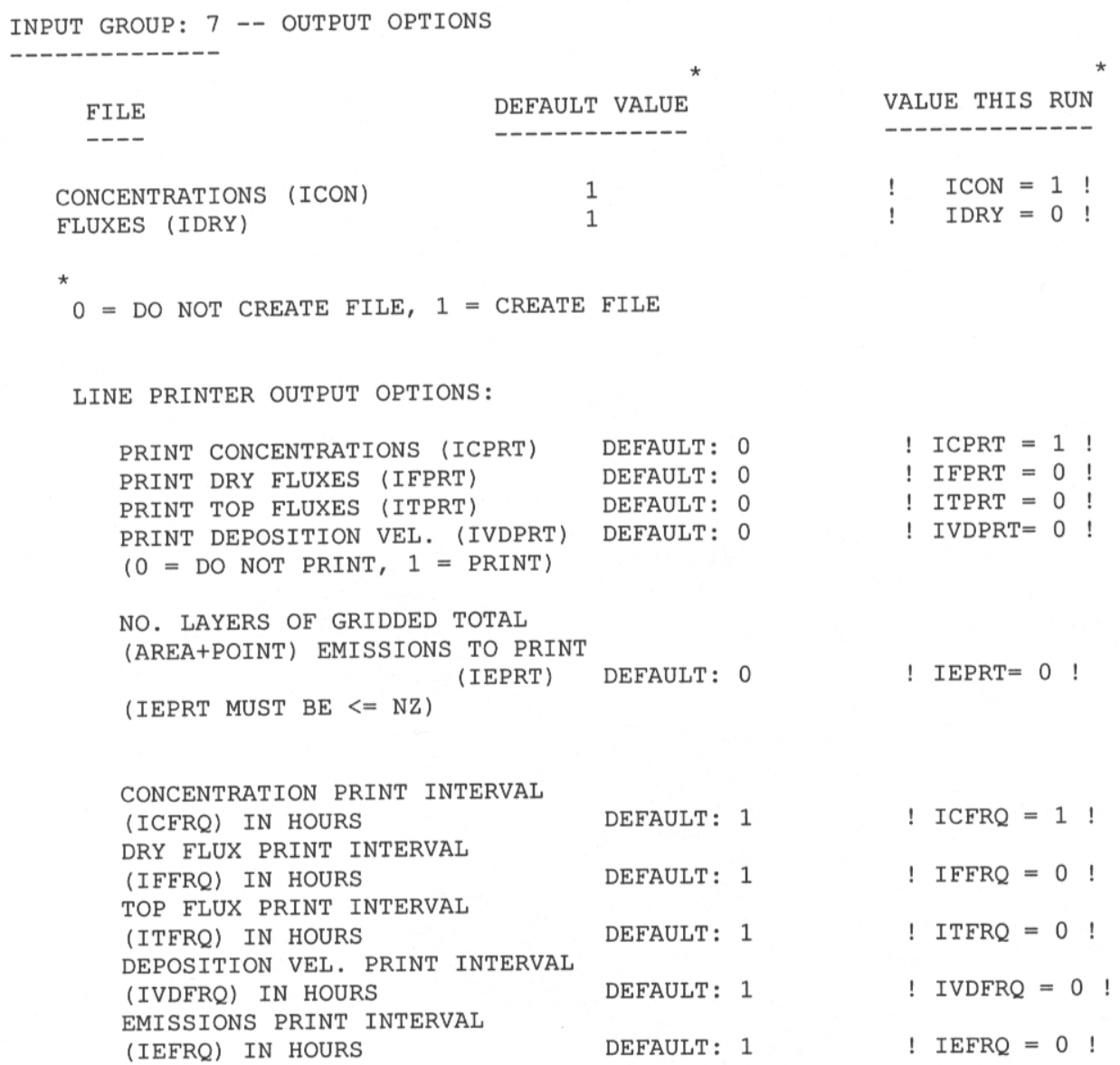

SPECIES LIST FOR OUTPUT OPTIONS

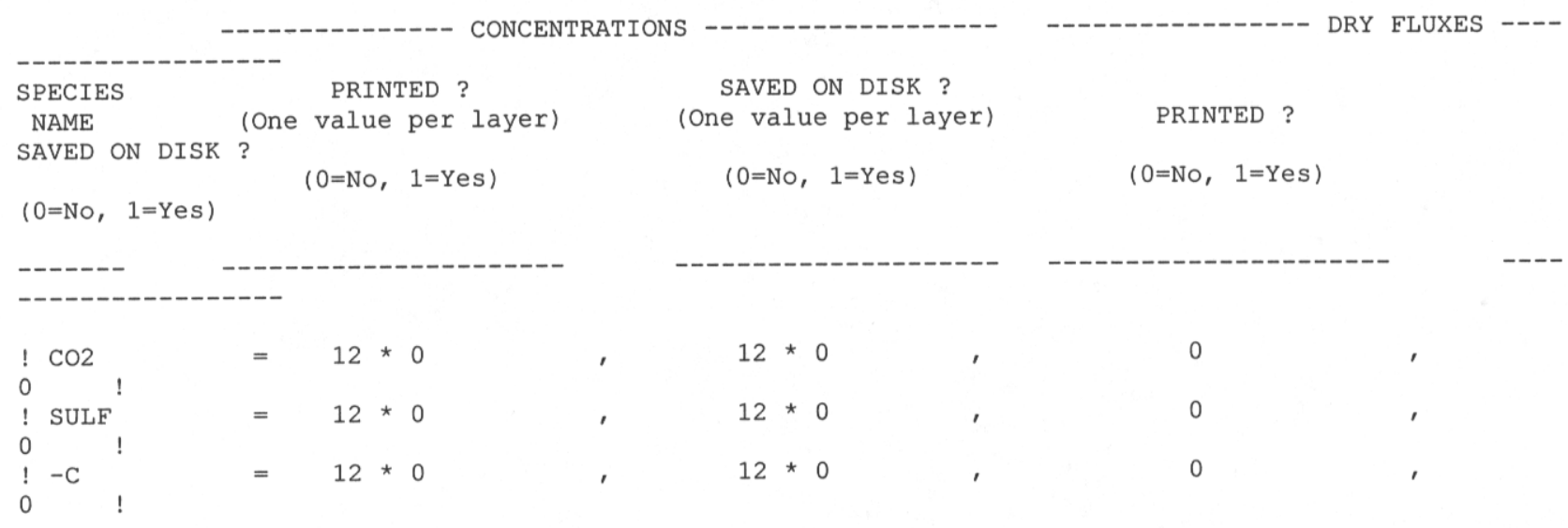




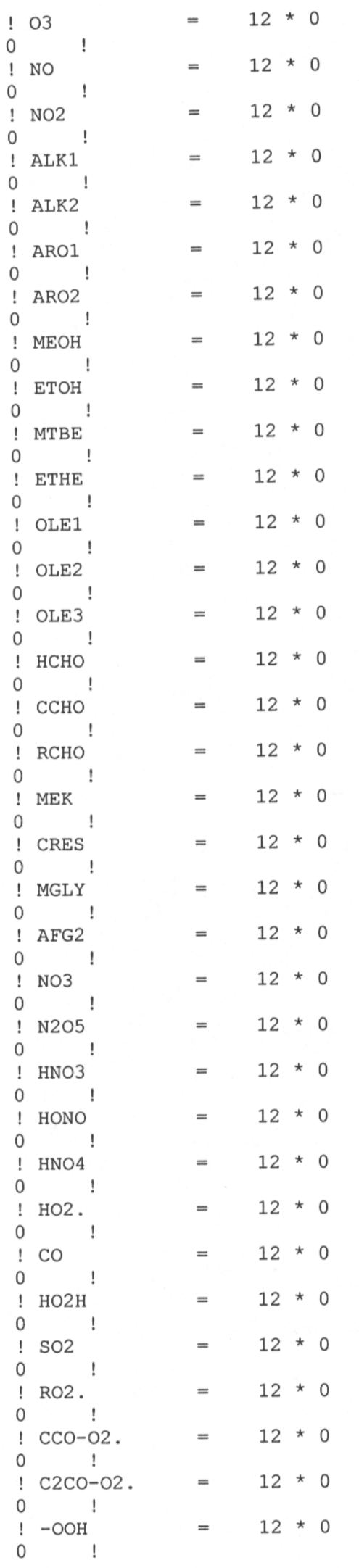

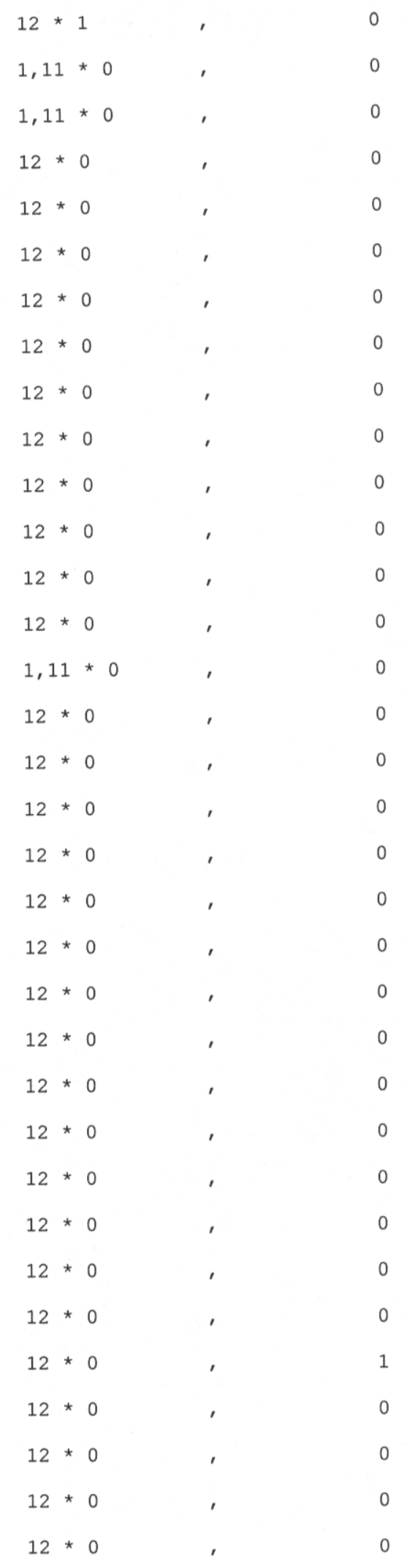




$\begin{array}{lll}\text { RNO3 } & =12 * 0 \\ 0 & =12 * 0 \\ \text { PAN } & =12 * 0 \\ 0 & =12 * 0 \\ \text { PPN } & =12 * 0 \\ 0 & \end{array}$

INPUT GROUP: 8 -- VERTICAL AND HORIZONTAL DIFFUSIVITY PARAMETERS

HORIZONTAL DIFFUSIVITY:

METHOD FLAG (KHMODE)

KHMODE $=0-$ PBL DIFFUSIVITIES ARE

DETERMINED BASED ON STABILITY

CLASS (SEE DKHSTB ARRAY)

KHMODE $=1$ - SAME AS ABOVE EXCEPT DIFFUSIVITIES

ARE ADJUSTED FOR WIND SPEED

KHMODE $=2$ - USES SMAGORINSKY METHOD

KHMODE $=3-$ ADDS THE RESULTS OF METHODS 1 AND 2

HORIZONTAL DIFFUSIVITY (M**2/S) ABOVE

THE DIFFBREAK HEIGHT (DKHUP)

DEFAULT: $0.0 \quad !$ DKHUP $=0.0$ !

(USED ONLY IF KHMODE $=0,1$, OR 3)

HORIZONTAL DIFFUSIVITY ( $M * * 2 / S$ ) BELOW

THE DIFFBREAK HEIGHT (DKHSTB(6)) DEFAULTS: $224 ., 96 ., 32 ., 0 ., 0 ., 0$. (USED ONLY IF KHMODE $=0,1$, OR 3)

! DKHSTB $=224,96 ., 32 ., 0 ., 0 ., 0$. !

(NOTE: IF KHMODE $=1$ OR 3, THESE

DKHSTB VALUES ARE SCALED BY WIND SPEED)

VERTICAL DIFFUSIVITY:

MINIMUM VERTICAL DIFFUSIVITY $(M * * 2 / S)$

(DKZMIN)

DEFAULT: 1.0 ! DKZMIN $=0.05 !$

VERTICAL DIFFUSIVITY $(M * * 2 / S)$ AT THE MODEL TOP (DKZTOP)

DEFAULT: $0.0 \quad$ ! DKZTOP $=0.0$ !

!END! 


\section{REPORT DOCUMENTATION PAGE}

Form Approved OMB NO. 0704-0188

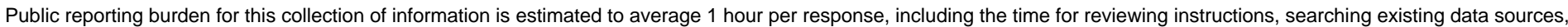

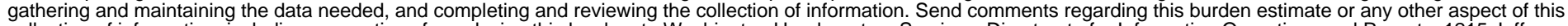

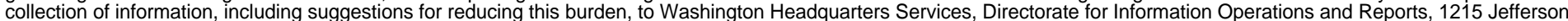
Davis Highway, Suite 1204, Arlington, VA 22202-4302, and to the Office of Management and Budget, Paperwork Reduction Project (0704-0188), Washington, DC 20503.

\begin{tabular}{l|l|l} 
1. AGENCY USE ONLY (Leave blank) & 2. REPORT DATE & 3. REPORT TYPE AND DATES COVERED
\end{tabular} November 1998 Subcontract report

\section{TITLE AND SUBTITLE}

CALGRID Photochemical Modeling of Air Quality Impacts of Alternative Transportation Fuel Use in Los Angeles

6. $\operatorname{AUTHOR}(\mathrm{S})$

G.E. Moore, R.J. Londergan, M.E. Fernau

7. PERFORMING ORGANIZATION NAME(S) AND ADDRESS(ES)

Earth Tech, Inc.

196 Baker Avenue

Concord, MA 01742

\section{SPONSORING/MONITORING AGENCY NAME(S) AND ADDRESS(ES)}

National Renewable Energy Laboratory

1617 Cole Blvd.

Golden, CO 80401

\section{PERFORMING ORGANIZATION} REPORT NUMBER

\section{SPONSORING/MONITORING} AGENCY REPORT NUMBER

NREL/SR-540-25204

\section{SUPPLEMENTARY NOTES}

\section{2a. DISTRIBUTION/AVAILABILITY STATEMENT}

National Technical Information Service

U.S. Department of Commerce

5285 Port Royal Road

Springfield, VA 22161

13. ABSTRACT (Maximum 200 words) The National Renewable Energy Laboratory has been conducting a comprehensive program to quantify and assess the air quality impacts of the emissions of ozone precursors, air toxins, and greenhouse gases from alternative fuel vehicles. This program includes both an emissions estimation component and a photochemical modeling component to study three fuels: reformulated gasoline, compressed natural gas, and $85 \%$ methanol (M85). This report describes the use of the CALGRID model in the Los Angeles modeling domain using the State-Wide Air Pollution Research Center (SAPRC90) chemical mechanism and an early version of the SAPRC93 mechanism. A variety of conclusions can be drawn from the results of this study, including results from chemical mechanism testing; development of meteorological inputs; model evaluation and comparison; and the analyses of the impacts of the emissions scenarios. The report summarizes the study's major findings in these areas.

\section{SUBJECT TERMS}

Alternative transportation fuels, urban air quality, emissions, photochemical modeling

15. NUMBER OF PAGES 187

16. PRICE CODE

\section{SECURITY CLASSIFICATION} OF ABSTRACT
20. LIMITATION OF ABSTRACT 